Roberto MÁRcio de OLIVEIRA JÚNIOR

\title{
Avaliação da estimulação ventricular direita crônica em crianças e adultos jovens com bloqueio atrioventricular congênito isolado
}

Tese apresentada à Faculdade de Medicina da Universidade de São Paulo para obtenção do título de Doutor em Ciências

Programa: Cirurgia Torácica e Cardiovascular Orientador: Prof. Dr. Roberto Costa 
"Senhores,

Aqui temos este livro, um ramalhete de flores escolhidas. Nada há nele de meu, a não ser o cordão que as ata."

Montaigne

"É indispensável querermos deitar a mão a mais do que podemos alcançar; senão para que serviria o céu?"

Robert Browning 
Dedico esta tese à minha família.

Meus amados pais, Roberto e Aparecida, mais uma etapa de nossa caminhada chega ao fim, pequeno passo no turbilhão da vida, mas conquista grandiosa no âmbito familiar, já os disse...

Minha amada esposa Marissol, na ascese avança-se gradativamente até que, depois das vicissitudes, na luta entre a dor e o amor, vence o amor; morre a dor que é reabsorvida no amor...

Sr. Rosivaldo e Tia Sônia, toda boa construção demanda tempo e inicia-se de baixo para cima, de dentro para fora, tal como a nossa...

Meus irmão Estevão e Fabiana, cunhados André e Diego, a vida flui como uma torrente, que leva consigo todos os resíduos do caminho percorrido e, sempre em marcha, deposita-as e se purifica...

E assim, meus amados, chegamos até aqui: juntos. Obrigado! 


\section{AGRADECIMENTOS}

Ao Prof. Dr. Roberto Costa, meu orientador e educador, pesquisador à dianteira de seu tempo, por ter me conduzido a seu reboque. Minha autêntica gratidão pela acolhida dentro e fora dos âmbitos desta tese, pelo exemplo de profissional tenaz e fervoroso, pela minha condução e formação profissional.

À Dra. Kátia Regina da Silva, pela elaboração, seleção, execução, coleta de dados, revisão da literatura, análise estatística, confecção dos gráficos, formatação, tradução, elaboração da capa, nova revisão, enfim, por cada linha e entrelinha deste trabalho. Alma abnegada e dedicada, com o árduo trabalho de espargir luzes à ignorância humana, os meus profundos e sinceros agradecimentos. Você não consegue imaginar o quanto você me beneficiou. O futuro vai mostrar...

Ao Prof. Dr. Martino Martinelli Filho e sua equipe da Unidade Clínica de Estimulação Cardíaca Artificial do InCor, pela cooperação, ensinamentos e apoio na execução desta tese.

Ao Dr. Rodrigo Tavares, meu primeiro encorajador dentro do Instituto do Coração (InCor). Apresentou-me à Pós-graduação através de seus estudos. Profissional perspicaz e competente que me contagiou e fez adentrar neste caminho científico. 
Ao Dr. W. Tamaki, pelos ensinamentos em técnicas cirúrgicas e incentivo profissional e intelectual dentro e fora do marca-passo.

À Dra. Elizabeth Sartori Crevelari, pelo apoio e amizade dentro e fora do centro cirúrgico.

Aos amigos e irmãos, os Doutores Luiz Tenório, Orly Larceda, José Renato e Aldryn Nunes, por terem me incentivado a entrar na Pósgraduação e, sobretudo, pela amizade espontânea que nos anima até hoje cada qual a seu modo e apesar das distâncias.

Ao Amigo Dr. Caio Marcos de Moraes Albertini, pelo companheirismo e incentivo pessoal e profissional.

À Dra. Sávia Cristina Bueno, ex-companheira de Pós-Graduação, pelo convívio e ajuda na execução dos créditos. Sem você teria sido mais difícil.

À Enfermeira Marianna Sobral Lacerda, pela amizade, apoio e diligência na coleta dos dados deste trabalho.

Aos Pesquisadores Tatiana Kawauchi e Lucas Bassolli, pela contribuição na finalização desta tese, seja na elaboração do artigo, seja na análise estatística, respectivamente.

Aos Amigos da Unidade de Estimulação Elétrica e Marcapasso da Divisão de Cirurgia do InCor, Neide Romão, Tiago Oliveira e Regina Costa, pelo convívio diário e colaboração em diversos níveis. 
À Profa. Dra. Eloisa Bonfá, pelo apoio científico prestado através da disponibilização de recursos humanos e laboratoriais oriundos do Serviço de Reumatologia do Hospital das Clínicas da Faculdade de Medicina da USP (HCFMUSP).

À Dra. Sandra Gofinet Pasotto, pelas avaliações clínicas reumatológicas no seu horário de almoço, o que denota dedicação extrema não tão somente a nossa tese, mas principalmente, à Medicina.

À Dra. Vilma dos Santos Trindade Viana e sua equipe do Laboratório de Imunologia Humoral do Serviço de Reumatologia do HCFMUSP, pela sua simpática e gentil busca pelos autoanticorpos.

Às Enfermeiras Adriana Yun Huang e Marina Bertelli Rossi, pelo auxílio na realização dos contatos telefônicos, coletas laboratoriais, testes de caminha e aplicação dos questionários de vida.

A todos os Médicos Estagiários que conviveram comigo na Unidade Clínica de Estimulação Cardíaca Artificial do InCor e na Unidade de Estimulação Elétrica e Marcapasso da Divisão de Cirurgia do InCor, pelos ensinamentos e, principalmente, pela amizade tão importantes no meu burilamento interior.

Aos amigos do Centro Cirúrgico do InCor, pela respeitosa convivência diária nos serviços assistenciais desde minha época de Estagiário. 
Às amigas do ambulatório da Unidade Clínica de Estimulação Cardíaca Artificial do InCor, Cristina, Paula, Mônica, Jeane, Michele, Camila, pelo auxílio nas avaliações clínicas e eletrônicas, sempre com bom humor e respeitosa alegria.

Ao Prof. Dr. Wilson Mathias Jr., por disponibilizar apoio estrutural e científico no Setor de Ecocardiografia do InCor.

À Dra. Gláucia Maria Penha Tavares, pela disposição e dedicação na realização e análise dos exames ecocardiográficos.

Ao Dr. Vitor Coimbra Guerra e Dra. Luciana Martins Menezes, pela ajuda na execução dos exames ecocardiográficos.

Ao Dr. Marcelo Luiz Campos Vieira, pela atenção, esforço e ensinamentos na leitura das imagens ecocardiográficas.

À Creusa Maria Roveri Dal Bó, pela presente análise estatística realizada com objetividade e profissionalismo.

À Neusa Rodrigues Dini, Juliana Lattari Sobrinho, Eva Malheiros G. de Oliveira, Nathalia Barbosa e Tatiane Lago, pela atenção, paciência, orientação e prestimosidade em manter os prazos e a burocracia institucional em ordem nestes últimos quatro anos de Pós-graduação.

À Senhora Maria Helena Vargas, pela gentil e prestativa assistência na diagramação e revisão gramatical para a finalização desta tese. Obrigado pelo grande empenho. 
À Coordenação de Aperfeiçoamento de Pessoal de Nível Superior (CAPES) pela bolsa de estudos de Doutorado.

Aos Professores Luiz Felipe Pinho Moreira, Renato Samy Assad e Moacyr Roberto Cucê Nobre, membros participantes da minha banca de qualificação, pelas sugestões que mudaram o resultado final desta tese.

A todos os sujeitos desta pesquisa e seus familiares que participaram deste estudo, pela credibilidade depositada em nossa equipe. 
Esta tese está de acordo com as seguintes normas, em vigor no momento desta publicação:

Referências: adaptado de International Committee of Medical Journals Editors (Vancouver).

Universidade de São Paulo. Faculdade de Medicina. Serviço de Biblioteca e Documentação. Guia de apresentação de dissertações, teses e monografias.

Elaborado por Anneliese Carneiro da Cunha, Maria Julia de A. L. Freddi, Maria F. Crestana, Marinalva de Souza Aragão, Suely Campos Cardoso, Valéria Vilhena. $3^{a}$ ed. São Paulo: Divisão de Biblioteca e Documentações; 2011.

Abreviatura dos títulos dos periódicos de acordo com List of Journals Indexed in Index Medicus. 


\section{SUMÁRIO}

Lista de abreviaturas e siglas

Lista de tabelas

Lista de figuras

Lista de gráficos

Resumo

Summary

1 INTRODUÇÃO

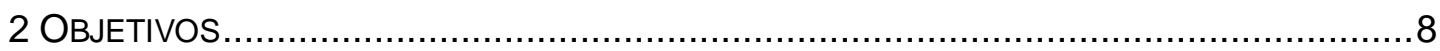

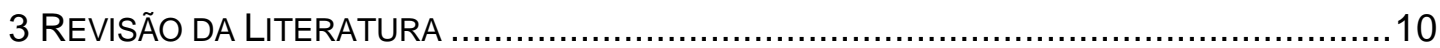

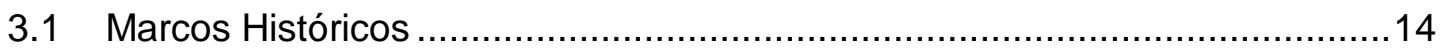

3.2 Etiologia do Bloqueio AV Congênito …………………………………....15

3.3 Fisiopatologia do Bloqueio AV Congênito ……………………………......17

3.4 Manifestações Clínicas do Bloqueio AV Congênito.........................................18

3.5 Alterações Eletrocardiográficas ……………………………………….....21

3.6 História Natural do Bloqueio AV Congênito....................................................22

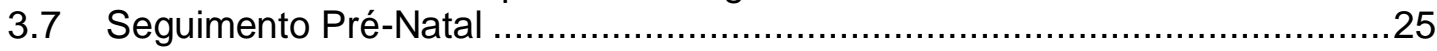

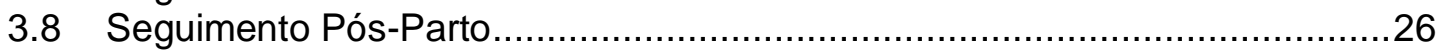

3.8.1 Indicações de implante de marca-passo...................................................26

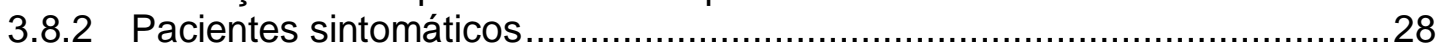

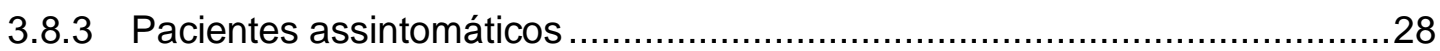

3.9 Estratégias de Estimulação Cardíaca Artificial ..............................................31

3.10 Efeitos do Marca-passo na Evolução de Portadores de Bloqueio Atrioventricular Congênito.......................................................................34

3.10.1 Desenvolvimento de miocardiopatia dilatada..............................................

3.10.2 Complicações relacionadas aos cabos-eletrodos ........................................40

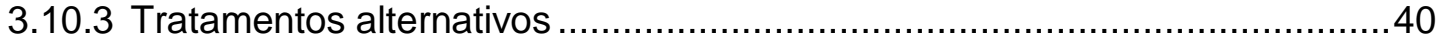

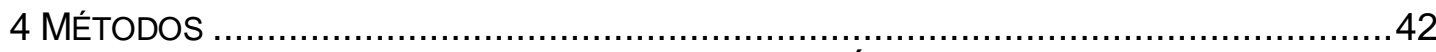

4.1 Local de Realização do Estudo e Aspectos Éticos.......................................43

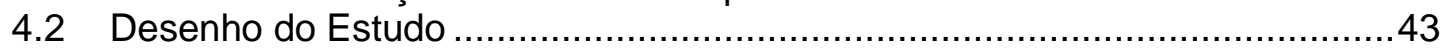

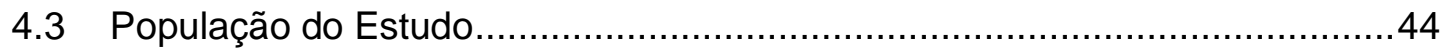

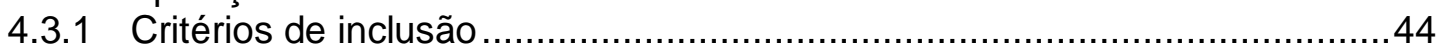

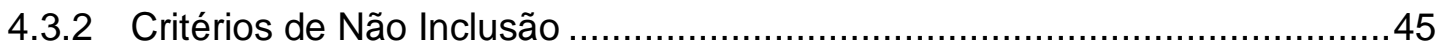

4.4 Composição dos Desfechos do Estudo ……………………………….....45

4.5 Dinâmica do Estudo...........................................................................46

4.5.1 Seleção e recrutamento dos sujeitos de pesquisa .......................................46

4.5.2 Análise do histórico dos participantes do estudo ......................................47

4.5.3 Análise das características da população no momento da inclusão no

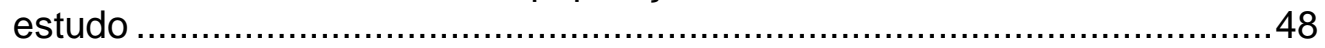

4.5.4 Avaliação das condições clínicas atuais ..................................................48

4.5.5 Avaliação do dispositivo cardíaco eletrônico implantável................................48

4.5.6 Avaliação laboratorial de marcadores de insuficiência cardíaca ....................49

4.5.7 Avaliação clínica e laboratorial de doenças reumatológicas autoimunes ......51 
4.5.8 Avaliação da qualidade de vida

4.5.9 Avaliação da Capacidade Funcional pelo Teste de Caminhada de Seis Minutos.

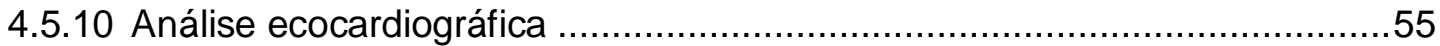

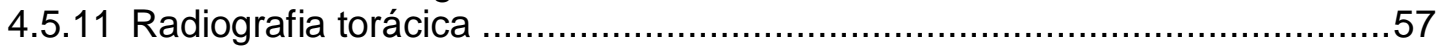

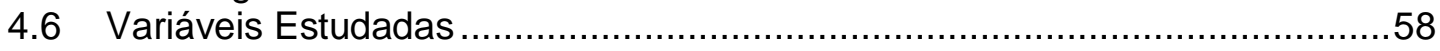

4.7 Coleta Eletrônica e Gerenciamento dos Dados .........................................62

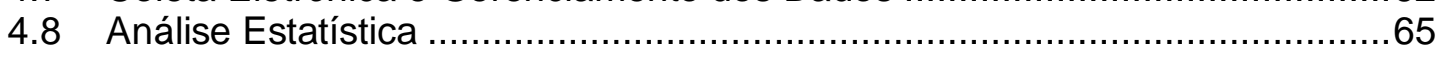

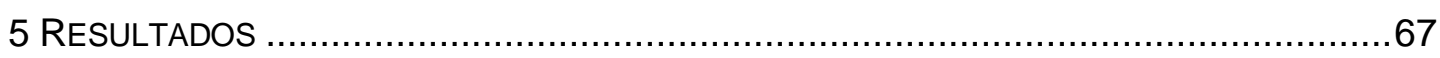

5.1 Descrição da População Selecionada.....................................................68

5.2 Análise Retrospectiva das Características da População no Momento do Diagnóstico do Primeiro Implante de Marca-passo .........................................69

5.2.1 Características demográficas e clínicas...................................................69

5.2.2 Primeiro implante de marca-passo .......................................................... 72

5.2.3 Reoperações para manutenção ou tratamento de complicações relacionadas ao marca-passo................................................................73

5.3 Características da população no momento da inclusão no estudo ................74

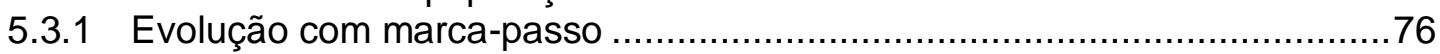

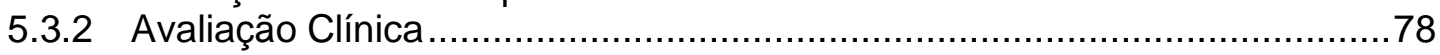

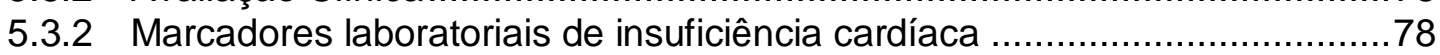

5.3.3 Avaliação eletrônica do marca-passo ................................................... 80

5.3.4 Avaliação da capacidade funcional pelo teste de caminhada de seis

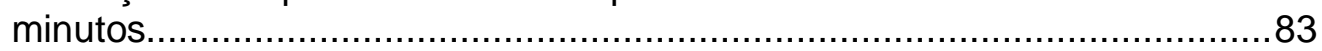

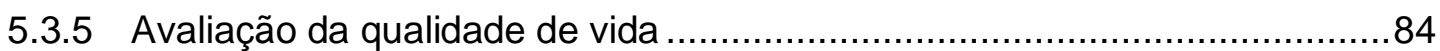

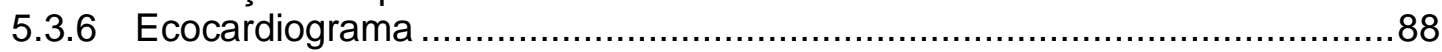

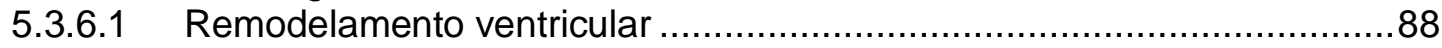

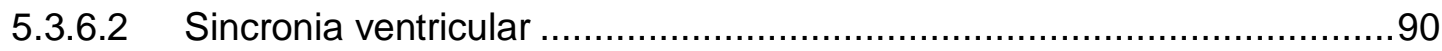

5.3.6.3 Insuficiência mitral ......................................................................... 92

5.3.7 Marcadores laboratoriais de doenças autoimunes..................................92

5.4 Análise dos Desfechos do Estudo e de seus Fatores Preditores ....................93

5.4.1 Evolução clínica ...........................................................................93

5.4.2 Marcadores laboratoriais de insuficiência cardíaca .................................96

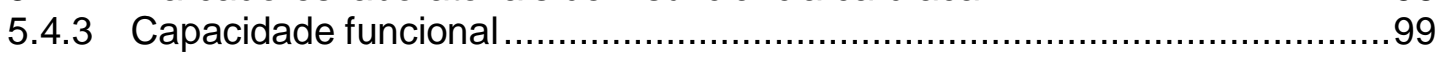

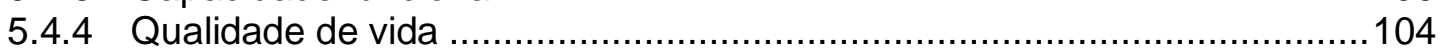

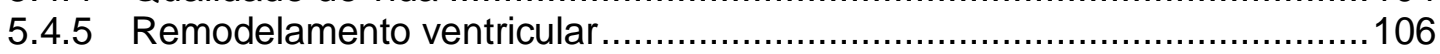

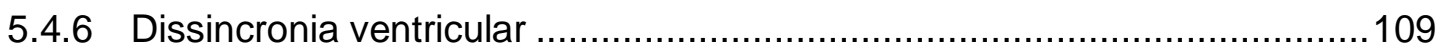

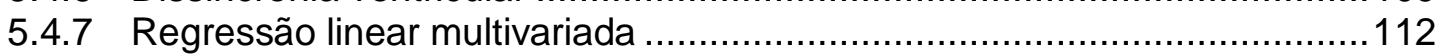

5.5 Influência dos Autoanticorpos Reumatológicos........................................ 113

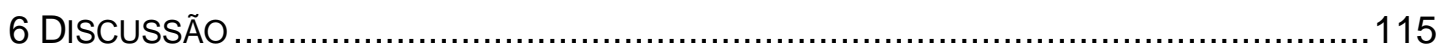

6.1 Limitações do Estudo ..................................................................... 130

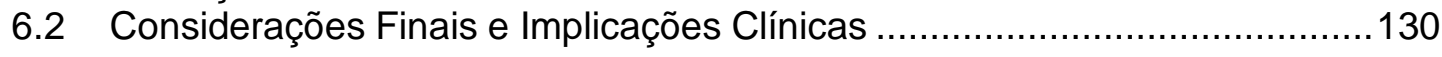

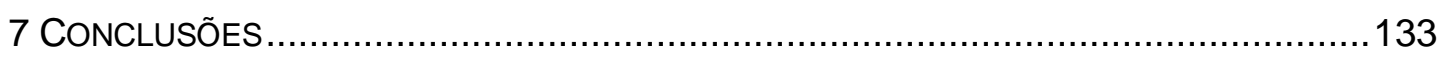

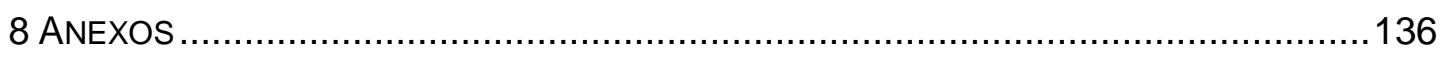

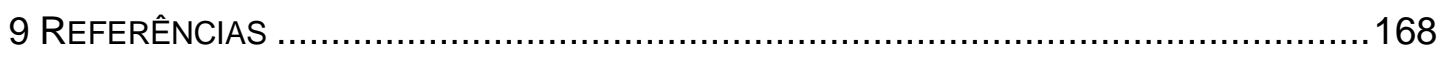

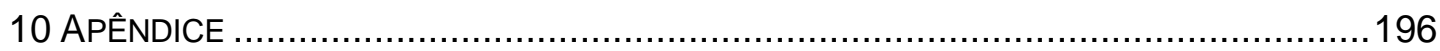




\title{
LISTA DE ABREVIATURAS E SIGLAS
}

\author{
ANA - Autoanticorpos contra antígenos nucleares \\ ATS - American Thoracic Society \\ AV - Atrioventricular \\ BAVTC - Bloqueio atrioventricular total congênito \\ BNP - Peptídeo natriurético tipo B \\ CAPPesq - Comissão para Análise de Projetos de Pesquisa \\ CHQ-PF50 - Child Health Questionnaire - Parent Form 50 \\ DCEI - Dispositivos cardíacos eletrônicos implantáveis \\ DDD - Marca-passo atrioventricular \\ DDVE - Diâmetro diastólico do ventrículo esquerdo \\ DP - Desvio padrão \\ ECG - Eletrocardiograma \\ FC - Frequência cardíaca \\ FEVE - Fração de ejeção ventricular esquerda \\ HCFMUSP - Hospital das Clínicas da Faculdade de Medicina da Universidade \\ de São Paulo \\ HP - Hewlett-Packard \\ IFI - Imunofluorescência indireta \\ IL-6 - Interleucina 6 \\ $\mathrm{LIH} \quad$ - Laboratório de Imunologia Humoral \\ MCD - Miocardiopatia dilatada \\ nCor - Instituto do Coração \\ NYHA - New York Heart Association \\ PCR-us - Proteína $C$ reativa ultrassensível \\ REDCap - Research Electronic Data Capture \\ SF-36 - Medical Outcomes Study 36-Item Short-Form Health Survey \\ TC6M - Teste de caminhada de seis minutos \\ TNF-alfa - Fator de necrose tumoral alfa
}


TRC - Terapia de ressincronização cardíaca

VD - Ventrículo direito

VE - Ventrículo esquerdo

VVI - Marca-passo ventricular

$\Delta \mathrm{D} \%$ - Fração de encurtamento do VE 


\section{LISTA DE TABELAS}

Tabela 1 - Características demográficas e clínicas dos sujeitos de pesquisa

Tabela 2 - Características dos sujeitos de pesquisa no momento da inclusão no estudo.

Tabela 3 - Caracterização dos indivíduos de acordo com o questionário utilizado para avaliação da qualidade de vida

Tabela 4 - Prevalência de anticorpos Anti-Ro/SSA e Anti-La/SSB e de manifestações clínicas de doenças reumatológicas nas mães de portadores de bloqueio atrioventricular congênito

Tabela 5 - Comparação dos indivíduos em relação à ausência e presença de sintomas de insuficiência cardíaca e uso de medicamentos de ação cardiovascular

Tabela 6 - Comparação dos indivíduos de acordo com os valores de TNF-alfa.

Tabela 7 - Comparação dos indivíduos de acordo com os valores de Interleucina-6.

Tabela 8 - Comparação dos indivíduos de acordo com os valores de PCR ultrassensível

Tabela 9- Coeficiente de correlação (Pearson) dos escores de qualidade de vida dos Sumários Físico e Mental (SF36) e Sumário Físico e Psicossocial (CHQ-PF50) com a idade no momento do implante de marca-passo, idade atual, tempo de estimulação no VD, tempo total de marca-passo e distância predita alcançada no teste de caminhada.

Tabela 10 - Análise de fatores preditores para a ocorrência de remodelamento ventricular.

Tabela 11 - Comparação dos indivíduos de acordo com a presença de auto anticorpos anti-Ro/SSA maternos 


\section{LISTA DE FIGURAS}

Figura 1 - Diagrama mostrando as principais fases do estudo .................44

Figura 2 - Exemplo de formulário eletrônico desenvolvido no REDCap para coleta de dados referentes à avaliação do marca-passo.

Figura 3 - Exemplo de formulário eletrônico desenvolvido no REDCap para coleta de dados referentes à avaliação reumatológica das mães .64

Figura 4- Constituição da população estudada.......................................69 


\section{LISTA DE GRÁFICOS}

Gráfico 1- Dados cirúrgicos do primeiro implante de marca-passo..........72

Gráfico 2- Procedimentos de reoperações para manutenção ou tratamento de complicações relacionadas ao marcapasso

Gráfico 3 - Evolução temporal dos sujeitos de pesquisa: idades no momento do diagnóstico do bloqueio atrioventricular congênito, no implante de marca-passo e na inclusão no estudo

Gráfico 4 - Mudança no modo de estimulação cardíaca nos portadores de bloqueio atrioventricular congênito isolado

Gráfico 5 - Marcadores laboratoriais de insuficiência cardíaca nos portadores de bloqueio atrioventricular congênito isolado

Gráfico 6 - Classificação dos resultados dos marcadores laboratoriais de insuficiência cardíaca de acordo com os valores de referência

Gráfico 7 - Tipo de marca-passo em uso de acordo com a faixa etária (anos) dos indivíduos no momento do estudo

Gráfico 8 - Duração do complexo QRS estimulado (A) e com o marca-passo inibido (B) obtidos durante a avaliação eletrônica do dispositivo

Gráfico 9 - Distância total caminhada e percentual da distância predita alcançada durante o teste de caminhada de seis minutos

Gráfico 10 - Correlação entre a distância total caminhada e a distância predita pela equação de Iwama

Gráfico 11 - Escores de qualidade de vida para cada um dos domínios e sumários físico e mental do Questionário SF-36

Gráfico 12 - Escores de qualidade de vida para cada um dos domínios e sumários físico e psicossocial do Questionário CHQ-PF50 
Gráfico 13 - Correlação entre as medidas sumárias dos questionários de qualidade de vida SF-36 e CHQ-PF50

Gráfico 14 - Fração de ejeção do VE (\%) obtida pelo modo bidimensional e calculada pelo Método de Simpson

Gráfico 15 - Diâmetro do ventrículo esquerdo (DDVE) de acordo com os valores definidos por faixas etárias (A) e classificação de acordo com os limites de normalidade (B).

Gráfico 16 - Escore Z do diâmetro diastólico do ventrículo esquerdo (A) e sua correlação com o diâmetro diastólico do ventrículo esquerdo (B)

Gráfico 17 - Medida do atraso eletromecânico (ms) intraventricular esquerdo (A) e interventricular (B) pelo Ecocardiograma com Doppler tecidual

Gráfico 18 - Correlação entre o atraso da ativação intraventricular esquerda e o atraso da ativação interventricular medidos pelo Ecocardiograma com Doppler Tecidual

Gráfico 19 - Classificação do grau de insuficiência mitral medido pelo Ecocardiograma Bidimensional com Doppler

Gráfico 20 - Classe funcional de insuficiência cardíaca (NYHA) e uso de medicamentos de ação cardiovascular nos portadores de bloqueio atrioventricular congênito isolado

Gráfico 21 - Correlação entre a distância predita alcançada no teste de caminhada de seis minutos com a idade no implante do marca-passo (A) , idade no momento do estudo (B), tempo de estimulação no ventrículo direito $(C)$ e tempo total de marca-passo (D) 100

Gráfico 22 - Correlação entre a distância predita alcançada no teste de caminhada de seis minutos com a duração do complexo QRS estimulado (A) e diâmetro diastólico do ventrículo esquerdo $(\mathrm{B})$

Gráfico 23 - Comparação entre a distância predita alcançada no teste de caminhada de seis minutos com o sexo (A), modo de estimulação (B), posição do cabo-eletrodo no VD (C) e autoanticorpos anti-Ro/SSA (D) 102

Gráfico 24 - Comparação entre a distância predita alcançada no teste de caminhada de acordo com a fração de ejeção do VE dos indivíduos. 
Gráfico 25 - Comparação entre a distância predita alcançada no teste de caminhada de acordo com a faixa etária dos indivíduos

Gráfico 26 - Comparação dos escores de qualidade de vida dos Sumários Físico e Mental (SF-36) e Sumário Físico e Psicossocial (CHQ-PF50) em relação ao sexo (A e C) e tipo de marca-passo (B e D)

Gráfico 27 - Comparação dos escores de qualidade de vida em relação a fração de ejeção do ventrículo esquerdo 106

Gráfico 28 - Comparação da fração de ejeção do ventrículo esquerdo em relação ao sexo (A), tipo de marca-passo (B), posição do cabo-eletrodo no VD (C) e autoanticorpos anti-Ro/SSA (D)

Gráfico 29 - Correlação entre a fração de ejeção do ventrículo esquerdo com a idade no implante do marca-passo (A), idade no momento do estudo (B), tempo de estimulação no VD (C) e tempo total de marca-passo (D) 108

Gráfico 30 - Correlação entre a fração de ejeção do VE com o atraso intra (A) e interventricular (B), duração do complexo QRS estimulado (C) e distância predita alcançada no teste de caminhada (D)

Gráfico 31 - Comparação do atraso intraventricular esquerdo com sexo (A), tipo de marca-passo (B), fração de ejeção do VE (C), insuficiência mitral (D), posição do caboeletrodo no VD (E) e autoanticorpos anti-Ro/SSA (F)

Gráfico 32 - Correlação entre o atraso intraventricular esquerdo com a idade no implante do marca-passo (A), idade no momento do estudo (B), tempo de estimulação no VD (C) e tempo total de marca-passo (D)

Gráfico 33 - Correlação entre o atraso intraventricular esquerdo com a duração do complexo QRS estimulado (A) e com o marca-passo inibido (B), porcentagem de estimulação ventricular (C) e distância predita alcançada no teste de caminhada (D)) 


\section{RESUMO}

Oliveira Júnior RM. Avaliação da estimulação ventricular direita crônica em crianças e adultos jovens com bloqueio atrioventricular congênito isolado [tese]. São Paulo: Faculdade de Medicina, Universidade de São Paulo; 2014.

Introdução: O bloqueio atrioventricular congênito isolado (BAVCi) é raro e tem múltiplas apresentações clínicas. O implante de marca-passo cardíaco permanente (MP) é o tratamento de escolha, resultando em evolução clínica satisfatória para a maioria dos casos, porém, aproximadamente $10 \%$ deles apresentam remodelamento ventricular e insuficiência cardíaca grave. Objetivos: Estudar a evolução tardia de crianças e adultos jovens com BAVCi e estimulação crônica do ventrículo direito (VD), visando determinar: a prevalência de sinais clínicos e laboratoriais de insuficiência cardíaca e de remodelamento ventricular; a capacidade funcional; a qualidade de vida e fatores preditores de alterações clínicas, funcionais ou ecocardiográficas. Métodos: Estudo transversal realizado em coorte de portadores de BAVCi e MP implantado antes de 21 anos de idade com estimulação no VD há mais de um ano. Todos os indivíduos foram submetidos a avaliação clínica e laboratorial, da capacidade funcional, da qualidade de vida e a ecocardiograma. Mães e sujeitos da pesquisa foram investigados para doenças reumatológicas. Os dados foram armazenados no sistema REDCap (Research Electronic Data Capture) e analisados pelos programas SAS (Statistical Analysis System), SPSS (Statistical Package for the Social Sciences) e R Studio. A análise dos dados incluiu: análise univariada para pesquisa de associações entre variáveis preditoras e desfechos, coeficiente de correlação de Pearson e modelo de regressão linear multivariado. Resultados: De março/2010 a dezembro/2013, foram avaliados 63 indivíduos, $68 \%$ do sexo feminino, com idade de 1 a 40 anos, com MP por $13,4 \pm 6,5$ anos e estimulação do VD por $10,0 \pm 5,4$ anos. O modo de estimulação era atrioventricular em $55,6 \%$, o percentual de estimulação de VD de $97,9 \pm 4,2 \%$ e a duração do complexo QRS estimulado de 152,4 \pm $20,1 \mathrm{~ms}$. A maioria $(88,9 \%)$ era assintomática e não utilizava medicamentos de ação cardiovascular. Maior tempo de MP $(P=0,013)$, maior tempo de estimulação do $\operatorname{VD}(P=0,005)$, maior idade na inclusão no estudo $(P=0,032)$ ou menor fração de ejeção do ventrículo (FEVE) $(P=0,013)$ associaram-se com a presença de classe funcional II (NYHA) e/ou uso medicamentos. Os valores do peptídeo natriurético tipo $B$ foram normais em todos os exames 
laboratoriais, mas houve alteração da proteína $\mathrm{C}$ reativa ultrassensível, fator de necrose tumoral alfa e interleucina- 6 em $66 \%, 34 \%$ e $13 \%$ exames, respectivamente. A distância média percorrida no teste de caminha de seis minutos foi de $546,9 \pm 76,2$ metros $(91,0 \pm 12,5 \%$ do valor predito). Os escores médios da qualidade de vida foram $78,1 \pm 17,7$ para o "Sumário Físico" e 76,6 \pm 17,1 para o "Sumário Mental" do questionário Short Form 36 (SF-36) e de 77,4 $\pm 18,5$, para o "Sumário Físico" e de 77,7 $\pm 21,6$ para o "Sumário Psicossocial", do Child Health Questionnaire - Parent Form 50 (CHQ-PF50). Diminuição da FEVE foi detectada em $39,7 \%$ e aumento do diâmetro diastólico do ventrículo esquerdo (DDVE) em $22,2 \%$ dos indivíduos. A idade mais avançada no primeiro implante de MP se correlacionou negativamente com menor FEVE $(r=-0,302 ; P=0,016)$; a duração do complexo QRS estimulado $(r=0,447 ; P=0,002)$ e maior tempo sob estimulação do $\operatorname{VD}(r=0,416 ; P=0,007)$ se correlacionaram positivamente ao aumento do DDVE. Foi detectada dissincronia ventricular em $60,3 \%$ dos indivíduos. $O$ retardo da ativação eletromecânica intraventricular esquerda foi de $86,5 \pm 56,9 \mathrm{~ms}$ e interventricular, de $141,9 \pm 88 \mathrm{~ms}$. Contudo, não houve correlação com os fatores estudados. Autoanticorpos anti-Ro/SSA foram detectados em $18(32,1 \%)$ mães, com associação entre idade no momento do implante do MP $(P=0,032)$ e uso de MP ventricular no momento do estudo $(P=0,022)$. A regressão linear multivariada confirmou a correlação entre a idade no momento do implante do MP com a FEVE ( $P=$ $0,016)$, da duração do complexo QRS estimulado $(P=0,004)$ e do tempo sob estimulação do VD $(P=0,014)$ com o DDVE. Conclusões: A prevalência de manifestações clínicas e laboratoriais de insuficiência cardíaca foi baixa; por outro lado, a de remodelamento ventricular esquerdo foi elevada. A capacidade funcional foi satisfatória, assim como a qualidade de vida, nos aspectos físicos e emocionais. Idade mais avançada no primeiro implante de MP, maior tempo sob estimulação cardíaca e complexo QRS estimulado mais alargado foram fatores independentes de remodelamento ventricular e/ou de manifestação de insuficiência cardíaca.

Descritores: Estimulação cardíaca. Pediatria. Marca-passo. Bloqueio cardíaco/Congênito. Bloqueio cardíaco congênito completo. Lúpus eritematoso sistêmico neonatal. Síndrome de lúpus neonatal. Ro anticorpos. Qualidade de vida. Teste de caminhada de 6 minutos. Dissincronia cardíaca. 


\section{SUMMARY}

Oliveira Júnior RM. Evaluation of chronic right ventricular pacing in children and young adults with isolated congenital complete atrioventricular block [thesis]. São Paulo: Faculdade de Medicina, Universidade de São Paulo; 2014.

Introduction: Isolated congenital atrioventricular block (iCAVB) is a rare condition with multiple clinical presentations. Permanent cardiac pacing is the most effective therapy for this population resulting in satisfactory long-term outcomes. However, approximately $10 \%$ of patients may have ventricular remodeling and severe heart failure. Objectives: To study the long-term effects of chronic right ventricular (RV) pacing in children and young adults with iCAVB in order to determine: prevalence of clinical and laboratory signs of heart failure and ventricular remodeling, functional capacity, quality of life and predictors of clinical, functional or echocardiographic abnormalities. Methods: Cross-sectional study of a cohort of iCAVB patients with $\leq 21$ years old at initial pacemaker (PM) implantation and single or dual-chamber pacing in a unique RV site for a minimum of one year. All subjects underwent clinical and laboratory assessment, functional capacity, quality of life and echocardiogram. Mothers and research subjects were investigated for rheumatic diseases. Data were stored in REDCap (Research Electronic Data Capture) system and analyzed by SAS (Statistical Analysis System), SPSS (Statistical Package for the Social Sciences) and R Studio programs. Data analysis included: univariate analysis for associations between predictor variables and outcomes, Pearson correlation coefficient and linear regression multivariate model. Results: Between March/2010 and December/2013, we evaluated 63 subjects aged $1-40$ years old, $68 \%$ female, under PM for $13.4 \pm$ 6.5 years and under RV pacing for $10.0 \pm 5.4$ years. Pacing mode was atrioventricular in $55.6 \%$, percentage of RV pacing was $97.9 \pm 4.2 \%$ and paced QRS duration was $152.4 \pm 20.1 \mathrm{~ms}$. Overall, the majority (88.9\%) were asymptomatic and did not use cardiovascular drugs. Longer time under PM $(P=0.013)$, or even under RV pacing $(P=0.005)$, higher age at study inclusion ( $P=0.032)$ and lower left ventricular ejection fraction (LVEF) $(P=$ $0.013)$ were associated with functional class II (NYHA) and / or drug use. Bnatriuretic peptide values were normal in all tests. $C$ reactive protein ultrasensitive, tumor necrosis factor alfa and interleukin-6 were increased in 
$66 \%, 34 \%$ and $13 \%$ tests, respectively. The mean walked distance in the sex minute walk test was $546.9 \pm 76.2$ meters $(91.0 \pm 12.5 \%$ of the predicted value). Mean scores of quality of life were $78.1 \pm 17.7$ for "Physical Summary" and 76.6 \pm 17.1 for "Mental Summary" in the Short Form 36 (SF36 ) and $77.4 \pm 18.5$ for "Physical Summary" and $77.7 \pm 21.6$ for "Psychosocial Summary", of Child Health Questionnaire - Parent Form 50 (CHQ-PF50). Decreased LVEF was detected in 39.7\% and increased left ventricular end-diastolic diameter (LVDD) in $22.2 \%$ of subjects. Higher age at the first PM implant was negatively correlated with lower LVEF $(r=-0.302 ; P=$ 0.016); paced $Q R S$ duration ( $r=0.447 ; P=0.002)$ and time under $R V$ pacing $(r=0.416 ; P=0.007)$ were positively correlated with LVDD. Ventricular dyssynchrony was detected in $60.3 \%$ of individuals. Intra-left ventricular electromechanical delay was $86.5 \pm 56.9 \mathrm{~ms}$ and interventricular was $141.9 \pm$ $88 \mathrm{~ms}$. However, ventricular dyssynchrony was not correlated with the studied variables. Autoantibodies anti-SSA/Ro were detected in $18(32.1 \%)$ mothers. There was association between age at $P M$ implant $(P=0.032)$ and use of ventricular $P M$ at the time of the study $(P=0.022)$ and presence of anti-SSA/Ro. Multivariate linear regression showed significant correlation between age at PM implant with LVEF $(P=0.016)$; and paced QRS duration $(P=0.005)$ and time under RV pacing $(P=0.014)$ with LVDD. Conclusions: Clinical and laboratorial manifestations of heart failure presented low prevalence in this population. On the other hand, the prevalence of left ventricular remodeling was high. Functional capacity was adequate, as well as quality of life, in both physical and emotional aspects. Higher age at first PM implant, longer time under pacing and wider paced QRS duration were independent factors of ventricular remodeling and/or manifestation of heart failure.

Descriptors: Cardiac pacing. Pediatrics. Pacemaker. Heart block/Congenital. Congenital complete heart block. Neonatal systemic lupus erythematosus. Neonatal lupus syndrome. Ro antibodies. Quality of life. 6-minute walk test. Cardiac dyssynchrony. 
1 INTRODUÇÃO 
O bloqueio atrioventricular (AV) congênito é uma doença rara, com incidência estimada de um novo caso a cada 20.000 nascimentos. A forma isolada dessa afecção corresponde a mais de $70 \%$ dos casos e pode estar associada a defeitos cardíacos congênitos ${ }^{1-3}$.

A fisiopatologia da lesão do sistema excito-condutor do coração está associada à autoimunidade materna em até $95 \%$ dos fetos e neonatos com bloqueio AV total, observando-se anticorpos Ro/SSA ou La/SSB na quase totalidade destes $\operatorname{casos}^{4}$. Quando o diagnóstico de colagenose materna é feito, o lúpus eritematoso sistêmico ou a síndrome de Sjögren são as doenças mais comuns. A lesão tecidual causada pela passagem placentária dos anticorpos aparece no segundo trimestre da gestação e resulta na substituição do tecido de condução por fibrose e calcificação do nó AV, podendo ocorrer, também, no nó sinoatrial e no feixe de $\mathrm{His}^{5,6}$.

Após o nascimento, uma grande gama de apresentações clínicas pode ser observada, desde a evolução completamente assintomática, com o diagnóstico feito em exames de rotina, até o desenvolvimento de quadros graves de insuficiência cardíaca, síncope ou morte cardíaca súbita ${ }^{7,8}$. Muitas vezes os sintomas são menos específicos como retardo do crescimento, cansaço, distúrbios do sono ou pesadelos frequentes ${ }^{9,10}$.

Com o advento da ecocardiografia fetal, o diagnóstico intrauterino passou a ser feito, o que permitiu tentativas de tratamento medicamentoso 
dos fetos que desenvolvem hidropisia, ou mesmo o acompanhamento da gestação e do parto dos fetos que apresentam desenvolvimento normal ou insuficiência cardíaca tolerável ${ }^{7,8,11}$.

Os achados eletrocardiográficos mais comuns em crianças com bloqueio AV congênito são de dissociação AV total, em até $93 \%$ dos casos, e, menos frequentemente, bloqueios do primeiro ou do segundo graus. Nos casos de bloqueio do terceiro grau, o complexo QRS tem duração normal em cerca de $90 \%$, sendo raro o achado de complexos com duração maior do que $120 \mathrm{~ms}^{12}$.

Quando essa doença não é tratada a mortalidade fetal e neonatal varia entre 14 e $34 \%{ }^{13,14}$. O tratamento intrauterino, com dexametasona ou fármacos beta-adrenérgicos, tem sido utilizado com resultados controversos ${ }^{14}$. Após o nascimento, o tratamento mais eficiente, se não o único disponível, é o implante de marca-passo ${ }^{10}$. Sua indicação varia em função dos sintomas e da idade das crianças. Independentemente da idade, existe consenso de que o marca-passo deve ser imediatamente implantado quando a doença se manifesta com síncopes, insuficiência cardíaca ou limitação da atividade física por incompetência cronotrópica ${ }^{15,16}$. A indicação da estimulação cardíaca artificial não é consensual, entretanto, quando os sintomas são menos evidentes como retardo do crescimento, fadiga ou pesadelos frequentes ${ }^{9,17}$.

Para os pacientes que se apresentam assintomáticos no momento do diagnóstico do bloqueio AV avançado, o habitual é não se indicar a estimulação cardíaca artificial até que os sintomas se manifestem ${ }^{18}$. 
Existem, contudo, alguns parâmetros que são considerados como fatores de risco para a evolução desfavorável dos pacientes, como: dilatação ou disfunção ventricular esquerda; frequência cardíaca menor do que 55 bpm em neonatos ou menor do que $50 \mathrm{bpm}$ nas demais faixas etárias; pausas maiores do que três segundos à monitoração contínua; complexo QRS com duração maior do que $120 \mathrm{~ms}$; extrassístoles ventriculares frequentes ou intervalo QT prolongado. Quando um ou mais destes fatores estão presentes, a estimulação cardíaca artificial tem sido indicada, mesmo em indivíduos assintomáticos ${ }^{9,16}$.

A escolha do modo de estimulação e da via de acesso para o implante do cabo-eletrodo tem sido influenciada pela idade e pelo tamanho do paciente. $O$ habitual é que crianças com peso menor do que $10 \mathrm{~kg}$ recebam cabos-eletrodos epicárdicos, por acesso subxifoide ou por toracotomia esquerda. Para as demais, os implantes transvenosos têm sido preferidos $^{19-21}$. Da mesma forma, neonatos, lactentes e pré-escolares têm recebido, preferencialmente, marca-passos ventriculares, ficando a estimulação AV reservada para os adolescentes ou para os escolares que já tenham um maior desenvolvimento físico ${ }^{22-24}$. Ressincronizadores são raramente utilizados no primeiro implante ${ }^{25}$.

Após o implante de marca-passo, em geral, a evolução clínica é muito satisfatória e a diminuição dos diâmetros do ventrículo esquerdo tem sido observada ${ }^{26}$.

O achado de miocardiopatia dilatada tem sido descrito em pacientes com ou sem marca-passo ${ }^{27}$. Na vida uterina a prevalência desse problema 
varia de $5 \%$ a $30 \%{ }^{28}$. Miorcardiopatia dilatada tardia tem sido reportada em cerca de $8 \%$ dos pacientes tratados com estimulação cardíaca artificial ${ }^{29}$. Acredita-se que o desenvolvimento de miocardiopatia tardia possa ser secundário à miocardite autoimune intrauterina ou por sua reativação pósnatal $^{2,30}$. Outras causas, todavia, também têm sido citadas como responsáveis pelo desenvolvimento de miocardiopatia dilatada nestes pacientes, em especial a miocardite viral e os efeitos deletérios da estimulação artificial crônica do ventrículo direito (VD) $)^{29,31-34}$.

$\mathrm{Na}$ população adulta, estudos recentes têm demonstrado que a estimulação crônica do VD pode causar alterações na sequência de ativação elétrica ventricular e provocar dissincronia eletromecânica ${ }^{35-37}$. Esse fenômeno tem sido correlacionado à deterioração da função ventricular esquerda e ao desenvolvimento de insuficiência cardíaca grave. Esse tipo de problema também tem sido reportado em crianças submetidas à estimulação ventricular direita crônica, por marca-passo de câmara única ou $A V^{31,34}$.

Estudos que avaliaram comparativamente a evolução de crianças com estimulação crônica do VD em relação a grupo controle constituído por indivíduos sem marca-passo identificaram 0 desenvolvimento de remodelamento e de disfunção ventricular, presença de dissincronia intraventricular esquerda, menor capacidade ao exercício físico, níveis elevados de peptídeo natriurético tipo B (BNP) e aumento da duração do complexo QRS, sendo que a estimulação apical do VD e o aumento da duração do complexo QRS foram fatores preditores da redução da função sistólica do ventrículo esquerdo ${ }^{33,38,39}$. A reversão do processo de 
remodelamento ventricular pela terapia de ressincronização cardíaca, que é obtida pela mudança do tipo de marca-passo de VD para biventricular, tem sido relatada em vários estudos ${ }^{40-49}$. Estes resultados têm reforçado a hipótese da relação de causa e efeito entre estimulação ventricular direita crônica e disfunção ventricular esquerda ${ }^{35}$.

Da mesma forma que em outras etiologias, o tratamento da insuficiência cardíaca resultante da disfunção ventricular esquerda em pacientes com bloqueio $A V$ congênito com estimulação crônica do VD é, inicialmente, farmacológico com betabloqueadores, inibidores da conversão da angiotensina e bloqueadores da ação da aldosterona. Quando ocorre refratariedade ao tratamento farmacológico, a terapia da ressincronização cardíaca tem apresentado excelentes resultados, sendo raramente necessário o transplante cardíaco ${ }^{27,50-51}$.

O panorama atual do tratamento de pacientes pediátricos com a forma isolada do bloqueio AV congênito é formado por uma doença rara, com grande variedade de apresentações clínicas, pela falta de consenso para tomada de condutas para o melhor momento do implante de marca-passo, a escolha do melhor modo de estimulação, assim como da via de acesso para o implante dos cabos-eletrodos ${ }^{18,21,52,53}$. A este cenário, juntam-se o desconhecimento de quais pacientes apresentarão evolução clínica e funcional satisfatória e quais apresentarão disfunção ventricular esquerda grave e insuficiência cardíaca ${ }^{29,51,54}$.

A justificativa do presente estudo reside na necessidade da melhor compreensão dos efeitos tardios da estimulação crônica do VD no 
sincronismo e na função ventricular esquerda dos pacientes. No mesmo sentido, existe a necessidade de se conhecer mais profundamente como é a evolução clínica, a capacidade funcional e a qualidade de vida destes indivíduos. A resposta a esses questionamentos poderá permitir a identificação de fatores de risco para o aparecimento da disfunção ventricular esquerda, de como se fazer seu diagnóstico precoce, a prevenção e, se possível, a reversão do remodelamento ventricular. 
2 OBJetivos 
Estudar a evolução tardia de crianças e adultos jovens com bloqueio atrioventricular congênito isolado e marca-passo cardíaco artificial com estimulação crônica do ventrículo direito, visando a determinar:

1) A prevalência de indivíduos que desenvolveram sinais clínicos e alterações em marcadores laboratoriais de insuficiência cardíaca.

2) A prevalência de anormalidades da sincronia e da função ventricular esquerda.

3) A capacidade funcional.

4) A qualidade de vida.

5) A presença de autoanticorpos e de doença autoimune nas mães dos sujeitos de pesquisa.

6) Os fatores de risco relacionados à ocorrência de alterações clínicas, funcionais ou ecocardiográficas. 
3 REVISÃo dA LITERATURA 
Marca-passos cardíacos permanentes têm sido usados em crianças há mais de 50 anos (Moquin $1962^{*}$ apud Serwer e Shetty ${ }^{55}$ ). Embora a estimulação cardíaca artificial pediátrica ainda seja um grande desafio para os especialistas, a utilização dessa modalidade terapêutica tem sido expandida graças aos avanços tecnológicos incorporados aos dispositivos cardíacos eletrônicos implantáveis (DCEI), assim como, às novas estratégias diagnósticas, que têm permitido o conhecimento mais detalhado da história natural e do comprometimento hemodinâmico que os distúrbios do ritmo cardíaco provocam nas crianças ${ }^{55}$.

Atualmente, as indicações de estimulação cardíaca artificial na população pediátrica deixaram de contemplar exclusivamente o tratamento das bradiarritmias, estendendo-se à prevenção da morte cardíaca súbita pelo uso de cardioversores-desfibriladores implantáveis ${ }^{56,57}$ e, mais recentemente, ao tratamento da insuficiência cardíaca causada por distúrbios da condução elétrica intraventricular, com o emprego da terapia de ressincronização cardíaca (TRC) ${ }^{25}$ Esses DCEI, utilizados isoladamente ou na forma de dispositivos combinados, permitem, ainda, o registro do ritmo cardíaco, batimento a batimento, servindo como poderosa ferramenta diagnóstica e de controle terapêutico ${ }^{58,59}$.

Moquin PM, Vaysse J, Durand M, Sprovieri L. Implantation d'um stimulateur interne pour correction d'un bloc auriculoventriculoventriculaire chirurgical chez une enfant de 7 ans. Arch Mal Coeur Vaiss. 1962; 55:241. 
Mesmo com a crescente expansão, o implante de DCEl em pacientes com idade inferior a 18 anos corresponde a menos de $1 \%$ dos procedimentos realizados, considerando-se os dados da Europa e Estados Unidos $^{53,60}$. Dados do Registro Brasileiro de Marcapassos mostram que, no período compreendido entre 1994 a 2011, dos 192.306 implantes iniciais reportados, apenas $1,5 \%$ se referiam a pacientes com idade inferior a 20 anos de idade, correspondendo a cerca de 160 novos procedimentos por ano em todo o país ${ }^{61}$. O Instituto do Coração (InCor) do Hospital das Clínicas da Faculdade de Medicina da Universidade de São Paulo (HCFMUSP), ao longo dos anos, tem sido considerado um centro de referência para estimulação cardíaca artificial pediátrica. Desse modo, a proporção de crianças submetidas a implante de dispositivos cardíacos eletrônicos é cerca de três vezes maior que a média reportada pelos demais hospitais brasileiros, correspondendo a 4,0\% dos implantes iniciais ${ }^{61}$.

Bloqueios AV avançados, à semelhança do que ocorre na população adulta, constituem-se na principal indicação de implante de marca-passo em crianças, ocorrendo em cerca de $80 \%$ dos implantes iniciais ${ }^{61}$. Historicamente, bloqueios AV secundários à lesão do sistema de condução elétrico do coração durante a correção de defeitos intracardíacos ainda permanecem como a causa mais frequente de implante de marca-passo em pacientes pediátricos. O bloqueio AV congênito, a despeito de sua raridade, é a segunda indicação mais comum de implante de DCEl em crianças, sendo responsável, classicamente, por 10 a $25 \%$ dos implantes iniciais ${ }^{55}$.

Poucos estudos não controlados e, em sua maioria, retrospectivos têm sido publicados para relatar experiências com a estimulação cardíaca 
artificial pediátrica, sobretudo em portadores de bloqueio AV congênito isolado $^{62,63}$. Desse modo, ainda faltam evidências quanto ao momento ideal para indicar o implante de DCEI ${ }^{18}$, o tipo de dispositivo a ser empregado (marca-passos convencionais ou ressincronizadores cardíacos) ${ }^{64}$, a escolha pelo implante de cabos-eletrodos endovenosos ou epicárdicos ${ }^{65}$, bem como, pelos sítios de estimulação ventricular ${ }^{66}$. Mais importante ainda, é a falta de melhor entendimento do prognóstico a longo prazo desses pacientes no que diz respeito ao desenvolvimento de disfunção e dilatação ventricular esquerda, insuficiência cardíaca ${ }^{54}$ e o impacto do dispositivo cardíaco na qualidade de vida e na capacidade funcional ${ }^{67}$.

Na tentativa de sintetizar as informações mais relevantes da literatura, foi realizada uma pesquisa bibliográfica em cinco bases de dados eletrônicas (PubMed, Embase, Lilacs, Cochrane CENTRAL-e ClinicalTrials.gov) até dezembro de 2013, sem restrição de data ou idioma de publicação. A estratégia de busca foi desenvolvida inicialmente no PubMed usando a terminologia do MeSH (Medical Subject Headings da National Library of Medicine) e, posteriormente, foi adaptada para as outras base de dados. As palavras-chaves incluídas foram cardiac pacing, pacemaker, heart block/congenital, congenital complete heart block, neonatal systemic lupus erythematosus, neonatal lupus syndrome, Ro antibodies, seguidos por seus respectivos termos relacionados. Foram localizados 619 artigos, dos quais 556 foram excluídos após a revisão de títulos e resumos, restando 63 artigos para revisão completa do conteúdo. Os critérios adotados para a inclusão de artigos na presente revisão da literatura foram: (a) População do estudo: 
pacientes com bloqueio AV congênito; (b) Intervenção: terem sido submetidos a implante de marca-passo; (c) Resultados reportados: mortalidade, hospitalização, insuficiência cardíaca, disfunção ventricular e dissincronia ventricular. Foram considerados todos os tipos de delineamento de estudos, tanto prospectivos quanto retrospectivos, exceto os relatos de casos. Nas próximas seções, apresentamos uma síntese das principais informações derivadas dessa revisão da literatura.

\subsection{Marcos Históricos}

A primeira descrição do bloqueio AV congênito foi publicada em 1901 por Morquio ${ }^{\dagger}$ apud Michaëlson ${ }^{1}$ que notou a ocorrência familiar de morte cardíaca súbita e síndrome de Stokes-Adams (bradicardia, síncope e crise convulsiva). Nessa época, a documentação eletrocardiográfica ainda não era possível. O primeiro relato documentado de bloqueio AV congênito foi, então, feito em 1908 por van den Heuvel ${ }^{\ddagger}$ apud Michaëlson ${ }^{1}$. A bradicardia fetal (40 a 80 bpm) como manifestação clínica do bloqueio AV congênito foi observada pela primeira vez em 1921 e, em muitos casos, permanece como o primeiro sinal deste distúrbio ${ }^{68}$. A partir desses relatos iniciais, houve grande interesse na descrição de novos casos, principalmente por causa do risco de episódios de Stokes-Adams ou de morte cardíaca súbita nesses pacientes.

\footnotetext{
$\dagger$ Morquio L. Sur une maladie infantile et familial characterisee par des modifications permanentes du pouls, des attaques syncopales et epileptiformes et la mort subite. Arch Med Enfants. 1901; 4:467-75.

¥ van den Heuvel GCJ. De ziekte van Stokes-Adams en een geval van aangehorene hart blok. Thesis Groningen 1908.
} 
Em 1929 Yater $^{\S}$ apud Pinsky ${ }^{69}$ propôs os primeiros critérios diagnósticos para o bloqueio AV congênito que mais tarde foram ampliados. Quatro décadas depois, Michaëlson e Engle $^{70}$ estimaram a incidência e, sobretudo, foram os primeiros a avaliar a história natural do bloqueio AV congênito. Embora o desenvolvimento embrionário anormal do sistema de condução cardíaco tenha sido identificado como uma causa de bloqueio AV congênito isolado ${ }^{68,71}$, cerca de 60 a $95 \%$ dos pacientes têm doença autoimune induzida por anticorpos e adquirida passivamente ${ }^{5}$.

\subsection{Etiologia do Bloqueio AV Congênito}

Uma vez que a associação entre doença do tecido conjuntivo materno e anticorpos anti-Ro/SSA e La/SSB foram sugeridos no final da década de $1970^{71}$, os esforços se concentraram em estudos clínicos e experimentais que resultaram em um amplo entendimento da patogênese e na evolução clínica do bloqueio AV congênito associado à doença autoimune ${ }^{72-74}$. A passagem transplacentária de autoanticorpos da circulação materna para a fetal ocorre entre a $16^{\mathrm{a}}$ e $24^{\mathrm{a}}$ semana de gestação ${ }^{75}$ e pode afetar o desenvolvimento do sistema de condução cardíaco e do tecido miocárdico em 1\% a 2\% das gestações autoanticorpos positivas, através de resposta inflamatória que resulta em lesão de tecidos, fibrose e cicatrização do sistema de condução ${ }^{5,6,76}$. Sinais de inflamação com deposição de anticorpos, fatores do complemento, infiltrados linfocitários, fibrose e calcificação foram encontrados no sistema de condução e descritos na literatura ${ }^{71,77}$.

$\S$ Yater WM. Congenital heart block. Review of the literature; report of a case with incomplete heterotaxy; the electrocardiogram in dextrocardia. Am J Dis Child. 1929; 38:112-36. 
Posterioremente, pelo uso da técnica de imunoensaio foi possível detectar anticorpos anti-Ro/SSA ou anti-La/SSB no soro de 95\% das mães de fetos ou neonatos que apresentaram bloqueio AV congênito ${ }^{10}$. Em contrapartida, autoanticorpos foram detectados em apenas uma minoria de mães de crianças em quem o bloqueio AV congênito foi diagnosticado após o período neonatal ( $5 \%$ conforme o relato de Hunscher et al. $\left.{ }^{78}\right)$. Também foi observado que uma vez que os anticorpos maternos tenham sido detectados, permanecem ao longo da vida nos soros das mães, embora os títulos de autoanticorpos possam mudar ao longo do tempo. Isto sugere um processo distinto de doença ${ }^{28,79}$.

Os anticorpos anti-Ro/SSA são detectados entre $1 \%$ e $2 \%$ das mulheres testadas randomicamente ${ }^{80,81}$. A maioria das mães é assintomática, apesar da positividade para autoanticorpos. Em apenas $20 \%$ a $30 \%$ das crianças com bloqueio $\mathrm{AV}$ congênito as mães apresentam um diagnóstico definido previamente de doença autoimune, como lúpus eritematoso sistêmico ou síndrome de Sjögren ${ }^{80,81} \mathrm{Na}$ maioria dos casos, o diagnóstico geralmente é feito somente após a detecção de autoanticorpos, como resultado de testes realizados após o diagnóstico do bloqueio AV congênito em seu recém nascido ${ }^{82}$. Entre $2 \%$ e $5 \%$ dos fetos e neonatos cujas mães têm autoanticorpos positivos desenvolvem bloqueio AV congênito e, em mães que tiveram uma criança com bloqueio AV congênito, o risco para as gestações futuras pode variar de $12 \%$ a $25 \%{ }^{83}$.

Anticorpos anti-Ro/SSA e La/SSB indutores de bloqueio AV congênito estão associados com substancial morbidade e mortalidade durante 0 
período gestacional e neonatal, com mais de $60 \%$ das crianças necessitando de terapia de estimulação cardíaca artificial no seu primeiro ano de vida ${ }^{32}$.

Nesses pacientes, a indicação mais comum para o implante de marca-passo, no período neonatal, é a insuficiência cardíaca congestiva ${ }^{80}$. Outras causas descritas na literatura incluem miocardite e vários defeitos cardíacos congênitos, particularmente isomerismo atrial esquerdo, transposição das grandes artérias, discordância atrioventricular ou poliesplenia associada a defeito do septo atrioventricular ${ }^{3}$.

Em pacientes com bloqueio $\mathrm{AV}$ congênito sem lúpus neonatal ou defeitos cardíacos congênitos associados, estimou-se uma probabilidade de herança familiar em $91 \%$. Constatou-se que os pais das crianças com bloqueio AV congênito eram significativamente mais propensos a ter distúrbios da condução cardíaca quando comparados a indivíduos saudáveis, incluindo bloqueio completo ou incompleto de ramo direito (39 vs $2 \%$ ), bloqueio do ramo esquerdo completo ou incompleto (15 vs 3\%), e PR prolongado (19 vs 0\%) ${ }^{84}$.

\subsection{Fisiopatologia do Bloqueio AV Congênito}

As primeiras descrições da fisiopatologia do bloqueio $A V$ congênito remontam ao início da década de $1970^{68}$. Na maioria dos casos, o bloqueio AV congênito é caracterizado patologicamente por tecido fibroso que substitui o nó AV e seu tecido circundante ou por uma interrupção entre o miocárdio atrial e o nó $A V^{68}$; outras lesões que podem ocorrer incluem ausência congênita do nó $A V^{85}$. $O$ efeito final é o bloqueio do estímulo elétrico que ocorre normalmente no nó $A V^{68,85,86}$. A partir dessas descrições 
iniciais, nuances têm sido adicionadas constantemente ao entendimento da fisiopatologia do bloqueio AV congênito, principalmente no âmbito molecular, no qual, especificamente para o lúpus neonatal, observou-se que a apoptose induz a translocação de anti-Ro/SSA e anti-La/SSB para a superfície de cardiomiócitos fetais ${ }^{77,87-89}$. Anticorpos anti-Ro/SSA e anti-La/SSB, em seguida, ligam-se à superfície dos cardiomiócitos fetais e induzem a liberação do fator de necrose tumoral pelos macrófagos, o que resulta em fibrose $^{87,90}$. Em adição à indução de danos ao tecido, anticorpos anti-Ro/SSA e/ou anti-La/SSB inibem a ativação dos canais de cálcio tipo $L$ ou tipo T. Os canais tipo L são considerados cruciais para a propagação do potencial de ação e pela condução através do nó $A V^{87-90}$.

\subsection{Manifestações Clínicas do Bloqueio AV Congênito}

As manifestações clínicas do bloqueio AV congênito variam conforme a idade de apresentação da doença. Alguns pacientes são assintomáticos, com bradicardia detectada apenas durante exames de rotina ${ }^{1,8,10}$. Outros podem apresentar-se com sintomas inespecíficos, como o atraso no crescimento, cansaço excessivo durante as mamadas, distúrbios do sono, ou pesadelos frequentes. A síncope, insuficiência cardíaca, ou morte súbita cardíaca podem ser a primeira manifestação do bloqueio AV congênito na ausência de sinais e sintomas anteriores de doença cardiovascular ${ }^{10}$. Em nosso meio, Cruz et al. ${ }^{52}$ observaram que os pacientes com a síndrome do lúpus neonatal tendem a apresentar alterações mais precocemente do que aqueles sem bloqueio AV associado ao lúpus neonatal. Além disso, os 
pacientes com essa síndrome podem ter como agravante uma variedade de anormalidades cardíacas, incluindo defeito do septo ventricular e fibroelastose endocárdica ${ }^{10,90}$.

Com o advento e desenvolvimento da ecocardiografia fetal, uma alta proporção de pacientes com bloqueio AV congênito mediado por autoanticorpos têm sido agora identificados no período intraútero (em populações onde a ecocardiografia fetal é realizada de rotina) ${ }^{10}$. Glickstein et al. ${ }^{91}$ demonstraram que através da mensuração do intervalo PR fetal é possível se detectar o bloqueio AV congênito intraútero. O diagnóstico do bloqueio $\mathrm{AV}$, em muitos casos, pode ser um achado incidental, ou alternativamente, a investigação diagnóstica pode ter sido realizada por causa de preocupações com o retardo no desenvolvimento fetal ${ }^{7,10}$.

Complicações intrauterinas do bloqueio AV congênito podem incluir hidropisia fetal, fibroelastose endocárdica, derrame pericárdico e morte fetal intrauterina espontânea ${ }^{10}$. Nos achados de Jaeggi et al. ${ }^{10}$, entre os 29 casos diagnosticados no período intraútero, houve um aborto terapêutico e seis mortes fetais. Uma menor taxa de morte intrauterina (6\% de $87 \%$ ) foi vista em outro estudo ${ }^{80}$. Também identificou-se que o bloqueio do segundo grau diagnosticado no útero pode progredir para bloqueio completo ${ }^{12,92}$.

Em um estudo de 127 mulheres grávidas com anticorpos anti-Ro/SSA monitoradas com ecocardiogramas fetais periódicos (semanais durante a $16^{\mathrm{a}}$ e a $26^{\mathrm{a}}$ semanas de gestação e quinzenais após a $26^{\mathrm{a}}$ ), o bloqueio avançado e a miocardiopatia apareceram após uma semana da realização de um ecocardiograma com achados normais ${ }^{93}$. A partir desses resultados, 
os autores sugerem que seja feito monitoramento intenso entre a $16^{\mathrm{a}}$ e $26^{\mathrm{a}}$ semanas de gestação.

Da mesma forma, a apresentação clínica cardinal encontrada no recém-nascido é uma bradicardia. Além da frequência cardíaca lenta, outros indícios clínicos no neonato incluem ondas "a" do pulso venoso do pescoço em canhão intermitentes, além de variações de intensidade da primeira bulha, a presença de ritmos de galope e frêmitos. Tal como acontece com os casos detectados no intraútero, quase todos diagnosticados no período neonatal (90\% na série $)^{10}$ são devido ao lúpus neonatal. Destacou-se também que o neonato em maior risco tem uma frequência atrial mais rápida, muitas vezes em torno de 150 bpm ou mais rápido, e uma frequência ventricular menor que 50 bpm. Mais comumente o eletrocardiograma mostra um complexo QRS estreito devido a um escape juncional ou nodal $\mathrm{AV}^{12}$. Jaeggi et al. ${ }^{10}$ também demonstraram que a evolução clínica para os pacientes diagnosticados no período neonatal é melhor do que para os pacientes diagnosticados no útero. Os autores diagnosticaram 33 pacientes no período perinatal, dentre os quais cinco evoluíram com sinais de insuficiência cardíaca, mas todos sem hidropisia fetal. Nenhum deles morreu nos primeiros seis meses, mas dois óbitos ocorreram aos 0,9 e 1,5 anos de idade.

Por outro lado, em $40 \%$ dos casos de bloqueio AV congênito as manifestações clínicas são evidentes a partir da infância (idade média de cinco a seis anos) $)^{10}$. Poucos destes pacientes (5\%) têm lúpus neonatal. 0 diagnóstico geralmente é incidental, quando um pulso lento é detectado e o bloqueio cardíaco é confirmado pelo eletrocardiograma convencional ou pela 
eletrocardiografia ambulatorial de 24 horas (Holter $)^{1,10,93}$. Na experiência de Jaeggi et al. ${ }^{10}$, o bloqueio $A V$ congênito pode ser intermitente nas fases iniciais da vida, mas geralmente torna-se persistente ao final da infância e, muitas vezes, não foi percebido porque se apresentava com uma frequência ventricular mais alta, com sinais e sintomas clínicos ausentes ${ }^{69}$. No entanto, dado que agora a ultrassonografia pré-natal é uma metodologia bem estabelecida, espera-se que os diagnósticos sejam mais precoces ${ }^{10}$.

\subsection{Alterações Eletrocardiográficas}

Michaëlsson et al. ${ }^{9}$ descreveram as características eletrocardiográficas do bloqueio $\mathrm{AV}$ congênito em uma coorte de 102 pacientes. A frequência cardíaca média foi de 41 bpm e, geralmente, diminuiu com o crescimento da criança. Ritmo de escape com complexo QRS largo foi observado em menos de $10 \%$ dos pacientes. Em cerca de $7 \%$ dos indivíduos foi identificado prolongamento do intervalo QT (intervalo QT corrigido > $450 \mathrm{~ms}$ ). Assim, recomenda-se mensurações seriadas no intervalo QT, tendo em vista que em $22 \%$ dos casos esses intervalos podem estar prolongados se forem feitas múltiplas avaliações ${ }^{95}$. Dois mecanismos têm sido propostos para o desenvolvimento de prolongamento do intervalo QT em pacientes com bloqueio AV congênito. Em primeiro lugar, o distúrbio de condução AV e a bradicardia podem conduzir ao desenvolvimento de repolarização alterada. Adicionalmente, os pacientes com bloqueio AV congênito, que desenvolvem prolongamento do intervalo QT, também podem ter uma manifestação fenotípica da síndrome do QT longo congênita ${ }^{95}$. 
Levy et al. ${ }^{96}$ relataram uma incidência de $35 \%$ de pausas durante a noite com intervalos R-R longos (3000-6000 ms) na mensuração da variação do intervalo R-R, pela monitorização ambulatorial de 24 horas, que também permitiu a documentação da frequência cardíaca média. O teste de esforço também tem sua importância na avaliação eletrocardiográfica de portadores de bloqueio AV congênito quando, apesar do distúrbio de condução, muitos pacientes têm um teste de esforço normal em esteira em termos de desempenho, considerando-se que nem a tolerância ao exercício, nem a frequência cardíaca máxima atingida com o exercício podem ser previstos a partir da frequência cardíaca de repouso. Ectopia ventricular ao o exercício é um achado frequente e pode ocorrer em $50 \%$ a $70 \%$ dos pacientes $^{97,98}$.

\subsection{História Natural do Bloqueio AV Congênito}

A história natural do bloqueio AV congênito isolado foi abordada em estudo prospectivo multicêntrico envolvendo 102 crianças e adultos jovens ${ }^{1,9}$. Todas as crianças eram assintomáticas nos primeiros 15 anos de vida. Observou-se que 10 pacientes morreram sem serem submetidos ao implante de marca-passo, dos quais seis pacientes não tiveram sintomas prévios. A taxa de mortalidade foi significativamente baixa nos pacientes com estimulação cardíaca artificial ao se comparar aos não estimulados artificialmente. Portanto, os autores concluíram que o prognóstico do bloqueio AV congênito pode ser modificado com o implante precoce de marca-passo.

Balmer et al. ${ }^{26}$ em seu estudo defenderam a ideia de "marca-passo profilático" em portadores de bloqueio AV congênito. Até o momento, sabe- 
se que mais de $94 \%$ das crianças portadoras de bloqueio $\mathrm{AV}$ congênito são submetidas ao implante de marca-passo antes de completar 15 anos de vida $^{28}$. Sendo assim, apesar da história natural do bloqueio AV congênito ainda não estar completamente elucidada, admite-se que a estimulação ventricular direita, unicameral ou dupla câmara, promova a modificação da evolução natural dos pacientes, principalmente dos que manifestam sintomas decorrentes do baixo fluxo sistêmico e cerebral ou são considerados com maior risco de morte cardíaca súbita ${ }^{99}$.

Outra questão importante quanto ao prognóstico destes pacientes é o desenvolvimento de miocardiopatia dilatada mediada por autoanticorpos ${ }^{2,30}$. Têm sido demonstrado que entre $6 \%$ e $11 \%$ dos portadores de bloqueio AV congênito e marca-passo com autoanticorpos positivos desenvolvem miocardiopatia dilatada num seguimento médio de $10 \pm 7$ anos $^{2,30,38}$. Dentre os fatores de risco, destaca-se a presença de anticorpos anti-Ro/SSA e antiLa/SSB induzindo dilatação cardíaca na primeira avaliação ainda sem marca-passo, ocorrendo, no entanto, a normalização do tamanho do ventrículo esquerdo após a estimulação cardíaca permanente no seguimento ${ }^{38}$. Não obstante, a disfunção ventricular esquerda induzida por marca-passo tenha sido apresentada como fator etiológico na patogênese da miocardiopatia dilatada em alguns pacientes ${ }^{27}$, crianças autoanticorpos positivas desenvolvem miocardiopatia dilatada antes da estimulação cardíaca permanente ${ }^{28,90}$. Esses dados sugerem que crianças anti-Ro/SSA e anti-La/SSB positivas apresentam dano miocárdico prévio, aumentando o risco de dilatação ventricular esquerda após o implante de marca-passo. 
Avaliação sequencial rigorosa da função ventricular torna-se mandatória ${ }^{28,90}$. O prognóstico dos portadores de bloqueio AV congênito autoanticorpos negativos parece ser diferente ao se comparar aos que possuem autoanticorpos positivos ${ }^{28,52}$. Em geral, os autoanticorpos negativos recebem o diagnóstico tardiamente e, frequentemente, têm bom prognóstico após o implante de marca-passo ${ }^{28}$. Ademais, doenças do tecido conjuntivo geralmente não são encontradas nessas mães e a recorrência de bloqueio AV em futuras gestações é muito baixa ${ }^{80}$.

A cicatriz sorológica na criança tem duração de aproximadamente seis meses e muitas das mães desconhecem o fato de serem portadoras de doença autoimune. Para o conhecimento da existência de fatores imunológicos associados a essa má formação, torna-se imperativa a avaliação materna. A definição do diagnóstico de doença autoimune materna, como lúpus eritematoso sistêmico ${ }^{100}$ ou síndrome de Sjögren ${ }^{101}$, pode ser fundamental, não apenas para o início do tratamento da mãe, mas, também, para o adequado seguimento da criança face ao risco do desenvolvimento de miocardiopatia dilatada tardia $2,33,76$.

O teste dessas várias hipóteses tem sido limitada pelo pequeno tamanho das amostras dos estudos publicados, mesmo por grandes centros. Por outro lado, a importância relativa destes mecanismos putativos é complexa e, de fato, podem existir uma interação de vários fatores ${ }^{16}$. 


\subsection{Seguimento Pré-Natal}

$\mathrm{O}$ bloqueio $\mathrm{AV}$ congênito não tratado está associado a uma mortalidade fetal e neonatal que varia entre $14 \%$ e $34 \%$. Tratamento transplacentário com dexametasona para prevenir a inflamação do miocárdio, bem como, a estimulação beta-adrenérgica com o intuito de aumentar a frequência ventricular foram propostos como opções de tratamento.

Um estudo recente demonstrou que a corticoterapia diminuiu significativamente a mortalidade fetal ${ }^{14}$. Não obstante, a administração transplacentária de corticosteroides para o tratamento de bloqueio cardíaco congênito ainda é considerada controversa. Ao contrário, um estudo multicêntrico retrospectivo não encontrou redução significativa na ocorrência de hidropisia fetal ${ }^{102,103}$. Além disso, há o potencial dano para a mãe e o bebê como resultado do uso de corticosteroides, em particular, o desenvolvimento neurológico do feto pode ser prejudicado (Modi* apud Bordachar $\left.{ }^{41}\right)$. A condução de estudos prospectivos randomizados se faz necessária com a finalidade de avaliar o real papel dessas estratégias terapêuticas na fase pré-natal.

Alternativamente, a estimulação percutânea intraútero tem sido proposta ${ }^{104}$ como um método para fornecer suporte de frequência cardíaca. Entretanto, as técnicas atualmente disponíveis não apresentam resultados satisfatórios no que se refere a complicações e sobrevida fetal. Além disso, muitos obstáculos ainda precisam ser superados, especialmente no que se

* Modi N, Lewis H, Al-Naqeeb N, Ajayi-Obe M, Dore CJ, Rutherford M. The effects of repeated antenatal glucocorticoid therapy on the developing brain. Pediatr Res. 2001; 50:581-5. 
refere ao aperfeiçoamento das técnicas cirúrgicas para implante de marcapasso fetal, bem como, no desenvolvimento de cabos-eletrodos para essa finalidade.

\subsection{Seguimento Pós-Parto}

\subsubsection{Indicações de implante de marca-passo}

As decisões sobre as indicações de estimulação cardíaca artificial devem levar em conta as peculiaridades técnicas associadas ao ritmo cardíaco de crianças pequenas. Vários estudos têm demonstrado a influência da idade do paciente no momento do implante sobre os resultados tardios do tratamento ${ }^{32,69,53,105}$. Um dos fatores que justificam esses achados é o fato de que, como a indicação do implante de marca-passo em crianças é feita mediante a manifestação de sintomas ou risco de morte, quanto mais precoce for a necessidade de estimulação artificial, maior será a gravidade da cardiopatia ${ }^{32,69,53,105}$. Por outro lado, alterações cardíacas importantes podem ocorrer ao se postergar demasiadamente a indicação da estimulação cardíaca artificial em pacientes assintomáticos ${ }^{9}$. Estudos observacionais, com seguimento, a longo prazo, de crianças com bloqueio $A V$ total, têm demonstrado que a bradicardia provoca danos irreversíveis à função cardíaca com importantes repercussões sobre a morbidade e mortalidade ${ }^{15,26}$.

O impacto da idade do paciente no momento do implante influencia, também, a realização do procedimento e seus resultados. Quanto menor for o paciente, maior será a desproporção entre o tamanho de seu corpo e o do 
dispositivo cardíaco a ser utilizado, aumentando a dificuldade para a realização do procedimento. Da mesma forma, maior será o impacto do crescimento sobre os cabos-eletrodos, aumentando o risco de fraturas e de mau funcionamento do marca-passo $24,26,106,107$.

Além do tamanho da criança, a capacitação técnica e as preferências individuais da equipe que realiza o implante do dispositivo influenciam na escolha do tipo de estimulação e na via de acesso a serem empregadas. Conquanto nas duas últimas décadas o uso de marca-passos AV com cabos-eletrodos transvenosos nas cavidades direitas tenha se estabelecido como a técnica preferida para estimulação cardíaca artificial de adultos, esta não tem sido a conduta mais utilizada em crianças com bloqueio $A V^{53,105}$. Ainda hoje, nos pré-adolescentes, utilizam-se, com maior frequência, marcapassos com um único cabo-eletrodo implantado no ventrículo direito ou esquerdo, pela técnica transvenosa, epimiocárdica subxifoide ou transtorácica. Esta simplificação tem como objetivo diminuir o número de cabos-eletrodos e facilitar tanto o implante inicial quanto as futuras intervenções para manutenção do sistema de estimulação. Por outro lado, em adolescentes, à semelhança do que se faz em adultos, os marca-passos AV transvenosos são os mais utilizados ${ }^{24,106,108}$. 


\subsubsection{Pacientes sintomáticos}

Tanto as diretrizes europeias quanto as norte-americanas recomendam implante de marca-passo em crianças com bloqueio cardíaco congênito na vigência de qualquer um dos seguintes sintomas: síncope, insuficiência cardíaca congestiva ou incompetência cronotrópica com limitações à atividade física. Existe consenso de que o implante de marcapasso é mandatório em pacientes com sinais de insuficiência cardíaca ou episódios de síncope s8,59,60. $^{\text {. }}$

Outrossim, tanto a literatura quanto a prática clínica mostram que o processo de tomada de decisão pode ser mais complexo, quando se trata de pacientes com sintomas mais sutis como: cansaço, atraso no crescimento, dispneia as mamadas, pesadelos frequentes, ou sonolência. Contudo, se a bradicardia for identificada como sendo a causa mais provável dos sintomas, a literatura recomenda o implante de marca-passo. A decisão sobre o melhor momento do implante nesses pacientes necessita de cuidadosa consideração, pesando-se os benefícios na melhora dos sintomas contra os riscos da terapia de estimulação a longo $\operatorname{prazo}^{1,9}$.

\subsubsection{Pacientes assintomáticos}

Tal como acontece com os pacientes que têm sintomas leves, a decisão crítica geralmente não é se, mas sim quando iniciar terapia de estimulação cardíaca artificial considerando que a maioria dos pacientes necessitará de marca-passo em algum momento de sua vida, mesmo não apresentando sintomas no momento do diagnóstico ${ }^{1,9}$. 
Diferentes parâmetros foram avaliados como marcadores de risco, às vezes com resultados conflitantes. Uma síntese dos principais parâmetros encontra-se descrita a seguir.

\section{Comprometimento ventricular}

Um estudo observacional de 36 pacientes demonstrou que a estimulação cardíaca é benéfica em pacientes assintomáticos com dilatação ou disfunção do ventrículo esquerdo (VE) ao ecocardiograma. As reduções nas dimensões ventriculares e melhora da função ventricular foram observadas após o início da terapia de estimulação cardíaca artificial ${ }^{109}$. Como resultado dessas descobertas, as diretrizes internacionais recomendam implante de marca-passo em pacientes sintomáticos ou assintomáticas com sinais clínicos ou ecocardiográficos de disfunção ou dilatação ventricular esquerda ${ }^{58,59,60}$.

\section{Frequência cardíaca}

Resultados conflitantes foram encontrados no que diz respeito à utilização da frequência cardíaca para predizer síncope ou morte cardíaca súbita. Na coorte de 102 pacientes estudados por Michaëlsson et al. ${ }^{70}$, constatou-se que pacientes com frequência cardíaca $<55$ bpm em repouso apresentaram mortalidade significativamente maior do que aqueles com uma frequência cardíaca mais elevada (29\% vs 4,3\%). Porém, estes resultados não foram replicados em dois estudos observacionais subsequentes ${ }^{9,17}$. 


\section{Pausa durante o ritmo espontâneo}

O valor preditivo das pausas detectadas com a monitorização eletrocardiográfica de 24 horas (Holter) também é controversa. Em um estudo observacional, Dewey et al. ${ }^{94}$ constataram que pacientes que tiveram uma frequência cardíaca $<50 \mathrm{bpm}$ ou pausa $>$ três segundos apresentaram aumento na incidência de síncope e morte cardíaca súbita. Apesar disso, em outro estudo, não foi observada diferença significativa na incidência de síncope entre pacientes com e sem pausas > três segundos durante o Holter ${ }^{94}$.

\section{Duração do complexo QRS}

Nos dias de hoje, os dados disponíveis derivam de um número relativamente pequeno de pacientes com ritmo de escape com complexos QRS largos e nenhum estudo identificou aumento do risco de morte ou síncope neste grupo de pacientes ${ }^{9,17}$. Ainda assim, dados de outras populações de pacientes sugerem que um ritmo de escape com complexo QRS largo ocorre devido ao bloqueio ser mais distal no sistema HisPurkinje $^{16}$. Portanto, embora faltem evidências definitivas na população com bloqueio AV congênito, as diretrizes internacionais recomendam o implante de marca-passo em pacientes assintomáticos que têm uma duração do complexo QRS superior a $120 \mathrm{~ms}^{58,59,60}$.

\section{Ectopia ventricular complexa}

A importância da ectopia ventricular como preditora de morte cardíaca súbita ainda não foi determinada ${ }^{17}$. 


\section{Prolongamento do intervalo QT}

Existem evidências razoáveis de que o prolongamento do intervalo QT é um fator de risco para síncope ou morte cardíaca súbita em pacientes com bloqueio AV congênito ${ }^{9,95,110}$. Desse modo, as diretrizes internacionais recomendam implante de marca-passo em pacientes com bloqueio AV congênito que apresentam intervalo QT prolongado ${ }^{58,59,60}$. O implante de cardiodesfibrilador é restrito a pacientes com episódios repetidos de síncope ou torsades des pointes documentadas, apesar da terapia otimizada. Esta opinião é corroborada pelos resultados de estudos observacionais que relatam resultados favoráveis após o implante de marca-passo ${ }^{110}$.

\subsection{Estratégias de Estimulação Cardíaca Artificial}

Numa população tão específica quanto a de portadores de bloqueio AV congênito, cada equipe médica tem sua estratégia na escolha do modo de estimulação, o que pode variar amplamente entre os diversos centros nacionais e internacionais. As crianças que se apresentam com bloqueio AV total e função ventricular normal podem, inicialmente, receber um marcapasso unicameral ventricular e, posteriormente, serem submetidos a um upgrade para o modo atrioventricular na adolescência ${ }^{22-24}$. Alternativamente, pode-se optar pelo implante de marca-passo dupla câmara já no primeiro implante. Habitualmente, sistemas epicárdicos são escolhidos para neonatos e lactentes, enquanto que a estimulação endocárdica é adiada até que a criança passe a pesar $>10 \mathrm{~kg}$ ou atinja dois anos ou mais de idade. Uma abordagem intracardíaca é, portanto, geralmente escolhida quando o 
substrato anatômico permita. Em alguns centros médicos, os implantes transvenosos são oferecidos mesmo para as crianças menores, estratégia essa que tem sido possibilitada pelo desenvolvimento de cabos-eletrodos de menor calibre. De modo distinto, outros centros postergam o implante de cabos-eletrodos endocárdicos até que a criança chegue pelo menos aos cinco a oito anos de idade ${ }^{19,20}$.

Uma série de fatores é levada em consideração no momento de decidir entre um cabo-eletrodo epicárdico e endocárdico. Algumas abordagens para a estimulação incluem:

a) Historicamente, a via de acesso preferencial tem sido a epimiocárdica e o modo de estimulação mais utilizado é o unicameral ventricular. Isso devido à pequena dimensão das superfícies torácicas e abdominal de neonatos e lactentes, o que torna difícil o alojamento dos $\mathrm{DCEl}$. Soma-se a isso, o reduzido calibre de suas veias que dificulta 0 acesso dos cabos transvenosos, associado a pouca elasticidade dos caboseletrodos que não se adapta à velocidade do crescimento da criança, fazendo com que, em pouco tempo, se tornem curtos em ralação ao tamanho corporal, ficando sujeitos a trações, que causam complicações, como aumento do limiar de estimulação ou rompimento do seu revestimento ou de seu condutor elétrico ${ }^{21,53}$.

b) Por sua vez, a via de acesso transvenosa tem apresentado melhores resultados quanto à ocorrência de aumento do limiar e perda do comando do marca-passo. Não obstante, quando 
utilizada da maneira clássica, pela veia subclávia ou jugular, fica difícil o alojamento do gerador de pulsos na parede abdominal, o local menos sujeito à erosão da pele ${ }^{21}$. Destacam-se ainda as obstruções venosas após o implante dos DCEI como resultado de lesões venosas diretas ou indiretas, associado a fatores de risco como disfunção ventricular e uso de acessos venosos centrais ipsilaterais ao lado do implante definitivo, em especial o caboeletrodo de marca-passo provisório ${ }^{111}$. Há também o risco de lesão valvar causada pelos cabos-eletrodos endocárdicos, relativamente mais frequentes em crianças devido a maior dificuldade técnica dos procedimentos ${ }^{21}$. Por fim, as complicações potencialmente fatais relacionadas às extrações de caboseletrodos endovenosos, consideravelmente aderidos em crianças $^{112}$.

$\mathrm{Na}$ falta de comparações diretas em estudos prospectivos randomizados, uma abordagem epicárdica inicial parece preferível na primeira infância, com vistas a preservar o sistema venoso em pacientes com expectativa de estimulação cardíaca artificial ao longo de toda a vida $^{22,108}$. 


\subsection{Efeitos do Marca-passo na Evolução de Portadores de Bloqueio Atrioventricular Congênito}

\subsubsection{Desenvolvimento de miocardiopatia dilatada}

No período compreendido entre 1995 a 2012, foram publicados 20 estudos que incluíram em sua amostra portadores de bloqueio AV congênito que haviam sido submetidos a implante de marca-passo (Quadro 1).

A despeito das diferenças entre a casuística, tempo de seguimento, delineamento dos estudos e desfechos estudados, a síntese dessas publicações evidencia que essa população apresenta, em geral, baixa taxa de mortalidade e de complicações relacionadas ao uso do marcapasso. ${ }^{9,21,26,29,31-33,38,51,52,63,84,106,109,113,115-119}$ Nesses estudos, a prevalência de micardiopatia dilatada (MCD), quando investigada, variou de $5 \%$ e $30 \%$.

O diagnóstico tardio da MCD pode ser decorrente de uma sequela de miocardite autoimune intraútero ou devido à sua reativação pósnatal $^{6,52,71,77,113}$. Os efeitos prejudiciais dos anticorpos maternos contra o tecido cardíaco fetal forneceu evidências em favor do papel imunopatológico desempenhado pelos anticorpos anti-Ro/SSA e anti-La/SSB em bloqueio AV congênito. A deposição de imunoglobulina $\mathrm{G}$ em todo o miocárdio observado em estudos de imunofluorescência post-mortem também sugere uma forte relação entre os anticorpos anti-Ro/SSA e anti-La/SSB no desenvolvimento de $\mathrm{MCD}^{7}$.

A maioria dos indivíduos com bloqueio $\mathrm{AV}$ congênito, quando submetida a implante definitivo de marca-passo, será estimulada em praticamente $100 \%$ do tempo. Tendo em vista as alterações distróficas do miocárdio e o remodelamento adverso causado pela dissincronia ventricular, 
a estimulação crônica do VD tem sido considerada como uma causa potencial de MCD nesta população $29-33,51,118,119$. Em alguns indivíduos, a normalização da função sistólica foi observada após a interrupção da estimulação do VD ou após o upgrade para terapia de ressincronização cardíaca, o que não seria esperado de ocorrer se houvesse miocardite em curso ou outros fatores autoimunes como única causa de $M C D^{27,43}$.

De fato, os mecanismos envolvidos no desenvolvimento de CMD em portadores de bloqueio AV congênito submetidos à estimulação crônica do VD ainda não foram completamente elucidados, fazendo-se necessária a condução de estudos prospectivos com larga escala de pacientes e adequadamente delineados para a pesquisa de desfechos clínicos. 


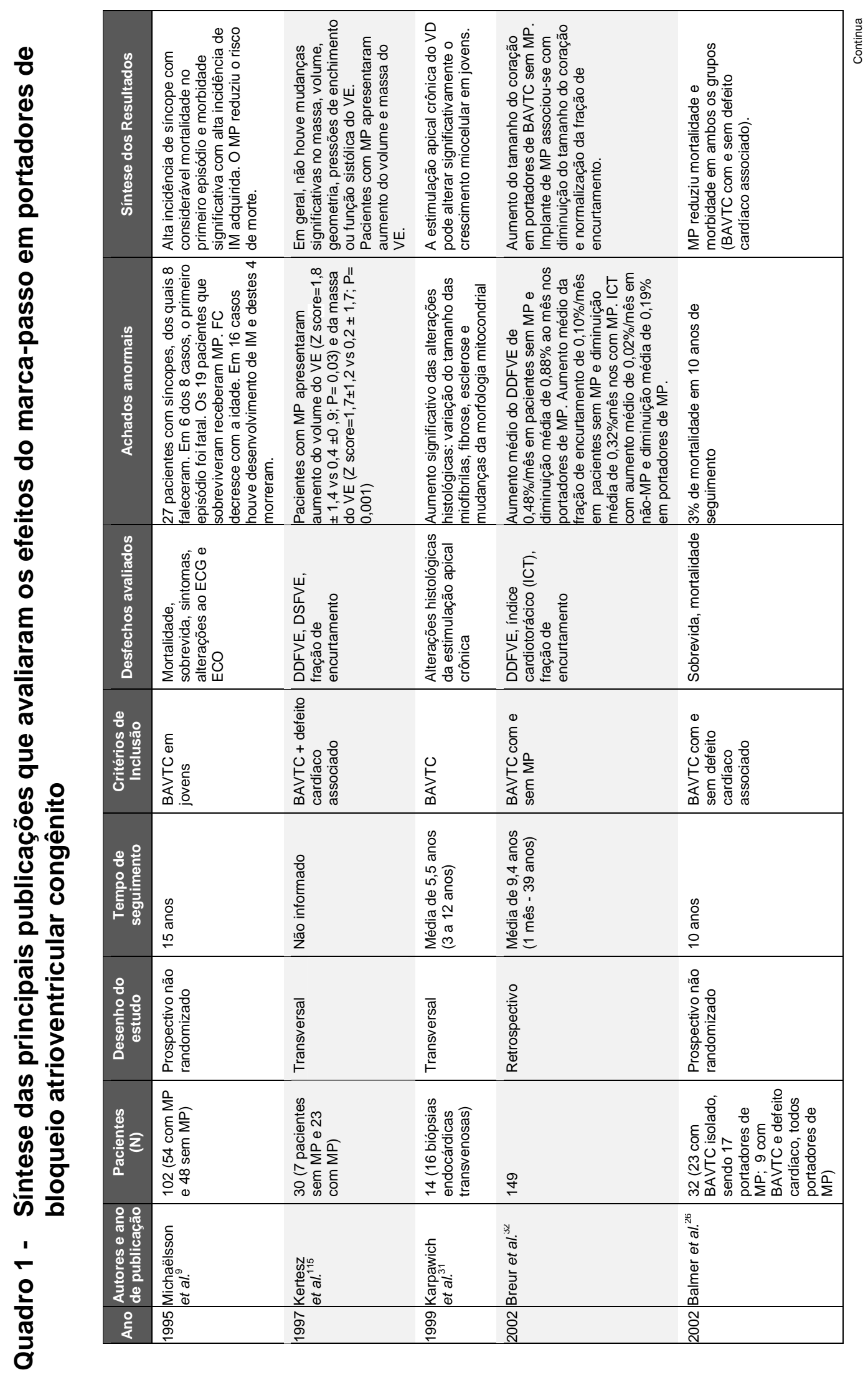




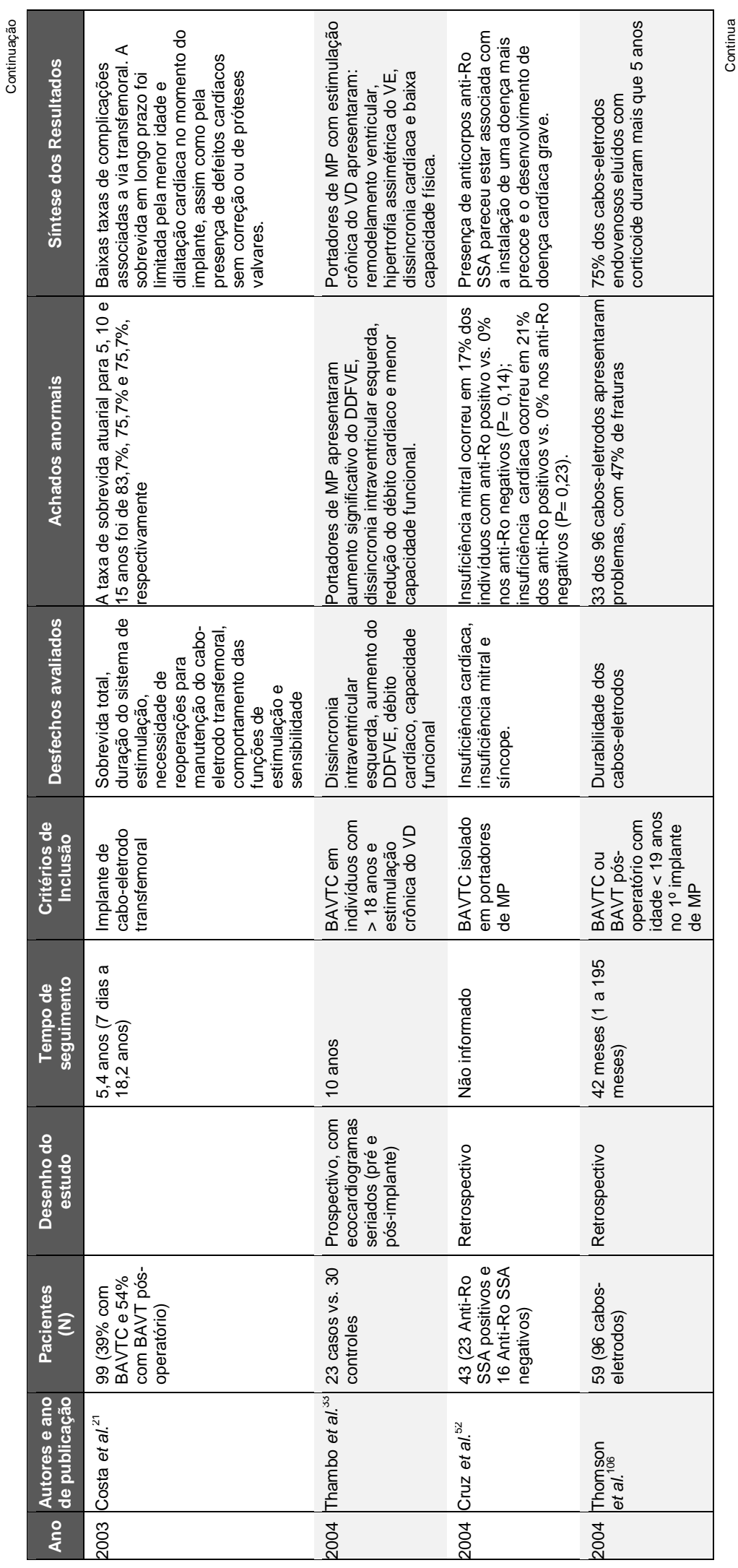




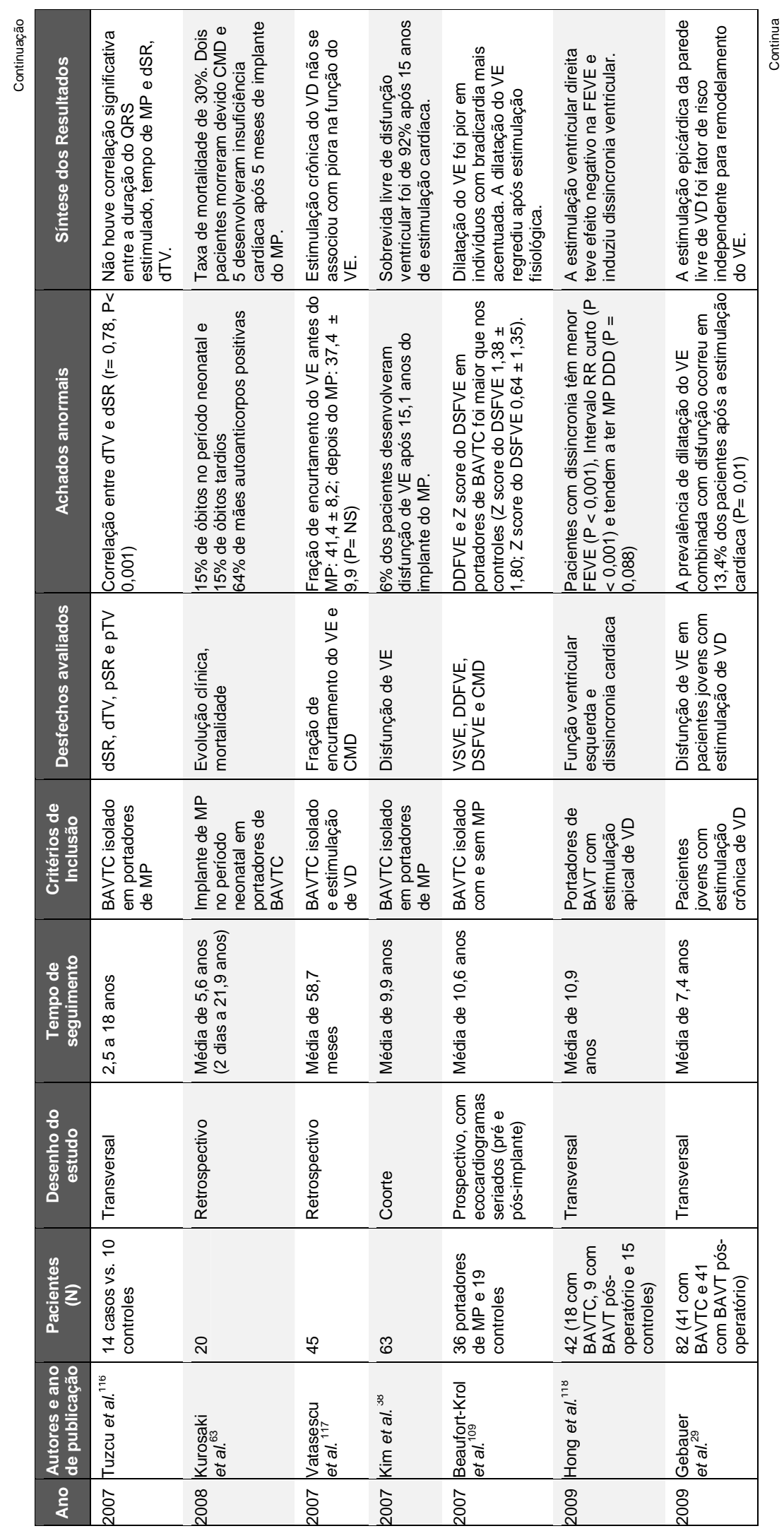



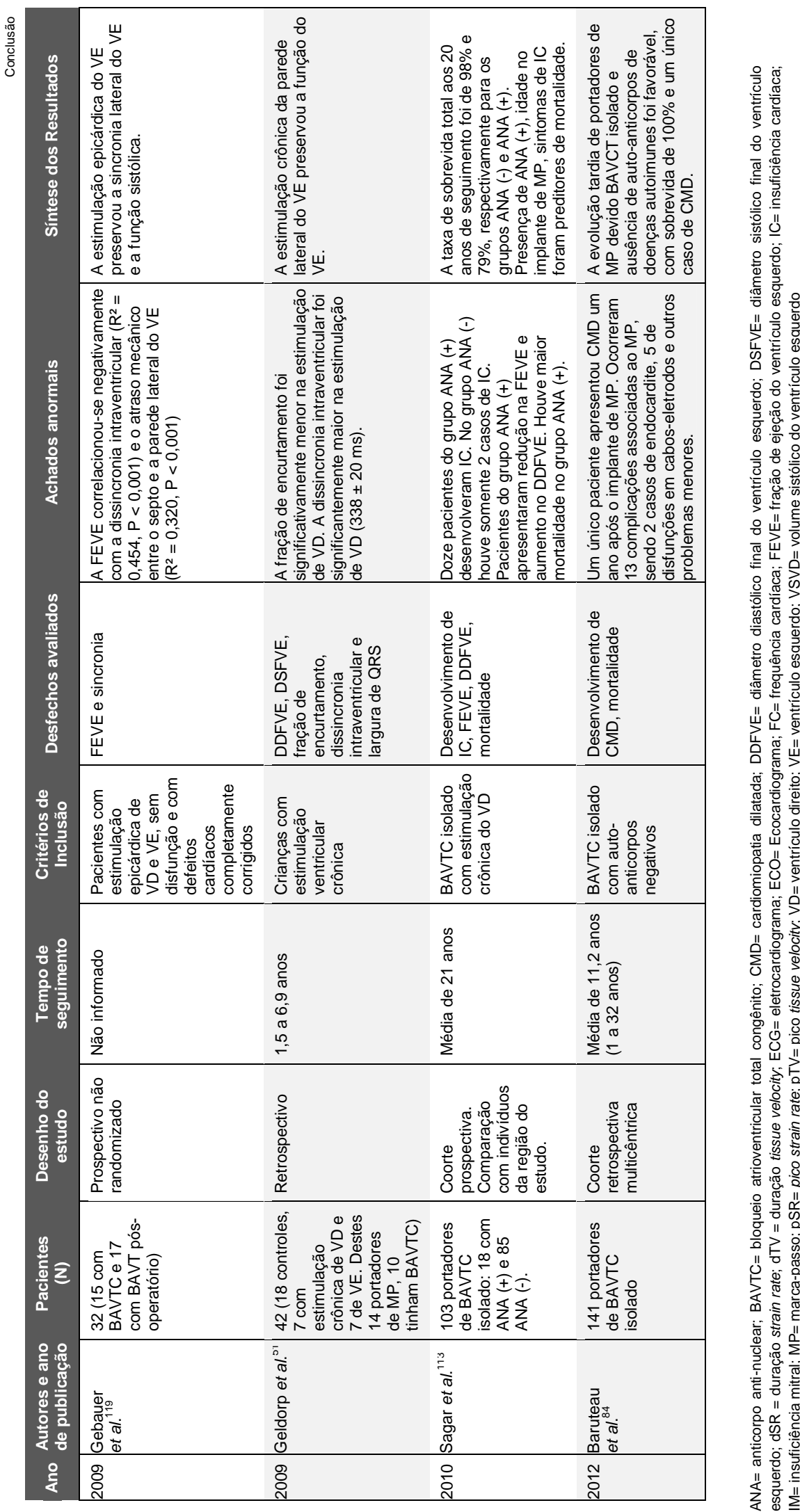


\subsubsection{Complicações relacionadas aos cabos-eletrodos}

A taxa de sobrevida média de cinco anos para cabos-eletrodos endocárdicos em crianças variou entre $76 \%$ e $89 \%$, enquanto reoperações ou complicações devido a cabos-eletrodos epicárdicos foram observadas em $15 \%$ a $20 \%$ dos pacientes ${ }^{12,19,20,22-24,31}$. Embora os dados de longo prazo sejam escassos, as taxas de disfunção dos cabos-eletrodos ao longo de várias décadas são próximas de 100\%. Flebografias obtidas após o implante de cabos-eletrodos transvenosos permanentes revelaram a presença de oclusões ou estenoses graves da grande veia cardíaca em quase $25 \%$ das crianças e jovens, bem como uma alta prevalência de oclusões que ocorrem após mais de 20 anos de estimulação cardíaca ${ }^{120}$. Enquanto complicações infecciosas têm sido descritas, o risco preciso de endocardite infecciosa ao longo do tempo de estimulação cardíaca ainda permanece desconhecido ${ }^{121}$.

\subsubsection{Tratamentos alternativos}

Implante de eletrodos epicárdicos de ventrículo esquerdo por videotoracoscopia robótica

A técnia de implante de marca-passo com assistência robótica pode permitir que os benefícios da estimulação epicárdica possam ser obtidos por meio de cirurgia minimamente invasiva. Requer uma curta hospitalização e, como os implantes transvenosos, é esteticamente favorável. Foi recentemente desenvolvida em poucos centros médicos altamente especializados e, tem sido considerada promissora porque resolve algumas limitações da estimulação cardíaca convencional, eliminando, por exemplo, os riscos de infecções endovasculares e tromboses venosas profundas. 
Por meio desta técnica, haverá a possibilidade de se implantar estes dispositivos na cavidade do VE evitando-se os potenciais efeitos deletérios da estimulação crônica do VD. Serão necessários estudos controlados para demonstrar as vantagens da estimulação do VE sobre a do VD. Atualmente, a principal limitação do implante com assistência robótica é que está disponível em poucos centros especializados ${ }^{122,123}$.

\section{Antecipando o próximo avanço: estimulação sem cabos-eletrodos}

Considerando-se que a maioria das complicações está associada à presença de cabos-eletrodos endovasculares na cavidade ventricular, o desenvolvimento de um sistema de estimulação cardíaca sem caboseletrodos por meio de cápsulas contendo baterias implantadas diretamente dentro do coração parece representar o mais promissor futuro da estimulação cardíaca artificial ${ }^{124}$. Os protótipos testados em animais têm sido implantados no VD via veia femoral. O pequeno tamanho dos dispositivos permite a rápida endotelização, limitando o risco de deslocamento ou endocardite. A implementação desta técnica em humanos é esperada para os próximos dois anos. Com o desenvolvimento dessa nova tecnologia, haverá a possibilidade de se implantar estes dispositivos na cavidade do VE, permitindo uma estimulação mais fisiológica. Estimulações biológicas também estão sob investigação, mas o caminho até a primeira aplicação clínica poderá ainda ser muito longo ${ }^{125}$. 


\section{MÉTodos}




\subsection{Local de Realização do Estudo e Aspectos Éticos}

O estudo foi realizado no Instituto do Coração do Hospital das Clínicas da Faculdade de Medicina da Universidade de São Paulo sob a coordenação da Unidade de Estimulação Elétrica e Marcapasso da Divisão de Cirurgia. Os pacientes foram incluídos no estudo e avaliados no período compreendido entre março de 2010 a dezembro de 2013.

O protocolo de pesquisa foi submetido e aprovado pela Comissão Científica do InCor-HCFMUSP e pela Comissão para Análise de Projetos de Pesquisa (CAPPesq) sob n1248/09 (Anexos A e B). Esta investigação seguiu as normas éticas estabelecidas pela Declaração de Helsinque ${ }^{126}$.

\subsection{Desenho do Estudo}

Trata-se de uma análise transversal de uma coorte de pacientes previamente submetidos a implante de marca-passo por bloqueio atrioventricular congênito. $O$ flux apresentado na Figura 1 sumariza as principais etapas do estudo. 


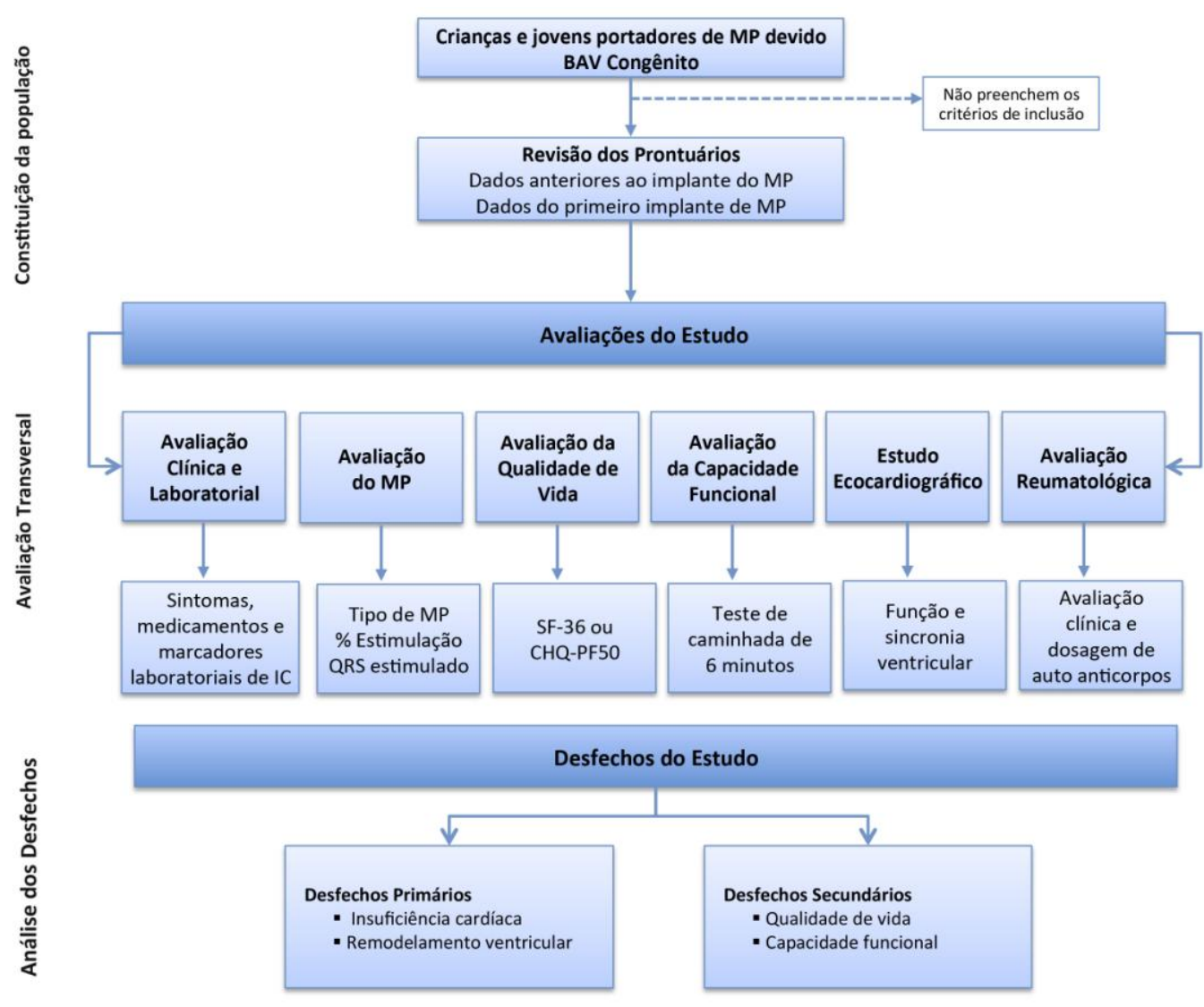

Figura 1 - Diagrama mostrando as principais fases do estudo

\subsection{População do Estudo}

\subsubsection{Critérios de inclusão}

Foram considerados elegíveis para o estudo, indivíduos submetidos a implante de marca-passo cardíaco artificial permanente, com as seguintes características:

a) Bloqueio atrioventricular do segundo ou terceiro graus de etiologia congênita.

b) Ausência de defeitos cardíacos congênitos associados, corrigidos ou não corrigidos cirurgicamente. 
c) Idade inferior a 21 anos no momento do implante inicial de marcapasso.

d) Presença de estimulação ventricular direita unifocal com tempo de implante superior a um ano.

\subsubsection{Critérios de Não Inclusão}

Não foram incluídos no estudo os indivíduos que apresentaram ao menos uma das seguintes situações:

a) Estimulação cardíaca bifocal ou biventricular no primeiro implante.

b) Impossibilidade de comparecimento ao serviço para a realização do ecocardiograma e demais exames relacionados ao estudo.

\subsection{Composição dos Desfechos do Estudo}

A descrição detalhada dos desfechos e como foram mensurados encontra-se na Quadro 2. 


\section{Quadro 2 - Definição dos desfechos do estudo}

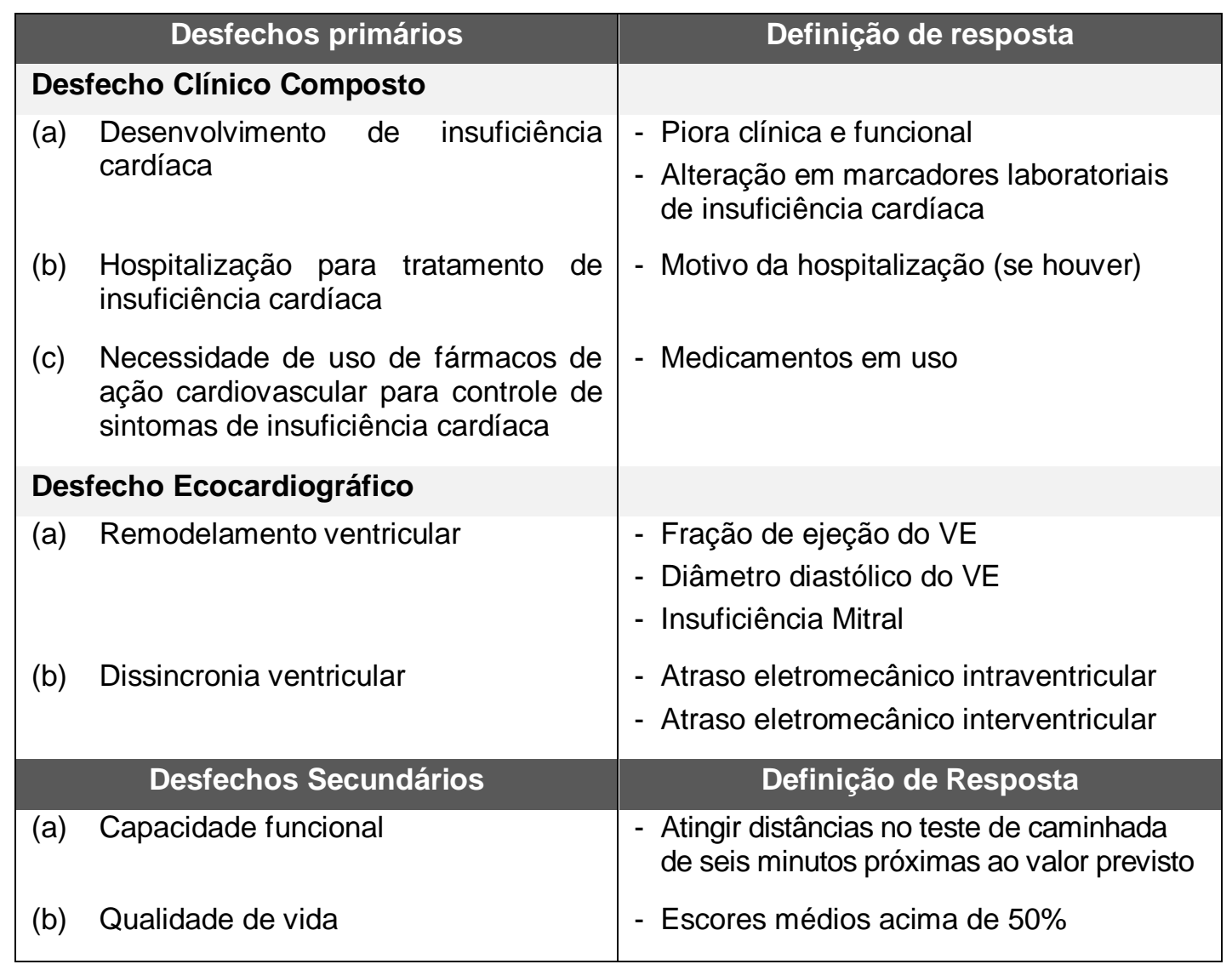

\subsection{Dinâmica do Estudo}

\subsubsection{Seleção e recrutamento dos sujeitos de pesquisa}

Os indivíduos foram selecionados de forma consecutiva durante 0 atendimento ambulatorial na Unidade de Estimulação Cardíaca Artificial do InCor-HCFMUSP ou mediante consulta ao Banco de Dados da Unidade Cirúrgica de Estimulação Elétrica e Marcapasso. Os indivíduos que preencheram os critérios de elegibilidade foram devidamente informados quanto aos objetivos, procedimentos que seriam realizados, desconfortos e riscos relacionados ao estudo. Foi empregado o Termo de Consentimento Livre e Esclarecido para formalizar as devidas garantias e direitos dos sujeitos de pesquisa (Anexo C). 


\subsubsection{Análise do histórico dos participantes do estudo}

O levantamento do histórico de cada sujeito de pesquisa foi realizado por entrevista, consulta ao banco de dados eletrônicos da Unidade de Estimulação Elétrica e Marcapasso do InCor-HCFMUSP e pela revisão dos prontuários. Foram coletadas as seguintes informações:

a) Dados anteriores ao implante do marca-passo: data do diagnóstico do bloqueio AV avançado; idade e momento do diagnóstico (intrauterino, neonatal, lactente, pré-escolar, escolar ou adolescência); grau de bloqueio AV; indicação clínica do implante de marca-passo; antecedentes pessoais/comorbidades associadas (síndrome do lúpus neonatal, rubéola congênita, miocardite); sintomas clínicos (pré-síncope, síncope, dispneia, palpitações, bradicardia assintomática); medicações em uso; dados relevantes do eletrocardiograma pré-implante do marca-passo (frequência cardíaca, ritmo de base, morfologia, duração e eixo do QRS, intervalo QT corrigido); análise funcional e estrutural ao ecocardiograma, bem como ausência de defeitos cardíacos associados.

b) Dados do primeiro implante do marca-passo: data e idade no momento do implante; tempo transcorrido entre o diagnóstico do bloqueio AV congênito e a idade no momento do implante; tipo de marca-passo implantado; via de acesso utilizada para implante do dispositivo; local do implante do cabo-eletrodo ventricular direito.

c) Eventos pós-operatórios anteriores à inclusão no presente estudo: número de trocas de gerador e outras reoperações para manutenção do sistema de estimulação cardíaca; complicações relacionadas ao dispositivo; procedimentos cirúrgicos não relacionados ao sistema de estimulação cardíaca artificial. 


\subsubsection{Análise das características da população no momento da inclusão no estudo}

Nessa fase do estudo foram atualizados os dados demográficos dos sujeitos de pesquisa, e foram realizadas todas as avaliações que compõem o presente protocolo de pesquisa, as quais estão descritas nas próximas seções.

\subsubsection{Avaliação das condições clínicas atuais}

A avaliação clínica do paciente priorizou a pesquisa das manifestações clínicas atuais e, em especial, sinais e sintomas de insuficiência cardíaca, o uso de medicamentos de ação cardiovascular e a pesquisa de comorbidades associadas; hospitalizações; operações não cardíacas, ou seja, aquelas não relacionadas à estimulação cardíaca. E, por fim, a situação atual no que se refere ao seguimento regular no InCor-HCFMUSP.

\subsubsection{Avaliação do dispositivo cardíaco eletrônico implantável}

A avaliação da função de estimulação cardíaca atual visou a determinação dos seguintes parâmetros: modo de estimulação em uso; ritmo atrial; ritmo ventricular; frequência cardíaca; o tipo de resposta ao marcapasso; a duração, morfologia, eixo de despolarização do complexo QRS, com marca-passo funcionando e com o marca-passo inibido; condições de funcionamento do dispositivo; porcentagem de estimulação ventricular.

A análise foi realizada com auxílio de programador específico de acordo com a marca do gerador de pulsos e o eletrocardiograma (ECG) de 
superfície de 12 derivações. O equipamento utilizado foi o da marca HewlettPackard (HP), modelo Page Writer 200, com capacidade para análise automática de eixos e intervalos. Para cada indivíduo, o aparelho de ECG avaliou tanto o ritmo durante a estimulação cardíaca artificial, quanto o ritmo cardíaco espontâneo, com o marca-passo inibido.

\subsubsection{Avaliação laboratorial de marcadores de insuficiência cardíaca}

A avaliação laboratorial visou a identificação de alterações em marcadores laboratoriais que indiquem a presença ou progressão da insuficiência cardíaca. Desse modo, foram coletadas amostras sanguíneas para determinação dos seguintes marcadores: Peptídeo Natriurético tipo B, Fator de Necrose Tumoral alfa (TNF-alfa), Interleucina 6 (IL-6) e Proteína C reativa ultrassensível (PCR-us). Todos os exames laboratoriais foram realizados no Laboratório de Análises Clínicas do InCor-HCFMUSP.

A concentração plasmática do BNP foi obtida por imunoensaio com tecnologia quimioluminescente direta e quantidades constantes de dois anticorpos monoclonais. Para tanto, foi utilizado o kit comercial ADVIA Centaur $^{\circledR}$ (Siemens Medical Solutions Diagnostic, Los Angeles, Estados Unidos) em equipamento automatizado da mesma marca. Os resultados foram apresentados em pg/mL, sendo o intervalo de referência $<100 \mathrm{pg} / \mathrm{dL}$.

As detecções e quantificações de IL-6 e do TNF-alfa foram realizadas

utilizando os kits específicos distribuídos comercialmente e seguindo o protocolo estabelecido pelo fabricante $\left(\right.$ IMMULITE $^{\circledR}$, Siemens Healthcare Diagnostics Inc., Estados Unidos), por meio da técnica de imunoensaios 
quimiluminescentes automatizados, utilizando o instrumento de acessor randômico contínuo (IMMULITE ${ }^{\circledR}$, Siemens Healthcare Diagnostics Inc., Estados Unidos). O sistema IMMULITE utilizou ensaios específicos, pérolas de plástico (poliestireno) recobertas com antígeno ou anticorpos que correspondeu a uma fase sólida, reagente marcado com fosfatase alcalina e um substrato quimiluminescente por reação enzimática. A pérola foi encerrada em uma unidade teste. A unidade teste serviu como vaso reacional para a reação imune, processo de incubação, lavagem e o desenvolvimento do sinal. Após a incubação da amostra com o reagente marcado com fosfatase alcalina, a mistura dos líquidos de reação da unidade teste foi rapidamente separada da pérola, quando a mesma foi lavada, e a unidade teste é girada em alta velocidade sob seu eixo vertical. Os conteúdos totais dos fluídos (amostra, reagente em excesso e solução de lavagem) foram transferidos a uma câmara coletora de resíduos da unidade teste. A pérola permanece sem marcador não ligado residual. O ligado marcado na pérola foi então quantificado com o substrato, éster fosfato de adamantil dioxetano, o qual produz luz. A emissão de luz foi detectada por um tubo fotomultiplicador e os relatórios impressos de cada amostra foram gerados pelo sistema de computação. As amostras de soro foram consideradas positivas quando na presença de reatividade. Os resultados foram apresentados em $\mathrm{pg} / \mathrm{mL}$, sendo o intervalo de referência de $<$ 8,1 e $<3,4$ para o TNF-alfa e IL-6, respectivamente.

Para as dosagens de PCR-us, o sangue foi coletado em tubo com gel separador. Após formação completa do coágulo, as amostras foram centrifugadas por 15 minutos a 3000 rpm e em seguida, encaminhadas para a análise. 
A PCR-us foi quantificada por meio de anticorpos monoclonais, pelo método de imunonefelometria em equipamento automatizado BN II Systems, utilizando o kit CARDIO PHASE ${ }^{\circledR}$ hs CRP (Siemens Healthcare Diagnostics Products, Marburg, Alemanha). O intervalo de referência adotado foi de < $1,0 \mathrm{mg} / \mathrm{L}$ para avaliação de risco de doença cardiovascular, sendo considerado risco moderado os valores entre 1-3 $\mathrm{mg} / \mathrm{L}$ e alto risco quando superiores a $3 \mathrm{mg} / \mathrm{L}$.

\subsubsection{Avaliação clínica e laboratorial de doenças reumatológicas autoimunes}

Cada par de sujeitos da pesquisa, paciente e sua mãe, foi submetido à avaliação clínica e laboratorial. Para tanto, as mães que concordaram em participar do estudo também assinaram o Termo de Consentimento Livre e Esclarecido (Anexo C).

A avaliação clínica das mães foi realizada por meio de consulta médica especializada com reumatologista que priorizou a investigação da história obstétrica pregressa; manifestações clínicas passadas e atuais de doenças reumatológicas autoimunes. O diagnóstico de doenças autoimunes mais frequentemente associadas ao lúpus neonatal foi definido de acordo com os critérios de classificação estabelecidos: lúpus eritematoso sistêmico, síndrome de Sjögren, outras colagenoses, diagnóstico indefinido e mãe assintomática $^{100,101}$.

Para os filhos priorizou-se a busca de diagnóstico de lúpus neonatal ao nascimento. Além disso, no momento da entrevista dos pares, buscou-se 
sinais e sintomas reumatológicos; sintomas constitucionais (febre, perda ponderal, fadiga); alterações musculoesqueléticas, cutâneas e nos órgãos e sistemas do aparelho cardiovascular, renal, sistema nervoso, respiratório, gastrointestinal, endocrinológico e hematológico.

A caracterização do painel de autoanticorpos circulantes com relevância no auxílio diagnóstico e no monitoramento da atividade clínica das doenças reumatológicas foi realizada no Laboratório de Imunologia Humoral (LIH) do Serviço de Reumatologia do HCFMUSP. A pesquisa de autoanticorpos contra antígenos nucleares (ANA) foi realizada pela técnica de imunofluorescência indireta (IFI) em células HEp-2 como substrato (NOVA Lite ${ }^{\mathrm{TM}}$, INOVA Diagnostics, Inc., San Diego, Estados Unidos). As amostras de soro foram consideradas positivas quando da presença de reatividade na diluição superior a 1:80. Anticorpos anti-dsDNA foram pesquisados também por imunofluorescência indireta empregando 0 hemoflagelado Crithidia luciliae como fonte de antígeno (EUROIMMUN Medizinische Labordiagnostika, AG, Alemanha) e as amostras foram consideradas positivas quando da presença de reatividade na diluição acima de 1:10. Os anticorpos anti-U1RNP, anti-Sm, anti-Ro/SS-A e anti-La/SS-B foram detectados pelo teste de ELISA utilizando-se kits específicos distribuídos comercialmente (QUANTA Lite ${ }^{T M}$, INOVA Diagnostics, Inc., San Diego, Estados Unidos) e seguindo o protocolo estabelecido pelo fabricante. A caracterização dos anticorpos anti-Ro/SSA de 52 kDa e de 60 kDa foi feita também pela técnica de ELISA utilizando kits comerciais padronizados (Orgentec, Diagnostika GmbH, Mainz, Alemanha). 


\subsubsection{Avaliação da qualidade de vida}

Em virtude das diferentes faixas etárias da população do estudo, foram utilizados dois instrumentos para avaliação da qualidade de vida relacionada à saúde: o Child Health Questionnaire - Parent Form 50 (CHQPF50), para os indivíduos com menos do que 14 anos de idade no momento do estudo e o Medical Outcomes Study 36-Item Short-Form Health Survey, conhecido como Short Form-36 ou SF-36, para os demais. Ambos os questionários já foram traduzidos e validados para a língua portuguesa ${ }^{127-131}$.

O CHQ-PF50 é um questionário utilizado para medida da qualidade de vida da criança e avaliação do impacto da doença segundo a percepção dos pais. Permite a avaliação do bem-estar físico e psicossocial por meio de 15 conceitos em saúde (domínios), cada qual com uma escala de 0 a 100, com maiores valores indicando melhor estado de saúde e bem-estar. Destes, 10 foram utilizados para obter dois escores agregados e sumários: o escore físico e o escore psicossocial, conforme as normas estabelecidas no manual de utilização do questionário ${ }^{130,131}$.

O SF-36 foi utilizado nos indivíduos com idade superior a 14 anos. Trata-se de um questionário multidimensional com 36 itens, englobados em oito domínios: capacidade funcional (10 itens); aspectos físicos (quatro itens); dor (dois itens), estado geral de saúde (cinco itens); vitalidade (quatro itens); aspectos sociais (dois itens); aspectos emocionais (três itens); saúde mental (cinco itens) e mais uma questão de avaliação comparativa entre as condições de saúde atual e de um ano antes. Após sua aplicação foi dado um escore para cada questão, que posteriormente foi transformado numa 
escala de 0 a 100, na qual zero corresponde a um pior estado de saúde e 100 a um melhor estado, sendo analisado cada domínio em separado. Adicionalmente, os oito domínios foram utilizados para obter dois escores agregados e sumários: o escore físico e o escore mental, conforme as normas estabelecidas no manual de utilização do questionário ${ }^{127-129}$.

\subsubsection{Avaliação da Capacidade Funcional pelo Teste de Caminhada de Seis Minutos}

O teste de caminhada de seis minutos (TC6M) foi realizado de acordo com as normas estabelecidas pela American Thoracic Society (ATS) ${ }^{132}$. Todos os participantes estavam descansados e foram instruídos a andar na velocidade máxima possível ao longo de um corredor de 45 metros de comprimento que apresenta marcações no chão a cada um metro. Incentivo verbal padronizado foi dado aos indivíduos a cada um minuto. O final do exame foi determinado pelo examinador ao término de seis minutos.

Antes do início como no final de cada teste, mensurações foram realizadas visando obter os parâmetros cardiorrespiratórios, como pressão arterial não invasiva, frequência cardíaca, saturação de oxigênio e avaliação de dispneia e fadiga, utilizando a escala de Borg (Apêndice A), onde o indivíduo aponta sua própria percepção de esforço ${ }^{132}$. Também foi avaliada a necessidade de pausas durante o teste ou a presença de sintomas como dor/desconforto precordial, tontura, pré-síncope, síncope, dor nas pernas ou nas panturrilhas. 
A capacidade funcional foi avaliada pela distância percorrida no TC6M. A distância total percorrida foi medida em metros e obtida individualmente. A distância predita foi calculada pela equação proposta por Iwama et al. ${ }^{134}$, que foi desenvolvida especificamente para indivíduos brasileiros, considerando-se a idade, o gênero e as medidas antropométricas.

\subsubsection{Análise ecocardiográfica}

Os estudos ecocardiográficos foram realizados no equipamento IE33 Philips Medical Systems, Andover, (Massachussets, Estados Unidos), disponível no setor de Ecocardiografia do InCor-HCFMUSP, equipado com transdutor eletrônico de frequência de 2,5 MHz para obtenção de imagens bidimensionais e das medidas de fluxos com as técnicas de Doppler pulsátil e de Doppler tecidual.

As imagens foram adquiridas com o indivíduo em repouso, posicionado em decúbito lateral esquerdo, monitorizado com eletrocardiograma contínuo, nos planos paraesternal longitudinal de câmaras esquerdas, transversal (eixo curto) e apical duas e quatro câmaras, de acordo com padronização da Sociedade Americana de Ecocardiografia ${ }^{135}$. As imagens obtidas em pelo menos cinco batimentos consecutivos foram registradas durante apneia e gravadas em compact disc para posterior análise por dois ecocardiografistas experientes. Foi realizada a análise morfológica biventricular e estudados os parâmetros de função ventricular sistólica, diastólica, de fluxos intracardíacos e sincronia intra e interventricular. Todas as medidas foram

comparadas com valores normais estabelecidos de acordo com a padronização do Serviço de Ecocardiografia do InCor-HCFMUSP ${ }^{136}$. 


\section{Análise pelo Modo M}

Foram avaliados os diâmetros do átrio esquerdo, aorta, parede posterior do VE, septo interventricular e diâmetro diastólico do VD, diâmetro diastólico e sistólico do VE e a fração de encurtamento do VE $(\Delta \mathrm{D} \%)$.

\section{Análise Bidimensional}

Foram avaliados os seguintes parâmetros pelo ecocardiograma bidimensional: (a) Diâmetros diastólico e sistólico do VE em projeção paraesternal longitudinal de câmaras esquerdas; (b) Fração de ejeção do VE (método de Simpson); (c) Avaliação do fluxo mitral para a análise da diástole ventricular com o emprego do estudo Doppler pulsátil.

\section{Análise da Sincronia Cardíaca}

Para a determinação da sincronia intra e interventricular foi utilizado o protocolo modificado do Saint Mary Hospital - Imperial College of Medicine (Londres, Grã-Bretanha) $^{136}$.

Com o uso do ecocardiograma com Doppler tecidual foi feita a medida do retardo eletromecânico intra e interventricular, por intermédio da avaliação dos intervalos QS (medido a partir do início do complexo QRS até o pico do componente sistólico evidenciado ao Doppler tecidual). Os intervalos QS do ventrículo esquerdo foram medidos nos segmentos basais (ânulo valvar mitral) e médios das paredes anterolateral, septal inferior, inferior, anterior, ínfero-lateral e septal anterior (análise de 12 segmentos). 0 intervalo QS ventricular direito foi medido no segmento basal da parede lateral do ventrículo direito (ânulo valvar tricúspide). Os critérios adotados para a definição de dissincronia estão descritos abaixo. 


\section{a) Dissincronia intraventricular esquerda}

- Medida do intervalo eletromecânico QS $\geq 65$ ms (maior diferença dos intervalos entre as paredes septal, lateral, anterior, inferior do ventrículo esquerdo).

\section{b) Dissincronia interventricular}

- Medida do intervalo eletromecânico QS $\geq 100$ ms levando-se em consideração a fórmula: $\{(\mathrm{N} 1-\mathrm{N} 2)+\mathrm{N} 3\}>100$ ms onde:

- N1 = intervalo eletromecânico QS do VD.

- N2 = menor intervalo eletromecânico QS do VE.

- N3 = maior diferença entre os intervalos do VE.

\subsubsection{Radiografia torácica}

A radiografia de tórax foi realizada, nas posições póstero-anterior, lateral e oblíqua anterior esquerda, com a finalidade de permitir a avaliação dos campos pulmonares, o tamanho da área cardíaca e, principalmente, para determinar a posição dos cabos-eletrodos implantados no coração, em uso ou abandonados. 


\subsection{Variáveis Estudadas}

Para análise dos resultados, foram consideradas as seguintes variáveis:

\section{Variáveis demográficas:}

Idade: considerada em três momentos distintos: (a) no diagnóstico do bloqueio $\mathrm{AV}$, (b) no implante do marca-passo e (c) no momento do presente estudo.

Sexo: masculino ou feminino.

\section{Variáveis anteriores ao implante do marca-passo}

Manifestações clínicas: foram consideradas as manifestações clínicas decorrentes da bradicardia: síncope, pré-síncope, insuficiência cardíaca congestiva, baixo desenvolvimento ponderal, retardo do desenvolvimento neuropsicomotor, arritmia ventricular complexa, palpitações e bradicardia assintomática.

Eletrocardiograma: foram considerados o ritmo de base (sinusal, fibrilação/flütter atrial, dentre outros), a frequência cardíaca, o intervalo QT corrigido, o eixo do complexo QRS avaliado nas 12 derivações e a média dos valores da duração complexo QRS avaliada nas seis derivações precordiais.

Ecocardiograma: quando realizado, pela diferença no sistema cardiovascular de neonatos, lactentes e crianças maiores que reflete na variabilidade de diâmetros, volumes e fração de ejeção, este exame foi utilizado apenas para confirmação da integridade dos septos cardíacos e ausência de outros defeitos congênitos. 


\section{Variáveis relacionadas ao primeiro implante de marca-passo}

Tipo de marca-passo: de acordo com o tipo de dispositivo cardíaco eletrônico implantado, os indivíduos foram agrupados em portadores de marcapasso ventricular (VVI) ou portadores de marca-passo atrioventricular (DDD).

Via de acesso para implante dos cabos-eletrodos: foi considerada a via de acesso utilizada para cada um dos cabos-eletrodos, podendo ser endocárdica transvenosa pela veia subclávia, endocárdica transvenosa pela veia femoral, epimiocárdica subxifoide e epimiocárdica transtorácica.

Local de implante dos cabos-eletrodos ventriculares: a posição do cabo-eletrodo ventricular foi subdividida em endocárdio do VD, epicárdio do VD ou VE.

Número de reoperações: foi considerado o número de procedimentos realizados para manutenção do marca-passo, como troca de gerador por depleção natural da bateria, ou para tratamento de complicações, como processos infecciosos e disfunção em cabos-eletrodos.

\section{Variáveis relacionadas às avaliações realizadas no presente estudo}

Uso de medicamentos: foi considerada a utilização de fármacos de ação cardiovascular para controle de sintomas de insuficiência cardíaca.

Sintomas atuais: foram pesquisada a manifestação de sinais e sintomas de hipofluxo cerebral e insuficiência cardíaca, assim como a classe funcional para insuficiência cardíaca (NYHA).

Hospitalizações: foram investigados o motivo e o momento de hospitalizações. 
Avaliação eletrônica do dispositivo: os indivíduos foram classificados de acordo com o modo de estimulação (ventricular ou atrioventricular) em uso no momento do presente estudo, assim como, em relação ao ritmo cardíaco (estimulação ventricular exclusiva com ondas $\mathrm{P}$ dissociadas, estimulação ventricular sincronizada às ondas $P$ espontâneas e estimulação atrioventricular sequencial) e quanto ao percentual de estimulação ventricular. A duração do complexo QRS foi considerada com o marca-passo inibido e em funcionamento, sendo adotado os valores de referência de 120 ms.

Biomarcadores laboratoriais de insuficiência cardíaca: foi realizada a dosagem de marcadores laboratoriais que indicam a presença ou progressão da insuficiência cardíaca (BNP, TNF-alfa, IL-6, PCR-us). Para a classificação dos resultados laboratoriais foram considerados os valores de referência adotados na nossa Instituição.

Qualidade de vida: foi avaliada por intermédio de questionários padronizados, sendo os resultados apresentados na forma de escores que variam numa escala de 0 a 100, na qual zero corresponde a um pior estado de qualidade de vida relacionada à saúde e 100 a um melhor estado.

Teste de Caminhada: foi considerada a distância total percorrida em função da distância predita de acordo com a equação usada no estudo.

Achado de doença autoimune: mães e pacientes foram classificados pela presença ou ausência de manifestações clínicas de doenças autoimunes.

Marcadores laboratoriais de doença autoimune nos sujeitos da pesquisa e em suas mães: mães e filhos foram classificados de acordo com a presença ou ausência de marcadores laboratoriais de doenças autoimunes. 


\section{Variáveis ecocardiográficas}

Diâmetro diastólico do ventrículo esquerdo (DDVE): foi determinado pelo Modo $\mathrm{M}$ e ecocardiograma bidimensional. Os valores de referência foram considerados de acordo com a idade, sendo: um a dois anos $=13,4 \mathrm{~mm}$; três a cinco anos $=15,2 \mathrm{~mm}$; seis a 10 anos $=17,5 \mathrm{~mm} ; 11$ a 15 anos = 20,3 mm; acima de 15 anos = $59 \mathrm{~mm}$ para indivíduos do sexo masculino e $53 \mathrm{~mm}$ para indivíduos do sexo feminino.

Fração de ejeção ventricular esquerda (FEVE): foi determinada pelo ecocardiograma transtorácico bidimensional e mensurada pelo método de Simpson. A função sistólica do ventrículo esquerdo foi considerada normal quando a $F E V E \geq 0,55$ e o grau de disfunção classificado em discreto (FEV E= $0,45$ a 0,54$)$, moderado ( $F E V E=0,44$ a 0,30 ) e importante ( $F E V E<0,30)$.

Sincronia intraventricular esquerda: foi considerada a presença de dissincronia quando a diferença do intervalo eletromecânico entre quaisquer dois segmentos distintos do ventrículo esquerdo foi igual ou superior a $65 \mathrm{~ms}$ pelo Doppler tecidual.

Sincronia interventricular: foi considerada a presença de dissincronia quando a relação de diferença entre o intervalo eletromecânico do VD e o menor intervalo eletromecânico do VE somada com a maior diferença entre os intervalos do VE foi igual ou superior a $100 \mathrm{~ms}$ pelo Doppler tecidual.

Valvopatias associadas: pelo método bidimensional e Doppler, foram pesquisadas alterações anatômicas, o grau de insuficiência e de estenose (discreto, moderado, importante), a presença de refluxo. 


\subsection{Coleta Eletrônica e Gerenciamento dos Dados}

Todos os formulários de coleta de dados foram desenvolvidos no sistema Research Electronic Data Capture (REDCap) que encontra-se hospedado no servidor da Faculdade de Medicina da Universidade de São Paulo.

O REDCap é um software baseado na web, desenvolvido pela Vanderbilt University (Tennessee, Estados Unidos) e que apresenta três principais funcionalidades: (a) coleta eletrônica de dados; (b) gerenciamento de dados; (c) gerenciamento de fluxo dos estudos. Este banco de dados atende as políticas internacionais de privacidade e segurança de dados na área da saúde. Além da estrutura de coleta e armazenamento, também foram utilizadas as ferramentas de validação, auditoria e exportação de dados do próprio sistema ${ }^{137}$.

As Figuras 2 e 3 ilustram algumas das funcionalidades do REDCap que foram adotadas neste estudo. 


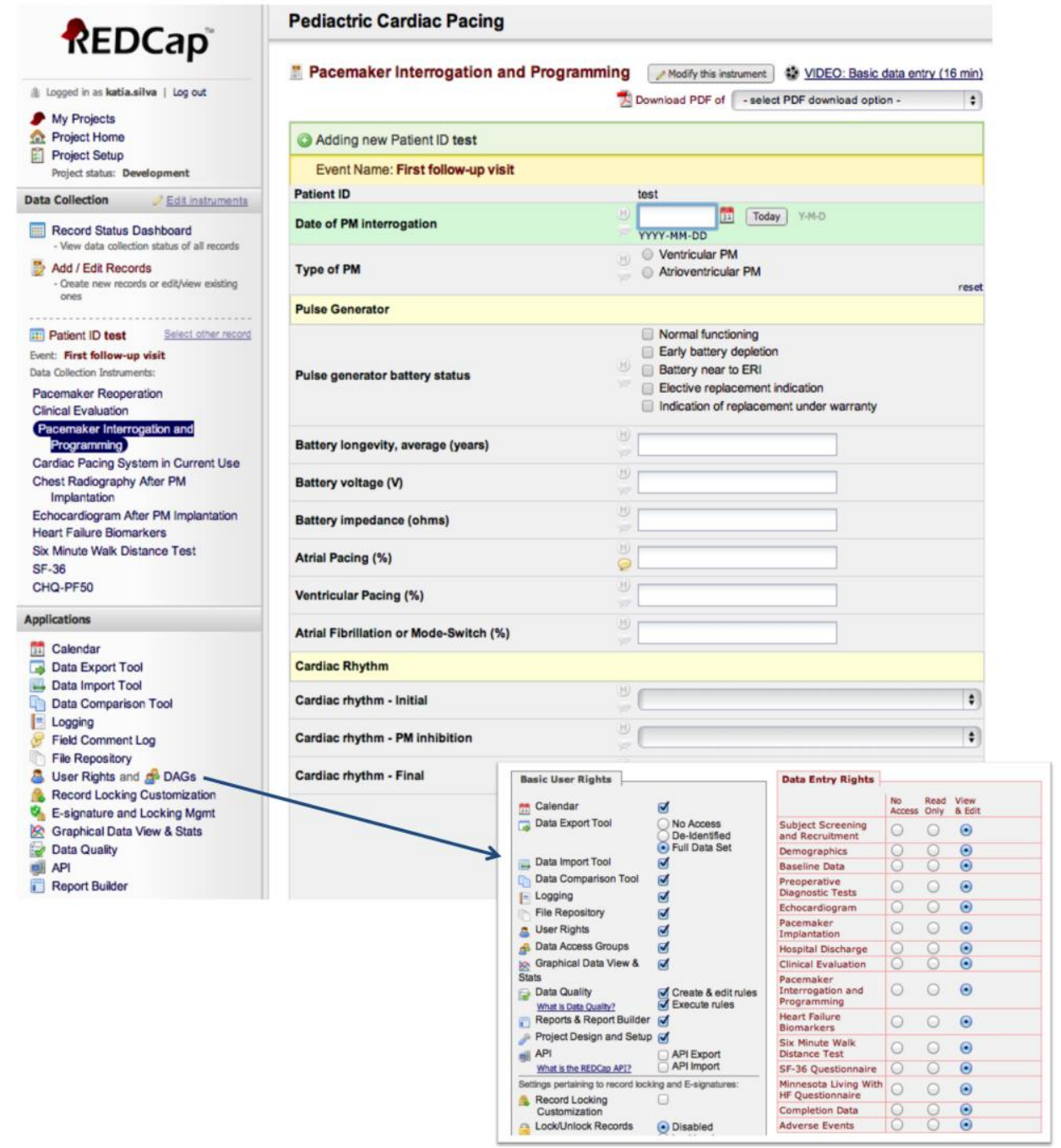

Figura 2 - Exemplo de formulário eletrônico desenvolvido no REDCap para coleta de dados referentes à avaliação do marca-passo 


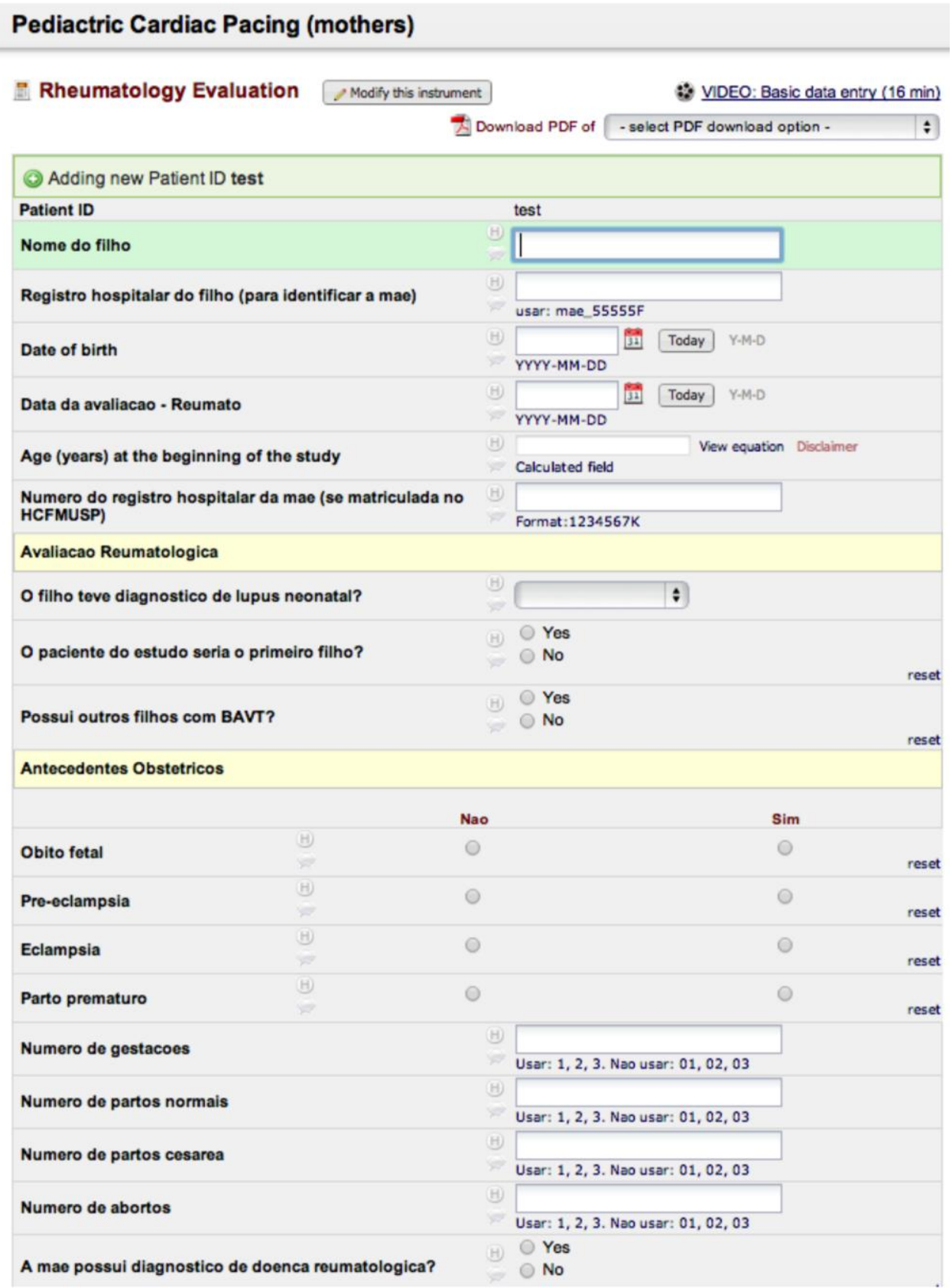

Figura 3 - Exemplo de formulário eletrônico desenvolvido no REDCap para coleta de dados referentes à avaliação reumatológica das mães 


\subsection{Análise Estatística}

Os dados cadastrados no REDCap foram exportados em formato de planilhas excel (Microsoft Excel) e analisados pelos programas SAS (Statistical Analysis System), SPSS (Statistical Package for the Social Sciences) e R Studio.

Foram definidas como variáveis preditoras: gênero, idade no momento do implante de marca-passo, idade no momento do estudo, tempo total de estimulação no VD, tempo total de uso do marca-passo, classe funcional (NYHA) na última avaliação, uso de medicamentos de ação cardiovascular, tipo de marca-passo em uso, sítio de estimulação no VD, duração do complexo QRS estimulado, presença de insuficiência mitral, alterações em biomarcadores de insuficiência cardíaca, presença de autoanticorpos antiRo/SSA nas mães dos sujeitos de pesquisa.

Inicialmente, essas variáveis preditoras, quando quantitativas foram descritas por média e desvio-padrão na presença de distribuição normal e, as variáveis qualitativas, foram apresentadas por frequências absolutas (número de indivíduos) e relativas (percentuais).

A relação das variáveis preditoras quantitativas com a presença dos desfechos do estudo foi analisada pelo teste "t" de Student e a associação das variáveis qualitativas com a presença dos desfechos do estudo foi avaliada pelos testes Qui-quadrado ou Exato de Fisher.

A correlação das variáveis preditoras quantitativas com a fração de ejeção do VE, com a distância percorrida no teste de caminhada e com os escores de qualidade de vida foi analisada pelo coeficiente de Pearson. 
Como não foi encontrada associação significativa entre as variáveis preditoras e as variáveis de desfechos, o modelo de regressão linear multivariado foi utilizado com a finalidade de analisar a interação e o grau de correlação entre as variáveis quantitativas preditoras e de desfechos. 0 modelo de regressão linear multivariado foi desenvolvido com base no processo stepwise de seleção de variáveis, as quais foram definidas previamente de acordo com o que tem sido preconizado na literatura internacional como fatores preditores de evolução desfavorável em indivíduos submetidos à estimulação crônica do VD $\mathrm{D}^{31,34,35,37,51,54}$.

Para analisar a confiabilidade interna dos questionários de qualidade de vida foi utilizado o coeficiente alfa de Cronbrach que é calculado a partir da variância e da intercorrelação existente entre os itens individuais de cada questionário. 
5 Resultados 


\subsection{Descrição da População Selecionada}

No período compreendido entre 1982 e dezembro de 2013, 165 indivíduos com diagnóstico de bloqueio AV congênito haviam sido submetidos ao primeiro implante de marca-passo cardíaco artificial permanente antes de completar 21 anos de idade no InCor-HCFMUSP. Destes, 45 indivíduos apresentavam defeitos cardíacos associados ao bloqueio AV congênito e não foram considerados elegíveis para o estudo. Dentre os 120 indivíduos candidatos ao estudo, 63 estavam em seguimento regular na nossa Instituição e preencheram os critérios de elegibilidade do estudo (Figura 4). Dentre os demais, dois já haviam falecido, quatro estavam em seguimento em outros serviços e 25 não foram localizados no período de inclusão do estudo, tendo sido considerados perdidos para seguimento.

O motivo da não inclusão de 26 indivíduos que estavam em seguimento clínico regular foi: tempo de estimulação no VD inferior a um ano ou cabo-eletrodo implantado em VE no momento do estudo em 13, já terem sido submetidos a TRC em quatro e um já havia sido submetido a transplante cardíaco. Oito indivíduos moravam em outra cidade ou Estado e optaram por não participar do estudo.

Dos 63 sujeitos de pesquisa incluídos, foi possível contar com a participação de 56 mães, que tiveram sua avaliação clínica e laboratorial realizada para pesquisa de doenças autoimunes. Das sete mães que não 
participaram, três já eram falecidas, uma estava com câncer em fase terminal, duas moravam em localidades distantes e uma cumpria pena em regime fechado.

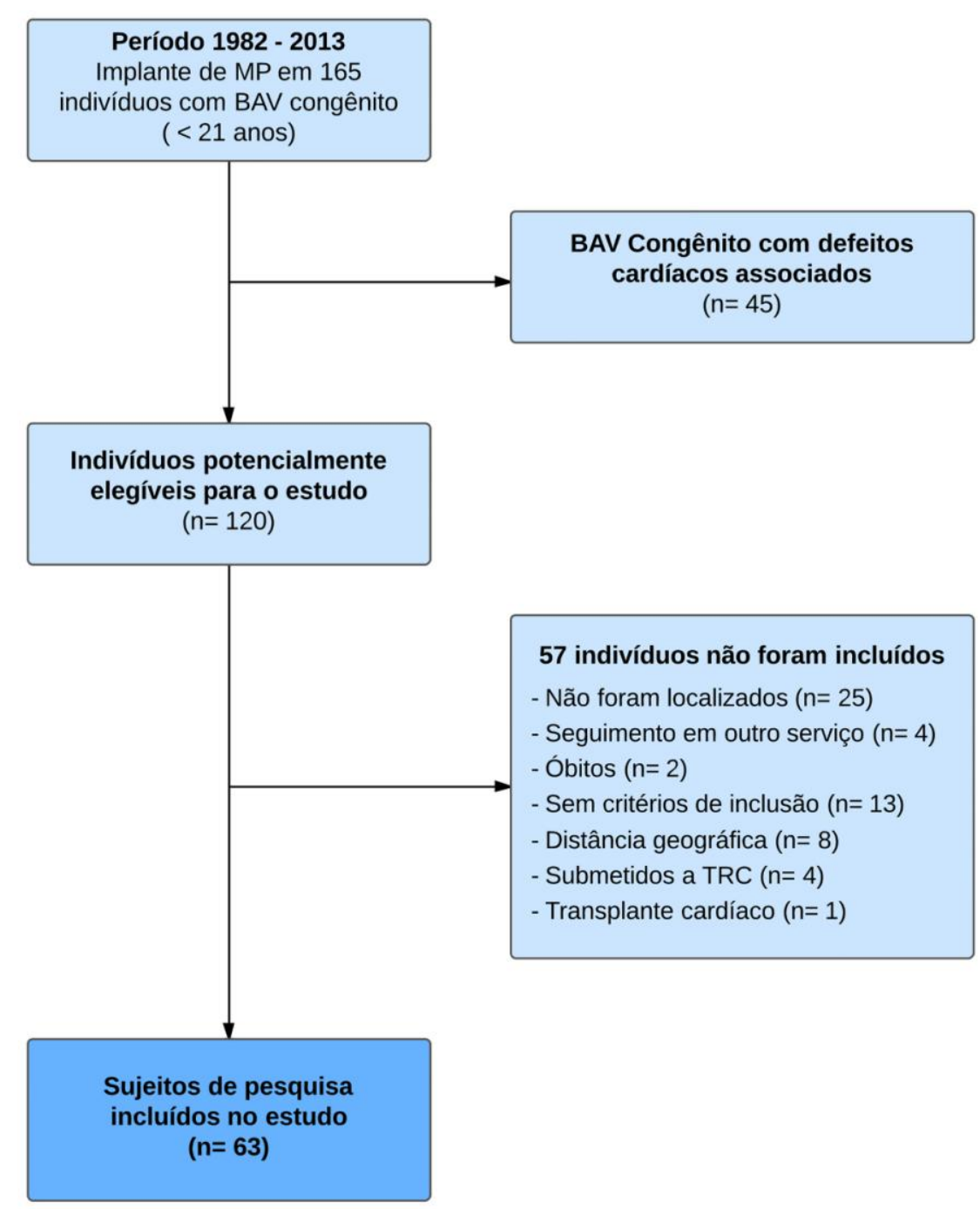

Figura 4- Constituição da população estudada. InCor-HCFMUSP (2010 a 2013)

5.2 Análise Retrospectiva das Características da População no Momento do Diagnóstico do Primeiro Implante de Marca-passo

\subsubsection{Características demográficas e clínicas}

As características demográficas e clínicas dos indivíduos no momento do implante inicial do marca-passo estão sumarizadas na Tabela 1. 


\section{Tabela 1 - Características demográficas e clínicas dos sujeitos de pesquisa. InCor-HCFMUSP (2010 - 2013)}

\begin{tabular}{|c|c|}
\hline Gênero feminino, n (\%) & $43(68,2)$ \\
\hline \multicolumn{2}{|l|}{ Raça referida, n (\%) } \\
\hline Branca & $29(46,0)$ \\
\hline Negra & $3(4,8)$ \\
\hline Parda & $31(49,2)$ \\
\hline \multicolumn{2}{|l|}{ Momento do diagnóstico do BAVTC, n (\%) } \\
\hline intraútero & $19(30,2)$ \\
\hline Neonatal & $8(12,7)$ \\
\hline Lactente & $12(19,0)$ \\
\hline Pré-escolar & $6(9,5)$ \\
\hline Escolar & $9(14,3)$ \\
\hline Adolescência & $9(14,3)$ \\
\hline \multicolumn{2}{|l|}{ Momento do implante do marca-passo, n (\%) } \\
\hline Neonatal & $7(11,1)$ \\
\hline Lactente & $9(14,3)$ \\
\hline Pré-escolar & $8(12,7)$ \\
\hline Escolar & $11(17,5)$ \\
\hline Adolescência & $28(44,4)$ \\
\hline \multicolumn{2}{|l|}{ Indicação do implante de marca-passo, n (\%) } \\
\hline Bradicardia sintomática & $44(69,8)$ \\
\hline Bradicardia isolada & $16(25,4)$ \\
\hline Bradicardia associada a intervalo QT prolongado & $3(4,8)$ \\
\hline \multicolumn{2}{|l|}{ Comorbidades, n (\%) } \\
\hline Nenhuma & $60(95,2)$ \\
\hline Hipertensão arterial sistêmica & $1(1,6)$ \\
\hline Prolapso valvar mitral & $1(1,6)$ \\
\hline Miocardite & $1(1,6)$ \\
\hline \multicolumn{2}{|l|}{ Medicamentos de ação cardiovascular, n (\%) } \\
\hline Não utilizados & $59(93,7)$ \\
\hline Inibidores de enzima conversora de angiotensina & $2(3,2)$ \\
\hline Furosemida & $1(1,6)$ \\
\hline Betabloqueador & $1(1,6)$ \\
\hline Frequência cardíaca antes do implante, bpm (média \pm DP) & $50,4 \pm 11,8$ \\
\hline Duração do complexo QRS antes do implante (média \pm DP) & $85,5 \pm 15,7$ \\
\hline Eixo do complexo QRS antes do implante (variação) & -30 a 175 graus \\
\hline \multicolumn{2}{|l|}{ Ritmo ventricular, n (\%) } \\
\hline Bloqueio Atrioventricular Total & $60(95,2)$ \\
\hline Bloqueio Atrioventricular do 20 grau Mobitz II & $1(1,6)$ \\
\hline Bloqueio Atrioventricular do $2^{\circ}$ grau $2: 1$ & $2(3,2)$ \\
\hline Fração de ejeção do VE (\%) - Teicholz (média \pm DP) & $56,9 \pm 20,4$ \\
\hline Diâmetro sistólico final do VE, mm (média \pm DP) & $23,7 \pm 9,5$ \\
\hline Diâmetro diastólico final do VE, mm (média \pm DP) & $39,0 \pm 12,2$ \\
\hline
\end{tabular}

BAVTC = bloqueio atrioventricular total congênito; DP = desvio padrão; FC = frequência cardíaca; bpm = batimentos por minuto. 
Dos 63 sujeitos incluídos, 43 (68,2\%) eram do sexo feminino e 29 $(46,0 \%)$ foram declarados brancos (Anexo D). O diagnóstico de bloqueio atrioventricular congênito havia sido realizado no período intrauterino em 19 $(30,2 \%)$ e no neonatal em 8 (12,7\%) indivíduos. Nos demais, o diagnóstico foi realizado durante a infância ou adolescência (Anexo E).

A idade média no momento do implante inicial foi de $8,2 \pm 6,4$ anos com variação de um dia a 20,2 anos. De acordo com a Tabela 1, é possível observar-se que $25,4 \%$ dos sujeitos haviam sido operados antes de completar dois anos de vida e que em $44,4 \%$ o procedimento foi realizado na adolescência. O tempo médio transcorrido entre o diagnóstico do bloqueio atrioventricular e o implante de marca-passo foi de 4,5 $\pm 5,3$ anos, com variação de um dia a 20 anos e mediana de 2,5 anos.

O quadro clínico que justificou o implante do marca-passo foi de bradicardia sintomática em $44(69,8 \%)$ indivíduos, que incluiu sinais e sintomas de insuficiência cardíaca, pré-síncopes, síncopes, tonturas e palpitações. Os demais, apresentavam bradicardia assintomática, sendo observados sinais de arritmia ventricular complexa, intervalo QT prolongado, incompetência cronotrópica e baixo desenvolvimento ponderal.

Somente $3(4,8 \%)$ indivíduos apresentavam comorbidades associadas ao bloqueio atrioventricular congênito, conforme descrito na Tabela 1, e medicamentos de ação cardiovascular eram utilizados por apenas 4 (6,3\%).

O eletrocardiograma realizado antes do implante de marca-passo mostrou que 60 (95,2\%) sujeitos apresentavam bloqueio atrioventricular total e $3(4,8 \%)$ bloqueio atrioventricular do segundo grau do tipo II ou 2:1. A frequência cardíaca medida pelos batimentos ventriculares variou de 30 a 90 
bpm, com média de 50,4 \pm 11,8. A duração do complexo QRS foi considerada normal em $44(88 \%)$ casos e $6(12 \%)$ apresentavam duração maior que 120 ms. No plano frontal, o eixo do complexo QRS variou de -30 a 175 graus (Anexo F).

Ecocardiograma pré-operatório foi realizado em 46 (73,0\%) indivíduos. Em todos os casos foi observado coração em situs solitus, em levocardia e ausência de defeitos em septo ou valvas cardíacas(Anexo G).

\subsubsection{Primeiro implante de marca-passo}

As características cirúrgicas dos indivíduos no momento do implante inicial do marca-passo encontram-se sumarizadas no Gráfico 1.

Gráfico 1- Dados cirúrgicos do primeiro implante de marca-passo. InCor-HCFMUSP (2010 - 2013)
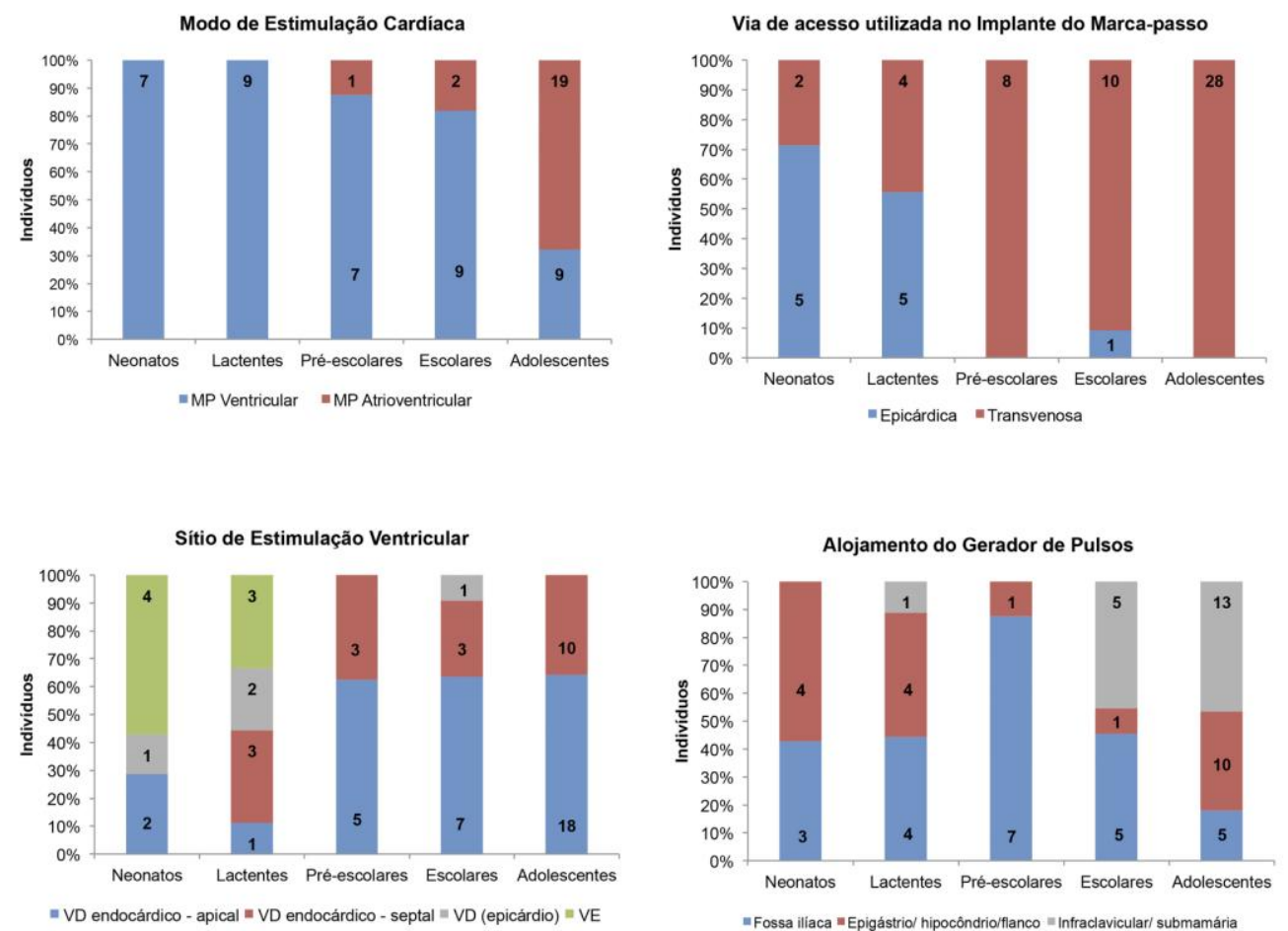

VD = ventrículo direito; VE = ventrículo esquerdo. VD endocárdio - apical = refere-se a ponta, septo apical e parede diafragmática endocárdica; VD endocárdio septal = refere-se ao septo médio, septo de saída (alto) e via de saída. 
Houve predomínio do uso da estimulação unicameral ventricular, utilizada em $65,8 \%$ dos implantes iniciais. Apenas $3(4,8 \%)$ crianças com idade $\leq 10$ anos foram submetidas a implante de marca-passo atrioventricular (Anexo $\mathrm{H}$ ).

A via de acesso epicárdica, pelo acesso subxifoide ou por toracotomia lateral esquerda, foi a preferida para o implante em neonatos e préescolares, seguida pelos implantes pela veia femoral. Nos pré-escolares, escolares e adolescentes, a via de acesso transvenosa foi utilizada em praticamente todos os casos.

O endocárdio apical do ventrículo direito foi o sítio de estimulação mais utilizado nessa população, o que ocorreu em $33(52,4 \%)$ dos casos. Dos 11 (17,5\%) implantes epicárdicos, 7 (11,1\%) haviam sido realizados, inicialmente, no ventrículo esquerdo.

O alojamento do gerador de pulsos foi realizado em posição subcutânea na fossa ilíaca nos implantes realizados pela veia femoral. Nos indivíduos que receberam implante transvenoso pelo território da veia subclávia a loja do gerador de pulsos foi submuscular ou subcutânea, em localização infraclavicular ou submamária, esta última, principalmente em adolescentes do sexo feminino.

\subsubsection{Reoperações para manutenção ou tratamento de complicações relacionadas ao marca-passo}

No momento da inclusão neste estudo, 53 (84,1\%) indivíduos já haviam sido submetidos a procedimentos de reoperação. Das 136 reoperações, a troca do gerador de pulsos por desgaste natural da bateria foi o procedimento mais comumente realizado. Procedimentos para 
tratamento de complicações foram mais frequentes em neonatos e lactentes, consistindo principalmente em disfunção de cabos-eletrodos e processos infecciosos. Troca do cabo-eletrodo ventricular foi realizada em 21 (33,3\%) casos, com mudança do sítio de estimulação no próprio ventrículo direito em 14 ou do ventrículo esquerdo para o direito em sete (Gráfico 2; Anexo I).

Gráfico 2- Procedimentos de reoperações para manutenção ou tratamento de complicações relacionadas ao marca-passo. InCor-HCFMUSP (2010 - 2013)

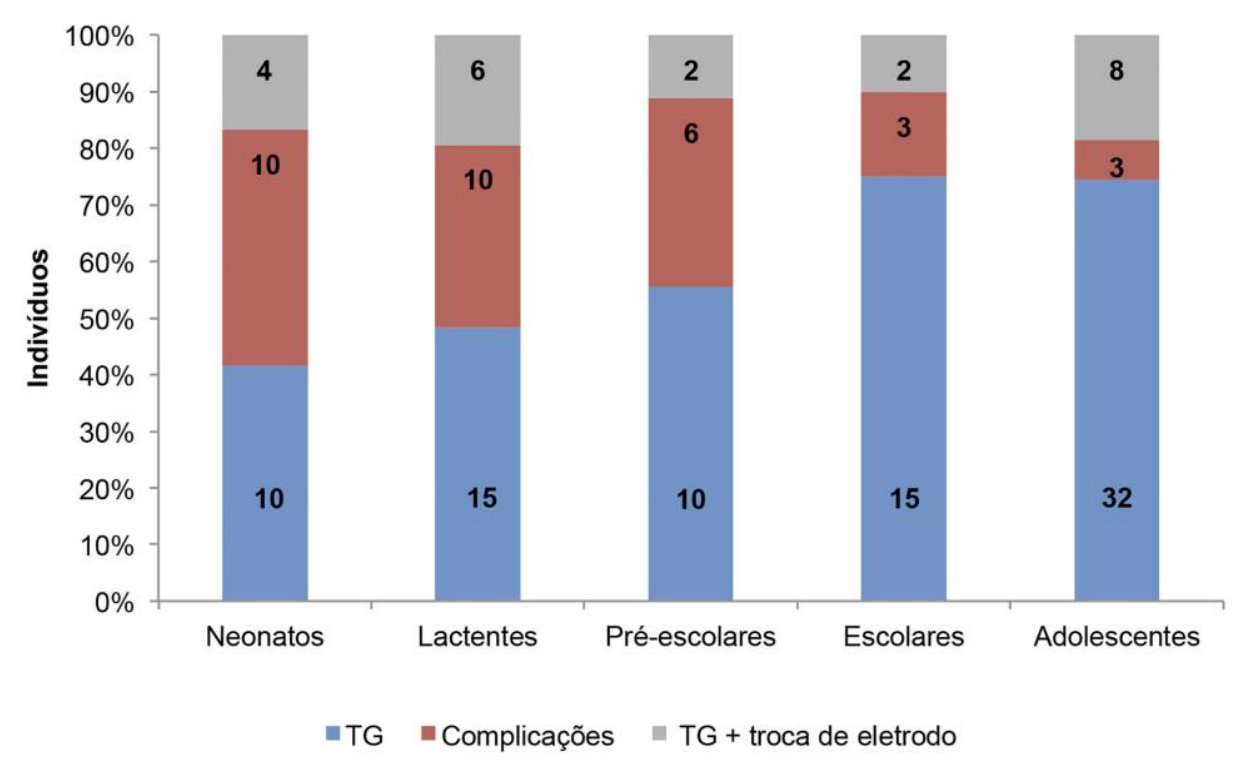

\subsection{Características da população no momento da inclusão no estudo}

As características dos sujeitos de pesquisa no momento da inclusão estão sumarizadas na Tabela 2. 


\section{Tabela 2 - Características dos sujeitos de pesquisa no momento da inclusão no estudo. InCor-HCFMUSP (2010 - 2013)}

\begin{tabular}{|c|c|}
\hline \multicolumn{2}{|l|}{ Características da população estudada } \\
\hline Idade no momento da avaliação, anos (média \pm DP) & $20,4 \pm 8,9$ \\
\hline Tempo de estimulação no VD, anos (média \pm DP) & $9,7 \pm 5,4$ \\
\hline Tempo total de marca-passo, anos (média $\pm \mathrm{DP}$ ) & $13,2 \pm 6,6$ \\
\hline \multirow{2}{*}{\multicolumn{2}{|c|}{ Avaliação Clínica }} \\
\hline & \\
\hline I & $59(95,2)$ \\
\hline II & $3(4,8)$ \\
\hline \multicolumn{2}{|l|}{ Uso de medicamentos de ação cardiovascular, n (\%) } \\
\hline Atenolol & $1(1,6)$ \\
\hline Atenolol e enalapril & $2(3,2)$ \\
\hline Captopril e aspirina & $1(1,6)$ \\
\hline Losartana e hidroclorotiazida & $1(1,6)$ \\
\hline \multicolumn{2}{|l|}{ Avaliação do marca-passo } \\
\hline \multicolumn{2}{|l|}{ Tipo de marca-passo em uso, n (\%) } \\
\hline Ventricular & $28(44,4)$ \\
\hline Atrioventricular & $35(55,6)$ \\
\hline Percentual de Estimulação ventricular, \% (média \pm DP) & $97,9 \pm 4,2$ \\
\hline Duração do QRS estimulado, ms (média \pm DP) & $152,4 \pm 20,1$ \\
\hline Duração do QRS inibido, ms (média \pm DP) & $87,4 \pm 14,3$ \\
\hline \multicolumn{2}{|l|}{ Ritmo cardíaco, n (\%) } \\
\hline Estimulação atrioventricular sequencial & $19(30,2)$ \\
\hline Estimulação ventricular exclusiva (dissociação AV) & $28(44,4)$ \\
\hline Estimulação ventricular sincronizada às ondas $P$ & $16(25,4)$ \\
\hline \multicolumn{2}{|l|}{ Sítio de estimulação no ventrículo direito, n (\%) } \\
\hline Septo interventricular & $20(31,7)$ \\
\hline Outras regiões do VD (inclusive o septo apical) & $43(68,3)$ \\
\hline \multicolumn{2}{|l|}{ Estudo ecocardiográfico } \\
\hline Fração de Ejeção do VE, \% (média \pm DP) & $54,8 \pm 7,1$ \\
\hline Diâmetro Diastólico do VE, mm (média \pm DP) & $47,4 \pm 7,4$ \\
\hline \multicolumn{2}{|l|}{ Insuficiência mitral, n (\%) } \\
\hline Ausente & $5(7,9)$ \\
\hline Discreta & $44(69,8)$ \\
\hline Leve/moderada & $13(20,6)$ \\
\hline Moderada/grave & $1(1,6)$ \\
\hline Atraso intraventricular, ms (média $\pm \mathrm{DP}$ ) & $86,6 \pm 57,4$ \\
\hline Atraso interventricular, ms (média \pm DP) & $141,9 \pm 88,7$ \\
\hline \multicolumn{2}{|l|}{ Teste de caminhada de seis minutos } \\
\hline Distância total percorrida, metros (média $\pm \mathrm{DP}$ ) & $546,9 \pm 76,2$ \\
\hline Distância predita alcançada, \% (média \pm DP) & $91,1 \pm 12,5$ \\
\hline \multicolumn{2}{|l|}{ Qualidade de Vida } \\
\hline \multicolumn{2}{|l|}{ Escores, (média $\pm \mathrm{DP}$ ) } \\
\hline Sumário Físico - SF-36 & $78,1 \pm 17,7$ \\
\hline Sumário Mental - SF-36 & $76,6 \pm 17,1$ \\
\hline Sumário Físico - CHQ-PF50 & $77,5 \pm 18,4$ \\
\hline Sumário Psicossocial - CHQ-PF50 & $77,7 \pm 21,6$ \\
\hline
\end{tabular}

$\mathrm{AV}=$ atrioventricular; $\mathrm{DP}=$ desvio padrão; NYHA $=$ New York Heart Association; VD = ventrículo direito; $\mathrm{VE}=$ ventrículo esquerdo; SF-36= Short-form 36; CHQ-PF50 = Child Health Questionnaire - Parent Form 50. 


\subsubsection{Evolução com marca-passo}

No momento da inclusão, a idade dos indivíduos variou de um a 40 anos, com mediana de 21. Nessa ocasião, já havia se passado um a 30 anos, com média de 13,4 $\pm 6,5$, desde o primeiro implante de marca-passo. O Gráfico 3 mostra a idade dos indivíduos no momento do diagnóstico do bloqueio atrioventricular, no implante do primeiro marca-passo e na inclusão no estudo.

Gráfico 3 - Evolução temporal dos sujeitos de pesquisa: idades no momento do diagnóstico do bloqueio atrioventricular congênito, no implante de marca-passo e na inclusão no estudo. InCor-HCFMUSP (2010 - 2013)

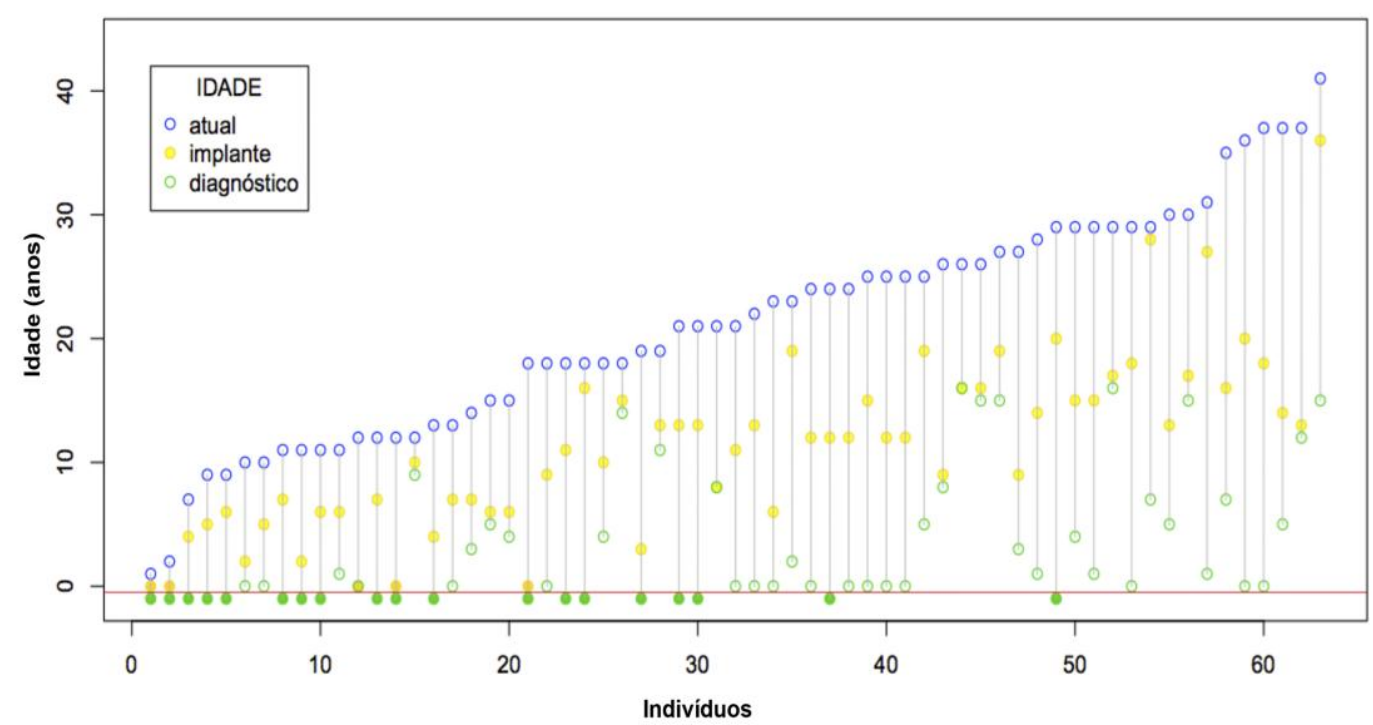

Indivíduos com diagnóstico intrauterino do bloqueio AV congênito estão representados abaixo da linha vermelha traçada horizontalmente.

Independentemente do tipo de marca-passo e do sítio de estimulação, os sujeitos incluídos neste estudo, permaneceram sob estimulação cardíaca artificial por um a 30,1 anos com média de 13,2 $\pm 6,5$ anos. Se considerarmos apenas o tempo de estimulação ventricular direita, os indivíduos permaneceram sob estimulação cardíaca artificial por um a 24,3 anos com média de 10,0 \pm 5,4 anos. 
No momento do estudo, a mudança de modo de estimulação ventricular para atrioventricular já havia sido realizada em 14 (22,2\%) sujeitos. Em todos os casos essa mudança havia sido indicada eletivamente, pela oportunidade cirúrgica. Não houve casos de síndrome do marca-passo ou outras consequências da assincronia atrioventricular provocada pela estimulação ventricular exclusiva. Os participante do estudo permaneceram sob estimulação ventricular exclusiva, em média, por 11,3 $\pm 4,0$ anos e com estimulação atrioventricular por 9,5 \pm 5,5 anos (Gráfico 4).

Gráfico 4 - Mudança no modo de estimulação cardíaca nos portadores de bloqueio atrioventricular congênito isolado. InCorHCFMUSP (2010 - 2013)

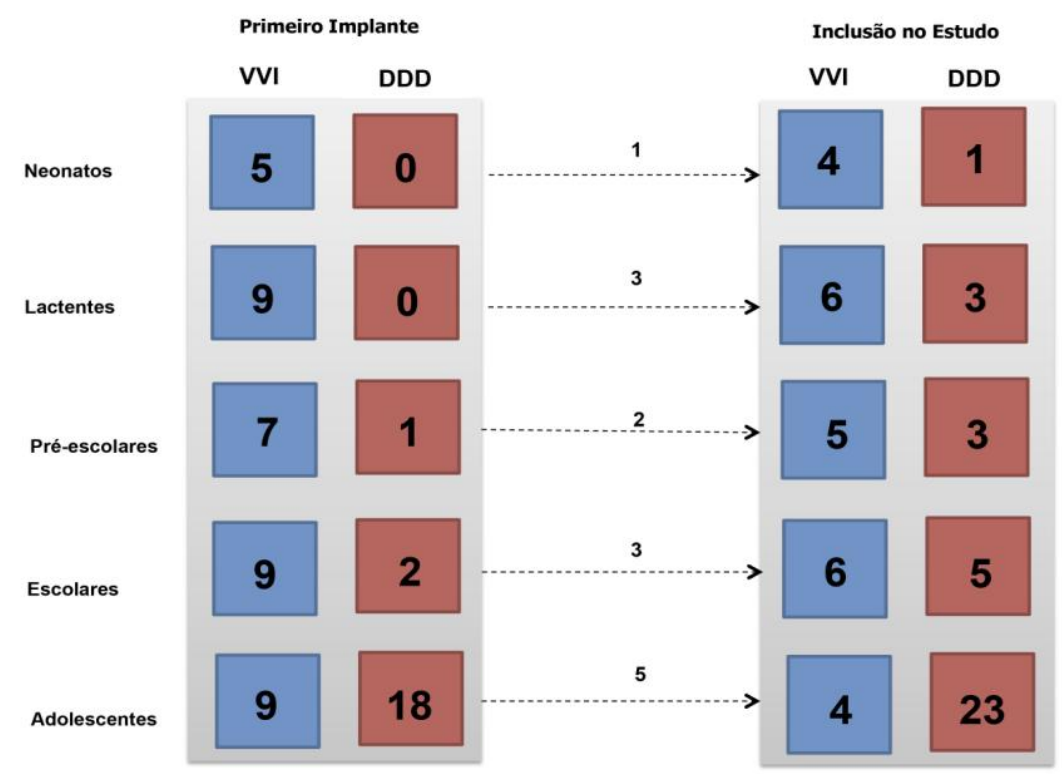

$\mathrm{VVI}=$ marca-passo ventricular; DDD = marca-passo atrioventricular. 


\subsubsection{Avaliação Clínica}

Pelas informações derivadas dos prontuários e das entrevistas realizadas, não houve relato de hospitalização para tratamento de insuficiência cardíaca no período transcorrido entre o primeiro implante de marca-passo e a inclusão dos sujeitos neste estudo.

No momento do estudo, apenas $3(4,8 \%)$ indivíduos relataram sintomas de cansaço aos grandes esforços. O uso de medicamentos de ação cardiovascular foi reportado por 5 (7,9\%) sujeitos, como observado na Tabela 2 (Anexo J).

\subsubsection{Marcadores laboratoriais de insuficiência cardíaca}

A dosagem de marcadores laboratoriais foi realizada em todos os sujeitos estudados, com exceção de um, que não compareceu à coleta sanguínea após várias convocações. A distribuição dos valores de cada marcador encontra-se no Gráfico 5 e a classificação dos resultados laboratoriais de acordo com os valores de referência, no Gráfico 6 (Anexo K). 
Gráfico 5 - Marcadores laboratoriais de insuficiência cardíaca nos portadores de bloqueio atrioventricular congênito isolado. InCor-HCFMUSP (2010 - 2013)
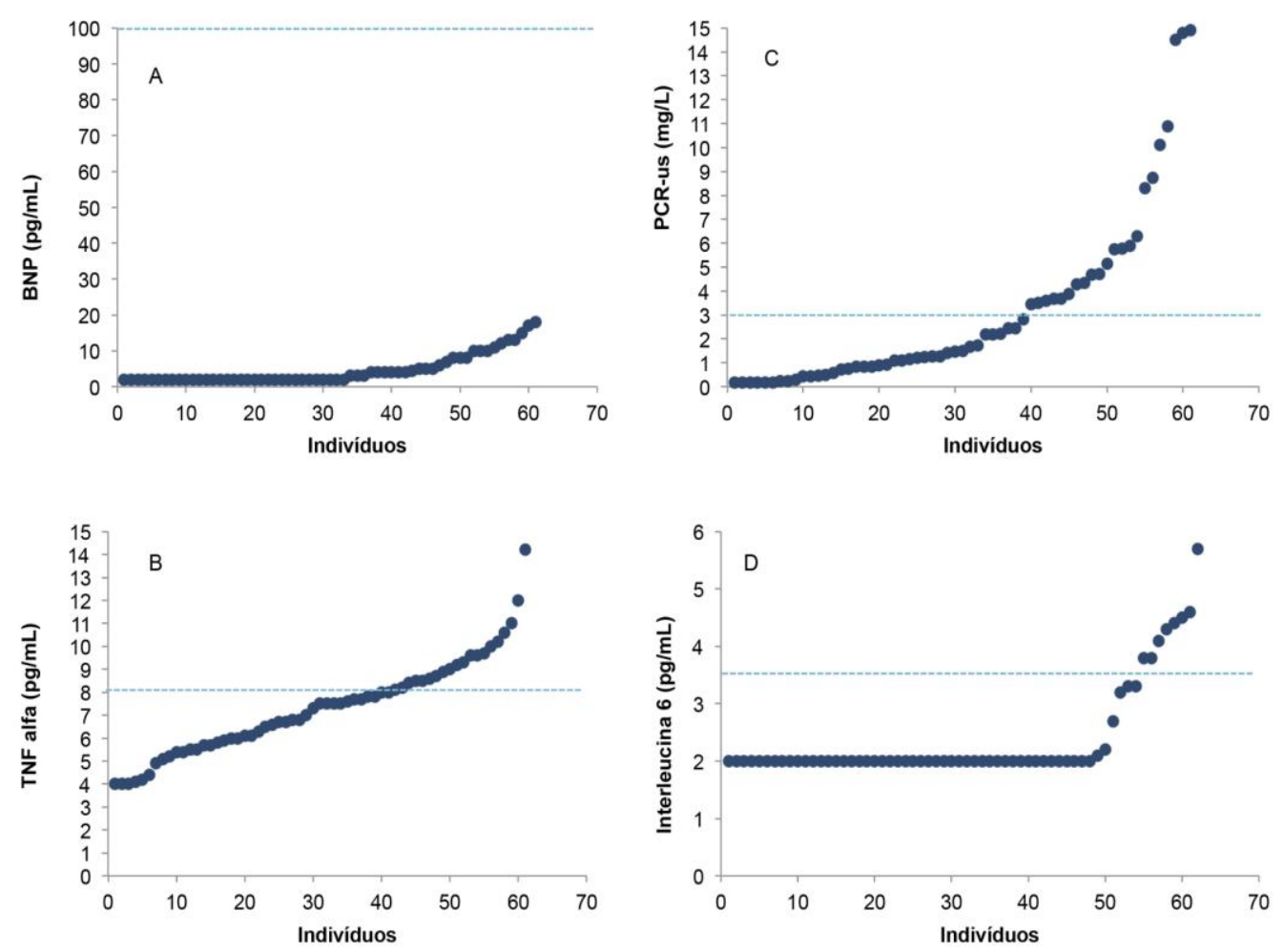

As dosagens do BNP mostraram-se dentro da faixa de normalidade para todos os indivíduos avaliados, considerando-se o valor de referência $\leq$ $100 \mathrm{pg} / \mathrm{mL}$. Os valores obtidos para o TNF-alfa e para a interleucina-6, entretanto, mostraram-se fora dos limites da normalidade em 21 (33,9\%) e 8 $(12,9 \%)$ indivíduos, respectivamente. O marcador que apresentou maiores taxas de exames fora da normalidade foi a PCR-us, o que foi observado em $41(66,1 \%)$ indivíduos. 


\section{Gráfico 6 - Classificação dos resultados dos marcadores laboratoriais de insuficiência cardíaca de acordo com os valores de referência. InCor-HCFMUSP (2010 - 2013)}

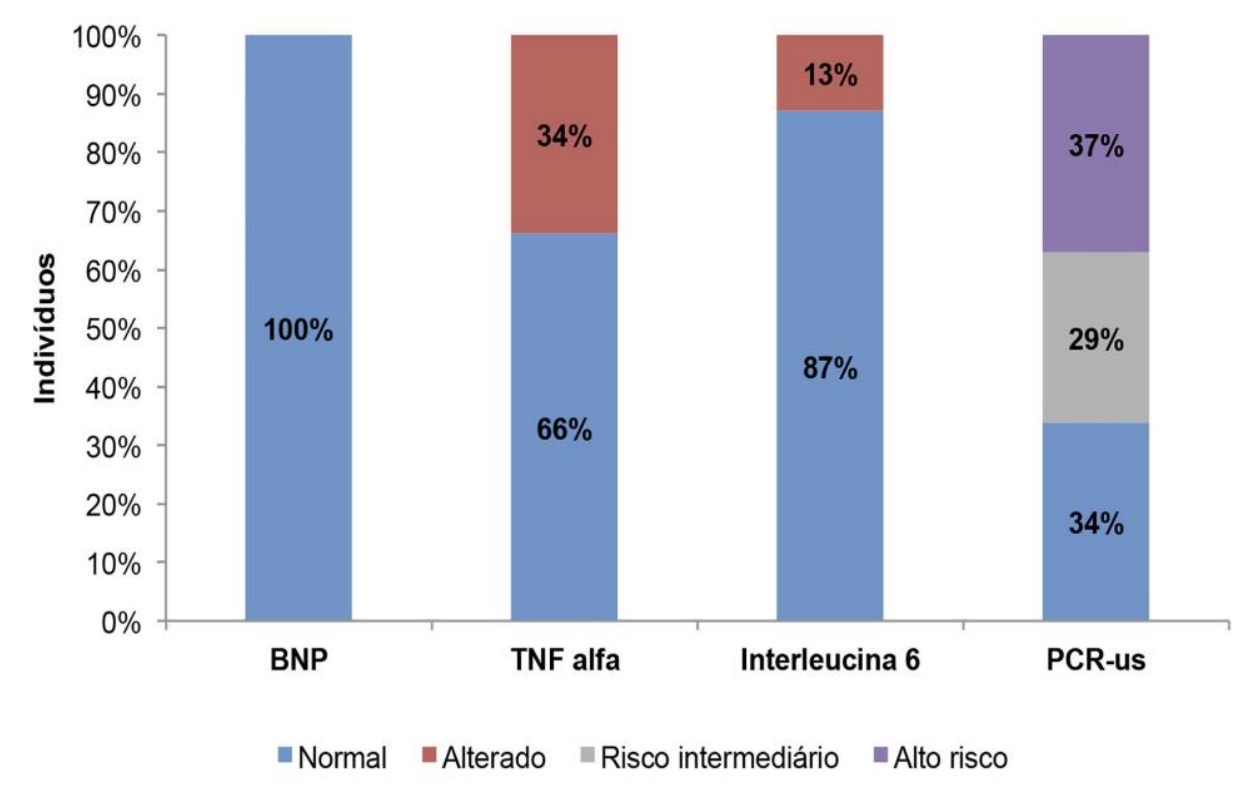

\subsubsection{Avaliação eletrônica do marca-passo}

No momento do estudo, 35 (55,6\%) indivíduos utilizavam marcapasso atrioventricular e $28(44,4 \%)$ haviam permanecido sob estimulação ventricular exclusiva. A distribuição do tipo de marca-passo em uso de acordo com a faixa etária dos indivíduos encontra-se no Gráfico 7. 


\section{Gráfico 7 - Tipo de marca-passo em uso de acordo com a faixa etária (anos) dos indivíduos no momento do estudo. InCor- HCFMUSP (2010 - 2013)}

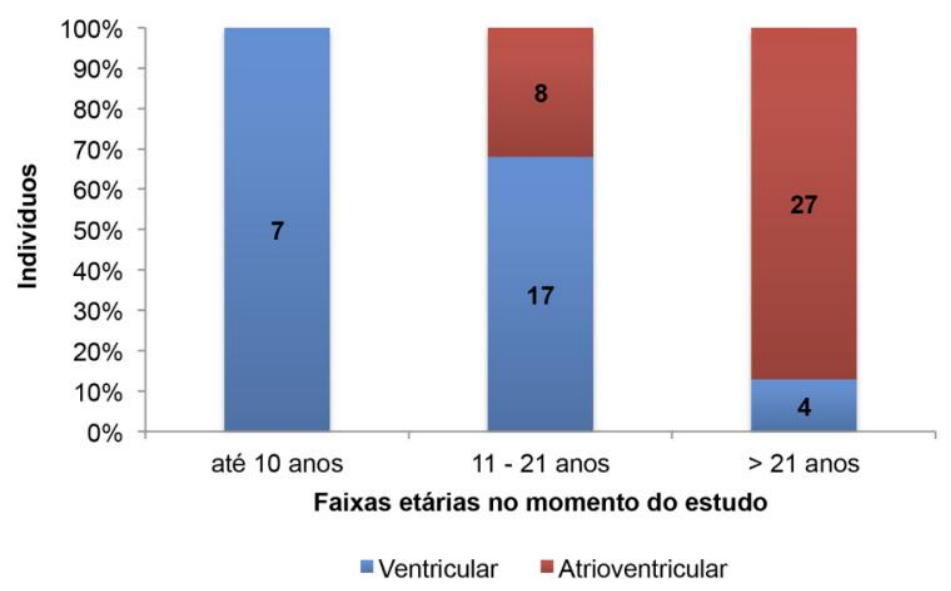

No registro eletrocardiográfico feito durante a avaliação, o ritmo ventricular era comandado pelo marca-passo em todos os casos, sendo: estimulação ventricular exclusiva com ondas P dissociadas, em 28 (44,4\%); estimulação ventricular sincronizada às ondas $P$ espontâneas, em 19 $(30,2 \%)$ e estimulação atrioventricular sequencial em 16 (25,4\%). Os contadores diagnósticos dos marca-passos, entretanto, mostravam que ao longo do tempo, o percentual de estimulação ventricular variou de 80 a 100\% com média de 97,9 \pm 4,2 (Anexos L e M).

Com a inibição do marca-passo por reprogramação foi possível observar-se o ritmo espontâneo em 49 (78\%) indivíduos. Em 14 (22,2\%), não foi possível observar-se ritmo de escape quando a frequência de estimulação era reduzida para 30 ppm (Anexo M).

O ritmo atrial era sinusal em todos os indivíduos, não tendo sido observados ritmos atriais ectópicos ou fibrilação atrial, no eletrocardiograma registrado no momento da avaliação ou nos contadores diagnósticos do marcapasso. 
A duração do complexo QRS com o marca-passo inibido, avaliada nos 49 indivíduos que apresentavam ritmo espontâneo, variou de 40 a 125 ms com média de $87,4 \pm 14,3$ ms. O eixo do complexo QRS inibido, no plano frontal, variou de -30 a 150 graus. A duração do complexo QRS estimulado foi avaliada nos 63 indivíduos estudados, e variou de 110 a 190 ms, com média de $152,4 \pm 20,1$ ms. O eixo do complexo QRS estimulado, no plano frontal variou de -120 a 122 graus (Gráfico 8; Anexo L).

\section{Gráfico 8 - Duração do complexo QRS estimulado (A) e com o marca- passo inibido (B) obtidos durante a avaliação eletrônica do dispositivo. InCor-HCFMUSP (2010 - 2013)}
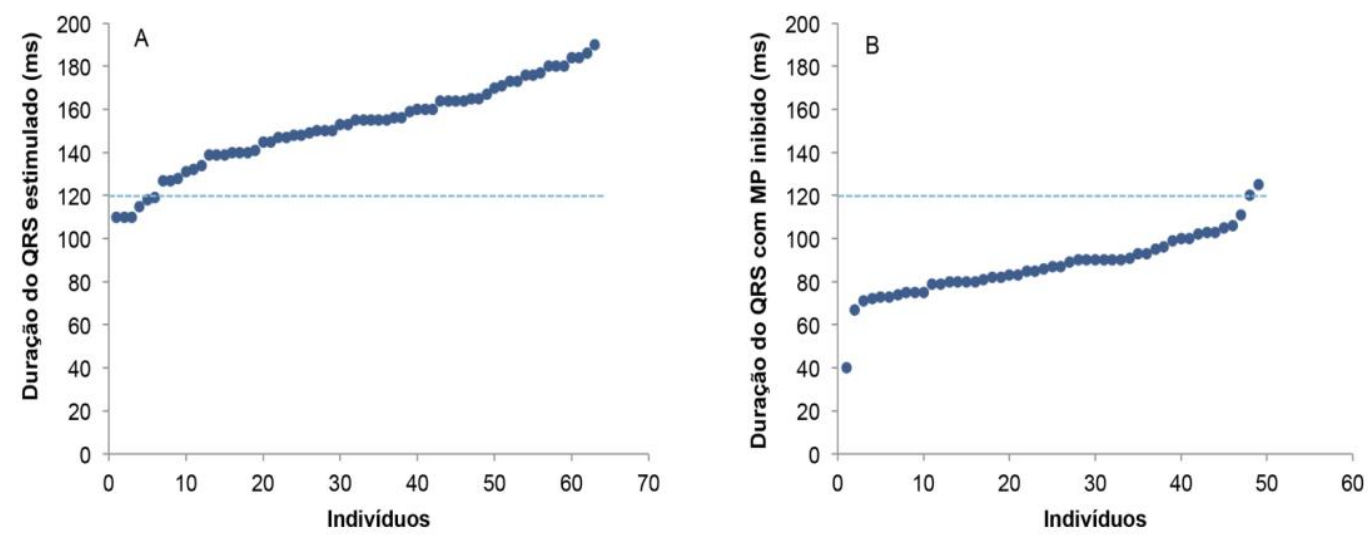

Não foram encontrados casos de disfunção de gerador de pulsos ou de cabos-eletrodos, assim como alterações das funções de estimulação ou da sensibilidade dos marca-passos.

A posição dos cabos-eletrodos ventriculares em uso foi confirmada pelo estudo radiológico do tórax nas projeções póstero-anterior e oblíqua esquerda. Foi possível observar que 20 (32,4\%) cabos-eletrodos estavam implantados no septo interventricular e $43(68,2 \%)$ em outras regiões do ventrículo direito inclusive o septo apical (Anexo N). 


\subsubsection{Avaliação da capacidade funcional pelo teste de caminhada de seis minutos}

O teste de caminhada de seis minutos foi aplicado em 61 indivíduos, que apresentavam idades entre sete e 41 anos de idade. Somente duas crianças com menos do que três anos de idade não realizaram este teste.

Não houve casos de interrupção do teste e nenhum dos indivíduos necessitou de cuidados especiais.

Esta avaliação mostrou que a maioria dos indivíduos apresentava boa capacidade funcional. A distância média percorrida foi de 546,9 \pm 76,2 metros, representando $91,0 \pm 12,5 \%$ do valor predito pela equação utilizada no estudo. A maioria dos indivíduos percorreu distâncias superiores a $80 \%$ do valor predito, sendo que destes, 18 (29,5\%) caminharam distâncias superiores aos valores estimados pela equação (Gráfico 9; Tabela 4; Anexo O).

\section{Gráfico 9 - Distância total caminhada e percentual da distância predita alcançada durante o teste de caminhada de seis minutos. InCor-HCFMUSP (2010 - 2013).}
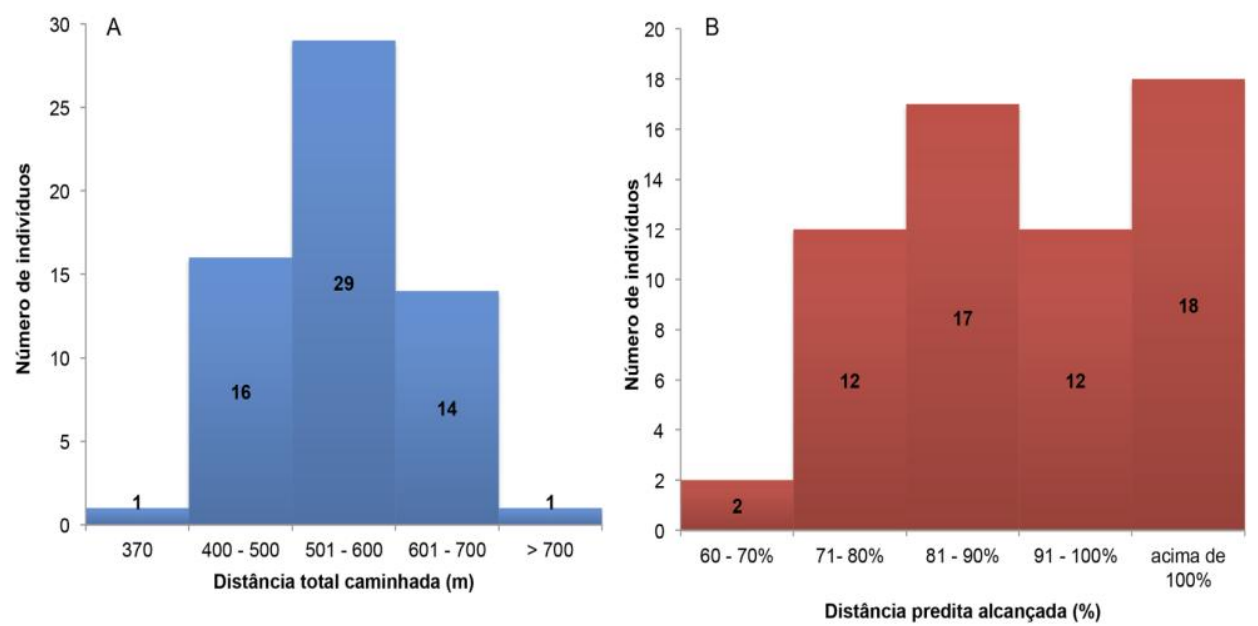
A análise do Gráfico 10, mostra que houve uma forte correlação entre a distância total caminhada e a distância predita $(r=0,907 ; P=0,001)$.

\section{Gráfico 10 -Correlação entre a distância total caminhada e a distância predita pela equação de Iwama ${ }^{134}$ InCor-HCFMUSP (2010 - 2013)}

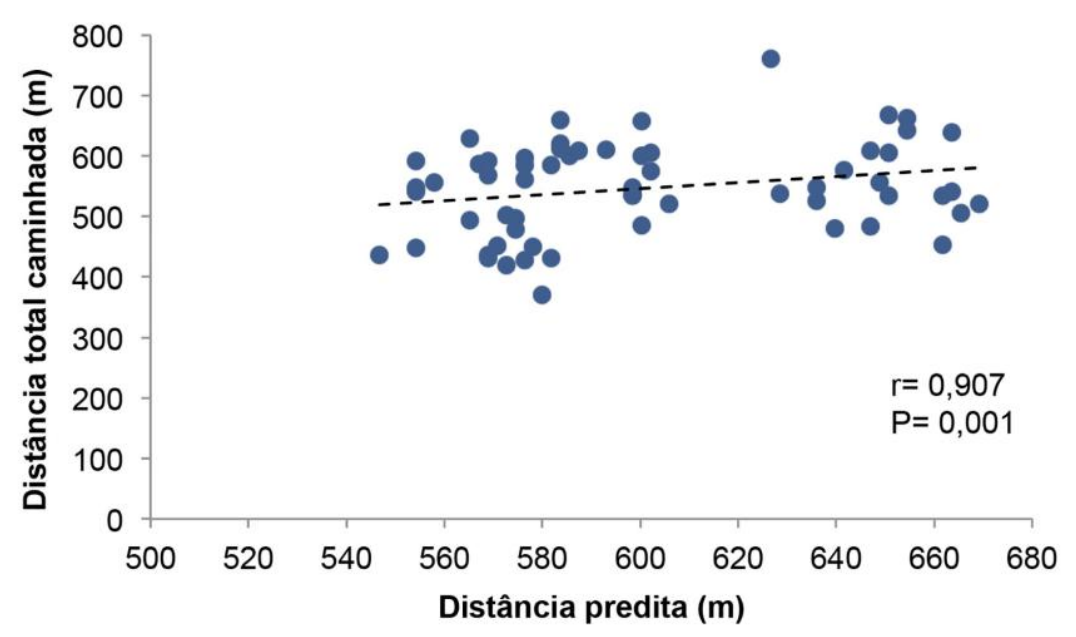

\subsubsection{Avaliação da qualidade de vida}

O questionário SF-36 foi utilizado para a avaliação da qualidade de vida dos 47 (74,6\%) indivíduos que apresentavam idade superior a 14 anos e o questionário CHQ-PF50 foi aplicado aos pais dos $16(25,4 \%)$ que não haviam atingido esta idade. A Tabela 3 apresenta as principais características dos indivíduos de acordo com o questionário utilizado para avaliação da qualidade de vida. 


\section{Tabela 3 - Caracterização dos indivíduos de acordo com 0 questionário utilizado para avaliação da qualidade de vida. InCor-HCFMUSP (2010 - 2013)}

\begin{tabular}{|c|c|c|}
\hline Características & $\begin{array}{l}\text { SF-36 } \\
(n=47)\end{array}$ & $\begin{array}{c}\text { CHQ-PF50 } \\
(n=16)\end{array}$ \\
\hline \multicolumn{3}{|l|}{ Gênero, n (\%) } \\
\hline Feminino & $32(68,1)$ & $10(62,5)$ \\
\hline Masculino & $15(31,9)$ & $6(37,5)$ \\
\hline $\begin{array}{l}\text { Idade no momento do implante de marca-passo, anos } \\
\text { (média } \pm \text { DP) }\end{array}$ & $9,7 \pm 5,8$ & $2,1 \pm 3,2$ \\
\hline Idade no momento da avaliação, anos (média \pm DP) & $25,8 \pm 6,5$ & $10,5 \pm 3,6$ \\
\hline $\begin{array}{l}\text { Tempo de estimulação no ventrículo direito, anos (média } \pm \\
\text { DP) }\end{array}$ & $11,1 \pm 5,2$ & $5,3 \pm 3,2$ \\
\hline Tempo total de marca-passo (média \pm DP) & $15,1 \pm 6,2$ & $7,6 \pm 3,9$ \\
\hline \multicolumn{3}{|l|}{ Tipo de marca-passo em uso, n (\%) } \\
\hline Ventricular & $12(25,5)$ & $16(100)$ \\
\hline Atrioventricular & $35(74,5)$ & - \\
\hline Classe Funcional I (NYHA) na última avaliação, n (\%) & $44(93,6)$ & $16(100)$ \\
\hline Uso de medicamentos de ação cardiovascular, n (\%) & $5(10,6)$ & - \\
\hline Fração de Ejeção do VE, \% (média \pm DP) & $54,4 \pm 7,3$ & $56,2 \pm 6,2$ \\
\hline Atraso intraventricular, ms (média \pm DP) & $90,4 \pm 59,3$ & $75,2 \pm 51,2$ \\
\hline Distância total percorrida, m (média \pm DP) & $545,6 \pm 81,4$ & $551,2 \pm 58,0$ \\
\hline Distância predita alcançada, \% (média \pm DP) & $91,9 \pm 12,9$ & $88,1 \pm 11,4$ \\
\hline
\end{tabular}

Conforme mostrado no Gráfico 11, foram obtidos escores médios superiores a $70 \%$ em praticamente todos os domínios do instrumento de qualidade de vida SF-36, exceto no domínio "Vitalidade", que recebeu a menor pontuação. Os escores médios do SF-36 para o "Sumário Físico" e "Sumário Mental" foram 78,1 $\pm 17,7$ e 76,6 $\pm 17,1$, respectivamente (Anexo P). 


\section{Gráfico 11 -Escores de qualidade de vida para cada um dos domínios e} sumários físico e mental do Questionário SF-36

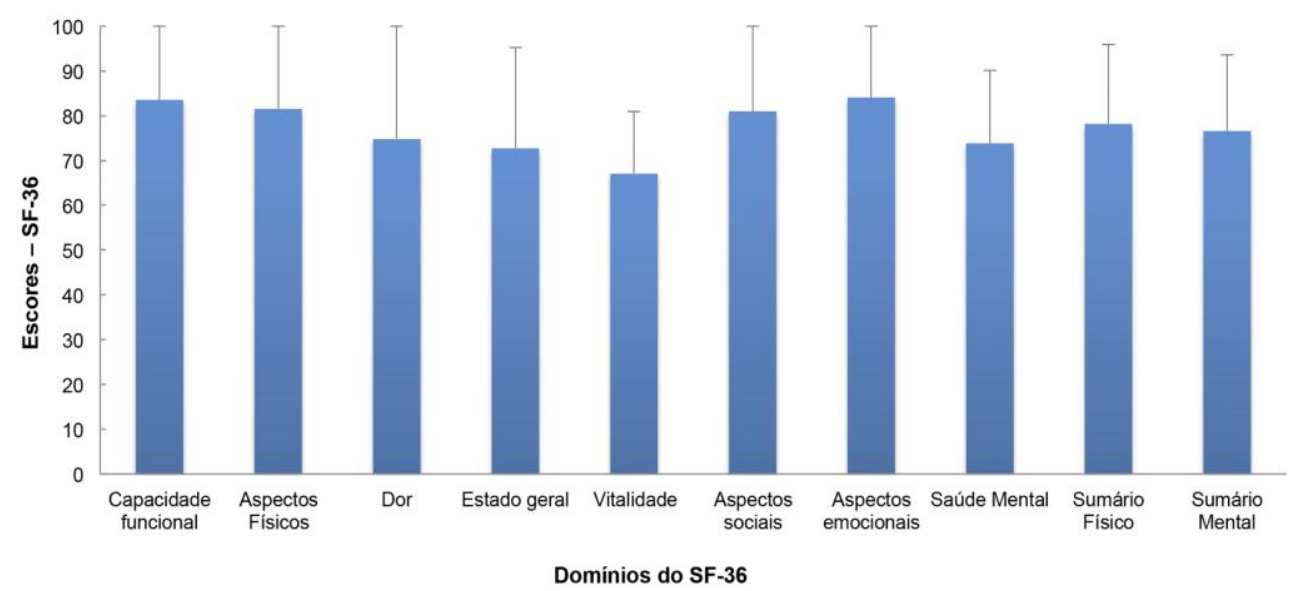

Os resultados obtidos com o instrumento CHQ-PF50 apresentaram foram semelhantes, com escores médios superiores a $70 \%$, à exceção do domínio "Percepção geral do estado de saúde", que apresentou valores médios de 59,7 $\pm 10,1$. Os escores médios do CHQ-PF50 para o "Sumário Físico" e "Sumário Psicossocial" foram 77,4 \pm 18,5 e 77,7 \pm 21,6, respectivamente (Gráfico 12, Anexo Q).

Gráfico 12 -Escores de qualidade de vida para cada um dos domínios e sumários físico e psicossocial do Questionário CHQ-PF50

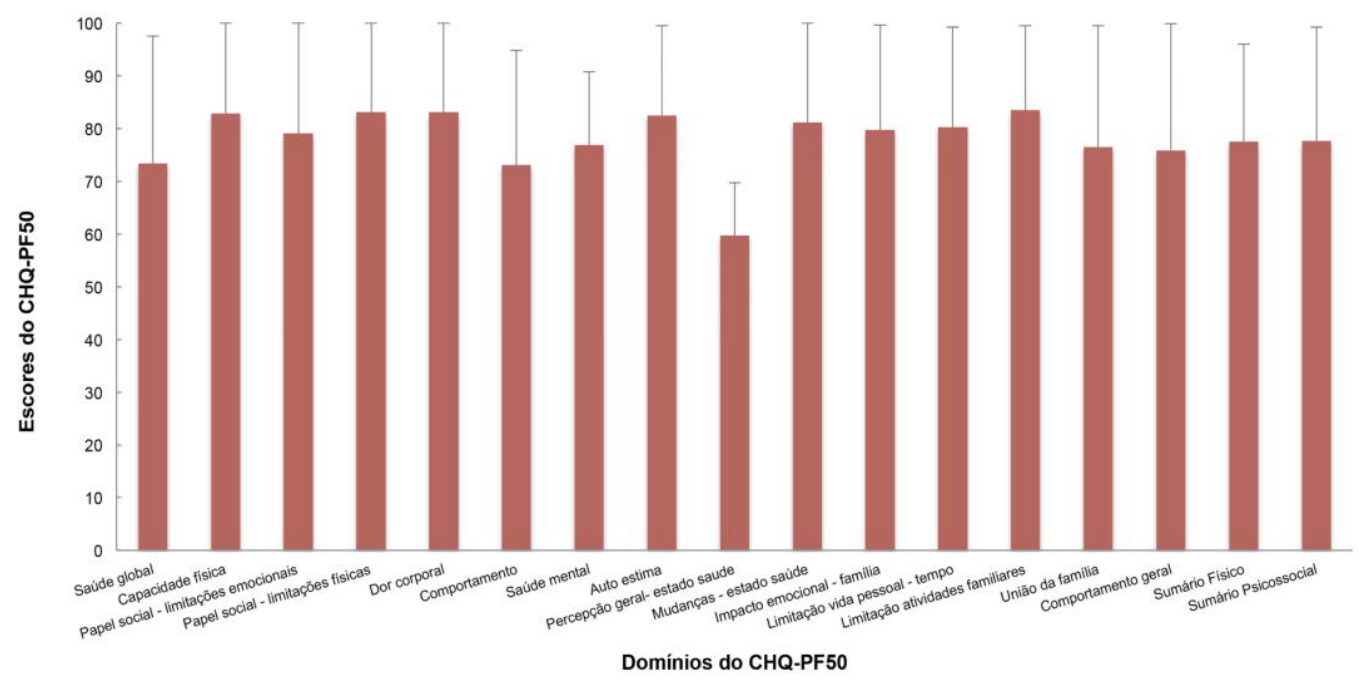


A comparação das medidas sumárias de ambos os questionários mostrou que existe forte correlação entre o "Sumário Físico" e "Sumário Mental" do questionário SF-36 ( $r=0,783 ; P<0,0001)$, assim como, entre 0 "Sumário Físico" e o "Sumário Psicossocial" do questionário CHQ-PF50 (r= 0,700; $P=0,003)$, indicando que, na maioria dos indivíduos, os escores dos domínios físicos e emocionais apresentam comportamento semelhante (Gráfico 13).

\section{Gráfico 13 -Correlação entre as medidas sumárias dos questionários de qualidade de vida SF-36 e CHQ-PF50}
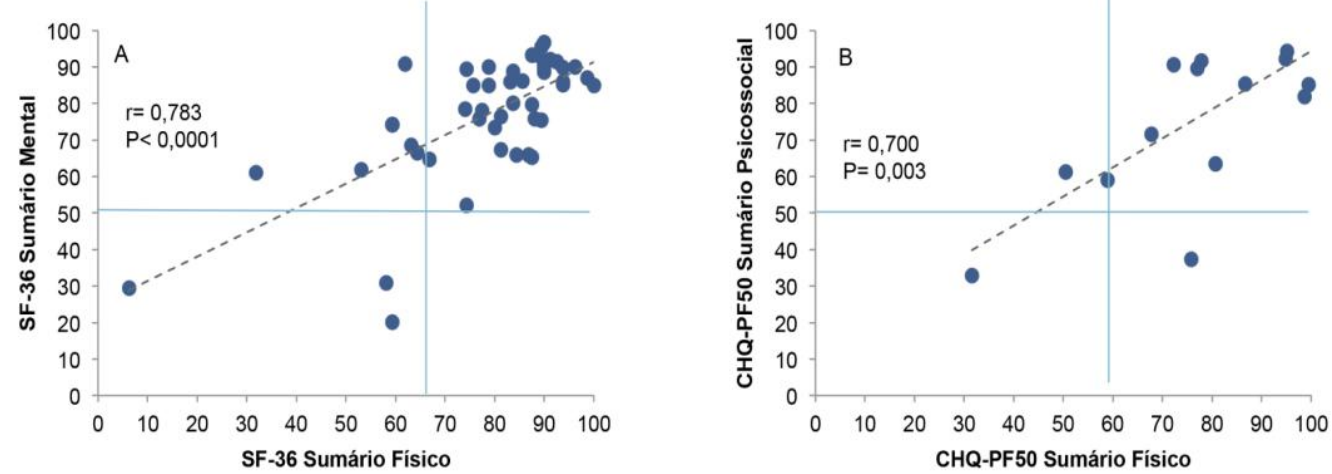

A análise da confiabilidade interna de ambos os questionários de qualidade de vida foi realizada com o teste alfa de Cronbach que demonstrou elevado grau de confiabilidade para ambos, na população estudada, com valores variando de 0,83 a 0,86 para os oito domínios do SF36 e de 0,89 a 0,91 para os 14 domínios do CHQ-PF50. 


\subsubsection{Ecocardiograma}

O estudo ecocardiográfico, realizado em todos os indivíduos pelos modos uni e bidimensional, confirmou a ausência de cardiopatias estruturais e a posição normal dos corações. No momento do estudo, a superfície corporal variou de 0,4 a 2,2 $\mathrm{m}^{2}$ com média de 1,6 $\pm 0,3 \mathrm{~m}^{2}$.

\subsubsection{Remodelamento ventricular}

A avaliação da fração de ejeção do ventrículo esquerdo pelo Método de Simpson foi considerada normal em 38 (60,3\%) indivíduos. Disfunção ventricular leve foi observada em 20 (31,7\%), moderada em $4(6,3 \%)$ e grave em apenas 1 (1,6\%) sujeito (Gráfico 14; Anexo R).

Gráfico 14 -Fração de ejeção do VE (\%) obtida pelo modo bidimensional e calculada pelo Método de Simpson. InCor-HCFMUSP (2010 - 2013)

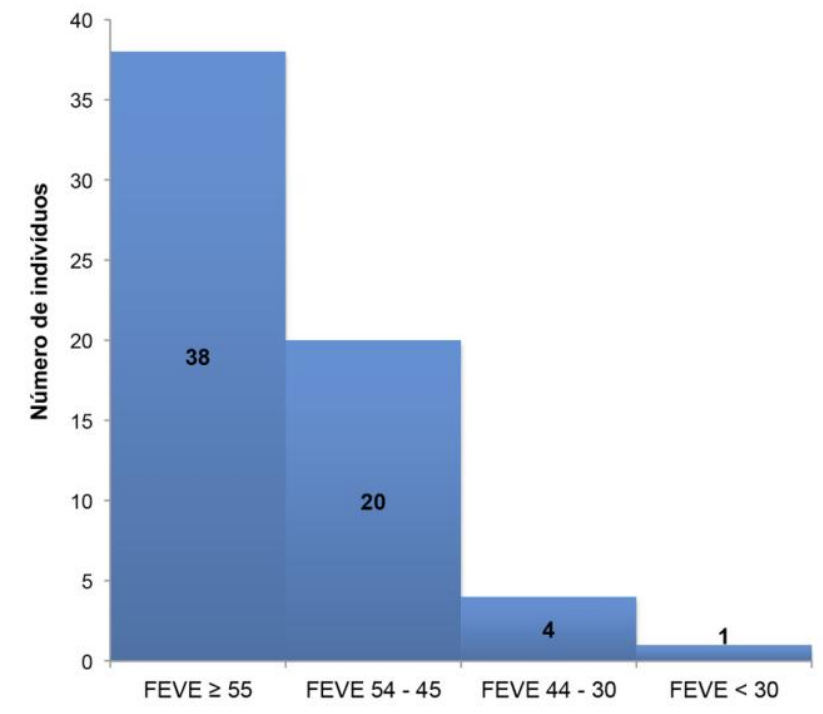

$F E V E=$ fração de ejeção do ventrículo esquerdo. 
As medidas do diâmetro diastólico do ventrículo esquerdo obtidas demonstraram que 49 (77,8\%) dos indivíduos apresentavam valores dentro dos limites da normalidade, considerando-se a idade (quando inferior a 15 anos) e o sexo (indivíduos adultos). Na maioria dos casos, foi observado aumento discreto, conforme detalhado no Gráfico 15.

Gráfico 15 -Diâmetro do ventrículo esquerdo (DDVE) de acordo com os valores definidos por faixas etárias (A) e classificação de acordo com os limites de normalidade (B). InCor-HCFMUSP (2010 - 2013)
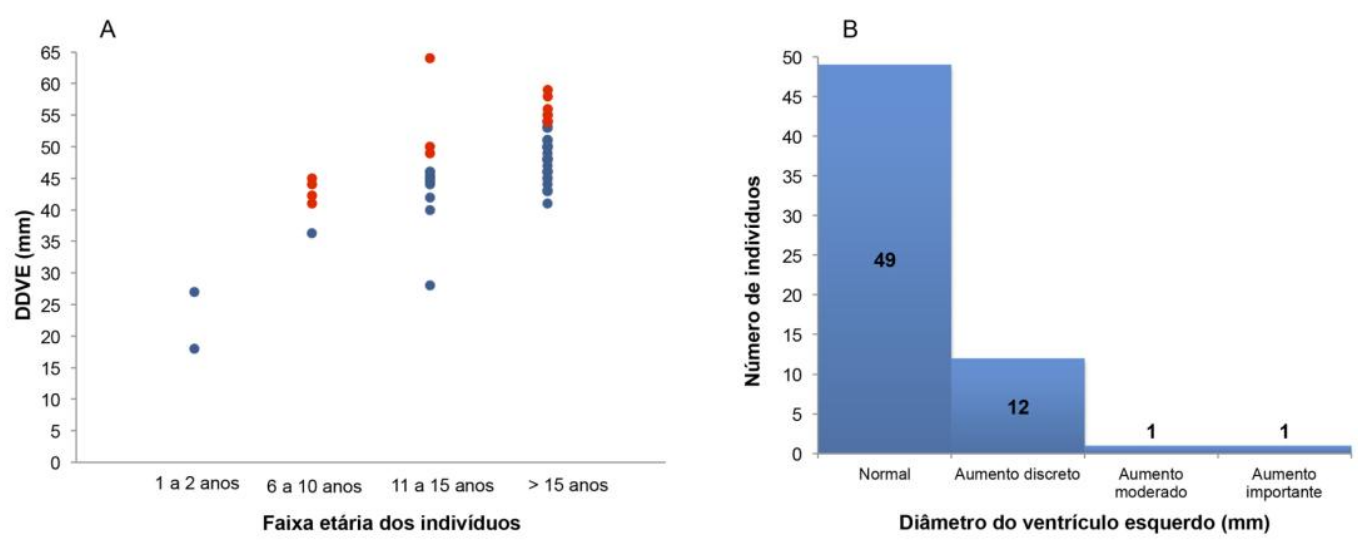

No Gráfico 15, os marcadores em azul referem-se aos valores dentro da normalidade e os marcadores vermelhos referem-se aos valores acima da normalidade.

Pela análise do Gráfico 16, nota-se que apenas um indivíduo apresentou dilatação ventricular de acordo com o escore Z (acima de 2) do diâmetro diastólico do ventrículo esquerdo. É possível observar-se, ainda, que o escore $Z$ apresentou excelente correlação $(r=1,0)$ com os valores brutos do diâmetro diastólico do ventrículo esquerdo. 


\section{Gráfico 16 -Escore Z do diâmetro diastólico do ventrículo esquerdo (A) e sua correlação com o diâmetro diastólico do ventrículo esquerdo (B). InCor-HCFMUSP (2010 - 2013)}
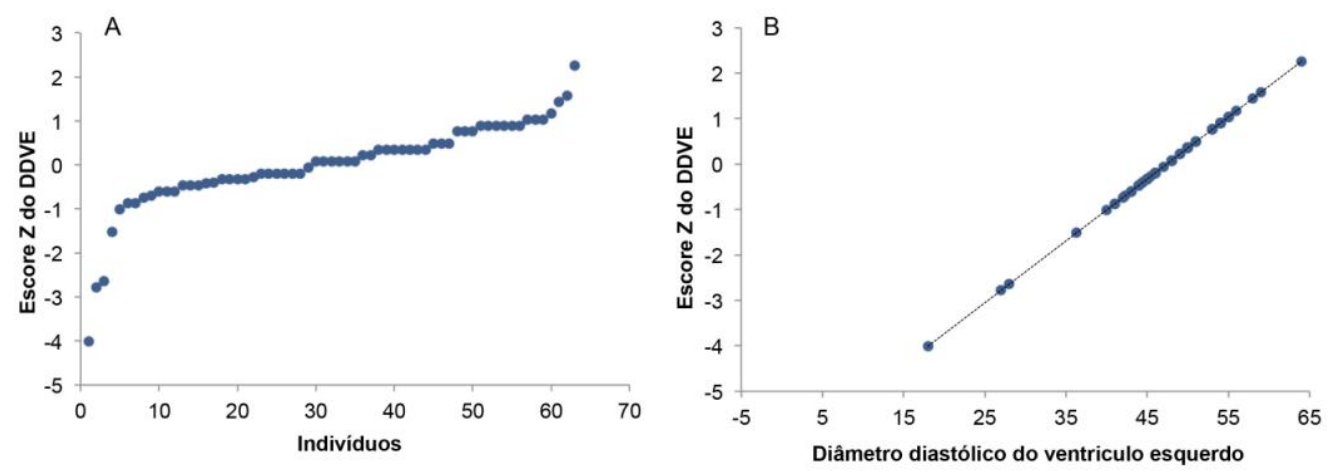

\subsubsection{Sincronia ventricular}

O estudo da sincronia ventricular esquerda pelo Doppler tecidual demonstrou a existência de dissincronia significativa, intra ou interventricular, em 38 (60,3\%) pacientes avaliados (Anexo S).

O retardo da ativação mecânica entre as paredes do ventrículo esquerdo variou de 15 a 288 ms, com média de 86,5 \pm 56,9 ms. Com base nesse método, a sincronia intraventricular esquerda foi considerada normal em apenas $29(46,0 \%)$ pacientes.

O retardo da ativação mecânica entre os ventrículos variou de 61 a 457 ms, com média de 141,9 \pm 88 ms. Com base nesse método, a sincronia interventricular foi considerada normal em 25 (39,7\%) pacientes (Gráfico 17). 
Gráfico 17 -Medida do atraso eletromecânico (ms) intraventricular esquerdo (A) e interventricular (B) pelo Ecocardiograma com Doppler tecidual. InCor-HCFMUSP (2010 - 2013)
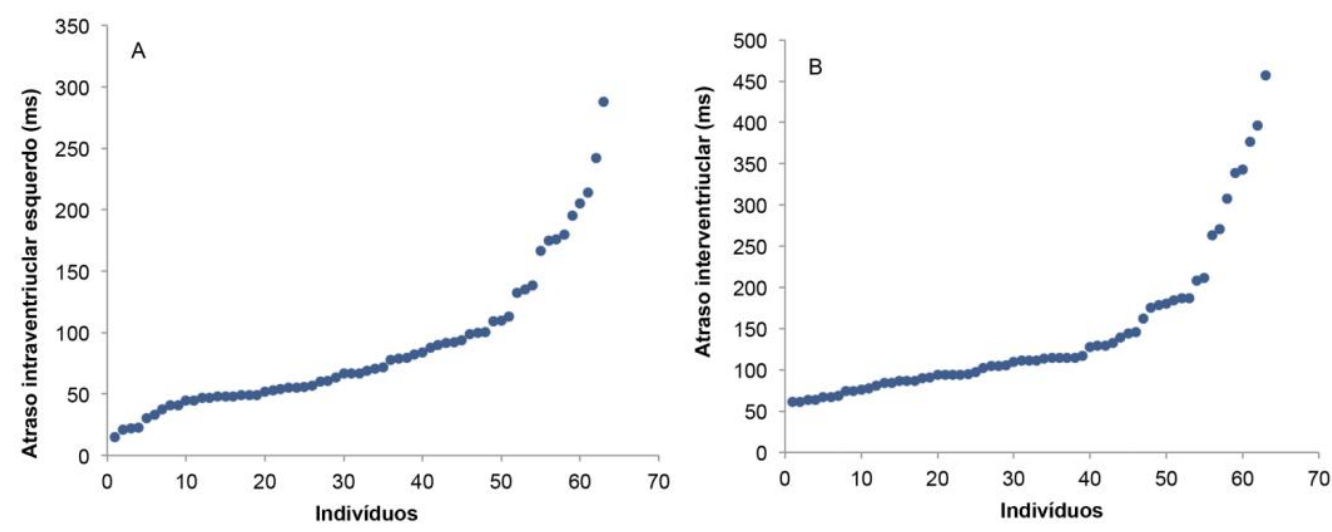

A análise da Gráfico 18 mostra a semelhança entre o sincronismo interventricular e o interventricular, em cada um dos pacientes avaliados $(r=$ $0,9404 ; P<0,0002)$

Gráfico 18 -Correlação entre o atraso da ativação intraventricular esquerda e 0 atraso da ativação interventricular medidos pelo Ecocardiograma com Doppler Tecidual. InCorHCFMUSP (2010 - 2013)

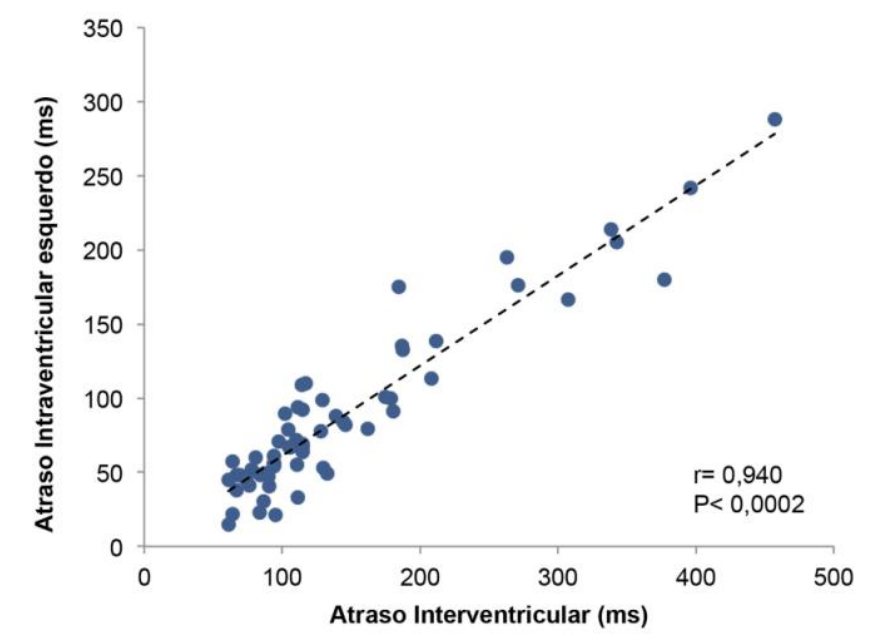




\subsubsection{Insuficiência mitral}

A presença de insuficiência mitral classificada como de leve para moderada foi identificada em $13(20,6 \%)$ indivíduos e de moderada para grave em apenas um 1 (1,6\%) (Gráfico 19; Anexo R).

\section{Gráfico 19 -Classificação do grau de insuficiência mitral medido pelo Ecocardiograma Bidimensional com Doppler. InCor- HCFMUSP (2010 - 2013)}

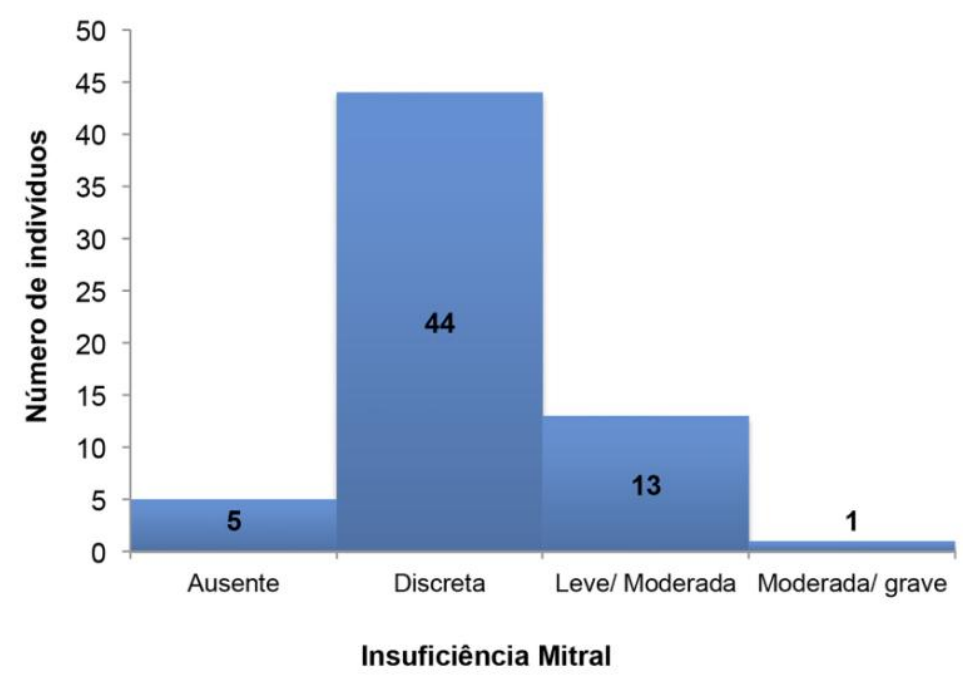

\subsubsection{Marcadores laboratoriais de doenças autoimunes}

A avaliação clínica e laboratorial para a pesquisa de doenças reumatológicas foi realizada em todos os sujeitos incluídos no estudo, com exceção de um único caso, já referido anteriormente, que não compareceu para a coleta de sangue. Em 56 casos, foi possível realizar a avaliação pareada dos sujeitos de pesquisa e suas respectivas mães.

Não houve detecção de quadro clínico compatível com doença reumatológica, da mesma forma que não foi identificada cicatriz sorológica nos sujeitos da pesquisa (Anexo T). 
A avaliação clínica das 56 mães, entretanto, permitiu o diagnóstico lúpus eritematoso sistêmico em $6(10,7 \%)$ e de síndrome de Sjögren em 7 $(12,5 \%)$ mães. A avaliação laboratorial mostrou a presença de autoanticorpos Anti-Ro/SSA e Anti-La/SSB em 18 (32,1\%) e 17 (30,9\%) mães, respectivamente (Tabela 4; Anexo U).

Tabela 4 - Prevalência de anticorpos Anti-Ro/SSA e Anti-La/SSB e de manifestações clínicas de doenças reumatológicas nas mães de portadores de bloqueio atrioventricular congênito. InCor-HCFMUSP (2010 - 2013)

\begin{tabular}{lc}
\hline Anti-Ro/SSA e/ ou Anti-La/SSB & Mães, $\mathbf{n}(\%)$ \\
\hline Positivo & \\
Anti-Ro/SSA 52kDa & $18(32,7)$ \\
Anti-Ro/SSA 60kDa & $18(32,7)$ \\
Anti-La/SSB 48kDa & $17(30,9)$ \\
Negativo & $38(67,8)$ \\
Não avaliado & $7(11,0)$ \\
Manifestações Clínicas & Mães, $\mathbf{n}(\%)$ \\
Lúpus eritematoso sistêmico & $6(10,7)$ \\
Síndrome de Sjögren & $7(12,5)$ \\
Outras colagenoses & $5(8,9)$ \\
Assintomática & $38(67,8)$ \\
\hline
\end{tabular}

\subsection{Análise dos Desfechos do Estudo e de seus Fatores Preditores}

\subsubsection{Evolução clínica}

A análise da presença combinada de sintomas de insuficiência cardíaca e do uso de medicamentos de ação cardiovascular mostrou que somente $1(1,6 \%)$ indivíduo apresentava essas duas condições associadas, enquanto que 56 (88,9\%), estavam assintomáticos e não utilizavam fármacos de ação cardiovascular (Gráfico 20). 


\section{Gráfico 20 -Classe funcional de insuficiência cardíaca (NYHA) e uso de medicamentos de ação cardiovascular nos portadores de bloqueio atrioventricular congênito isolado. InCor- HCFMUSP (2010 - 2013)}

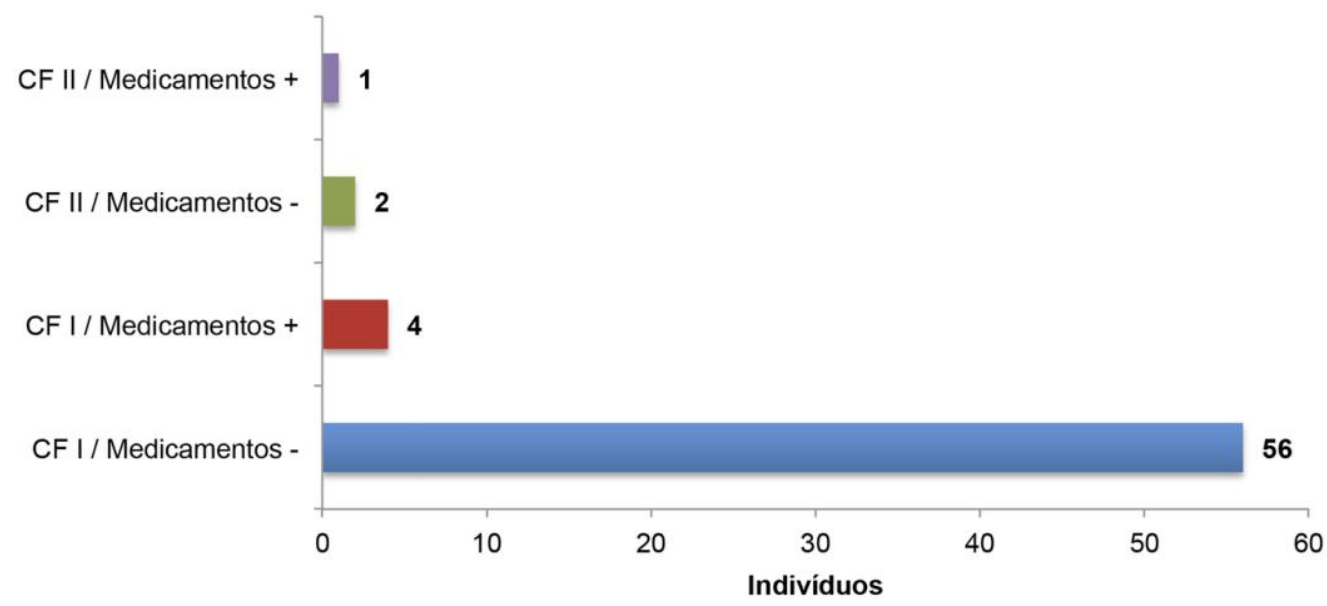

$\mathrm{CF}=$ classe funcional para insuficiência cardíaca segundo os critérios da New York Heart Association (NYHA); Medicamentos (-) refere-se ao não uso de fármacos de ação cardiovascular; Medicamentos (+) refere-se ao uso de fármacos de ação cardiovascular.

A comparação entre os pacientes que estavam assintomáticos e que não usavam medicamentos em relação aos que estavam em classe funcional II (NYHA) e/ou em uso de medicamentos mostrou que os últimos eram portadores de marca-passo por mais tempo, tanto no que se referia ao tempo total de uso destes dispositivos $(P=0,013)$, quanto ao tempo de estimulação ventricular direita $(P=0,005)$; eram mais velhos no momento da inclusão no estudo $(P=0,032)$, além de, em concordância com o quadro clínico, apresentarem menores valores de fração de ejeção do ventrículo esquerdo $(P=0,013)$ (Tabela 5). 
Tabela 5 - Comparação dos indivíduos em relação à ausência e presença de sintomas de insuficiência cardíaca e uso de medicamentos de ação cardiovascular. InCor-HCFMUSP (2010 - 2013)

\begin{tabular}{|c|c|c|c|}
\hline \multirow[t]{2}{*}{ Características } & \multicolumn{2}{|c|}{$\begin{array}{l}\text { Sintomas e uso de } \\
\text { medicamentos }\end{array}$} & \multirow{2}{*}{$\begin{array}{l}\text { Valor } \\
\text { de P }\end{array}$} \\
\hline & Ausentes & Presentes & \\
\hline Gênero, n (\%) & & & \\
\hline Feminino & $39(69,6)$ & $4(57,1)$ & 0,669 \\
\hline $\begin{array}{l}\text { Masculino } \\
\text { Idade no momento do implante de marca- }\end{array}$ & $17(30,4)$ & $3(42,8)$ & \\
\hline passo, anos (média \pm DP) & $7,6 \pm 6,2$ & $9,4 \pm 6,4$ & 0,463 \\
\hline $\begin{array}{l}\text { Idade no momento da avaliação, anos (média } \pm \\
\text { DP) }\end{array}$ & $21,8 \pm 8,2$ & $28,6 \pm 7,1$ & 0,043 \\
\hline $\begin{array}{l}\text { Tempo de estimulação no VD, anos (média } \pm \\
\text { DP) }\end{array}$ & $8,9 \pm 5,1$ & $14,9 \pm 4,9$ & 0,005 \\
\hline Tempo total de marca-passo (média \pm DP) & $12,4 \pm 5,9$ & $18,8 \pm 8,7$ & 0,013 \\
\hline Tipo de marca-passo em uso, $n(\%)$ & & & \\
\hline Ventricular & $27(49,1)$ & $1(14,3)$ & 0116 \\
\hline Atrioventricular & $28(59,9)$ & $6(85,7)$ & \\
\hline Sítio de estimulação no VD, n (\%) & & & \\
\hline Não septal & $38(67,8)$ & $5(71,4)$ & 1000 \\
\hline Septal & $18(32,1)$ & $2(28,6)$ & 1,000 \\
\hline Fração de ejeção do VE, n (\%) & & & \\
\hline $\begin{array}{l}<55 \\
\geq 55\end{array}$ & $\begin{array}{l}19(33,9) \\
37(66,1)\end{array}$ & $\begin{array}{l}6(85,7) \\
1(14,3)\end{array}$ & 0,013 \\
\hline Atraso intraventricular, n (\%) & & & \\
\hline $\begin{array}{l}<65 \\
\geq 65\end{array}$ & $\begin{array}{l}26(46,4) \\
30(53,6)\end{array}$ & $\begin{array}{l}3(42,9) \\
4(57,1)\end{array}$ & 1,000 \\
\hline Atraso interventricular, n (\%) & & & \\
\hline $\begin{array}{l}<100 \\
\geq 100\end{array}$ & $\begin{array}{l}23(41,1) \\
33(58,9)\end{array}$ & $\begin{array}{l}2(28,6) \\
5(71,4)\end{array}$ & 0,693 \\
\hline Insuficiência mitral, n (\%) & & & \\
\hline Ausente & $44(78,6)$ & $5(71,4)$ & 0,646 \\
\hline $\begin{array}{l}\text { Presente } \\
\text { Distância nredita alcancada } \mathrm{n}(\%)\end{array}$ & $12(21,4)$ & $2(28,6)$ & \\
\hline $\begin{array}{l}\text { Distância predita alcançada, n (\%) } \\
\quad<90 \% \\
\quad \geq 90 \%\end{array}$ & $\begin{array}{l}28(51,8) \\
26(48,1)\end{array}$ & $\begin{array}{l}3(42,8) \\
4(57,2)\end{array}$ & 0,707 \\
\hline Qualidade de Vida, (média \pm DP) & & & \\
\hline Sumário Físico - SF-36 & $80,2 \pm 12,6$ & $66,7 \pm 33,9$ & 0,336 \\
\hline Sumário Mental - SF-36 & $77,6 \pm 16,3$ & $70,7 \pm 21,2$ & 0,330 \\
\hline Autoanticorpos Anti-Ro/SSA nas mães, n (\%) & & & \\
\hline $\begin{array}{l}\text { Negativo } \\
\text { Positivo }\end{array}$ & $\begin{array}{l}32(65,3) \\
17(34,7)\end{array}$ & $\begin{array}{l}5(83,3) \\
1(16,7)\end{array}$ & 0,651 \\
\hline
\end{tabular}

$\mathrm{DP}=$ desvio padrão; $\mathrm{VD}=$ ventrículo direito; $\mathrm{VE}=$ ventrículo esquerdo. 


\subsubsection{Marcadores laboratoriais de insuficiência cardíaca}

Os valores obtidos para a dosagem do BNP, que foram normais para todos os indivíduos estudados, mostraram-se concordantes com a ausência de quadro clínico de insuficiência cardíaca grave ou mal controlada. Por outro lado, as dosagens da PCR-us, do TNF-alfa e da Interleucina-6 que estavam fora do limite considerado normal em $66 \%$, 34\% e $13 \%$ dos exames realizados, respectivamente, não se associaram com a presença de sinais clínicos de insuficiência cardíaca.

A análise dos resultados obtidos para estes três marcadores demonstrou haver associação significativa entre os valores anormais da Interleucina-6 e PCR-us $(P=0,029)$. Não houve, entretanto associação significativa entre os valores elevados de Interleucina-6 com o TNF-alfa.

A Tabela 6 mostra que houve associação entre valores alterados das dosagens do TNF alfa com o menor tempo de estimulação cardíaca artificial $(P=0,021)$, e a ausência de associação com os outros preditores estudados. 


\section{Tabela 6 - Comparação dos indivíduos de acordo com os valores de TNF-alfa. InCor-HCFMUSP (2010 - 2013)}

\begin{tabular}{|c|c|c|c|}
\hline Características & $\begin{array}{l}\text { TNF-alfa } \\
<8,1 \mathrm{pg} / \mathrm{mL} \\
(\mathrm{n}=41)\end{array}$ & $\begin{array}{l}\text { TNF-alfa } \\
\geq 8,1 \mathrm{pg} / \mathrm{mL} \\
\quad(\mathrm{n}=21)\end{array}$ & $\begin{array}{l}\text { Valor } \\
\text { de P }\end{array}$ \\
\hline $\begin{array}{l}\text { Gênero, } \mathrm{n}(\%) \\
\text { Feminino } \\
\text { Masculino }\end{array}$ & $\begin{array}{l}29(70,7) \\
12(29,3)\end{array}$ & $\begin{array}{c}12(57,1) \\
9(42,9)\end{array}$ & 0,284 \\
\hline $\begin{array}{l}\text { Idade no momento do implante de marca- } \\
\text { passo, anos (média } \pm \mathrm{DP})\end{array}$ & $7,5 \pm 6,5$ & $8,1 \pm 6,0$ & 0,732 \\
\hline $\begin{array}{l}\text { Idade no momento da avaliação, anos (média } \pm \\
\text { DP) }\end{array}$ & $23,1 \pm 9,0$ & $21,7 \pm 7,1$ & 0,564 \\
\hline $\begin{array}{l}\text { Tempo de estimulação no VD, anos (média } \pm \\
\text { DP) }\end{array}$ & $9,9 \pm 5,5$ & $8,9 \pm 5,3$ & 0,530 \\
\hline Tempo total de marca-passo (média \pm DP) & $14,4 \pm 5,9$ & $10,4 \pm 6,9$ & 0,021 \\
\hline $\begin{array}{l}\text { Tipo de marca-passo em uso, n (\%) } \\
\text { Ventricular } \\
\text { Atrioventricular }\end{array}$ & $\begin{array}{l}20(48,8) \\
21(51,2)\end{array}$ & $\begin{array}{c}8(40,0) \\
12(60,0)\end{array}$ & 0,518 \\
\hline $\begin{array}{l}\text { Sítio de estimulação no VD, n (\%) } \\
\text { Não septal } \\
\text { Septal }\end{array}$ & $\begin{array}{l}30(73,2) \\
11(26,8)\end{array}$ & $\begin{array}{l}13(61,9) \\
8(38,1)\end{array}$ & 0,362 \\
\hline $\begin{array}{l}\text { Fração de ejeção do VE, n (\%) } \\
\quad<55 \\
\quad \geq 55\end{array}$ & $\begin{array}{l}16(39,0) \\
25(61,0)\end{array}$ & $\begin{array}{c}9(42,8) \\
12(57,2)\end{array}$ & 0,770 \\
\hline $\begin{array}{l}\text { Diâmetro diastólico do VE, n (\%) } \\
\text { Normal } \\
\text { Alterado }\end{array}$ & $\begin{array}{c}32(78,1) \\
9(21,9)\end{array}$ & $\begin{array}{l}16(76,2) \\
5(23,8)\end{array}$ & 1,000 \\
\hline $\begin{array}{l}\text { Insuficiência mitral, n (\%) } \\
\text { Ausente } \\
\text { Presente }\end{array}$ & $\begin{array}{c}33(80,5) \\
8(19,5)\end{array}$ & $\begin{array}{l}15(71,4) \\
6(28,6)\end{array}$ & 0,524 \\
\hline $\begin{array}{l}\text { Autoanticorpos Anti-Ro/SSA nas mães, n (\%) } \\
\text { Negativo } \\
\text { Positivo }\end{array}$ & $\begin{array}{l}26(70,3) \\
11(29,7) \\
\end{array}$ & $\begin{array}{l}11(61,1) \\
7(38,9) \\
\end{array}$ & 0,497 \\
\hline
\end{tabular}

$\mathrm{DP}=$ desvio padrão; VD = ventrículo direito; $\mathrm{VE}=$ ventrículo esquerdo.

A dosagem da Interleucina-6, que mostrou valores anormais em apenas $13 \%$ das amostras colhidas, não apresentou associação com os fatores preditores estudados, como é possível se observar na Tabela 7. 


\section{Tabela 7 - Comparação dos indivíduos de acordo com os valores de} Interleucina-6. InCor-HCFMUSP (2010 - 2013)

\begin{tabular}{|c|c|c|c|}
\hline Características & $\begin{array}{c}\text { IL- } 6 \\
<3,4 \mathrm{pg} / \mathrm{mL} \\
(\mathrm{n}=54)\end{array}$ & $\begin{array}{l}\text { IL- } 6 \\
\geq 3,4 \mathrm{pg} / \mathrm{mL} \\
(\mathrm{n}=8)\end{array}$ & $\begin{array}{l}\text { Valor } \\
\text { de P }\end{array}$ \\
\hline $\begin{array}{l}\text { Gênero, n (\%) } \\
\text { Feminino } \\
\text { Masculino }\end{array}$ & $\begin{array}{l}36(66,7) \\
18(33,3)\end{array}$ & $\begin{array}{l}5(62,5) \\
3(37,5)\end{array}$ & 1,000 \\
\hline $\begin{array}{l}\text { Idade no momento do implante de marca- } \\
\text { passo, anos (média } \pm \mathrm{DP} \text { ) }\end{array}$ & $7,3 \pm 6,1$ & $10,2 \pm 7,5$ & 0,223 \\
\hline $\begin{array}{l}\text { Idade no momento da avaliação, anos } \\
\text { (média } \pm \text { DP) }\end{array}$ & $22,5 \pm 8,5$ & $23,4 \pm 8,0$ & 0,763 \\
\hline $\begin{array}{l}\text { Tempo de estimulação no VD, anos (média } \pm \\
\text { DP) }\end{array}$ & $9,8 \pm 5,5$ & $8,0 \pm 4,5$ & 0,375 \\
\hline Tempo total de marca-passo (média \pm DP) & $13,2 \pm 6,6$ & $12,1 \pm 6,2$ & 0,675 \\
\hline $\begin{array}{l}\text { Tipo de marca-passo em uso, } \mathrm{n}(\%) \\
\text { Ventricular } \\
\text { Atrioventricular }\end{array}$ & $\begin{array}{l}25(47,2) \\
28(52,8)\end{array}$ & $\begin{array}{l}3(37,5) \\
5(62,5)\end{array}$ & 0,715 \\
\hline $\begin{array}{l}\text { Sítio de estimulação no VD, n (\%) } \\
\text { Não septal } \\
\text { Septal }\end{array}$ & $\begin{array}{l}39(72,2) \\
15(27,8)\end{array}$ & $\begin{array}{l}4(50,0) \\
4(50,0)\end{array}$ & 0,234 \\
\hline $\begin{array}{l}\text { Fração de ejeção do VE, n (\%) } \\
\quad<55 \\
\quad \geq 55\end{array}$ & $\begin{array}{l}22(40,7) \\
32(59,3)\end{array}$ & $\begin{array}{l}3(37,5) \\
5(62,5)\end{array}$ & 1,000 \\
\hline $\begin{array}{l}\text { Diâmetro diastólico do VE, n (\%) } \\
\text { Normal } \\
\text { Alterado }\end{array}$ & $\begin{array}{l}41(75,9) \\
13(24,1)\end{array}$ & $\begin{array}{l}7(87,5) \\
1(12,5)\end{array}$ & 0,669 \\
\hline $\begin{array}{l}\text { Insuficiência mitral, n (\%) } \\
\text { Ausente } \\
\text { Presente }\end{array}$ & $\begin{array}{l}42(77,8) \\
12(22,2)\end{array}$ & $\begin{array}{l}6(75,0) \\
2(25,0)\end{array}$ & 1,000 \\
\hline $\begin{array}{l}\text { Autoanticorpos Anti-Ro/SSA nas mães, n (\%) } \\
\text { Negativo } \\
\text { Positivo }\end{array}$ & $\begin{array}{l}31(64,6) \\
17(35,4) \\
\end{array}$ & $\begin{array}{l}6(85,7) \\
1(14,3) \\
\end{array}$ & 0,405 \\
\hline
\end{tabular}

$\mathrm{DP}=$ desvio padrão; $\mathrm{VD}=$ ventrículo direito; $\mathrm{VE}$ = ventrículo esquerdo.

A comparação dos valores de PCR ultrassensível com os fatores preditores mostrou que houve associação desse marcador com o tempo total de uso do marca-passo $(P=0,018)$, ou seja, os indivíduos com menor tempo de implante de marca-passo apresentaram valores normais de PCR (Tabela 8). 
Tabela 8 - Comparação dos indivíduos de acordo com os valores de PCR ultrassensível. InCor-HCFMUSP (2010 - 2013)

\begin{tabular}{|c|c|c|c|c|}
\hline Características & $\begin{aligned} & \text { PCR } \\
&< 1 \mathrm{mg} / \mathrm{L} \\
&(\mathrm{n}=21)\end{aligned}$ & $\begin{array}{c}\text { PCR } \\
1-3 \mathrm{mg} / \mathrm{L} \\
(\mathrm{n}=18)\end{array}$ & $\begin{array}{c}\text { PCR } \\
>3 \mathrm{mg} / \mathrm{L} \\
(\mathrm{n}=23)\end{array}$ & $\begin{array}{l}\text { Valor } \\
\text { de P }\end{array}$ \\
\hline $\begin{array}{l}\text { Gênero, n (\%) } \\
\text { Feminino } \\
\text { Masculino }\end{array}$ & $\begin{array}{c}11(52,4) \\
10(47,6)\end{array}$ & $\begin{array}{c}13(72,2) \\
5(27,8)\end{array}$ & $\begin{array}{c}17(73,9) \\
6(26,1)\end{array}$ & 0,260 \\
\hline $\begin{array}{l}\text { Idade no momento do implante de } \\
\text { marca-passo, anos (média } \pm D P \text { ) }\end{array}$ & $6,8 \pm 5,5$ & $6,6 \pm 5,9$ & $9,4 \pm 7,0$ & 0,253 \\
\hline $\begin{array}{l}\text { Idade no momento da avaliação, } \\
\text { anos (média } \pm D P \text { ) }\end{array}$ & $23,8 \pm 7,7$ & $21,5 \pm 9,6$ & $22,3 \pm 8,1$ & 0,688 \\
\hline $\begin{array}{l}\text { Tempo de estimulação no VD, anos } \\
\text { (média } \pm \text { DP) }\end{array}$ & $10,2 \pm 5,8$ & $9,4 \pm 4,7$ & $9,1 \pm 5,6$ & 0,783 \\
\hline $\begin{array}{l}\text { Tempo total de marca-passo (média } \\
\pm \mathrm{DP} \text { ) }\end{array}$ & $9,9 \pm 5,4$ & $15,7 \pm 6,3$ & $13,7 \pm 6,8$ & 0,018 \\
\hline $\begin{array}{l}\text { Tipo de marca-passo em uso, } \mathrm{n}(\%) \\
\text { Ventricular } \\
\text { Atrioventricular }\end{array}$ & $\begin{array}{c}8(40,0) \\
12(60,0)\end{array}$ & $\begin{array}{l}8(44,4) \\
10(55,6)\end{array}$ & $\begin{array}{l}12(52,2) \\
11(47,8)\end{array}$ & 0,718 \\
\hline $\begin{array}{l}\text { Sítio de estimulação no VD, n (\%) } \\
\text { Não septal } \\
\text { Septal }\end{array}$ & $\begin{array}{l}16(76,2) \\
5(23,8)\end{array}$ & $\begin{array}{l}14(77,8) \\
4(22,2)\end{array}$ & $\begin{array}{l}13(56,5) \\
10(43,5)\end{array}$ & 0,241 \\
\hline $\begin{array}{l}\text { Fração de ejeção do VE, n (\%) } \\
\quad<55 \\
\quad \geq 55\end{array}$ & $\begin{array}{c}7(33,3) \\
14(66,7)\end{array}$ & $\begin{array}{c}7(38,9) \\
11(61,1)\end{array}$ & $\begin{array}{l}11(47,8) \\
12(52,2)\end{array}$ & 0,612 \\
\hline $\begin{array}{l}\text { Diâmetro diastólico do VE, n (\%) } \\
\text { Normal } \\
\text { Alterado }\end{array}$ & $\begin{array}{c}16(76,2) \\
5(23,8)\end{array}$ & $\begin{array}{c}17(94,4) \\
1(5,6)\end{array}$ & $\begin{array}{c}15(65,2) \\
8(34,8)\end{array}$ & 0,079 \\
\hline $\begin{array}{l}\text { Insuficiência mitral, n (\%) } \\
\text { Ausente } \\
\text { Presente }\end{array}$ & $\begin{array}{c}13(61,9) \\
8(38,1)\end{array}$ & $\begin{array}{c}16(88,9) \\
2(11,1)\end{array}$ & $\begin{array}{c}19(82,6) \\
4(17,4)\end{array}$ & 0,129 \\
\hline $\begin{array}{l}\text { Autoanticorpos Anti-Ro/SSA nas } \\
\text { mães, } \mathrm{n}(\%) \\
\text { Negativo } \\
\text { Positivo }\end{array}$ & $\begin{array}{c}13(68,4) \\
6(31,6) \\
\end{array}$ & $\begin{array}{c}11(73,3) \\
4(26,7) \\
\end{array}$ & $\begin{array}{c}13(61,9) \\
8(38,1)\end{array}$ & 0,764 \\
\hline
\end{tabular}

$\mathrm{DP}=$ desvio padrão; VD = ventrículo direito; VE = ventrículo esquerdo.

\subsubsection{Capacidade funcional}

A despeito da variação detectada entre a capacidade funcional dos indivíduos avaliados, não houve correlação entre a distância caminhada e idade no implante inicial $(r=0,030 ; P=0,816)$ ou no momento do estudo $(r=$ 0,053; $P=0,684)$, assim como, com o tempo em que permaneceram sob estimulação no ventrículo direito $(r=0,099 ; P=0,448)$ e tempo total de uso do marca-passo $(r=0,057 ; P=0,664)$ (Gráfico 21). 
Gráfico 21 -Correlação entre a distância predita alcançada no teste de caminhada de seis minutos com a idade no implante do marca-passo (A), idade no momento do estudo (B), tempo de estimulação no ventrículo direito (C) e tempo total de marca-passo (D). InCor-HCFMUSP (2010 - 2013)
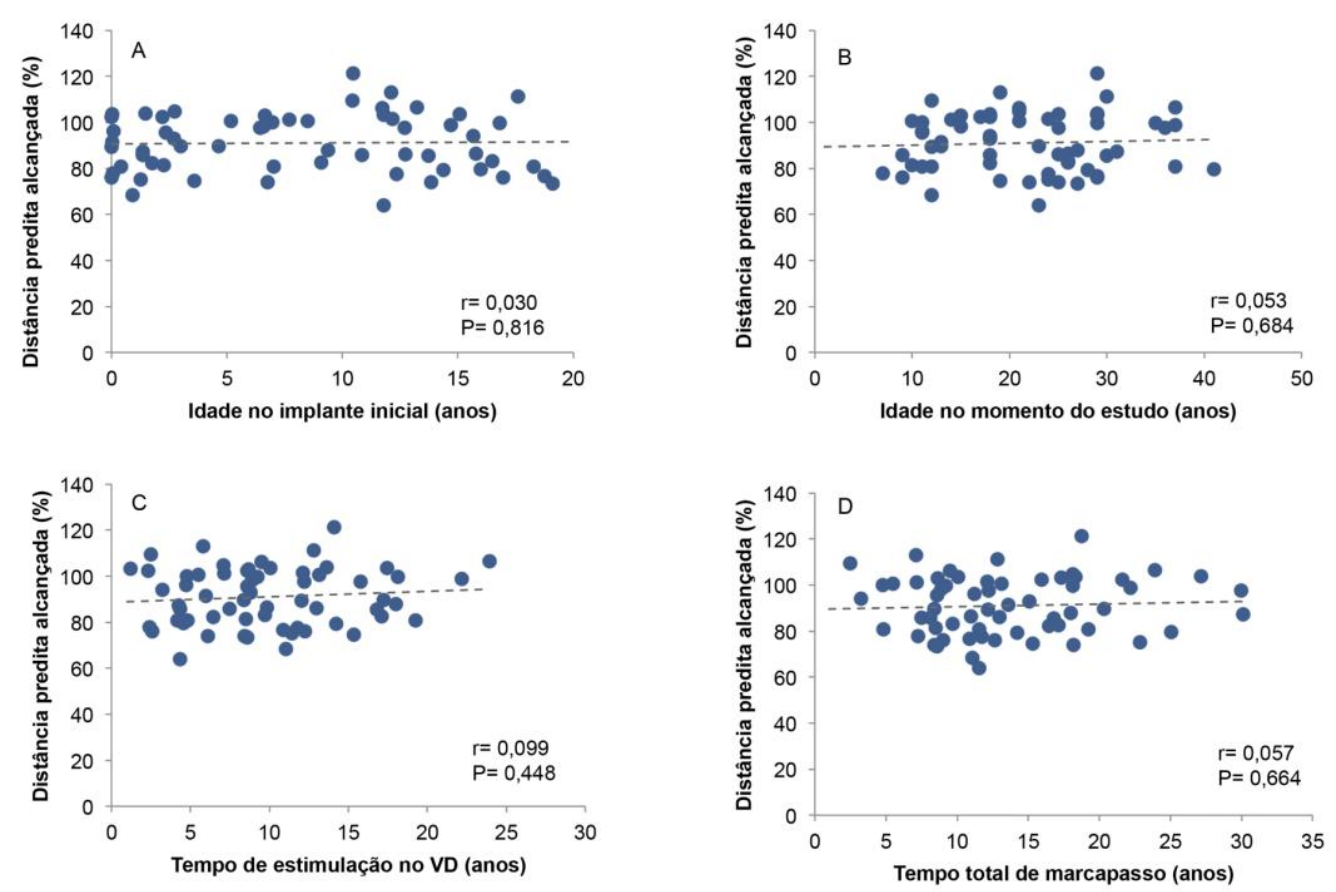

Da mesma forma, não houve correlação entre a capacidade funcional com a duração do complexo QRS estimulado $(r=0,057 ; P=0,664)$ ou com o diâmetro diastólico do ventrículo esquerdo ( $r=0,161 ; P=0,216)$ (Gráfico 22). 
Gráfico 22 -Correlação entre a distância predita alcançada no teste de caminhada de seis minutos com a duração do complexo QRS estimulado (A) e diâmetro diastólico do ventrículo esquerdo (B). InCor-HCFMUSP (2010 - 2013)
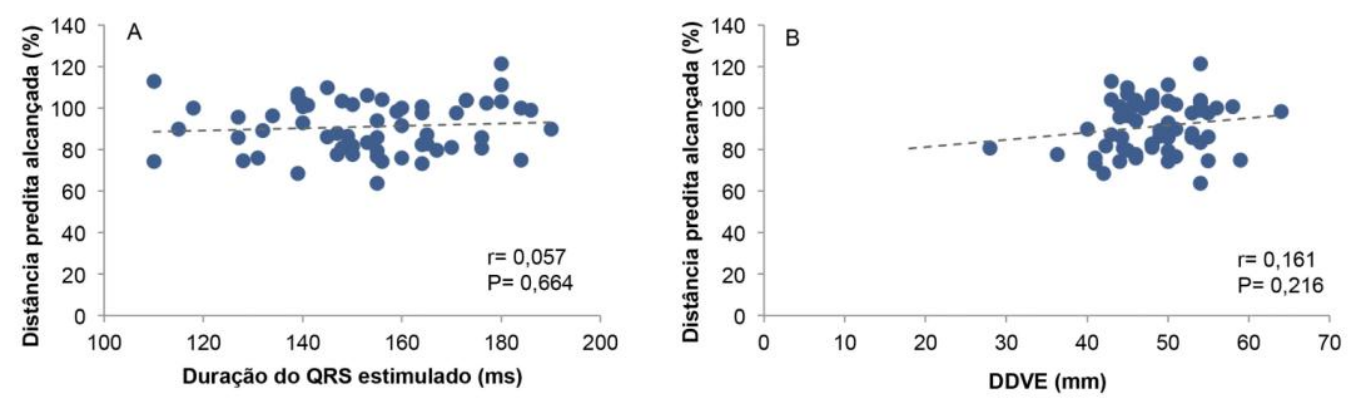

A observação da Gráfico 23 , mostra que também não houve associação entre a distância caminhada com o sexo $(P=0,121)$, modo de estimulação utilizado $(P=0,821)$, posição do cabo-eletrodo no VD $(P=$ $0,928)$ e presença de autoanticorpos anti-Ro/SSA $(P=0,288)$ nas mães dos pacientes. 
Gráfico 23 -Comparação entre a distância predita alcançada no teste de caminhada de seis minutos com o sexo (A), modo de estimulação (B), posição do cabo-eletrodo no VD (C) e autoanticorpos anti-Ro/SSA (D). InCor-HCFMUSP (2010 2013)
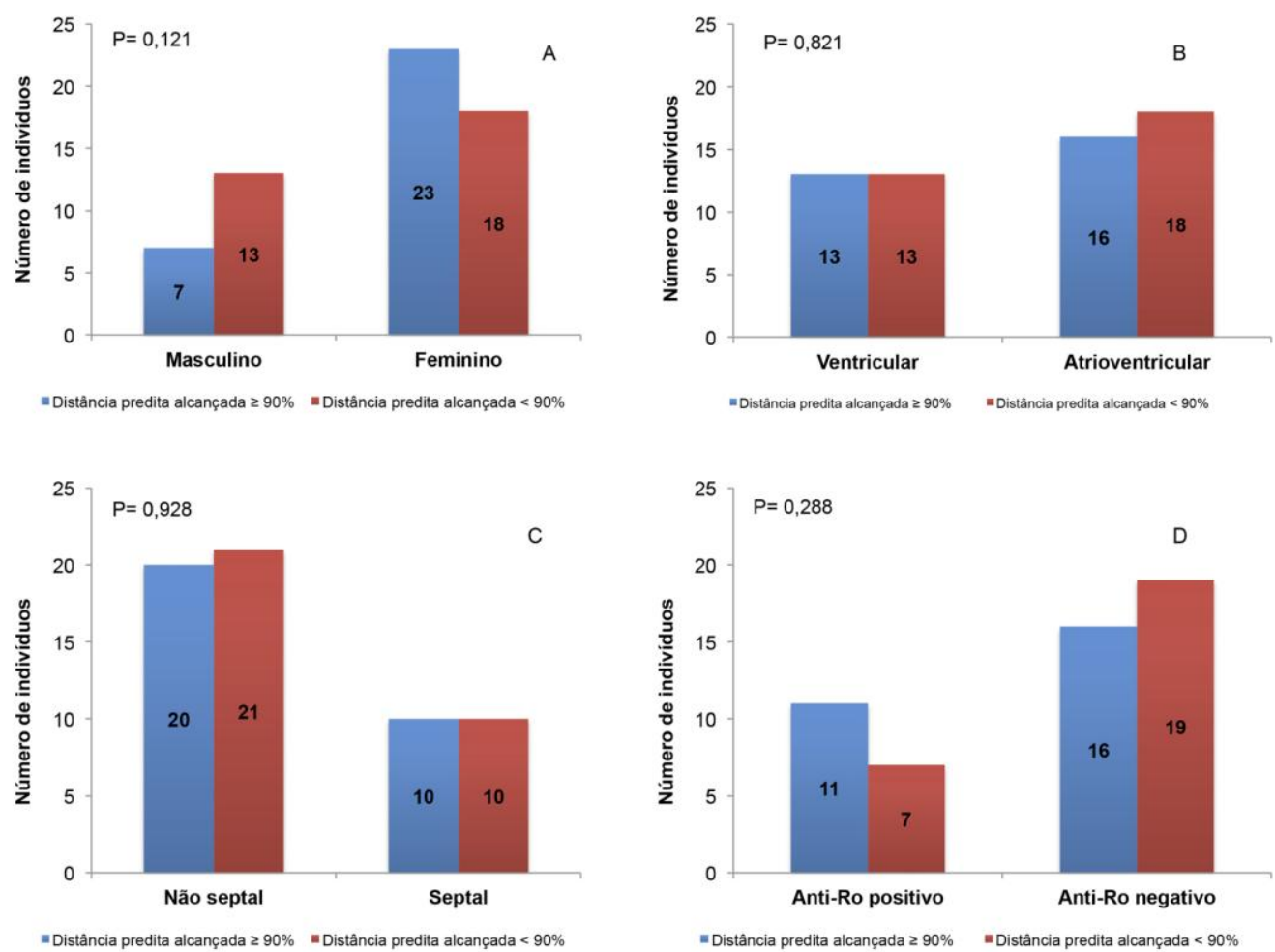

O Gráfico 24, mostra a distância caminhada por indivíduos com disfunção ventricular classificada como grave, moderada, leve, ou com fração ventricular considerada normal. 
Gráfico 24 -Comparação entre a distância predita alcançada no teste de caminhada de acordo com a fração de ejeção do VE dos indivíduos. InCor-HCFMUSP (2010 - 2013)

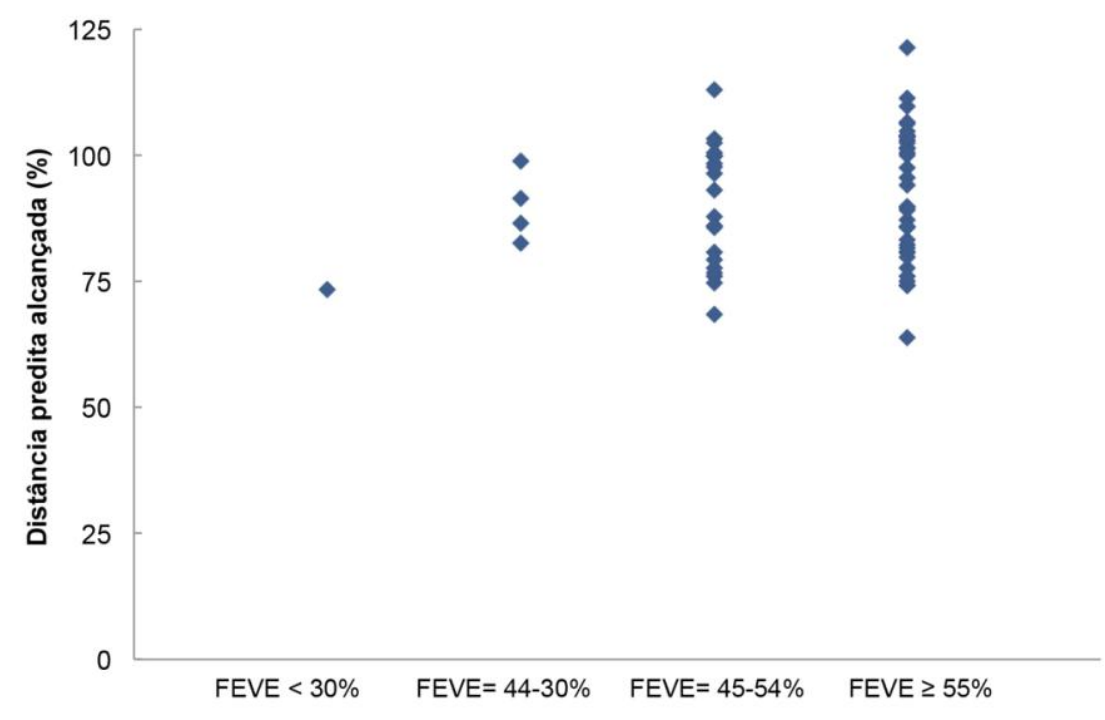

No Gráfico 25 é possível observar-se a distância caminhada pelos pacientes em função da faixa etária.

Gráfico 25 -Comparação entre a distância predita alcançada no teste de caminhada de acordo com a faixa etária dos indivíduos. InCor-HCFMUSP (2010 - 2013)

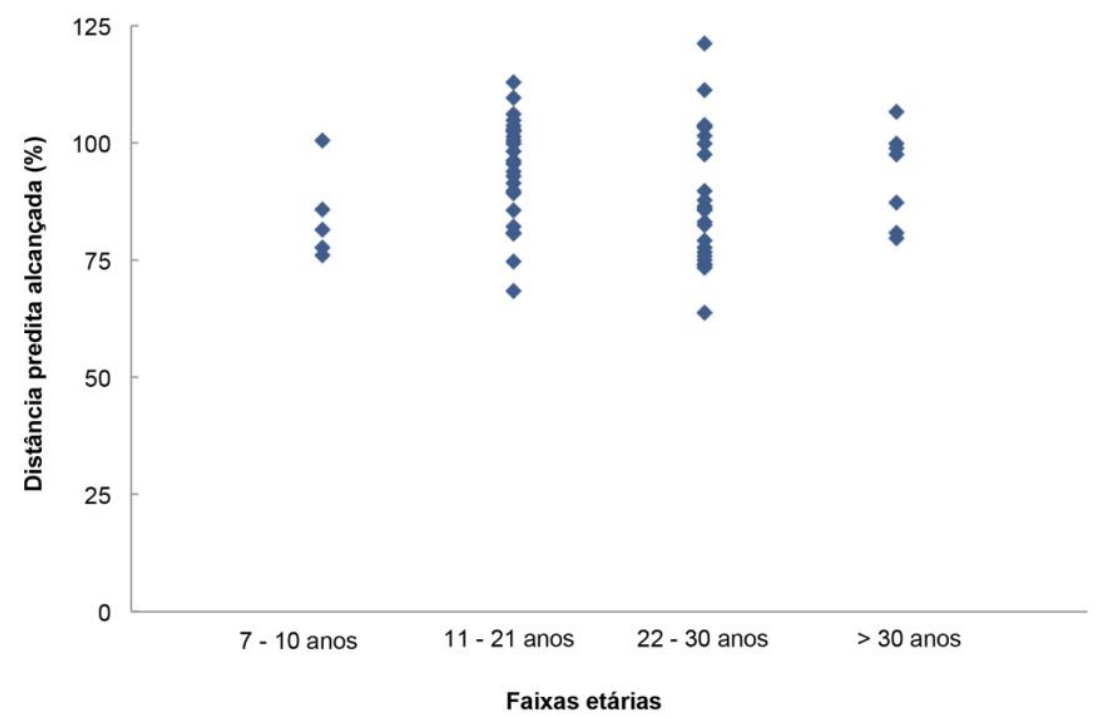




\subsubsection{Qualidade de vida}

A avaliação da qualidade de vida dos sujeitos da pesquisa, independentemente do questionário utilizado, não mostrou associação com nenhum dos fatores preditores estudados, conforme detalhado no Gráfico 26 e na Tabela 9.

Gráfico 26 -Comparação dos escores de qualidade de vida dos Sumários Físico e Mental (SF-36) e Sumário Físico e Psicossocial (CHQ-PF50) em relação ao sexo (A e C) e tipo de marca-passo (B e D). InCor-HCFMUSP (2010 - 2013)
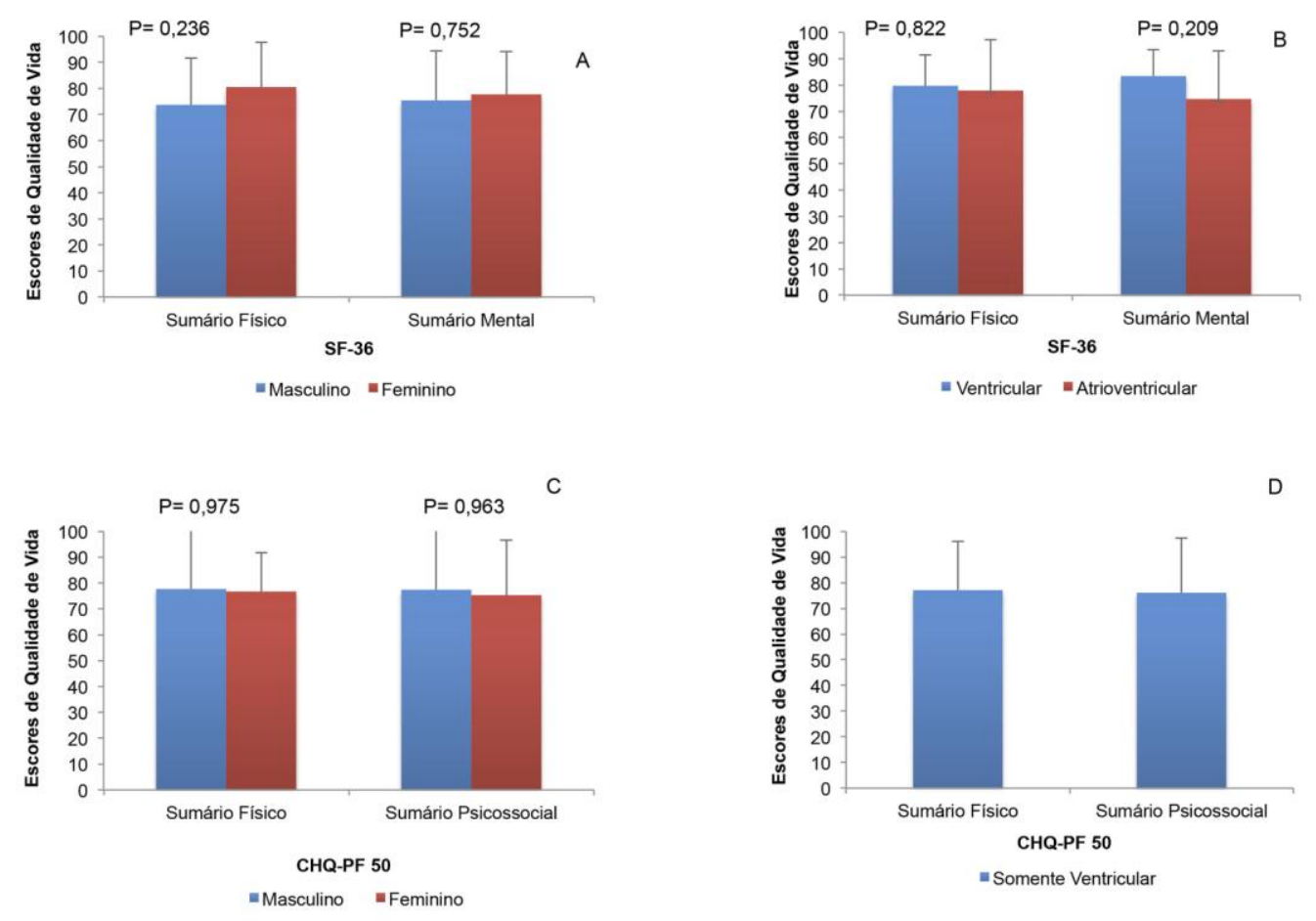
Tabela 9- Coeficiente de correlação (Pearson) dos escores de qualidade de vida dos Sumários Físico e Mental (SF-36) e Sumário Físico e Psicossocial (CHQ-PF50) com a idade no momento do implante de marca-passo, idade atual, tempo de estimulação no VD, tempo total de marca-passo e distância predita alcançada no teste de caminhada. InCorHCFMUSP (2010 - 2013)

\begin{tabular}{lcccc}
\hline \multirow{2}{*}{ Variáveis estudadas } & \multicolumn{2}{c}{ SF-36 } & \multicolumn{2}{c}{ CHQ-PF50 } \\
\cline { 2 - 5 } & $\begin{array}{c}\text { Sumário } \\
\text { Físico }\end{array}$ & $\begin{array}{c}\text { Sumário } \\
\text { Mental }\end{array}$ & $\begin{array}{c}\text { Sumário } \\
\text { Físico }\end{array}$ & $\begin{array}{c}\text { Sumário } \\
\text { Psicossocial }\end{array}$ \\
\hline $\begin{array}{l}\text { Idade no momento do implante } \\
\text { de marca-passo }\end{array}$ & 0,148 & 0,151 & 0,292 & 0,141 \\
Idade no momento da avaliação & $-0,015$ & $-0,003$ & 0,085 & 0,250 \\
Tempo de estimulação no VD & $-0,076$ & 0,042 & $-0,051$ & 0,037 \\
Tempo total de marca-passo & $-0,109$ & $-0,077$ & $-0,141$ & 0,232 \\
Distância predita alcançada (\%) & 0,154 & 0,031 & 0,058 & 0,039 \\
\hline
\end{tabular}

A comparação da fração de ejeção do VE com cada um dos domínios dos questionários SF-36 e CHQ-PF50 mostrou que, em geral, indivíduos com fração de ejeção inferior a 55\% apresentaram menores escores de qualidade de vida, sendo essa diferença significativa para os domínios "Papel social - limitações emocionais" $(P=0,020)$ e "Papel social - limitações físicas" ( $P=0,013)$ (Gráfico 27). 


\section{Gráfico 27 -Comparação dos escores de qualidade de vida em relação a fração de ejeção do ventrículo esquerdo. InCor-HCFMUSP (2010 - 2013)}
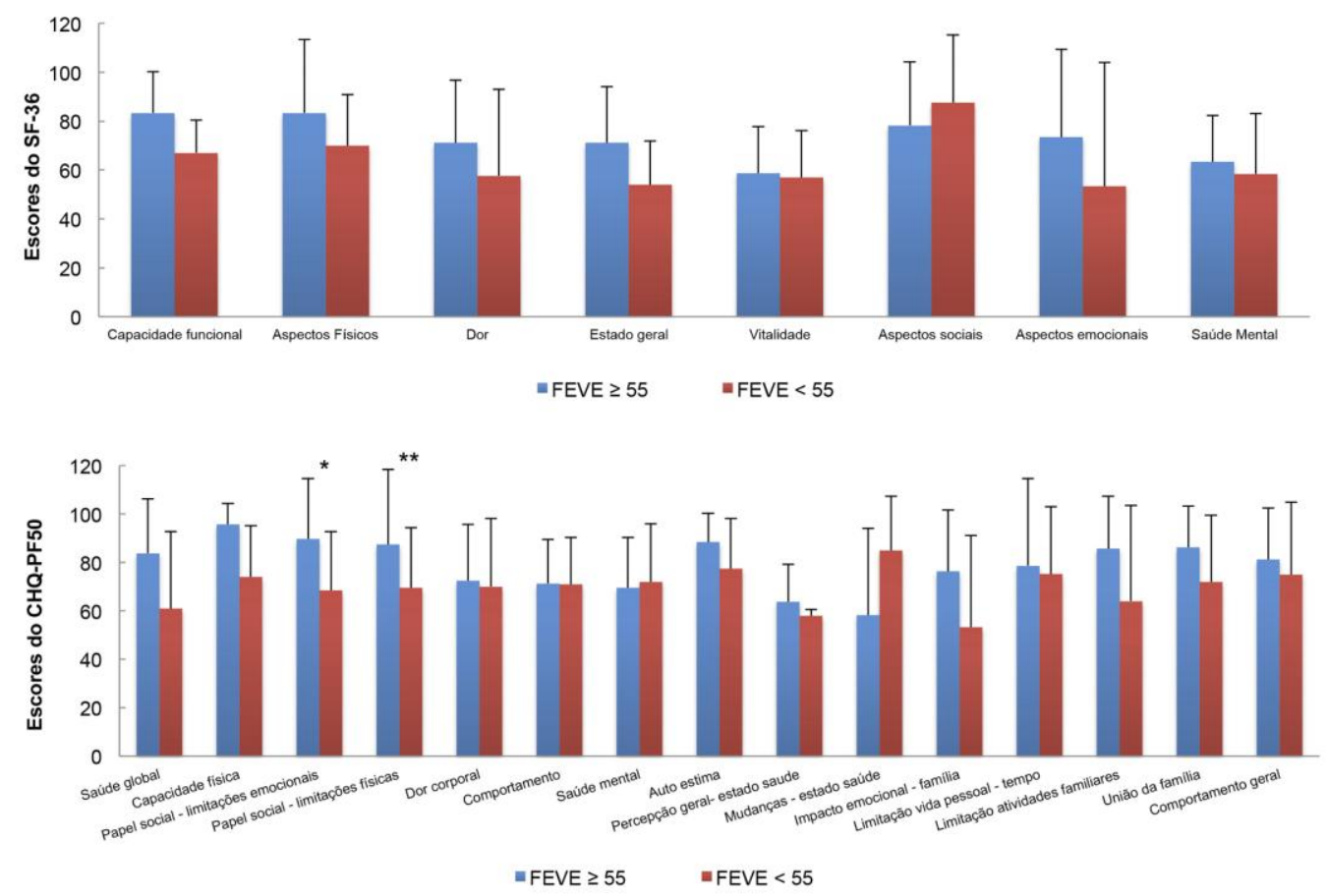

\subsubsection{Remodelamento ventricular}

O remodelamento ventricular esquerdo pode ser observado pelo aumento do diâmetro diastólico dessa cavidade em 14 dos 63 indivíduos estudados, pela diminuição da fração de ejeção em 25 dos 63 e pela taxa de insuficiência mitral classificada como de leve/moderada a moderada/grave repercussão em 14 dos 63 indivíduos.

A presença de disfunção ventricular, caracterizada por valores inferiores a 0,55 não esteve associada ao sexo do indivíduo $(P=0,090)$, ao modo de estimulação utilizado $(P=0,086)$, à região do ventrículo direito onde o cabo-eletrodo estava implantado $(P=0,253)$, ou à presença de autoanticorpos maternos ( $P=0,373)$ (Gráfico 28). 


\section{Gráfico 28 -Comparação da fração de ejeção do ventrículo esquerdo em relação ao sexo (A), tipo de marca-passo (B), posição do cabo-eletrodo no VD (C) e autoanticorpos anti-Ro/SSA (D). InCor-HCFMUSP (2010 - 2013)}
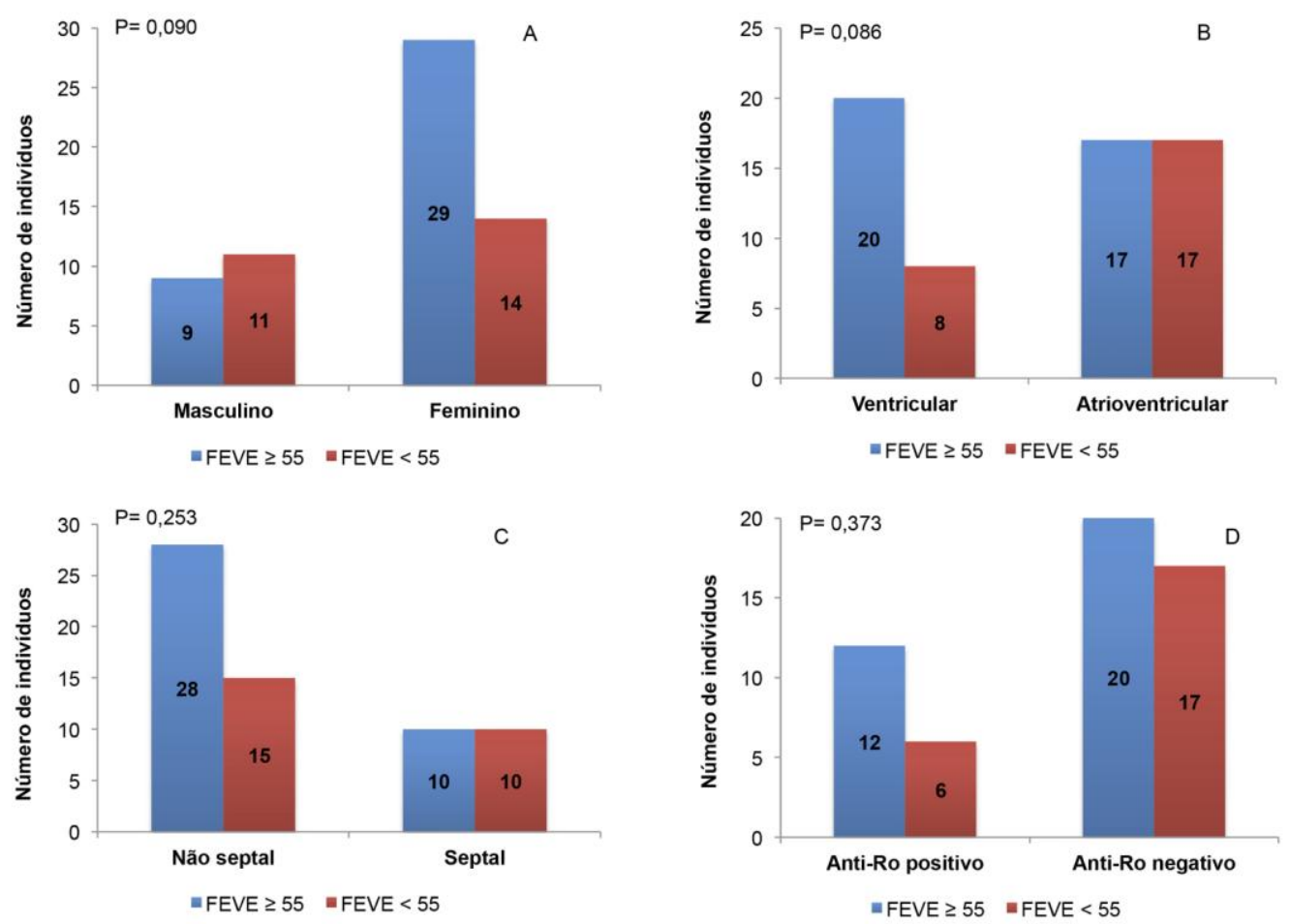

Foi possível detectar, entretanto, correlação entre a fração de ejeção do VE e o tempo que o indivíduo permaneceu sem o uso do marca-passo. $O$ Gráfico 29 mostra a correlação negativa entre a idade no implante inicial do marca-passo com a fração de ejeção do $\operatorname{VE}(r=-0,302 ; P=0,016)$, e a ausência de correlação significativa com a idade atual $(r=-0,240 ; P=0,058)$, o tempo total em que o indivíduo foi mantido com marca-passo ( $r=-0,163$; $P=0,202)$, ou sob estimulação ventricular direita $(r=-0,036 ; P=0,126)$. 


\section{Gráfico 29 -Correlação entre a fração de ejeção do ventrículo esquerdo com a idade no implante do marca-passo (A), idade no momento do estudo (B), tempo de estimulação no VD (C) e tempo total de marca-passo (D). InCor-HCFMUSP (2010 - 2013)}
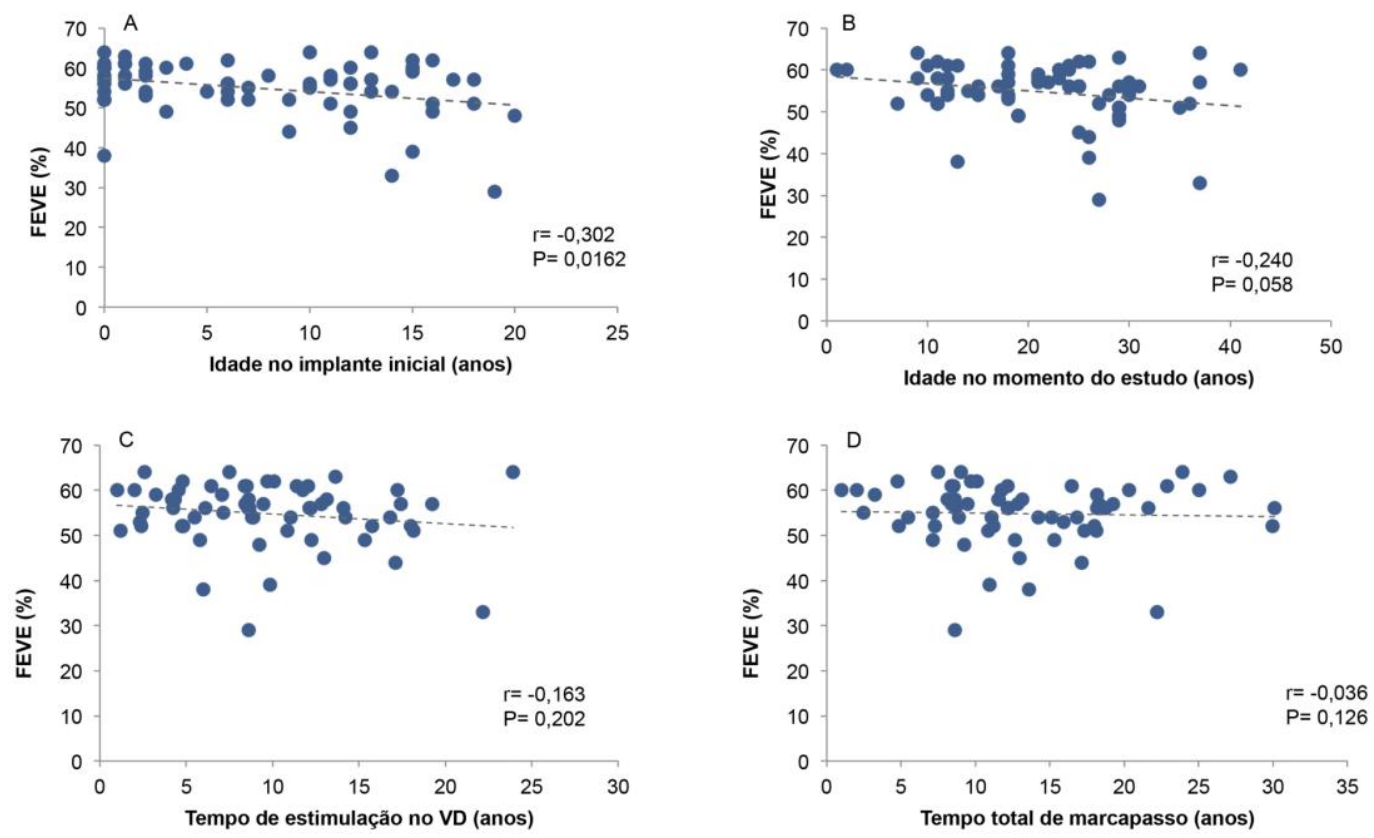

A observação do Gráfico 30 mostra que também não houve correlação entre a fração de ejeção do VE e a sincronia ventricular, avaliada pela pelo retardo eletromecânico, interventricular $(r=-0,124 ; P=0,334)$ e intraventricular esquerdo $(r=-0,177 ; P=0,166)$, ou pela duração do complexo QRS estimulado pelo marca-passo $(r=-0,146 ; P=0,252)$. Da mesma forma, a distância caminhada não teve correlação com a fração de ejeção do ventrículo esquerdo $(r=0,072 ; P=0,363)$. 


\section{Gráfico 30 -Correlação entre a fração de ejeção do VE com o atraso} intra (A) e interventricular (B), duração do complexo QRS estimulado (C) e distância predita alcançada no teste de caminhada (D). InCor-HCFMUSP (2010 - 2013)
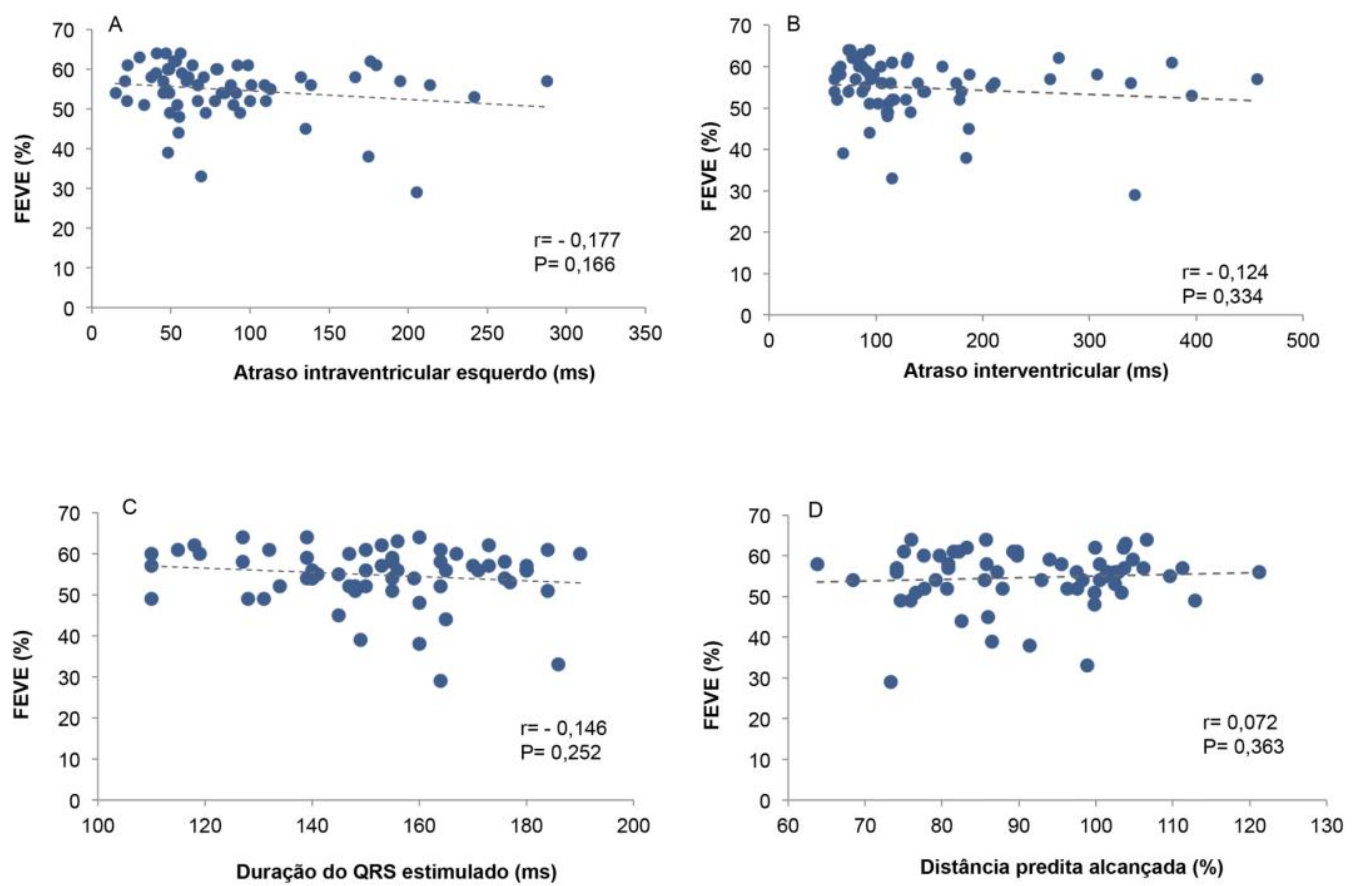

Dentre as variáveis estudadas, o aumento do DDVE apresentou correlação positiva com a duração do complexo QRS estimulado $(r=0,447 ; P=$ 0,002) e com o maior tempo sob estimulação do VD $(r=0,416 ; P=0,007)$.

\subsubsection{Dissincronia ventricular}

A despeito da elevada prevalência de retardo eletromecânico intraventricular detectados pelo ecocardiograma tecidual, não foi observada associação deste parâmetro com os preditores estudados. O Gráfico 31 mostra que a presença ou ausência de dissincronia intraventricular não foi influenciada pelo sexo dos indivíduos $(P=0,666)$, pelo modo de estimulação empregado ( $P$ $=0,574)$, pelo local onde o cabo-eletrodo estava implantado no VD $(P=0,512)$, 
pela função ventricular $(P=0,435)$, pela presença de insuficiência mitral $(P=$ 0,787 ) ou pela presença de autoanticorpos maternos $(P=0,291)$.

\section{Gráfico 31 -Comparação do atraso intraventricular esquerdo com sexo} (A), tipo de marca-passo (B), fração de ejeção do VE (C), insuficiência mitral (D), posição do cabo-eletrodo no VD (E) e autoanticorpos anti-Ro/SSA (F). InCor-HCFMUSP (2010 2013)
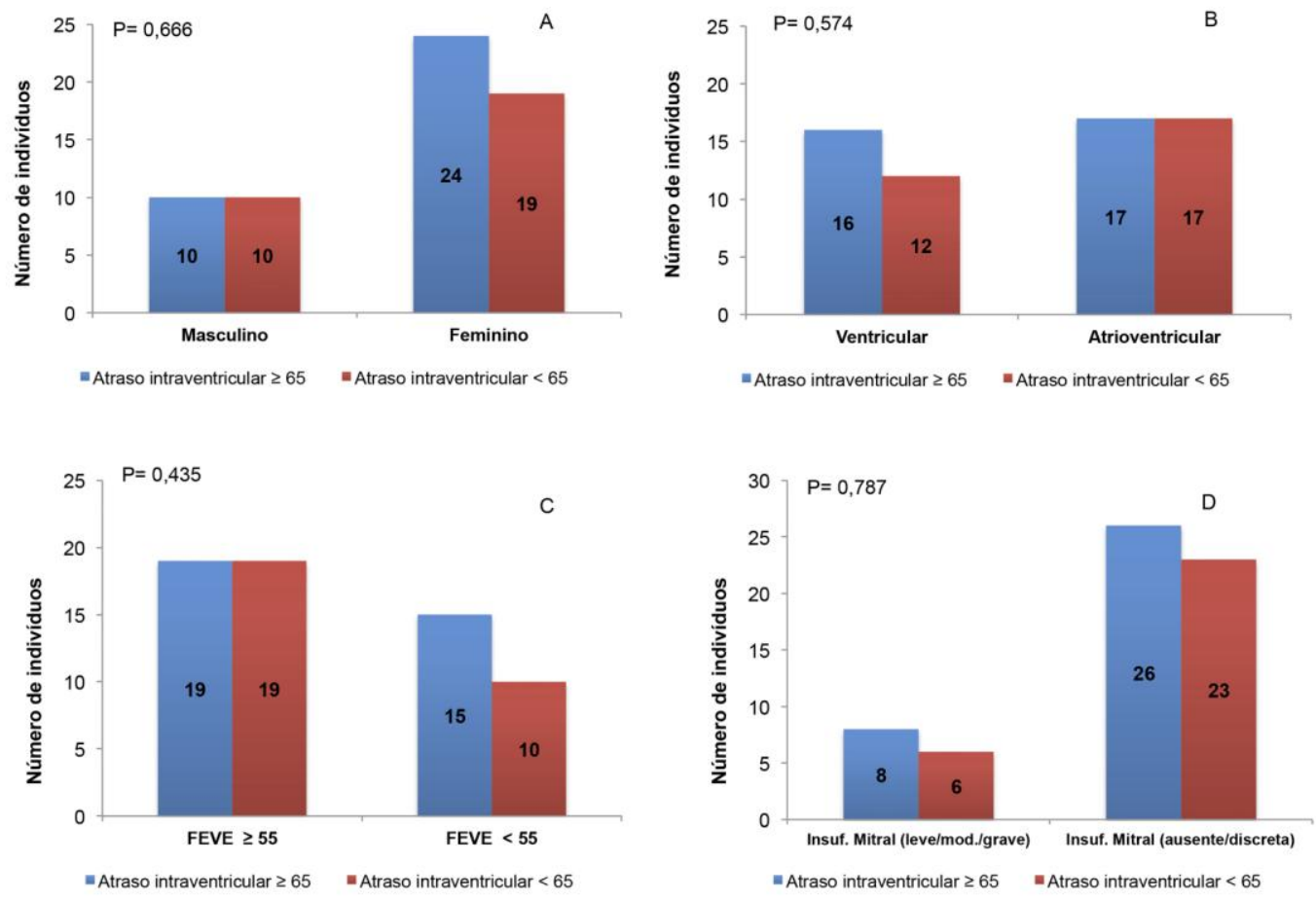

Da mesma forma, também não foi detectada influência da idade ou do tempo de estimulação cardíaca artificial no aparecimento de dissincronia ventricular. O Gráfico 32 permite a observação da distribuição do atraso intraventricular calculado para os indivíduos estudados em função da idade no implante inicial $(r=-0,098 ; P=0,443)$ e no momento do estudo $(r=-$ 0,023; $P=0,855)$, assim como o tempo total que os pacientes permaneceram sob estimulação cardíaca artificial $(r=0,070 ; P=0,586)$ e especificamente no ventrículo direito $(r=-0,038 ; P=0,765)$. 


\section{Gráfico 32 -Correlação entre o atraso intraventricular esquerdo com a idade no implante do marca-passo (A), idade no momento do estudo (B), tempo de estimulação no VD (C) e tempo total de marca-passo (D). InCor-HCFMUSP (2010 - 2013)}
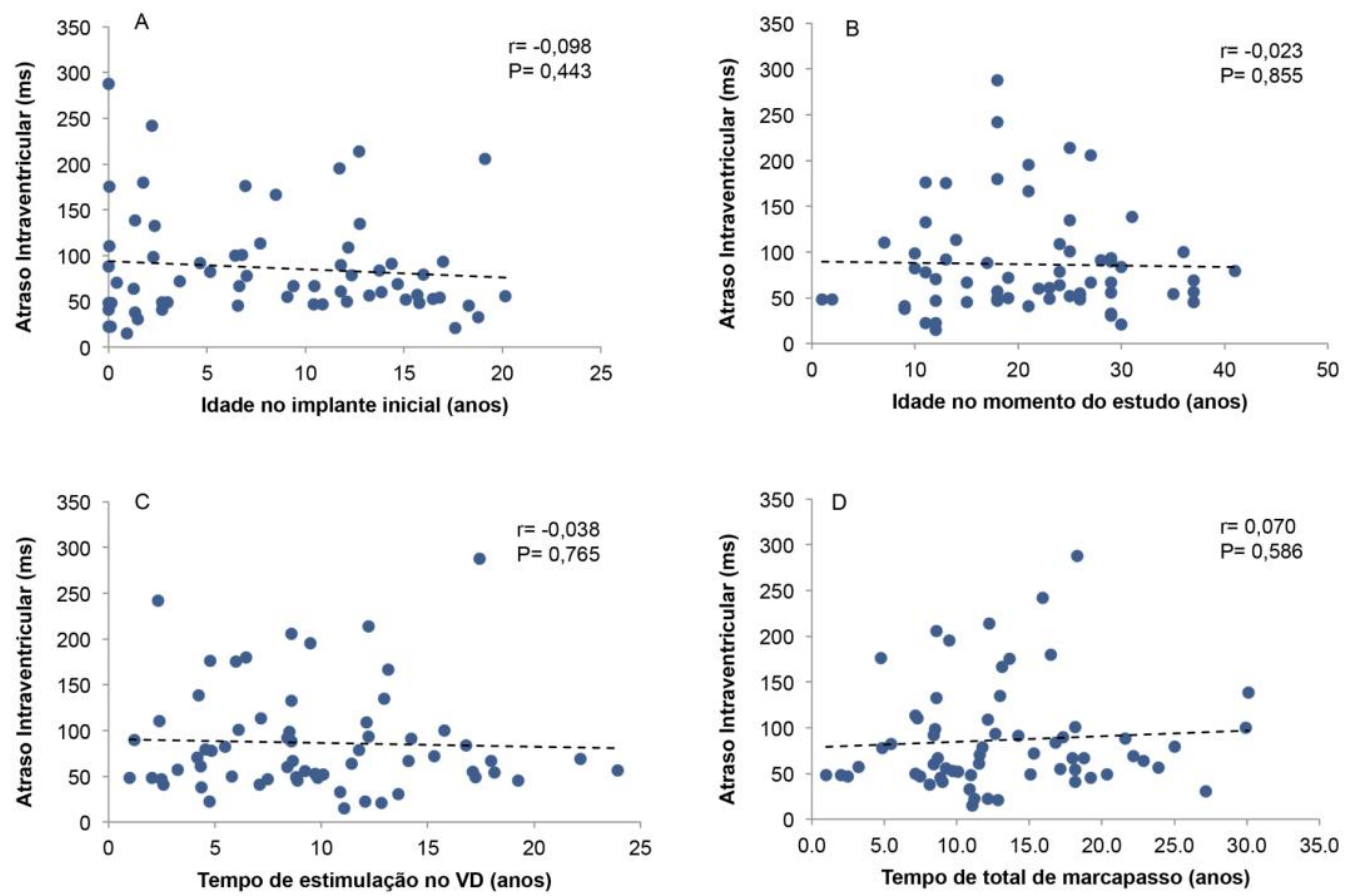

No Gráfico 33 encontram-se representados os valores do atraso intraventricular esquerdo em função da duração do complexo QRS, estimulado $(r=0,168 ; P=0,1888)$ ou com o marca-passo inibido $(r=-0,207$; $P=0,120)$, da porcentagem de estimulação ventricular $(r=-0,003 ; P=$ 0,980) e da distância predita alcançada no teste de caminhada de seis minutos $(r=0,106 ; P=0,415)$. 
Gráfico 33 -Correlação entre o atraso intraventricular esquerdo com a duração do complexo QRS estimulado (A) e com o marcapasso inibido (B), porcentagem de estimulação ventricular (C) e distância predita alcançada no teste de caminhada (D). InCor-HCFMUSP (2010 - 2013)
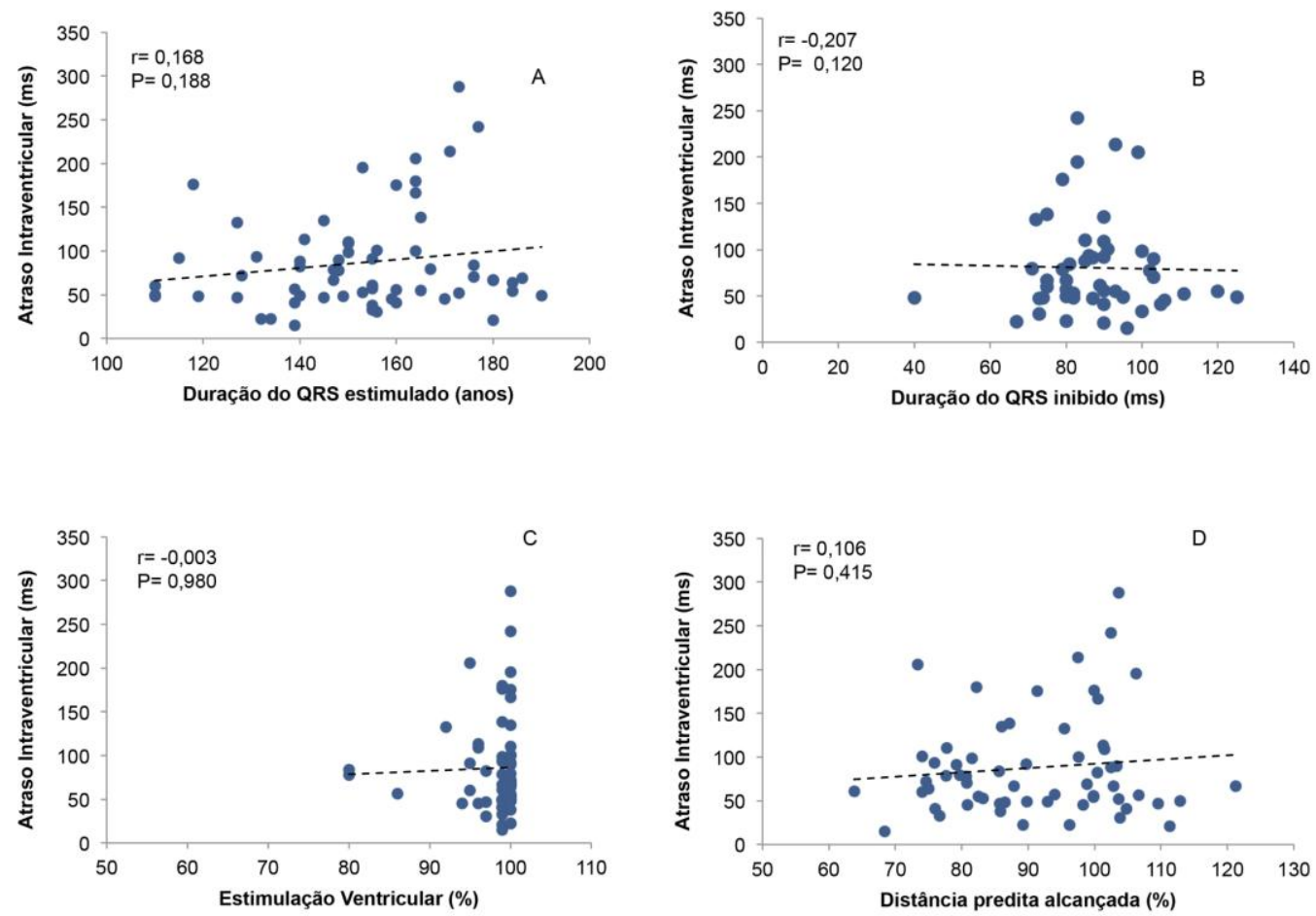

\subsubsection{Regressão linear multivariada}

O modelo de regressão linear multivariada foi aplicado para 0 remodelamento ventricular que foi o desfecho mais prevalente nesta população. Das variáveis incluídas no modelo (Tabela 10), somente a idade do paciente no momento do primeiro implante de marca-passo apresentou correlação negativa e significativa com a fração de ejeção do ventrículo esquerdo $(P=0,016)$, sendo possível observar que a partir da idade de oito anos no implante inicial a fração de ejeção estimada torna-se inferior a 55\%.

O mesmo tipo de análise foi realizado para o diâmetro diastólico do ventrículo esquerdo, tendo sido observada correlação positiva e significativa 
com a duração do complexo QRS estimulado $(P=0,005)$ e com o tempo em que o indivíduo havia sido mantido sob estimulação ventricular direita $(P=$ 0,014).

Tabela 10 -Análise de fatores preditores para a ocorrência de remodelamento ventricular. InCor-HCFMUSP (2010 - 2013)

\begin{tabular}{|c|c|c|}
\hline \multirow[t]{2}{*}{ Fatores Preditores } & $\begin{array}{c}\text { Redução na } \\
\text { fração de ejeção } \\
\text { VE }\end{array}$ & $\begin{array}{l}\text { Aumento no } \\
\text { diâmetro } \\
\text { diastólico do VE }\end{array}$ \\
\hline & \multicolumn{2}{|c|}{ Valor de P } \\
\hline Sexo & 0,429 & 0,160 \\
\hline Idade no momento do implante de marca-passo & 0,016 & 0,769 \\
\hline Tempo de estimulação no VD & 0,875 & 0,0139 \\
\hline Tempo total de marca-passo & 0,109 & 0,222 \\
\hline Duração do complexo QRS estimulado & 0,541 & 0,004 \\
\hline Tipo de marca-passo & 0,324 & 0,130 \\
\hline Sítio de estimulação no VD & 0,413 & 0,715 \\
\hline Autoanticorpos anti-Ro/SSA maternos & 0,922 & 0,362 \\
\hline
\end{tabular}

\subsection{Influência dos Autoanticorpos Reumatológicos}

A comparação dos indivíduos cujas mães apresentavam autoanticorpos anti-Ro/SSA positivos com os fatores preditores mostrou que houve associação desse marcador com a idade no momento do implante do marca-passo $(P=0,032)$ e com o tipo de marca-passo em uso atual $(P=$ 0,022). Desse modo, a presença desse autoanticorpo se associou a maiores idades no momento do implante inicial do marca-passo, assim como, a maiores taxas de uso de sistemas de estimulação unicamerais (Tabela 11). 
Tabela 11 - Comparação dos indivíduos de acordo com a presença de auto anticorpos anti-Ro/SSA maternos. InCor-HCFMUSP (2010 - 2013)

\begin{tabular}{|c|c|c|c|}
\hline Características & $\begin{array}{l}\text { Anti-Ro/SSA } \\
\text { Negativo } \\
(\mathrm{n}=38)\end{array}$ & $\begin{array}{l}\text { Anti-Ro/SSA } \\
\text { Positivo } \\
(n=18)\end{array}$ & $\begin{array}{l}\text { Valor } \\
\text { de P }\end{array}$ \\
\hline $\begin{array}{c}\text { Gênero, n (\%) } \\
\text { Feminino } \\
\text { Masculino }\end{array}$ & $\begin{array}{l}24(63,2) \\
14(36,8)\end{array}$ & $\begin{array}{c}13(72,2) \\
5(27,8)\end{array}$ & 0,503 \\
\hline $\begin{array}{l}\text { Idade no momento do implante de marca- } \\
\text { passo, anos (média } \pm D P \text { ) }\end{array}$ & $6,3 \pm 5,9$ & $10,2 \pm 6,7$ & 0,032 \\
\hline $\begin{array}{l}\text { Idade no momento da avaliação, anos (média } \\
\pm \text { DP) }\end{array}$ & $22,4 \pm 8,5$ & $18,2 \pm 9,2$ & 0,100 \\
\hline $\begin{array}{l}\text { Tempo de estimulação no VD, anos (média } \pm \\
\text { DP) }\end{array}$ & $9,3 \pm 5,2$ & $9,7 \pm 5,8$ & 0,820 \\
\hline Tempo total de marca-passo (média \pm DP) & $13,1 \pm 6,2$ & $9,7 \pm 5,8$ & 0,703 \\
\hline $\begin{array}{l}\text { Tipo de marca-passo em uso, } \mathrm{n}(\%) \\
\text { Ventricular } \\
\text { Atrioventricular }\end{array}$ & $\begin{array}{l}13(34,2) \\
25(65,8)\end{array}$ & $\begin{array}{l}12(66,7) \\
6(33,4)\end{array}$ & 0,022 \\
\hline $\begin{array}{l}\text { Sítio de estimulação no VD, n (\%) } \\
\text { Não septal } \\
\text { Septal }\end{array}$ & $\begin{array}{l}23(60,5) \\
15(39,5)\end{array}$ & $\begin{array}{l}14(77,8) \\
4(22,2)\end{array}$ & 0,202 \\
\hline \multicolumn{4}{|l|}{ Ecocardiograma } \\
\hline $\begin{array}{l}\text { Fração de ejeção do VE, n (\%) } \\
\quad<55 \\
\quad \geq 55\end{array}$ & $\begin{array}{l}16(42,1) \\
22(57,9)\end{array}$ & $\begin{array}{l}5(27,8) \\
13(72,2)\end{array}$ & 0,301 \\
\hline $\begin{array}{l}\text { Diâmetro diastólico do VE, n (\%) } \\
\text { Normal } \\
\text { Alterado }\end{array}$ & $\begin{array}{l}30(78,9) \\
8(21,1)\end{array}$ & $\begin{array}{l}14(77,8) \\
4(22,2)\end{array}$ & 0,545 \\
\hline Atraso intraventricular, $n(\%)$ (média $\pm \mathrm{DP}$ ) & $83,1 \pm 56,4$ & $81,5 \pm 57,8$ & 0,922 \\
\hline Atraso interventricular, $n(\%)$ (média $\pm \mathrm{DP}$ ) & $138,8 \pm 94,1$ & $136,4 \pm 80,1$ & 0,923 \\
\hline $\begin{array}{l}\text { Insuficiência mitral, n (\%) } \\
\text { Ausente } \\
\text { Presente }\end{array}$ & $\begin{array}{l}31(81,6) \\
7(18,4)\end{array}$ & $\begin{array}{l}14(77,8) \\
4(22,2)\end{array}$ & 0,732 \\
\hline \multicolumn{4}{|l|}{ Teste de caminhada de seis minutos } \\
\hline Distância total percorrida, metros (média \pm DP) & $549,5 \pm 64,8$ & $550,2 \pm 91,8$ & 0,972 \\
\hline Distância predita alcançada, \% (média \pm DP) & $91,0 \pm 13,0$ & $93,0 \pm 13,0$ & 0,488 \\
\hline \multicolumn{4}{|l|}{ Qualidade de vida } \\
\hline Escores, (média \pm DP) & $80,9 \pm 21,4$ & $77,5 \pm 13,9$ & 0,958 \\
\hline Sumário Físico - SF-36 & $78,2 \pm 14,1$ & $74,2 \pm 20,2$ & 0,461 \\
\hline \multicolumn{4}{|l|}{ Sumário Mental - SF-36 } \\
\hline Sumário Físico - CHQ-PF50 & $77,9 \pm 22,1$ & $76,4 \pm 3,5$ & 0,837 \\
\hline Sumário Psicossocial - CHQ-PF50 & $80,9 \pm 21,4$ & $70,3 \pm 25,3$ & 0,436 \\
\hline
\end{tabular}

$\mathrm{DP}=$ desvio padrão; VD = ventrículo direito; VE = ventrículo esquerdo. 


\section{DiscussÃo}


Os critérios de seleção utilizados neste estudo permitiram a formação de um grupo homogêneo de indivíduos com bloqueio $\mathrm{AV}$ congênito isolado que, em sua maioria, estavam sob estimulação ventricular direita por longo período. Estes 63 casos selecionados pertencem a uma coorte maior de pacientes operados no InCor-HCFMUSP, dos quais dois já haviam falecido; um havia desenvolvido insuficiência cardíaca grave e necessitou de transplante cardíaco, quatro necessitaram de terapia de ressincronização e 25 haviam sido perdidos para seguimento. Foi possível, ainda, enriquecer os resultados da pesquisa com a participação de 56 mães, dentre as quais $32,7 \%$ mostraram-se portadoras de marcadores laboratoriais para doenças autoimunes e destas, 23,2\% tiveram o diagnóstico clínico de lúpus eritematoso sistêmico ou a síndrome de Sjögren confirmado.

A passagem de autoanticorpos anti-Ro/SSA e/ou anti-La/SSB maternos pela barreira placentária tem sido considerada como o principal fator na fisiopatologia do bloqueio $\mathrm{AV}$ congênito ${ }^{4,5,6}$. A presença destes autoanticorpos vem sendo reportada em até $95 \%$ das mães, quando o diagnóstico do bloqueio é feito na fase intrauterina ou no período neonata $\left.\right|^{5,10}$. No presente estudo, entretanto, autoanticorpos foram detectados em apenas $32,7 \%$ das mães avaliadas, o que está em concordância com o reportado por outras publicações que avaliaram amostras com características semelhantes a esta ${ }^{78}$. 
Nos casos em que o bloqueio congênito é secundário à miocardite provocada pelos autoanticorpos maternos, a cicatriz sorológica permanece no paciente por aproximadamente seis meses, até que desaparece por completo $5,6,28,71,76,77,79$. Os achados dos exames sorológicos para autoanticorpos, que foram negativos em todos os sujeitos do presente estudo, são esperados uma vez que todos eram maiores do que um ano de idade no momento do estudo.

$A$ raridade do bloqueio $A V$ congênito e a multiplicidade de formas de apresentação clínica dessa afecção podem ser a justificativa para o diagnóstico ter sido tardio em parte dos indivíduos avaliados ${ }^{1-3,7,8}$. Pode-se verificar, na análise retrospectiva das informações, que a doença foi detectada antes do nascimento ou no período neonatal em apenas $40 \%$ dos casos, sendo que em $16 \%$ deles o diagnóstico somente foi feito na adolescência. Nesta faixa etária as manifestações clínicas do bloqueio da condução estiveram associadas, principalmente, ao desenvolvimento de insuficiência cardíaca, que foi detectada em 38\% dos indivíduos, e de síncope, em 8\%, sendo que $30,2 \%$ foram considerados assintomáticos na ocasião do diagnóstico. Na literatura, os sintomas tornam-se evidentes já na infância (idade média de cinco a seis anos) ${ }^{10}$ em até $40 \%$ dos casos, e o diagnóstico é feito, usualmente, pela detecção de pulsação lenta com confirmação pelo eletrocardiograma de superfície ou ambulatorial de 24 horas $^{9,94}$.

A localização da lesão anatômica que provoca o bloqueio da condução de etiologia congênita é considerada intranodal pela maioria dos estudiosos do assunto. Por ser o restante do sistema de condução íntegro, a 
expressão eletrocardiográfica do bloqueio congênito se faz, habitualmente, com complexo QRS de duração normal ${ }^{9,12}$. Nota-se também, em muitos casos, resposta cronotrópica aceitável aos esforços ${ }^{97,98}$. No presente estudo, em $88 \%$ dos eletrocardiogramas registrados na avaliação pré-operatória e em $96 \%$ dos traçados registrados durante a inibição do marca-passo no momento do estudo, a duração do complexo QRS espontâneo era menor do que 120 ms, dentro, portanto, dos parâmetros considerados normais. A variabilidade de frequência cardíaca observada entre os indivíduos antes do primeiro implante de marca-passo foi grande: a menor FC detectada foi de $30 \mathrm{bpm}$ e a maior foi $90 \mathrm{bpm}$, com FC média de 50,4 bpm. Estes achados estão em concordância com os dados publicados por Michaëlson et al. ${ }^{9}$ que descreveram as características eletrocardiográficas de 102 indivíduos com bloqueio AV congênito e frequência cardíaca média de 41 bpm. Estes autores relataram que a frequência cardíaca diminuiu com o aumento da idade dos pacientes e que o complexo QRS com mais do que $120 \mathrm{~ms}$ foi observado em menos do que $10 \%$ dos indivíduos.

Em função das manifestações clínicas e da ocasião do diagnóstico, o momento em que o primeiro implante de marca-passo foi realizado também diferiu entre os sujeitos do presente estudo ${ }^{9,10}$. Assim, o tempo transcorrido entre o nascimento da criança e o início do uso da estimulação cardíaca artificial variou desde poucas horas até 20 anos. Além das repercussões clínicas decorrentes da bradicardia per si, a manutenção do paciente por longo tempo com FC abaixo de sua necessidade fisiológica tem sido associada ao aumento das dimensões e do volume do VE. O 
remodelamento reverso promovido pela simples correção da frequência cardíaca foi demonstrado no estudo de Breuer et al. ${ }^{32}$ e Beaufort et al. ${ }^{109}$. Em ambas as casuísticas, houve redução do DDVE após o uso da estimulação artificial, o que foi mais frequente no indivíduos assintomáticos. No presente estudo, entretanto, a falta do ecocardiograma pré-operatório em $27 \%$ dos prontuários, assim como, o longo tempo que se passou entre 0 implante inicial e a presente avaliação, dificultaram esta análise.

O modo de estimulação e a via de acesso utilizados em indivíduos com bloqueio AV congênito são influenciados pela idade, ou, mais precisamente, pelo peso e pela estatura. Nas crianças com menos do que $10 \mathrm{~kg}$ utiliza-se, com maior frequência, a via epicárdica associada ao modo de estimulação ventricular exclusivo. Por outro lado, crianças com peso acima de $10 \mathrm{~kg}$ têm recebido marca-passos transvenosos. Marca-passos atrioventriculares vem sendo utilizados, usualmente, em adolescentes e adultos jovens ${ }^{19-21}$. No presente estudo foi possível observar que estes conceitos foram utilizados no que diz respeito ao modo de estimulação, com idade média de 2,7 $\pm 2,5$ anos para os implantes ventriculares e de 6,0 $\pm 6,2$ para os atrioventriculares. A via de acesso venosa, todavia, teve ampla preferência, mesmo em neonatos e lactentes. Acreditamos que o uso do acesso femoral, proposto para a população pediátrica por nosso serviço a partir do início dos anos $1980^{21}$, que permitiu o implante venoso mesmo em neonatos, foi o principal responsável por essa divergência com os dados de literatura.

Existem evidências de que a estimulação crônica do VD pode provocar efeitos deletérios à função ventricular esquerda. $O$ retardo da 
ativação, principalmente da parede livre do VE, em relação à do septo interventricular, tem sido referida como importante causa de diminuição da eficiência da contração, causando aumento do volume, modificação da geometria e disfunção do ventrículo esquerdo. Este fenômeno tem sido reportado, maiormente, na população adulta com distúrbios adquiridos da condução elétrica cardíaca ${ }^{34,37}$. A despeito do pequeno número de estudos encontrados na literatura, a dissincronia e o remodelamento ventricular também foram reportados em crianças com bloqueio $A V$ congênito ${ }^{27,29,33}$. No presente estudo, os indivíduos permaneceram com estimulação ventricular direita por, no mínimo, um ano e, no máximo, 23,9 anos, tempo considerado suficiente para a ocorrência de remodelamento ventricular pela estimulação artificial.

A população avaliada, constituída por indivíduos sem outros defeitos cardíacos que não o bloqueio $\mathrm{AV}$, representa um excelente modelo para a compreensão dos efeitos causados pela dissincronia cardíaca induzida pela estimulação cardíaca artificial, uma vez que, além da anatomia cardíaca normal, a condução intraventricular do estímulo também é normal na maioria dos casos. Importante ressaltar, apesar disso, que o aparecimento de miocardiopatia tardia pela sequela da miocardite intrauterina provocada pelos autoanticorpos maternos ou pela reativação desse problema, pode ser a causa da disfunção e da insuficiência ventricular. Esse fator confundidor, ainda assim, somente ocorreria nos indivíduos cujas mães são portadoras de marcadores laboratoriais ou de doença reumatológica clinicamente detectada. 
O presente estudo teve como principais objetivos descrever a evolução clínica e funcional de pacientes com bloqueio AV congênito submetidos a estimulação crônica do VD e identificar desfechos relacionados ao desenvolvimento de remodelamento ventricular esquerdo e de insuficiência cardíaca. Ao mesmo tempo, tentou-se identificar preditores destes desfechos, analisando variáveis já descritas na literatura como: a) o tempo em que o indivíduo foi mantido sem marca-passo ${ }^{109}$; b) o modo de estimulação empregado (ventricular ou atrioventricular) ${ }^{32}$; c) o local do implante do caboeletrodo no $\mathrm{VD}^{31,35,46}$; d) o tempo total que o paciente foi mantido com estimulação cardíaca artificial, assim como o tempo de estimulação ventricular direita $^{42,43,62,105}$; e) a duração do complexo QRS quando o coração é estimulado pelo marca-passo ${ }^{27,42,46}$; f) a presença de dissincronia ao ecocardiograma ${ }^{41,118}$ e, g) a presença de autoanticorpos maternos s,71,78. $^{4}$

A evolução clínica dos portadores de bloqueio AV congênito isolado submetidos a implante de marca-passo é habitualmente favorável, todavia, insuficiência cardíaca grave por miocardiopatia dilatada tardia seja reportada em cerca de $8 \%$ dos $\operatorname{casos}^{29}$. O tratamento desta condição tem sido feito com o uso de medicamentos, pela ressincronização cardíaca e menos comumente por transplante cardíaco $^{27,50,51}$. O presente estudo, pelos critérios de seleção e pelo desenho transversal, apresentou um viés para a análise desta condição, uma vez que os indivíduos com pior evolução não foram recrutados, por já terem sido submetidos à terapia de ressincronização, a transplante cardíaco ou por falecerem antes do início do recrutamento. Dos 63 sujeitos estudados, sintomas de insuficiência cardíaca 
foram detectados em apenas $4,8 \%$, todos eles com limitações aos grandes esforços. Medicamentos de ação cardiovascular foram utilizados em apenas $8,0 \%$, sem relatos de hospitalizações para controle de insuficiência cardíaca. Estes achados foram concordantes com os resultados das avaliações da qualidade de vida, da capacidade funcional e do BNP, que também demonstraram resultados favoráveis na maioria dos pacientes. A dosagem da PCR-us, da IL-6 e do TNF-alfa, porém, estava elevada em parte dos indivíduos, o que pode sugerir a ocorrência de remodelamento ventricular em parte dos sujeitos estudados. A análise dos dados também demonstrou que quem se apresentava com sintomas de insuficiência cardíaca ou em uso de fármacos de ação cardiovascular apresentaram, em sua maioria, FEVE abaixo dos limites da normalidade.

A despeito dos desfechos clínicos, funcionais, laboratoriais e de qualidade de vida demonstrarem-se favoráveis, o estudo da função ventricular pelo ecocardiograma expressou alta prevalência de disfunção ventricular esquerda, que esteve abaixo dos limites considerados normais em $39,6 \%$ dos indivíduos. Não obstante, apenas 7,9\% apresentavam disfunção ventricular esquerda grave ou moderada. Essas taxas de disfunção ventricular esquerda são concordantes com os dados de literatura que mostram prevalência de miocardiopatia dilatada variando de $5 \%$ a $30 \%^{2,31,33,43}$.

A análise da sincronia cardíaca, pela ecocardiografia, revelou que a maioria dos indivíduos apresentava retardo significativo da ativação eletromecânica ventricular, e que houve excelente correlação entre a sincronia interventricular e a intraventricular esquerda. Os dados de literatura 
evidenciam que, independentemente do método utilizado, a taxa de concordância inter observador para avaliações da sincronia ventricular tem sido baixa ${ }^{138}$. É importante ressaltar que no presente estudo, estes dois parâmetros foram sempre avaliados pelo mesmo observador e em condições semelhantes. Nenhum deles, contudo, apresentou correlação forte com a duração do complexo QRS ou com o sítio de estimulação do VD. Estes resultados não permitiram o melhor entendimento da relação entre estimulação crônica do VD e desenvolvimento de miocardiopatia dilatada. Importante considerar, inclusive, que a prevalência de autoanticorpos, que seriam fatores desencadeadores de uma miocardite autoimune, foi baixa $^{22,43,113}$.

O aumento do volume ventricular provocado pela frequência cardíaca persistentemente baixa e a resposta cronotrópica inadequada podem causar disfunção ventricular transitória ou permanente ${ }^{32,109}$. Dessa forma, o retardo em se diagnosticar ou em se iniciar a estimulação cardíaca artificial, poderia induzir o remodelamento ventricular. Os resultados do presente estudo indicaram a existência de correlação negativa e significativa entre a idade do paciente no momento do primeiro implante de marca-passo e a fração de ejeção do VE. Estes dados nos permitem sugerir que a manutenção de portadores de bloqueio $\mathrm{AV}$ congênito, mesmo assintomáticos, sem a correção da frequência cardíaca pelo marca-passo, poderia provocar danos irreversíveis ao miocárdio. O aumento do DDVE em pacientes bradicárdicos já foi reportado na literatura que demonstrou, entretanto, regressão deste diâmetro após o início da estimulação cardíaca atrioventricular ${ }^{109}$. 
$\mathrm{A}$ falta de sincronia $\mathrm{AV}$ inerente à estimulação ventricular, direita ou esquerda exclusivas, faz com que os átrios se contraiam durante a sístole ventricular, quando as valvas atrioventriculares estão fechadas. Essa concomitância provoca o aumento da pressão atrial, direita e esquerda, e a diminuição do enchimento dos ventrículos, fazendo com que o débito cardíaco diminua em até $30 \%{ }^{139}$. Este fenômeno, quando associado a sinais e sintomas de insuficiência cardíaca, é conhecido como síndrome do marcapasso e é, classicamente, tratado pela mudança de modo de estimulação, de ventricular para atrioventricular. No presente estudo, não houve casos de necessidade de mudança terapêutica de modo de estimulação. As mudanças de modo realizadas foram sempre eletivas, concomitantes à necessidade de troca de gerador de marca-passo por fim de vida normal da bateria. No mesmo sentido, a análise dos dados mostrou que o modo de estimulação, ventricular ou $\mathrm{AV}$, não se correlacionou com os desfechos estudados, inclusive com a distância percorrida no teste de caminhada, uma vez que, teoricamente, pacientes com marca-passo AV deveriam apresentar resposta de frequência cardíaca mais fisiológica pela sincronização dos estímulos ventriculares às ondas $\mathrm{P}$ espontâneas dos pacientes. Devido à raridade do bloqueio $\mathrm{AV}$ congênito ainda faltam evidências embasadas em estudos adequadamente delineados para avaliação comparativa dos modos de estimulação em populações pediátricas. As experiências reportadas até 0 momento, comparando os modos de estimulação ventricular com atrioventricular, falharam ao apontar desfechos como insuficiência cardíaca e mortalidade ${ }^{27,28,109}$. 
O sítio de estimulação cardíaca artificial no endocárdio ou no epicárdio ventricular tem influência direta na propagação do estímulo artificial pelas diferentes porções dos ventrículos direito e esquerdo e, consequentemente, na ativação ventricular ${ }^{65,106,119}$. Esse aspecto é facilmente observado no eletrocardiograma pela duração e pelo eixo do complexo $\mathrm{QRS}^{24,29,42}$. De maneira mais detalhada, também pode ser avaliado por exames de imagem cardíaca, frequentemente pelo ecocardiograma, com o emprego do Doppler tecidual ou pela avaliação tridimensional. Estudos publicados têm sugerido a superioridade da estimulação septal, incluídos os septos de entrada e de saída, sobre a estimulação das paredes livres ou do ápice, incluído o septo apical do $V^{41,109,118}$. No presente estudo, $31,7 \%$ sujeitos tinham o cabo-eletrodo ventricular direito implantado no septo interventricular enquanto em $68,2 \%$, o eletrodo estava implantado em outras regiões do VD, incluindo-se o ápice, o septo apical, a parede anterior e a parede diafragmática. A análise dos resultados, conquanto, não detectou associação entre o sítio de estimulação utilizado e os desfechos estudados. A literatura não apresenta dados conclusivos quanto ao melhor sítio de estimulação em pacientes pediátricos. Algumas publicações sugerem, nada obstante, a superioridade da estimulação biventricular quando comparada à univentricular direita ou esquerda ${ }^{25,27,44,50}$.

O tempo pelo qual os indivíduos são mantidos cronicamente sob estimulação ventricular direita também vem sendo relacionado ao desenvolvimento de disfunção ventricular esquerda, ao aparecimento de 
sintomas de insuficiência cardíaca, à taxa de hospitalização e à mortalidade ${ }^{34,50}$. Outro conceito fundamental é a relação entre batimentos espontâneos e batimentos estimulados artificialmente. Tem sido reportado que pacientes com mais do que $40 \%$ dos batimentos estimulados artificialmente estão mais propensos a desenvolver estes defechos ${ }^{140-142}$. No presente estudo, além do longo tempo de estimulação ventricular direita, todos os indivíduos apresentavam taxa de estimulação ventricular maior do que $80 \%$, sendo que, a maioria estava com $100 \%$ de estimulação artificial. A análise dos resultados do presente estudo mostrou associação significativa entre o tempo total de estimulação cardíaca artificial e do tempo em que o VD foi estimulado, com a presença de sintomas de ICC ou uso de medicamentos de ação cardiovascular. O tempo de estimulação do VD mostrou correlação positiva e significativa com o aumento do DDVE. Estes dados sugerem que quanto maior o tempo pelo qual o individuo é mantido sob estimulação cardíaca artificial do VD, maior a chance de desenvolver remodelamento ventricular e quadro clínico de insuficiência cardíaca. A comparação de indivíduos adultos com bloqueio AV total congênito e marca-passo ventricular direito após $10 \pm$ três anos de seguimento, com controles normais, demonstrou diferenças significativas na medida do retardo eletromecânico intraventricular, com valores respectivos de $59 \pm 18 \mathrm{~ms}$ e $19 \pm 9 \mathrm{~ms}(\mathrm{P}<0,001)$, na percentagem de pacientes com aumento do DDVE, de 57 e 13\% $(P<0,05)$ e no débito cardíaco, de 3,8 \pm 0,6 e 4,9 \pm 0,8 $\mathrm{L} / \min (\mathrm{P}<0,05)^{33}$

Os principais estudos que avaliaram a terapia de ressincronização cardíaca em adultos utilizaram o eletrocardiograma para a detecção de 
pacientes com dissincronia cardíaca. A duração do complexo QRS acima de $150 \mathrm{~ms}$, em indivíduos com ou sem bloqueio completo do ramo esquerdo, está associada à melhor resposta à $\mathrm{TRC}^{143}$. Nos pacientes previamente portadores de marca-passo, que necessitaram de TRC, a redução da duração do complexo QRS também tem sido reportada e associada à boa resposta clínica ${ }^{46,144}$. No presente estudo, a duração do complexo QRS estimulado pelo marca-passo variou de 110 a 190 ms, com mediana de 141 . A análise dos resultados do presente estudo apresentou correlação positiva e significativa entre a duração do complexo QRS estimulado por marcapasso com o aumento do diâmetro do VE. O modelo transversal do presente estudo, porém, impediu o melhor entendimento da relação entre causa e efeito dessas duas variáveis: tanto o aumento da duração do complexo QRS poderia induzir o remodelamento ventricular, quanto o aumento ventricular poderia prejudicar a propagação do estimulo e aumentar a duração do complexo QRS. Estudos realizados em animais de experimentação ${ }^{145}$ ou com pacientes adultos ${ }^{146}$ ou pediátricos ${ }^{147}$, verificaram a falta de correlação entre a duração do complexo QRS e a função ventricular esquerda quando o ventrículo está sendo estimulado artificialmente.

A partir de 2005, com a publicação do estudo CARE-HF ${ }^{143}$, a ecocardiografia ganhou grande importância para deteç̧ão de retardo eletromecânico em pacientes candidatos à terapia de ressincronização. Dentre as técnicas ecocardiográficas empregadas com essa finalidade, o cálculo do intervalo Q-S pelo Doppler tecidual é o mais utilizado para avaliação da sincronia intraventricular esquerda e interventricular. O retardo da ativação 
eletromecânica em crianças e adultos jovens com bloqueio AV congênito submetidos a estimulação crônica do VD tem sido reportado na literatura e tem embasado a indicação da TRC como forma de tratamento e também da prevenção da disfunção ventricular esquerda nessa população $25,27,41,50$. No presente estudo a prevalência de dissincronia ventricular foi alta. Não houve, contudo, correlação entre esses valores com a duração do complexo QRS estimulado, o que poderia ser esperado. Não houve, também, correlação entre a sincronia ventricular avaliada pelo ecocardiograma, com os desfechos estudados. O aumento da duração do complexo QRS acima de $120 \mathrm{~ms}$ associou-se à piora da sincronia eletromecânica ventricular e ao aparecimento de insuficiência cardíaca ${ }^{148}$. Embora resultados conclusivos não tenham sido reportados, a melhora clínica de indivíduos que apresentaram remodelamento após o início da estimulação ventricular direita foi relatado com o uso da terapia de ressincronização cardíaca ${ }^{149}$.

A influência da miocardite intrauterina provocada pelos autoanticorpos maternos, já previamente discutida, é considerada pela literatura como o fator mais importante para a evolução tardia desfavorável dos portadores de bloqueio $A \bigvee$ congênito ${ }^{5,6,71,76,77}$. No presente estudo, para um terço dos sujeitos de pesquisa, foi detectada a presença de autoanticorpos maternos. A análise dos resultados mostrou que estes indivíduos foram submetidos mais tardiamente ao primeiro implante de marca-passo, assim como, atualmente, apresentam maior taxa de uso de marca-passo ventricular exclusivo do que aqueles cujas mães não são portadoras de autoanticorpos. Cabe ressaltar que esses indivíduos, no momento do presente estudo, apresentavam menor faixa 
etária. Importante enfatizar também que não houve diagnóstico de síndrome de lúpus neonatal nos casos estudados e que, na maioria das vezes, o diagnóstico de doença reumatológica materna foi feito tardiamente.

A prevalência do sexo feminino no presente estudo, de $68,2 \%$, é intrigante, embora, a predominância do gênero feminino também seja reportada na literatura, entre 50,4 e $59,8 \%$ dos $\operatorname{casos}^{9,80}$. Na tentativa de explicar esse fato, realizamos levantamento retrospectivo do gênero de todos os indivíduos com a forma isolada do BAVTC submetidos a implante de marca-passo em nossa instituição, verificando que, da coorte de 165 portadores de bloqueio AV congênito isolado e marca-passo, o sexo era feminino em $66,7 \%$ do casos. Dessa coorte, dos dois casos que evoluíram para óbito um era do sexo feminino e para os que necessitaram de TRC ou transplante cardíaco, o sexo era feminino em um caso. Estes dados poderiam sugerir que pacientes do sexo masculino apresentam pior evolução e, por isso, não preencheram os critérios de elegibilidade do presente estudo. A análise dos resultados, apesar disso, não detectou associação entre o sexo do paciente e os desfechos estudados. Cruz et al. ${ }^{52}$ estudando pacientes com bloqueio AV congênito de nossa instituição, com ou sem marca-passo, reportaram $67 \%$ de mulheres na amostra de seu estudo, o que foi justificado pela maior prevalência de doenças reumáticas autoimunes no gênero feminino e, também, por influências hormonais.

O estudo realizado apresentou limitações inerentes aos desenhos transversais, bem como restrições relacionadas com a coleta retrospectiva dos dados que antecederam ao implante de marca-passo. 


\subsection{Limitações do Estudo}

Os objetivos do presente estudo visaram a estudar a evolução de um subgrupo específico de portadores de bloqueio AV congênito isolado, que estava sendo submetido à estimulação crônica do VD e que não haviam necessitado de TRC ou transplante. Dessa forma, suas conclusões não poderão ser estendidas a pacientes que já necessitaram de tratamento não farmacológico para insuficiência cardíaca, assim como, não poderão ser utilizadas para a compreensão de aspectos relacionados à evolução dos pacientes que já haviam evoluído para o óbito antes do início do estudo.

Embora a estimulação ventricular direita seja o método mais utilizado para o tratamento de pacientes com bloqueio $\mathrm{AV}$ congênito, os que estão sendo mantidos com estimulação ventricular esquerda não foram incluídos no presente estudo, de tal forma que sua evolução também não poderá ser analisada com base no presente estudo.

\subsection{Considerações Finais e Implicações Clínicas}

$\mathrm{O}$ bloqueio $\mathrm{AV}$ congênito apresenta peculiaridades que dificultam a padronização de rotinas de atendimento. Por sua raridade, fisiopatologia e multiplicidade de formas de apresentação clínica não existe consenso quanto ao melhor momento para indicação do implante de marca-passo, ao modo de estimulação ou à via de acesso a serem empregados. Dentre as dificuldades encontradas para o seguimento desses indivíduos, acreditamos que a mais importante seja a incapacidade de se prever qual deles será candidato a desenvolver miocardiopatia tardia, insuficiência cardíaca grave e 
necessidade de tratamento, farmacológico ou não farmacológico. A exaustiva investigação clínica, funcional e laboratorial, realizada nos sujeitos da presente pesquisa, confirmou que sua maioria apresenta excelente evolução clínica, independentemente do tipo de estimulação cardíaca utilizada, do momento em que sua utilização foi iniciada ou da presença de doença autoimune materna. A avaliação ecocardiográfica, por outro lado, demonstrou que a prevalência de disfunção ventricular esquerda de qualquer grau foi elevada, atingindo aproximadamente a metade da amostra estudada.

Pela raridade do bloqueio AV congênito isolado, a amostra de 63 indivíduos com estimulação crônica do VD do presente estudo representa, até onde é do nosso conhecimento, a maior experiência de um único centro já reportada na literatura. A despeito do pequeno tamanho amostral, foi possível identificar fatores preditores do remodelamento ventricular esquerdo e da insuficiência cardíaca. Foi factível, ainda, a observação de tendências que permitirão, com o passar do tempo e com aumento do número de casos, melhor direcionar a atenção dos profissionais de saúde para o atendimento desses indivíduos.

Finalmente, dentro da linha de pesquisa que estuda os efeitos da estimulação cardíaca artificial permanente na população pediátrica, o presente estudo servirá como ponto de partida para uma nova fase do seguimento longitudinal desta coorte. Esta observação, com conhecimento prévio da capacidade funcional, qualidade de vida, sincronia e geometria ventricular, possibilitará a definição da incidência dos desfechos mais 
importantes e, a partir do mapeamento já realizado, conhecer melhor a evolução clínico-funcional, a morbidade e mortalidade desta doença. No nosso entendimento, o objetivo maior desta linha de pesquisas é identificar, com maior precisão, qual o melhor momento para iniciar a estimulação cardíaca artificial dos pacientes assintomáticos, qual modo de estimulação utilizar e quando indicar o tratamento farmacológico ou não farmacológico para evitar o remodelamento ventricular e a insuficiência cardíaca. 
7 ConClusões 
O estudo da evolução tardia de 63 indivíduos, mantidos com estimulação crônica do ventrículo direito por até 20 anos, como forma de tratamento para o bloqueio atrioventricular congênito isolado nos permitiu concluir que:

1) A evolução clínica foi favorável na maioria dos indivíduos, com baixa prevalência de sinais ou sintomas de insuficiência cardíaca, não tendo sido possível, com os exames realizados, identificar marcadores laboratoriais para insuficiência cardíaca ou remodelamento ventricular.

2) A prevalência de dissincronia ventricular e de disfunção sistólica ventricular esquerda foi elevada, embora, em sua maioria, representada por disfunção ventricular leve.

3) A capacidade funcional, avaliada pelo teste de caminhada de seis minutos, mostrou-se adequada para a maioria dos indivíduos avaliados, que atingiram percentual elevado da distância caminhada prevista.

4) A qualidade de vida foi satisfatória, tanto nos aspectos físicos quanto emocionais, independentemente da faixa etária ou do tipo de questionário utilizado na sua avaliação.

5) A presença de autoanticorpos anti-Ro/SSA maternos não permitiu a identificação de indivíduos com maior risco de desenvolver remodelamento ventricular ou insuficiência cardíaca. Esta condição esteve associada, 
entretanto, a indivíduos com idade mais avançada no momento do primeiro implante de marca-passo e, em sua maior parte, ao uso mais frequente de marca-passo ventricular.

6) Dentre os fatores de risco analisados, o tempo que o VD foi estimulado artificialmente associou-se significativamente com 0 aparecimento do quadro clínico de insuficiência cardíaca. A duração do complexo QRS estimulado pelo marca-passo, assim como, o tempo de estimulação do VD foram fatores independentes de remodelamento ventricular esquerdo. Da mesma forma, a idade mais avançada no momento do primeiro implante de marca-passo foi fator independente de pior fração de ejeção do ventrículo esquerdo no momento do estudo. 


\section{ANEXOS}




\section{Anexo A - Aprovação da Comissão de Ética para Análise de Projetos de Pesquisa}

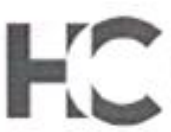

\section{APROVAÇÃO}

A Comissão de Ética para Análise de Projetos de PesquisaCAPPesq da Diretoria Clínica do Hospital das Clinicas e da Faculdade de Medicina da Universidade de São Paulo, em sessào de 16/12/2009. APROVOU O Prolocolo de Pesquisa $n^{\circ}$ 1248/09, intifulado: "ESTUDO DOS EFEITOS DA ESTIMULAÇÃO VENTRICULAR DIREITA CRÓNICA EM CRIANÇAS COM BIOQUEIO ATRIOVENTRICULAR AVANÇADO" e O SUb-estudo intifulado "AVALIAÇÃo da dissincronia Ventricular mecânica pelo ECOCARDIOGRAMA IRIDIMENSIONAL EM PACIENTES PORTADORES DE BLOQUEIO ATRIOVENTRICULAR TOTAL E MARCAPASSO", opresentodo pela COMISSÃO CIENTÍFICA DO INCOR, inclusive Termo de Consentimento tivre e Esciarecido.

Cabe ao pesquisador elaborar e apresentar à CAPPesq. os relatórios parciais e final sobre a pesquisa (Resoluçăo do Conselho Nacional de Saúde $n^{\circ} 196$, de 10/10/1996, incisa IX.2, letra "c"].

Pesquisador (a) Responsável: DR. ROBERTO COSTA

Pesquisador (a) Executante: DR. ROBERTO MARCIO DE OUIVEIRA JÚNIOR

CAPpesq, 17 de Dezembro de 2009

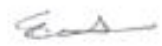

PROF. DR. EDUARDO MASSAD Presidente

Comissoa de Etica para Análise de Projetos de Pesquisa

Consedo de Esca para Anaise do Projetos de Pesquisa do HCFMUSP e da FVUSP Overona Cinica do Hosptal das Ciricas da Faculdase de Medicna da Unversichde de Sso Pa do Rua Orido Pires de Campos 225. $5^{\circ}$ ander - CEP 05403010 - 590 Paur - SP Fone: 0113069 C442 Fax 01130696432 emsil

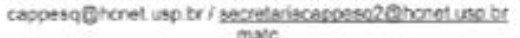




\title{
Anexo B - Aprovação da Comissão de Ética para a versão 2 do protocolo e Termo de Consentimento Livre e Esclarecido para as mães
}

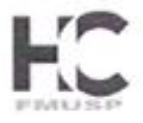

\author{
Hospital das Clínicas da FMUSP \\ Comissao de Etica para Análise de Projetos de Pesquisa \\ CAPPesq
}

N' Protocolo: 1248/09

Título: ESTUDO DOS EFEITOS DA ESTIMULAÇÃO VENTRICULAR DIRETA CRONICA EM CRIANÇAS COM BLOQUEIO ATRIOVENTRICULAR AVANÇADO Pesquisador Responsável: Roberto Costa

Pesquisador Executante: Roberto Márcio de Oliveira Júnior Finalidade Acadêmica: Doutorado

Departamento: COMISSĀO CIENTÍFICA DO INCOR

A Comissảo de Ética para Análise de Projetos de Pesquisa CAppesa da Diretoria Clínica do Hospital das Cínicas da Faculdado de Mecicina da Universidade de São Paulo, APROVOU / TOMOU CIENCIA na sessao datada de 05/09/2012. do(s) documento(s) abaixo mencionodo|sl:

- Carta datada de 26.06.12 - Versâo 02 do protocolo junho/2012, Termo de Consentimento Uvre e Esclarecido para as mães; Relatório Parclal; Pronrogação do prazo de termino do projelo de pesquisa por mais 12 meses
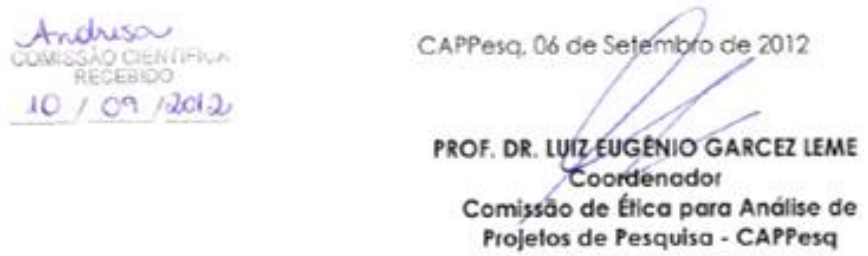

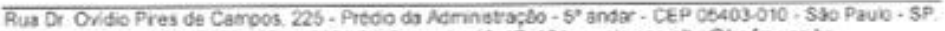

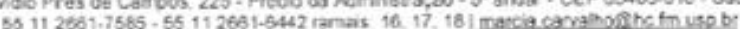




\section{Anexo C - Termo de Consentimento Livre e Esclarecido}

\section{Pacientes}

HOSPITAL DAS CLÍNICAS DA FACULDADE DE MEDICINA DA UNIVERSIDADE DE SÃO PAULO-HCFMUSP

TERMO DE CONSENTIMENTO LIVRE E ESCLARECIDO

DADOS DE IDENTIFICAÇÃO DO SUJEITO DA PESQUISA OU RESPONSÁVEL LEGAL

1.NOME:

DOCUMENTO DE IDENTIDADE № :

SEXO : $M \square F \square$

DATA NASCIMENTO:

ENDEREÇO № APTO:

BAIRRO:. CIDADE:

CEP: .TELEFONE: DDD ( ..)

2.RESPONSÁVEL LEGAL

NATUREZA (grau de parentesco, tutor, curador etc.)

DOCUMENTO DE IDENTIDADE : SEXO: $M \square F \square$

DATA NASCIMENTO.:

ENDEREÇO № APTO:

BAIRRO: CIDADE

CEP: ELEFONE: DDD ...)........

\section{DADOS SOBRE A PESQUISA}

1. TÍTULO DO PROTOCOLO DE PESQUISA: Estudo dos Efeitos da Estimulação Ventricular Direita Crônica em Crianças com Bloqueio Atrioventricular Avançado

2. PESQUISADOR: Roberto Costa

CARGO/FUNÇÃO: Médico INSCRIÇÃO CONSELHO REGIONAL № $31455 / \mathrm{SP}$

UNIDADE DO HCFMUSP: Instituto do Coração - Unidade Cirúrgica de Estimulação Elétrica e Marcapasso

3. AVALIAÇÃO DO RISCO DA PESQUISA:

$\begin{array}{ll}\text { RISCO MÍNIMO } x & \text { RISCO MÉDIO } \square \\ \text { RISCO BAIXO } & \text { RISCO MAIOR } \square\end{array}$

4.DURAÇÃO DA PESQUISA: 24 meses 


\section{HOSPITAL DAS CLÍNICAS DA FACULDADE DE MEDICINA DA UNIVERSIDADE DE SÃO PAULO-HCFMUSP}

1) O motivo para a realização deste estudo é porque alguns pacientes portadores de marcapasso cardíaco podem apresentar insuficiência cardíaca (diminuição na força do coração), necessitando de tratamento com medicamentos e até mesmo trocar o tipo de marca-passo.

2) Após ter sido operado para colocar o marca-passo, você começou a ser acompanhado em várias consultas no nosso hospital e já realizou alguns exames como radiografia e ecocardiograma. Como já faz mais do que um ano que você foi operado é importante realizarmos uma nova avaliação para verificarmos como o seu coração está respondendo aos estímulos do aparelho. Desse modo, você realizará uma avaliação clínica que incluirá algumas perguntas sobre o seu estado de saúde e exame físico. Também iremos revisar todas as informações do seu prontuário e rever os seus exames antigos.

3) Os novos exames que serão realizados vão incluir: radiografia de tórax, exame de sangue e ecocardiograma. Esses exames serão realizados no InCor e não apresentam nenhum risco à sua saúde. Somente para informá-lo, o ecocardiograma é realizado com um aparelho de ultrassom e serve para o médico ter informações sobre o tamanho, a forma e como está o funcionamento do seu coração.

4) O beneficio da sua participação será a chance de identificarmos algum problema no funcionamento do seu coração que poderia passar despercebido durante algum tempo. Mas, somente no final do estudo poderemos concluir a presença desse benefício.

5) Em qualquer etapa do estudo, você terá acesso aos profissionais responsáveis pela pesquisa para esclarecimento de eventuais dúvidas. O principal investigador, o Prof. Dr. Roberto Costa, pode ser encontrado na Unidade de Estimulação Elétrica e Marcapasso do Instituto do Coração (InCor) situada no seguinte endereço: Av. Dr. Enéas de Carvalho Aguiar, 44, 2ํaㅁ andar, sala 3, CEP: 05403-900, Telefone: (11) 3069-5284. Se você tiver alguma consideração ou dúvida sobre a ética da pesquisa, entre em contato com o Comitê de Ética em Pesquisa (CEP) - Rua Ovídio Pires de Campos, 225 - 5ํandar - tel: 30696442 ramais 16, 17, 18 ou 20, FAX: 3069-6442 ramal 26 - E-mail: cappesq@hcnet.usp.br

6) Você poderá desistir de participar do estudo a qualquer momento, sem qualquer prejuízo para o seu tratamento nessa Instituição. O seu nome não será divulgado em nenhum momento e você terá o direito de ser mantido atualizado sobre os resultados deste estudo. Os pesquisadores assumem o compromisso de utilizar os dados e o material coletado somente para este estudo.

7) Em qualquer etapa do estudo, você terá acesso aos profissionais responsáveis pela pesquisa para esclarecimento de suas dúvidas.

8) Você não vai pagar nenhuma consulta médica ou exame e, também não vai receber nenhum dinheiro por estar participando do estudo. Em caso de qualquer problema de saúde que tenha sido causado pelos procedimentos deste estudo, você terá direito a tratamento médico na Instituição.

Acredito ter sido suficientemente informado a respeito das informações que li ou que foram lidas para mim, descrevendo o estudo "Estudo dos Efeitos da Estimulação Ventricular Direita Crônica em Crianças com Bloqueio Atrioventricular Avançado”. 


\section{HOSPITAL DAS CLÍNICAS DA FACULDADE DE MEDICINA DA UNIVERSIDADE DE SÃO PAULO-HCFMUSP}

Eu discuti com o Dr. Roberto Costa sobre a minha decisão em participar nesse estudo. Ficaram claros para mim quais são os propósitos do estudo, os procedimentos a serem realizados, seus desconfortos e riscos, as garantias de confidencialidade e de esclarecimentos permanentes. Ficou claro também que minha participação é isenta de despesas e que tenho garantia do acesso a tratamento hospitalar quando necessário. Concordo voluntariamente em participar deste estudo e poderei retirar o meu consentimento a qualquer momento, antes ou durante o mesmo, sem penalidades ou prejuízo ou perda de qualquer benefício que eu possa ter adquirido, ou no meu atendimento neste Serviço.

Assinatura do paciente/representante legal

Data

Assinatura da testemunha

Data

para casos de pacientes menores de 18 anos, analfabetos, semi-analfabetos ou portadores de deficiência auditiva ou visual.

(Somente para o responsável do projeto)

Declaro que obtive de forma apropriada e voluntária o Consentimento Livre e Esclarecido deste paciente ou representante legal para a participação neste estudo.

Assinatura do responsável pelo estudo

Data

11




\section{Mães}

HOSPITAL DAS CLÍNICAS DA FACULDADE DE MEDICINA DA UNIVERSIDADE DE SÃO PAULO-HCFMUSP

TERMO DE CONSENTIMENTO LIVRE E ESCLARECIDO

DADOS DE IDENTIFICAÇÃO DO SUJEITO DA PESQUISA OU RESPONSÁVEL LEGAL

1.NOME:

DOCUMENTO DE IDENTIDADE № : SEXO : $M \square F \square$ DATA NASCIMENTO: № APTO

ENDEREÇO CIDADE:

BAIRRO: .TELEFONE: DDD

CEP: SEXO: $M \square \quad F \square$

DOCUMENTO DE IDENTIDADE №. APTO:

ENDEREÇO CIDADE

BAIRRO: ...).

CEP: TELEFONE: DDD

\section{DADOS SOBRE A PESQUISA}

1. TíTULO DO PROTOCOLO DE PESQUISA: Estudo dos Efeitos da Estimulação Ventricular Direita Crônica em Crianças com Bloqueio Atrioventricular Avançado

2. PESQUISADOR: Roberto Costa

CARGO/FUNÇÃO: Médico INSCRIÇÃO CONSELHO REGIONAL № $31455 / \mathrm{SP}$

UNIDADE DO HCFMUSP: Instituto do Coração - Unidade Cirúrgica de Estimulação Elétrica e Marcapasso

3. AVALIAÇÃO DO RISCO DA PESQUISA:

$\begin{array}{ll}\text { RISCO MÍNIMO } x & \text { RISCO MÉDIO } \square \\ \text { RISCO BAIXO } \square & \text { RISCO MAIOR } \square\end{array}$

4.DURAÇÃO DA PESQUISA: 24 meses 


\section{HOSPITAL DAS CLÍNICAS DA FACULDADE DE MEDICINA DA UNIVERSIDADE DE SÃO PAULO-HCFMUSP}

1) O motivo de incluir a senhora no estudo é porque existe a possibilidade de o problema cardíaco do seu (sua) filho (a) ter sido causado por substâncias desenvolvidas em seu corpo, chamadas de auto-anticorpos. Quando esse tipo de auto-anticorpo passa para o feto em desenvolvimento pode causar bloqueio cardíaco.

2) Este tipo de problema é mais freqüente quando a mãe apresenta problemas reumatológicos. A maioria das mães sabe que possui alguma doença reumatológica, mas algumas desconhecem sua presença. Por conta disso, a senhora está sendo convidada para uma consulta médica com reumatologista e coleta de sangue.

3) O benefício da sua participação será a chance de identificarmos a causa do problema cardíaco de seu (sua) filho (a), assim como acompanhar a senhora, caso tenha alguma doença reumatológica.

4) Em qualquer etapa do estudo, você terá acesso aos profissionais responsáveis pela pesquisa para esclarecimento de eventuais dúvidas. O principal investigador, o Prof. Dr. Roberto Costa, pode ser encontrado na Unidade de Estimulação Elétrica e Marcapasso do Instituto do Coração (InCor) situada no seguinte endereço: Av. Dr. Enéas de Carvalho Aguiar, 44, 2ํaㅁ andar, sala 3, CEP: 05403-900, Telefone: (11) 2661-5284. Se você tiver alguma consideração ou dúvida sobre a ética da pesquisa, entre em contato com o Comitê de Ética em Pesquisa (CEP) - Rua Ovídio Pires de Campos, 225 - 5ํandar - tel: 26616442 ramais 16, 17, 18 ou 20, FAX: 2661-6442 ramal 26 - E-mail: cappesa@hcnet.usp.br

5) Você poderá desistir de participar do estudo a qualquer momento, sem qualquer prejuízo para o seu tratamento nessa Instituição. O seu nome não será divulgado em nenhum momento e você terá o direito de ser mantido atualizado sobre os resultados deste estudo. Os pesquisadores assumem o compromisso de utilizar os dados e o material coletado somente para este estudo.

6) Em qualquer etapa do estudo, você terá acesso aos profissionais responsáveis pela pesquisa para esclarecimento de suas dúvidas.

7) Você não vai pagar nenhuma consulta médica ou exame e, também não vai receber nenhum dinheiro por estar participando do estudo. Em caso de qualquer problema de saúde que tenha sido causado pelos procedimentos deste estudo, você terá direito a tratamento médico na Instituição.

Acredito ter sido suficientemente informado a respeito das informações que li ou que foram lidas para mim, descrevendo o estudo "Estudo dos Efeitos da Estimulação Ventricular Direita Crônica em Crianças com Bloqueio Atrioventricular Avançado". 


\section{HOSPITAL DAS CLÍNICAS DA FACULDADE DE MEDICINA DA UNIVERSIDADE DE SÃO PAULO-HCFMUSP}

Eu discuti com o Dr. Roberto Costa sobre a minha decisão em participar nesse estudo. Ficaram claros para mim quais são os propósitos do estudo, os procedimentos a serem realizados, seus desconfortos e riscos, as garantias de confidencialidade e de esclarecimentos permanentes. Ficou claro também que minha participação é isenta de despesas e que tenho garantia do acesso a tratamento hospitalar quando necessário. Concordo voluntariamente em participar deste estudo e poderei retirar o meu consentimento a qualquer momento, antes ou durante o mesmo, sem penalidades ou prejuízo ou perda de qualquer benefício que eu possa ter adquirido, ou no meu atendimento neste Serviço.

Assinatura do paciente/representante legal

Data 11

Assinatura do paciente/representante legal

Assinatura da testemunha

Data 11

para casos de pacientes menores de 18 anos, analfabetos, semi-analfabetos ou portadores de deficiência auditiva ou visual.

\section{(Somente para o responsável do projeto)}

Declaro que obtive de forma apropriada e voluntária o Consentimento Livre e Esclarecido deste paciente ou representante legal para a participação neste estudo. 


\section{Anexo D - Dados demográficos dos sujeitos de pesquisa}

\begin{tabular}{|c|c|c|c|c|c|}
\hline № & Gênero & Raça & $\begin{array}{c}\text { Idade no implante } \\
\text { do MP (anos) }\end{array}$ & $\begin{array}{c}\text { Idade no momento do } \\
\text { estudo (anos) }\end{array}$ & $\begin{array}{c}\text { Tempo sob estimulação } \\
\text { cardíaca (anos) }\end{array}$ \\
\hline 1 & $\mathrm{M}$ & parda & 10,8 & 17 & 7 \\
\hline 2 & $\mathrm{~F}$ & parda & 15,1 & 23 & 8 \\
\hline 3 & $\mathrm{~F}$ & branca & 13,9 & 21 & 8 \\
\hline 4 & M & branca & 3,6 & 19 & 16 \\
\hline 5 & M & parda & 9,1 & 25 & 16 \\
\hline 6 & $\mathrm{~F}$ & parda & 0,2 & 2 & 2 \\
\hline 7 & $\mathrm{~F}$ & parda & 6,6 & 14 & 8 \\
\hline 8 & $\mathrm{~F}$ & branca & 15,8 & 25 & 10 \\
\hline 9 & $\mathrm{~F}$ & parda & 20,2 & 27 & 7 \\
\hline 10 & $\mathrm{~F}$ & parda & 11,8 & 29 & 18 \\
\hline 11 & $\mathrm{~F}$ & parda & 12,2 & 23 & 11 \\
\hline 12 & $M$ & negra & 15,7 & 18 & 3 \\
\hline 13 & $\mathrm{~F}$ & parda & 1,5 & 28 & 27 \\
\hline 14 & $\mathrm{~F}$ & parda & 12,3 & 23 & 11 \\
\hline 15 & $\mathrm{~F}$ & parda & 0,4 & 11 & 11 \\
\hline 16 & $M$ & parda & 13,7 & 29 & 16 \\
\hline 17 & $\mathrm{~F}$ & branca & 12,1 & 19 & 7 \\
\hline 18 & $\mathrm{~F}$ & branca & 11,7 & 20 & 9 \\
\hline 19 & $\mathrm{~F}$ & branca & 0,0 & 17 & 17 \\
\hline 20 & $M$ & parda & 2,3 & 10 & 8 \\
\hline 21 & $M$ & branca & 0,9 & 12 & 12 \\
\hline 22 & $\mathrm{M}$ & negra & 0,1 & 11 & 11 \\
\hline 23 & $\mathrm{~F}$ & branca & 12,7 & 25 & 13 \\
\hline 24 & $\mathrm{~F}$ & parda & 5,2 & 9 & 4 \\
\hline 25 & $M$ & parda & 7,7 & 14 & 7 \\
\hline 26 & $\mathrm{~F}$ & parda & 17,6 & 29 & 12 \\
\hline 27 & $\mathrm{~F}$ & parda & 18,8 & 28 & 10 \\
\hline 28 & $\mathrm{~F}$ & parda & 2,4 & 10 & 8 \\
\hline 29 & $\mathrm{~F}$ & parda & 0,0 & 12 & 12 \\
\hline 30 & $M$ & parda & 2,2 & 17 & 15 \\
\hline 31 & $\mathrm{~F}$ & parda & 16,5 & 25 & 9 \\
\hline 32 & $\mathrm{~F}$ & branca & 2,7 & 19 & 17 \\
\hline 33 & $\mathrm{~F}$ & branca & 1,3 & 8 & 7 \\
\hline 34 & $M$ & parda & 12,7 & 25 & 13 \\
\hline 35 & $\mathrm{M}$ & branca & 7,0 & 11 & 4 \\
\hline 36 & $\mathrm{~F}$ & branca & 0,0 & 11 & 11 \\
\hline 37 & $\mathrm{~F}$ & branca & 6,4 & 36 & 30 \\
\hline 38 & $\mathrm{~F}$ & branca & 8,5 & 21 & 13 \\
\hline 39 & $\mathrm{~F}$ & branca & 19,1 & 27 & 8 \\
\hline 40 & $M$ & branca & 3,0 & 21 & 18 \\
\hline 41 & $M$ & branca & 0,0 & 8 & 8 \\
\hline 42 & $\mathrm{M}$ & parda & 0,1 & 6 & 6 \\
\hline 43 & $\mathrm{M}$ & parda & 2,7 & 18 & 16 \\
\hline 44 & $\mathrm{~F}$ & parda & 7,0 & 11 & 5 \\
\hline 45 & $\mathrm{~F}$ & branca & 0,0 & 18 & 18 \\
\hline 46 & $\mathrm{~F}$ & branca & 0,0 & 1 & 1 \\
\hline 47 & $\mathrm{~F}$ & parda & 4,7 & 13 & 9 \\
\hline 48 & $\mathrm{~F}$ & branca & 18,3 & 36 & 18 \\
\hline 49 & $M$ & branca & 10,5 & 29 & 19 \\
\hline 50 & $\mathrm{~F}$ & branca & 9,4 & 27 & 18 \\
\hline 51 & $\mathrm{~F}$ & parda & 17,0 & 29 & 13 \\
\hline 52 & $\mathrm{~F}$ & parda & 1,3 & 31 & 30 \\
\hline 53 & $\mathrm{~F}$ & branca & 14,7 & 36 & 22 \\
\hline 54 & $\mathrm{~F}$ & parda & 13,2 & 36 & 23 \\
\hline 55 & $\mathrm{~F}$ & branca & 16,0 & 40 & 25 \\
\hline 56 & $\mathrm{~F}$ & branca & 6,8 & 24 & 18 \\
\hline 57 & $\mathrm{~F}$ & negra & 14,4 & 28 & 14 \\
\hline 58 & $M$ & branca & 1,3 & 23 & 22 \\
\hline 59 & $\mathrm{~F}$ & parda & 16,8 & 33 & 17 \\
\hline 60 & $\mathrm{~F}$ & branca & 10,4 & 12 & 2 \\
\hline 61 & $M$ & parda & 1,8 & 17 & 16 \\
\hline 62 & $\mathrm{M}$ & branca & 6,6 & 15 & 9 \\
\hline 63 & $\mathrm{~F}$ & branca & 11,8 & 22 & 11 \\
\hline
\end{tabular}

$F=$ feminino; $M=$ masculino; $M P=$ marca-passo 


\section{Anexo E - Dados clínicos antes do implante do marca-passo}

\begin{tabular}{|c|c|c|c|c|}
\hline № & $\begin{array}{l}\text { Idade no diagnóstico } \\
\text { (anos) }\end{array}$ & $\begin{array}{l}\text { Momento do } \\
\text { diagnóstico }\end{array}$ & $\begin{array}{c}\text { Indicação do } \\
\text { implante } \\
\text { do marca-passo }\end{array}$ & $\begin{array}{l}\text { Tempo do diagnóstico } \\
\text { ao implante do MP (anos) }\end{array}$ \\
\hline 1 & 4,0 & Pré-escolar & Bradi sintomática & 6,8 \\
\hline 2 & 0,0 & Neonatal & Bradi sintomática & 15,0 \\
\hline 3 & 0,0 & Neonatal & Bradi sintomática & 13,9 \\
\hline 4 & $-0,8$ & Intraútero & Bradicardia isolada & 4,4 \\
\hline 5 & 8,7 & Escolar & Bradi sintomática & 0,3 \\
\hline 6 & $-0,2$ & Intraútero & Bradicardia isolada & 0,4 \\
\hline 7 & 5,4 & Escolar & Bradi sintomática & 1,2 \\
\hline 8 & 15,0 & Adolescência & Bradi sintomática & 0,6 \\
\hline 9 & $-0,3$ & Intraútero & Bradi sintomática & 20,5 \\
\hline 10 & 7,4 & Escolar & Bradicardia isolada & 4,3 \\
\hline 11 & $-0,8$ & Intraútero & Bradi sintomática & 13,0 \\
\hline 12 & 14,2 & Adolescência & Bradi sintomática & 1,3 \\
\hline 13 & 1,5 & Lactente & Bradicardia isolada & 0,0 \\
\hline 14 & 0,4 & Lactente & Bradicardia isolada & 11,9 \\
\hline 15 & $-0,2$ & Intraútero & Bradi sintomática & 0,7 \\
\hline 16 & 5,1 & Escolar & Bradi sintomática & 8,6 \\
\hline 17 & 11,5 & Adolescência & Bradi sintomática & 0,5 \\
\hline 18 & 0,4 & Lactente & Bradi sintomática & 11,3 \\
\hline 19 & $-0,6$ & Intraútero & Bradicardia isolada & 0,7 \\
\hline 20 & 0,9 & Lactente & Bradicardia isolada & 1,4 \\
\hline 21 & $-0,3$ & Intraútero & Bradicardia isolada & 1,3 \\
\hline 22 & $-0,2$ & Intraútero & Bradi sintomática & 0,3 \\
\hline 23 & 0,7 & Lactente & Bradi sintomática & 12,1 \\
\hline 24 & 0,0 & Neonatal & Bradi sintomática & 5,2 \\
\hline 25 & 3,0 & Pré-escolar & Bradicardia isolada & 4,7 \\
\hline 26 & 15,3 & Adolescência & Bradicardia isolada & 2,1 \\
\hline 27 & 0,5 & Lactente & Bradi sintomática & 18,3 \\
\hline 28 & $-0,4$ & Intraútero & Bradicardia isolada & 2,7 \\
\hline 29 & 0,0 & Neonatal & Bradi sintomática & 0,0 \\
\hline 30 & $-0,3$ & Intraútero & Bradi sintomática & 2,5 \\
\hline 31 & 16,2 & Adolescência & Bradi sintomática & 0,1 \\
\hline 32 & $-0,1$ & Intraútero & Bradicardia isolada & 2,9 \\
\hline 33 & $-0,1$ & Intraútero & Bradi sintomática & 1,4 \\
\hline 34 & 0,0 & Neonatal & Bradi sintomática & 12,8 \\
\hline 35 & $-0,4$ & Intraútero & Bradicardia isolada & 7,4 \\
\hline 36 & 0,0 & Neonatal & Bradi sintomática & 0,0 \\
\hline 37 & 0,4 & Lactente & Bradi sintomática & 6,0 \\
\hline 38 & 8,3 & Escolar & Bradi sintomática & 0,1 \\
\hline 39 & 15,0 & Adolescência & Bradi sintomática & 3,9 \\
\hline 40 & 0,6 & Lactente & Bradicardia isolada & 2,4 \\
\hline 41 & $-0,8$ & Intraútero & Bradi sintomática & 0,8 \\
\hline 42 & $-0,5$ & Intraútero & Bradi sintomática & 0,5 \\
\hline 43 & 0,0 & Neonatal & Bradi sintomática & 2,7 \\
\hline 44 & 1,9 & Lactente & Bradicardia isolada & 5,0 \\
\hline 45 & $-0,6$ & Intraútero & Bradi sintomática & 0,7 \\
\hline 46 & $-0,5$ & Intraútero & Bradicardia isolada & 0,5 \\
\hline 47 & $-0,6$ & Intraútero & Bradi sintomática & 5,3 \\
\hline 48 & 0,0 & Neonatal & Bradi sintomática & 18,3 \\
\hline 49 & 4,7 & Pré-escolar & Bradi sintomática & 5,7 \\
\hline 50 & 3,7 & Pré-escolar & Bradi sintomática & 5,7 \\
\hline 51 & 16,7 & Adolescência & Bradi sintomática & 0,0 \\
\hline 52 & 1,3 & Lactente & Bradicardia isolada & 0,0 \\
\hline 53 & 5,6 & Escolar & Bradi sintomática & 9,0 \\
\hline 54 & 12,3 & Adolescência & Bradi sintomática & 0,8 \\
\hline 55 & 15,4 & Adolescência & Bradicardia isolada & 0,4 \\
\hline 56 & 5,5 & Escolar & Bradi sintomática & 1,1 \\
\hline 57 & 1,5 & Lactente & Bradi sintomática & 12,9 \\
\hline 58 & 0,7 & Lactente & Bradicardia isolada & 0,6 \\
\hline 59 & 7,4 & Escolar & Bradi sintomática & 9,3 \\
\hline 60 & 9,2 & Escolar & Bradi sintomática & 1,1 \\
\hline 61 & $-0,1$ & Intraútero & Bradi sintomática & 1,9 \\
\hline 62 & 4,1 & Pré-escolar & Bradi sintomática & 2,4 \\
\hline 63 & 2,7 & Pré-escolar & Bradi sintomática & 9,0 \\
\hline
\end{tabular}

Diag= diagnóstico; MP= marca-passo . 


\section{Anexo F - Dados do eletrocardiograma obtidos antes do implante do marca-passo}

\begin{tabular}{|c|c|c|c|c|c|c|}
\hline № & FC (bpm) & Duração P (ms) & Condução AV & Duração QRS (ms) & Eixo QRS ( $\left.{ }^{\circ}\right)$ & QTc (ms) \\
\hline 1 & 53 & 85 & BAVT & 80 & 62 & 433 \\
\hline 2 & 34 & 100 & BAVT & 86 & 64 & 491 \\
\hline 3 & 45 & 80 & BAVT & 73 & 80 & 190 \\
\hline 4 & ND & ND & BAVT & ND & ND & ND \\
\hline 5 & 45 & 80 & BAVT & 70 & 30 & 420 \\
\hline 6 & 30 & 90 & BAVT & 110 & 150 & 190 \\
\hline 7 & 59 & 90 & BAVT & 83 & 84 & 395 \\
\hline 8 & 41 & 100 & BAVT & 93 & 30 & 418 \\
\hline 9 & 41 & 90 & BAVT & 131 & 152 & 569 \\
\hline 10 & ND & ND & BAVT & ND & ND & ND \\
\hline 11 & 46 & 80 & BAVT & 78 & 67 & 402 \\
\hline 12 & ND & ND & BAVT & ND & ND & ND \\
\hline 13 & ND & ND & BAVT & ND & ND & ND \\
\hline 14 & 46 & 90 & BAV $2^{\circ}$ grau Mobitz II & 90 & 90 & 201 \\
\hline 15 & 72 & 80 & BAVT & 60 & 30 & 230 \\
\hline 16 & 49 & 80 & BAVT & 80 & 60 & 343 \\
\hline 17 & 42 & 90 & BAVT & 75 & 87 & 379 \\
\hline 18 & 50 & 80 & BAVT & 79 & 60 & 402 \\
\hline 19 & ND & ND & BAVT & ND & ND & ND \\
\hline 20 & 60 & 90 & BAVT & 89 & 97 & 521 \\
\hline 21 & ND & ND & BAVT & ND & ND & ND \\
\hline 22 & 56 & 70 & BAVT & 60 & 90 & 203 \\
\hline 23 & 49 & 100 & BAVT & 90 & 90 & 362 \\
\hline 24 & 53 & 90 & BAVT & 125 & 175 & 472 \\
\hline 25 & 51 & 80 & BAVT & 70 & 91 & 410 \\
\hline 26 & 57 & 80 & BAVT & 80 & 90 & 292 \\
\hline 27 & 35 & 80 & BAVT & 90 & 90 & - \\
\hline 28 & 61 & 60 & BAVT & 68 & 61 & 418 \\
\hline 29 & ND & ND & BAVT & ND & ND & ND \\
\hline 30 & 90 & 80 & BAVT & 66 & 99 & 940 \\
\hline 31 & 36 & 90 & BAVT & 90 & 80 & 357 \\
\hline 32 & 75 & 80 & BAVT & 80 & 90 & 402 \\
\hline 33 & 48 & 90 & BAVT & 97 & 66 & 457 \\
\hline 34 & 44 & 80 & BAVT & 80 & 0 & 248 \\
\hline 35 & 58 & ND & BAVT & 84 & 36 & 391 \\
\hline 36 & 55 & 80 & BAVT & 80 & 0 & 191 \\
\hline 37 & ND & ND & BAVT & ND & ND & ND \\
\hline 38 & 48 & 90 & BAV $2^{\circ}$ grau tipo $2: 1$ & 110 & 90 & 376 \\
\hline 39 & 39 & 80 & BAVT & 84 & 51 & 376 \\
\hline 40 & 48 & 78 & BAVT & 120 & 0 & 483 \\
\hline 41 & 53 & 80 & BAVT & 90 & 120 & 282 \\
\hline 42 & ND & ND & BAVT & ND & ND & ND \\
\hline 43 & 55 & 80 & BAVT & 85 & 60 & 402 \\
\hline 44 & 51 & 60 & BAVT & 78 & 90 & 402 \\
\hline 45 & 48 & 40 & BAVT & 85 & -30 & 197 \\
\hline 46 & 46 & 80 & BAVT & 60 & 120 & 595 \\
\hline 47 & 55 & ND & BAVT & 70 & 62 & 506 \\
\hline 48 & 35 & 80 & BAVT & 90 & 90 & 382 \\
\hline 49 & 44 & 60 & BAV $2^{\circ}$ grau tipo $2: 1$ & 90 & 0 & 360 \\
\hline 50 & 50 & 90 & BAVT & 77 & 123 & 425 \\
\hline 51 & 85 & 85 & BAVT & 80 & 90 & 354 \\
\hline 52 & ND & ND & BAVT & ND & ND & ND \\
\hline 53 & 46 & 80 & BAVT & 100 & 60 & 376 \\
\hline 54 & ND & ND & BAVT & ND & ND & ND \\
\hline 55 & ND & ND & BAVT & ND & ND & ND \\
\hline 56 & 44 & 90 & BAVT & 80 & 30 & 411 \\
\hline 57 & 55 & 100 & BAVT & 73 & 104 & 440 \\
\hline 58 & ND & ND & BAVT & ND & ND & ND \\
\hline 59 & 38 & 100 & BAVT & 90 & 60 & 382 \\
\hline 60 & 46 & 90 & BAVT & 84 & 69 & 473 \\
\hline 61 & 35 & 60 & BAVT & 120 & 89 & 548 \\
\hline 62 & 69 & 90 & BAVT & 89 & 96 & 414 \\
\hline 63 & 51 & 90 & BAVT & 84 & 81 & 407 \\
\hline
\end{tabular}

$\mathrm{FC}=$ Frequência cardíaca; $\mathrm{P}=$ Onda $\mathrm{P} ; \mathrm{AV}=$ Atrioventricular; $\mathrm{QRS}=$ Complexo $\mathrm{QRS} ; \mathrm{QTc}=$ Intervalo $\mathrm{QT}$ corrigido; bpm= batimentos por minuto; $\mathrm{ms}=$ milisegundos; ${ }^{\circ}=$ graus; $\mathrm{ND}=$ informação não disponível no prontuário. 


\section{Anexo G - Dados do ecocardiograma realizado antes do implante do marca-passo}

\begin{tabular}{|c|c|c|c|c|c|c|c|}
\hline № & $\begin{array}{c}\text { DSFVE } \\
(\mathrm{mm})\end{array}$ & $\begin{array}{c}\text { DDFVE } \\
(\mathrm{mm})\end{array}$ & $\begin{array}{c}\text { FEVE \%) } \\
\text { (Teicholz) }\end{array}$ & $\begin{array}{l}\text { Disfunção } \\
\text { ventricular }\end{array}$ & Valvopatias & $\begin{array}{c}\text { Anatomia } \\
\text { normal }\end{array}$ & Laudo descritivo \\
\hline 1 & 22 & 36 & 38,8 & - & Não & Sim & - \\
\hline 2 & 31 & 54 & 80 & Não & Não & Sim & - \\
\hline 3 & 28 & 47 & 40 & - & Não & Sim & - \\
\hline 4 & - & - & - & - & - & - & - \\
\hline 5 & 52 & 64 & 81 & Não & Não & Sim & - \\
\hline 6 & 13 & 23 & 78 & Não & Não & Sim & $\mathrm{FOP}+\mathrm{PCA}$ \\
\hline 7 & 20 & 36 & - & - & Não & Sim & - \\
\hline 8 & 32 & 52 & - & - & Não & Sim & - \\
\hline 9 & 36 & 56 & 73 & Não & Não & Sim & - \\
\hline 10 & - & - & - & - & - & - & - \\
\hline 11 & 33 & 49 & 32,6 & - & Não & Sim & - \\
\hline 12 & - & - & - & - & - & - & - \\
\hline 13 & - & - & - & - & - & - & - \\
\hline 14 & - & - & - & - & - & - & $\begin{array}{l}\text { Não foram feitas } \\
\text { quantificações }\end{array}$ \\
\hline 15 & 15 & 26 & 42,3 & - & Não & Sim & - \\
\hline 16 & - & - & 88 & Não & Não & Sim & Prolapso da valva Mi \\
\hline 17 & - & - & - & - & - & - & - \\
\hline 18 & 29 & 46 & 36,9 & - & Não & Sim & - \\
\hline 19 & - & - & - & - & - & - & - \\
\hline 20 & 19 & 34 & 44,1 & - & Não & Sim & - \\
\hline 21 & - & - & - & - & - & - & - \\
\hline 22 & 14 & 22 & - & - & Não & Sim & - \\
\hline 23 & 28 & 45 & 75 & Não & Não & Sim & - \\
\hline 24 & 24 & 37 & - & - & - & - & - \\
\hline 25 & 20 & 37 & 46 & - & Não & Sim & - \\
\hline 26 & 27 & 43 & 75 & Não & Não & Sim & - \\
\hline 27 & 31 & 48 & 73 & Não & Não & Sim & - \\
\hline 28 & 11 & 17 & - & - & - & - & PCA \\
\hline 29 & - & - & - & - & - & - & - \\
\hline 30 & - & - & - & - & - & - & - \\
\hline 31 & - & - & - & - & - & - & - \\
\hline 32 & 16 & 28 & 43 & - & Não & Sim & - \\
\hline 33 & & 39 & 38,4 & - & Não & Sim & FOP \\
\hline 34 & 34 & 57 & 40,3 & Sim & Não & Sim & - \\
\hline 35 & 21 & 37 & 43,2 & & Não & Sim & FOP \\
\hline 36 & 13 & 19 & 32 & - & - & - & - \\
\hline 37 & - & - & - & - & - & - & - \\
\hline 38 & 28 & 46 & - & - & - & - & - \\
\hline 39 & 39 & 55 & - & - & Não & Sim & - \\
\hline 40 & - & - & - & - & - & - & - \\
\hline 41 & 14 & 22 & - & - & - & - & - \\
\hline 42 & 15 & 22 & 31,8 & Sim & - & - & PCA \\
\hline 43 & 16 & 31 & 48,3 & - & Não & Sim & - \\
\hline 44 & 25 & 40 & 37,5 & - & - & - & - \\
\hline 45 & 17 & 24 & - & Sim & - & - & PCA \\
\hline 46 & 10 & 16 & 74 & Não & Não & Sim & $\mathrm{PCA}+\mathrm{AN}$ SIA \\
\hline 47 & 20 & 34 & 41,1 & Sim & Não & Sim & - \\
\hline 48 & 32 & 50 & - & - & - & - & - \\
\hline 49 & 26 & 43 & 77 & Não & Não & Sim & - \\
\hline 50 & - & - & 80 & Não & Não & Sim & - \\
\hline 51 & - & - & - & & Não & Sim & - \\
\hline 52 & 2,5 & - & 78 & - & - & - & - \\
\hline
\end{tabular}




\begin{tabular}{|c|c|c|c|c|c|c|c|}
\hline № & $\begin{array}{c}\text { DSFVE } \\
(\mathbf{m m})\end{array}$ & $\begin{array}{c}\text { DDFVE } \\
(\mathbf{m m})\end{array}$ & $\begin{array}{c}\text { FEVE \%) } \\
(\text { (Teicholz) }\end{array}$ & Disfunção & Valvopatias & $\begin{array}{c}\text { Anatomia } \\
\text { normal }\end{array}$ & Laudo descritivo \\
\hline 53 & - & 52 & 77 & Não & Não & Sim & - \\
54 & - & - & - & - & - & - & - \\
55 & - & - & - & - & - & - & - \\
56 & - & - & - & - & - & - & - \\
57 & 20 & 34 & 79 & Não & Não & Sim & - \\
58 & - & - & - & - & - & - & - \\
59 & 31 & 48 & - & - & - & - & - \\
60 & 26 & 47 & 75 & Não & Não & Sim & - \\
61 & 34 & 43 & 20,9 & Sim & Não & Sim & - \\
62 & - & - & - & - & - & - & - \\
63 & 26 & 40 & - & - & Não & Sim & \\
\hline
\end{tabular}

DSFVE = Diâmetro sistólico final do ventrículo esquerdo; DDFVE = diâmetro diastólico final do ventrículo esquerdo; Delta $D=$ fração de encurtamento ventricular; $F E V E=$ Fração de ejeção de ventrículo esquerdo pela fórmula de Teichholz; $\mathrm{FOP}=$ Forame oval pérvio; $\mathrm{PCA}=$ Persistência do Canal Arterial; $\mathrm{Mi}=\mathrm{Mitral}$; $\mathrm{AN} \mathrm{SIA}=$ aneurisma septo interatrial; $\mathrm{mm}=$ milímetro; \%= porcentagem. 


\section{Anexo H - Dados do implante inicial do marca-passo}

\begin{tabular}{|c|c|c|c|c|}
\hline № & $\begin{array}{c}\text { Via de acesso } \\
\text { utilizada }\end{array}$ & $\begin{array}{c}\text { Sítio de } \\
\text { estimulação } \\
\text { ventricular }\end{array}$ & Tipo de gerador & $\begin{array}{c}\text { Local gerado } \\
\text { de pulsos }\end{array}$ \\
\hline 1 & Transvenosa & VD endocardico & Unicameral & Submamaria \\
\hline 2 & Transvenosa & VD endocardico & Dupla câmara & Fossa iliaca \\
\hline 3 & Transvenosa & VD endocardico & Dupla câmara & Submamaria \\
\hline 4 & Transvenosa & VD endocardico & Unicameral & Submamaria \\
\hline 5 & Transvenosa & VD endocardico & Unicameral & Infraclavicular \\
\hline 6 & Transvenosa & VD endocardico & Unicameral & Hipocondrio \\
\hline 7 & Transvenosa & VD endocardico & Unicameral & Fossa iliaca \\
\hline 8 & Transvenosa & VD endocardico & Dupla câmara & Fossa iliaca \\
\hline 9 & Transvenosa & VD endocardico & Dupla câmara & Fossa iliaca \\
\hline 10 & Transvenosa & VD endocardico & Unicameral & Epigastrio \\
\hline 11 & Transvenosa & VD endocardico & Unicameral & Fossa iliaca \\
\hline 12 & Transvenosa & VD endocardico & Dupla câmara & Fossa iliaca \\
\hline 13 & Epicardica & VE & Unicameral & Hipocondrio \\
\hline 14 & Transvenosa & VD endocardico & Dupla câmara & Submamaria \\
\hline 15 & Transvenosa & VD endocardico & Unicameral & Infraclavicular \\
\hline 16 & Transvenosa & VD endocardico & Dupla câmara & Fossa iliaca \\
\hline 17 & Transvenosa & VD endocardico & Dupla câmara & Fossa iliaca \\
\hline 18 & Transvenosa & VD endocardico & Dupla câmara & Fossa iliaca \\
\hline 19 & Epicardica & VE & Unicameral & Epigastrio \\
\hline 20 & Transvenosa & VD endocardico & Unicameral & Submamaria \\
\hline 21 & Transvenosa & VD endocardico & Unicameral & Fossa iliaca \\
\hline 22 & Epicardica & VD epicardico & Unicameral & Submamaria \\
\hline 23 & Transvenosa & VD endocardico & Unicameral & Submamaria \\
\hline 24 & Transvenosa & VD endocardico & Unicameral & Infraclavicular \\
\hline 25 & Transvenosa & VD endocardico & Unicameral & Fossa iliaca \\
\hline 26 & Transvenosa & VD endocardico & Dupla câmara & Hipocondrio \\
\hline 27 & Transvenosa & VD endocardico & Dupla câmara & Fossa iliaca \\
\hline 28 & Transvenosa & VD endocardico & Unicameral & Infraclavicular \\
\hline 29 & Epicardica & VE & Unicameral & Submamaria \\
\hline 30 & Transvenosa & VD endocardico & Unicameral & Infraclavicular \\
\hline 31 & Transvenosa & VD endocardico & Dupla câmara & Epigastrio \\
\hline 32 & Transvenosa & VD endocardico & Dupla câmara & Submamaria \\
\hline 33 & Epicardica & VE & Unicameral & Fossa iliaca \\
\hline 34 & Transvenosa & VD endocardico & Dupla câmara & Submamaria \\
\hline 35 & Transvenosa & VD endocardico & Unicameral & Infraclavicular \\
\hline 36 & Transvenosa & VD endocardico & Unicameral & Fossa iliaca \\
\hline 37 & Epicardica & VD epicardico & Unicameral & Infraclavicular \\
\hline 38 & Transvenosa & VD endocardico & Dupla câmara & Infraclavicular \\
\hline 39 & Transvenosa & VD endocardico & Dupla câmara & Infraclavicular \\
\hline 40 & Transvenosa & VD endocardico & Unicameral & Fossa iliaca \\
\hline 41 & Epicardica & VE & Unicameral & Flanco \\
\hline 42 & Epicardica & VE & Unicameral & Submamaria \\
\hline 43 & Transvenosa & VD endocardico & Unicameral & Fossa iliaca \\
\hline 44 & Transvenosa & VD endocardico & Unicameral & Infraclavicular \\
\hline 45 & Transvenosa & VD endocardico & Unicameral & Fossa iliaca \\
\hline 46 & Epicardica & VD epicardico & Unicameral & Fossa iliaca \\
\hline 47 & Transvenosa & VD endocardico & Unicameral & Fossa iliaca \\
\hline 48 & Transvenosa & VD endocardico & Dupla câmara & Infraclavicular \\
\hline 49 & Transvenosa & VD endocardico & Unicameral & Submamaria \\
\hline 50 & Transvenosa & VD endocardico & Dupla câmara & Flanco \\
\hline 51 & Transvenosa & VD endocardico & Dupla câmara & Hipocondrio \\
\hline 52 & Epicardica & VE & Unicameral & Fossa iliaca \\
\hline 53 & Transvenosa & VD endocardico & Unicameral & Infraclavicular \\
\hline 54 & Transvenosa & VD endocardico & Unicameral & Infraclavicular \\
\hline 55 & Transvenosa & VD endocardico & Unicameral & Dorsal \\
\hline 56 & Transvenosa & VD endocardico & Unicameral & Fossa iliaca \\
\hline 57 & Transvenosa & VD endocardico & Dupla câmara & Fossa iliaca \\
\hline 58 & Epicardica & VD epicardico & Unicameral & Fossa iliaca \\
\hline 59 & Transvenosa & VD endocardico & Dupla câmara & Submamaria \\
\hline 60 & Transvenosa & VD endocardico & Unicameral & Infraclavicular \\
\hline 61 & Transvenosa & VD endocardico & Unicameral & Submamaria \\
\hline 62 & Transvenosa & VD endocardico & Unicameral & Submamaria \\
\hline 63 & Transvenosa & VD endocardico & Unicameral & Fossa iliaca \\
\hline
\end{tabular}


Anexol- Dados das reoperações realizadas para manutenção do sistema de estimulação

\begin{tabular}{|c|c|c|c|}
\hline № & № reoperações & $\begin{array}{l}\text { Mudança de modo } \\
\text { de estimulação }\end{array}$ & $\begin{array}{c}\text { Tempo entre } 01^{\circ} \text { implante } \\
\text { e a mudança de modo (anos) }\end{array}$ \\
\hline 1 & 0 & Não & - \\
\hline 2 & 1 & Não & - \\
\hline 3 & 1 & Não & - \\
\hline 4 & 5 & Não & - \\
\hline 5 & 3 & Sim & 6,1 \\
\hline 6 & 0 & Não & - \\
\hline 7 & 1 & Não & - \\
\hline 8 & 2 & Não & - \\
\hline 9 & 0 & Não & - \\
\hline 10 & 2 & Sim & 8,8 \\
\hline 11 & 1 & Não & - \\
\hline 12 & 0 & Não & - \\
\hline 13 & 6 & Sim & 13,5 \\
\hline 14 & 2 & Não & - \\
\hline 15 & 3 & Não & - \\
\hline 16 & 2 & Não & - \\
\hline 17 & 2 & Não & - \\
\hline 18 & 1 & Não & - \\
\hline 19 & 8 & Sim & 13,0 \\
\hline 20 & 1 & Não & - \\
\hline 21 & 2 & Não & - \\
\hline 22 & 5 & Não & - \\
\hline 23 & 1 & Não & - \\
\hline 24 & 0 & Não & - \\
\hline 25 & 1 & Não & - \\
\hline 26 & 1 & Não & - \\
\hline 27 & 1 & Não & - \\
\hline 28 & 2 & Não & - \\
\hline 29 & 2 & Não & - \\
\hline 30 & 3 & Sim & 13,6 \\
\hline 31 & 1 & Não & - \\
\hline 32 & 2 & Não & - \\
\hline 33 & 2 & Não & - \\
\hline 34 & 2 & Não & - \\
\hline 35 & 0 & Não & - \\
\hline 36 & 4 & Não & - \\
\hline 37 & 5 & Sim & 14,2 \\
\hline 38 & 2 & Não & - \\
\hline 39 & 1 & Não & - \\
\hline 40 & 2 & Não & - \\
\hline 41 & 3 & Não & - \\
\hline 42 & 2 & Não & - \\
\hline 43 & 2 & Sim & 15,1 \\
\hline 44 & 0 & Não & - \\
\hline 45 & 5 & Não & - \\
\hline 46 & 0 & Não & - \\
\hline 47 & 0 & Não & - \\
\hline 48 & 2 & Não & - \\
\hline 49 & 4 & Sim & 4,7 \\
\hline 50 & 4 & Não & - \\
\hline 51 & 2 & Não & - \\
\hline 52 & 7 & Sim & 10,2 \\
\hline 53 & 3 & Sim & 8,2 \\
\hline 54 & 2 & Não & - \\
\hline 55 & 2 & Sim & 20,5 \\
\hline 56 & 3 & Sim & 12,1 \\
\hline 57 & 2 & Não & - \\
\hline 58 & 4 & Sim & 11,5 \\
\hline 59 & 3 & Não & - \\
\hline 60 & 0 & Não & - \\
\hline 61 & 2 & Não & - \\
\hline 62 & 1 & Não & - \\
\hline 63 & 1 & Sim & 7,2 \\
\hline
\end{tabular}




\section{Anexo J - Avaliação clínica realizada durante o estudo}

\begin{tabular}{|c|c|c|c|c|}
\hline № & CF NYHA & $\begin{array}{c}\text { Medicamentos } \\
\text { ação cardiovascular }\end{array}$ & $\begin{array}{c}\text { Hospitalizações } \\
\text { prévias }\end{array}$ & Motivo \\
\hline 1 & $\mathrm{I}$ & não & não & - \\
\hline 2 & I & não & não & - \\
\hline 3 & I & não & não & - \\
\hline 4 & I & não & não & - \\
\hline 5 & I & não & não & - \\
\hline 6 & I & não & não & - \\
\hline 7 & I & não & não & - \\
\hline 8 & I & não & não & - \\
\hline 9 & II & não & não & - \\
\hline 10 & I & não & não & - \\
\hline 11 & i & não & não & - \\
\hline 12 & I & não & não & - \\
\hline 13 & I & não & não & - \\
\hline 14 & I & não & não & - \\
\hline 15 & I & não & não & - \\
\hline 16 & I & não & não & - \\
\hline 17 & I & não & não & - \\
\hline 18 & I & não & não & - \\
\hline 19 & I & não & não & - \\
\hline 20 & I & não & não & - \\
\hline 21 & I & não & não & - \\
\hline 22 & I & não & não & - \\
\hline 23 & i & não & não & - \\
\hline 24 & I & não & não & - \\
\hline 25 & I & não & não & - \\
\hline 26 & I & não & não & - \\
\hline 27 & I & não & não & - \\
\hline 28 & I & não & não & - \\
\hline 29 & I & não & não & - \\
\hline 30 & I & não & não & - \\
\hline 31 & I & não & não & - \\
\hline 32 & I & não & não & - \\
\hline 33 & I & não & não & - \\
\hline 34 & I & $\operatorname{sim}$ & não & - \\
\hline 35 & I & não & não & - \\
\hline 36 & I & não & não & - \\
\hline 37 & II & $\operatorname{sim}$ & não & - \\
\hline 38 & I & não & não & - \\
\hline 39 & I & não & não & - \\
\hline 40 & I & $\operatorname{sim}$ & não & - \\
\hline 41 & I & não & não & - \\
\hline 42 & I & não & não & - \\
\hline 43 & II & não & não & - \\
\hline 44 & I & não & não & - \\
\hline 45 & I & não & não & - \\
\hline 46 & I & não & não & - \\
\hline 47 & I & não & não & - \\
\hline 48 & I & não & não & - \\
\hline 49 & I & não & não & - \\
\hline 50 & I & $\operatorname{sim}$ & não & - \\
\hline 51 & i & não & não & - \\
\hline 52 & 1 & não & não & - \\
\hline 53 & i & $\operatorname{sim}$ & não & - \\
\hline 54 & I & não & não & - \\
\hline 55 & I & não & não & - \\
\hline 56 & I & não & não & - \\
\hline 57 & I & não & não & - \\
\hline 58 & I & não & não & - \\
\hline 59 & I & não & não & - \\
\hline 60 & I & não & não & - \\
\hline 61 & I & não & não & - \\
\hline 62 & I & não & não & - \\
\hline 63 & I & não & não & - \\
\hline
\end{tabular}

$\mathrm{CF}=$ Classe Funcional; NYHA $=$ New York Heart Association 
Anexo K - Marcadores laboratoriais de insuficiência cardíaca

\begin{tabular}{|c|c|c|c|c|}
\hline № & BNP (pg/dL) & TNF-alfa (pg/dL) & Interleucina 6 (pg/dL) & PCR-us (mg/L) \\
\hline 1 & 2 & 9,2 & 2 & 1,51 \\
\hline 2 & 2 & 8 & 2 & 6,28 \\
\hline 3 & 2 & 5,2 & 2 & 2,43 \\
\hline 4 & 15 & 10,2 & 2 & 3,68 \\
\hline 5 & 2 & 5,7 & 2 & 3,59 \\
\hline 6 & 3 & 9,6 & 2 & 0,18 \\
\hline 7 & 10 & 7,5 & 2 & 0,5 \\
\hline 8 & 2 & 4 & 2 & 4,35 \\
\hline 9 & 2 & 7,5 & 2 & 8,73 \\
\hline 10 & 3 & 5,4 & 2 & 0,58 \\
\hline 11 & 13 & 9,6 & 3,3 & 5,77 \\
\hline 12 & 4 & 4,2 & 2 & 0,17 \\
\hline 13 & 4 & 6 & 2 & 21,3 \\
\hline 14 & 2 & 5,9 & 4,5 & 4,28 \\
\hline 15 & 2 & 8 & 2 & 0,85 \\
\hline 16 & 5 & 6,8 & 4,3 & 1,74 \\
\hline 17 & 4 & 8,4 & 2 & 5,13 \\
\hline 18 & 2 & 6,3 & 2 & 2,19 \\
\hline 19 & - & - & - & - \\
\hline 20 & 12 & 6,7 & 2 & 3,88 \\
\hline 21 & 10 & 7,5 & 2 & 0,43 \\
\hline 22 & 17 & 14,2 & 2 & 0,44 \\
\hline 23 & 7 & 6,6 & 2 & 1,68 \\
\hline 24 & 2 & 6,8 & 2 & 0,19 \\
\hline 25 & 3 & 8,2 & 2 & 0,72 \\
\hline 26 & 2 & 4 & 2 & 2,22 \\
\hline 27 & 2 & 7,5 & 2 & 2,19 \\
\hline 28 & 5 & 8,7 & 2 & 0,24 \\
\hline 29 & 2 & 8,6 & 2 & 0,23 \\
\hline 30 & 8 & 7 & 2 & 0,83 \\
\hline 31 & 2 & 5,1 & 2 & 8,3 \\
\hline 32 & 2 & 5,8 & 2 & 2,44 \\
\hline 33 & 4,4 & 9,3 & 2 & 3,5 \\
\hline 34 & 2 & 5,4 & 2 & 1,15 \\
\hline 35 & 2 & 9,7 & 2 & 0,93 \\
\hline 36 & 2 & 8,5 & 2,1 & 0,9 \\
\hline 37 & 2 & 4,9 & 2 & 1,1 \\
\hline 38 & 4 & 7,7 & 5,7 & 3,44 \\
\hline 39 & 2 & 4,1 & 2 & 4,69 \\
\hline 40 & 2 & 6,1 & 2 & 1,46 \\
\hline 41 & 6 & 10 & 2,2 & 0,17 \\
\hline 42 & 45 & 8,1 & 4,1 & 10,9 \\
\hline 43 & 2 & 7,7 & 2 & 0,17 \\
\hline 44 & 2 & 6 & 2 & 0,3 \\
\hline 45 & 2 & 8,9 & 2 & 1,23 \\
\hline 46 & 10 & 12 & 2 & 0,17 \\
\hline 47 & 2 & 11 & 3,8 & 1,4 \\
\hline 48 & 2 & 5,5 & 2 & 0,84 \\
\hline 49 & 2 & 6,1 & 2 & 0,46 \\
\hline 50 & 2 & 7,8 & 2,7 & 5,76 \\
\hline 51 & 4 & 5,7 & 2 & 1,26 \\
\hline 52 & 8 & 21,6 & 3,2 & 5,88 \\
\hline 53 & 2 & 4 & 2 & 14,5 \\
\hline 54 & 13 & 4,4 & 2 & 1,27 \\
\hline 55 & 2 & 6,5 & 2 & 2,82 \\
\hline 56 & 8 & 6,7 & 2 & 1,22 \\
\hline 57 & 2 & 5,5 & 3,8 & 10,1 \\
\hline 58 & 11 & 10,6 & 4,6 & 14,9 \\
\hline 59 & 18 & 7,8 & 3,3 & 4,72 \\
\hline 60 & 2 & 9 & 4,4 & 3,68 \\
\hline 61 & 4 & 7,3 & 2 & 1,1 \\
\hline 62 & 5 & 8,5 & 2 & 0,76 \\
\hline 63 & 2 & 7,6 & 2 & 14,8 \\
\hline
\end{tabular}




\section{Anexo L - Eletrocardiograma realizado durante a avaliação do marca- passo}

\begin{tabular}{|c|c|c|c|c|c|c|c|}
\hline № & $\begin{array}{c}\text { Tempo } \\
\text { neste sítio } \\
\text { (anos) }\end{array}$ & $\begin{array}{c}\% \\
\begin{array}{c}\text { estimulação } \\
\text { atrial }\end{array}\end{array}$ & $\begin{array}{c}\% \\
\text { estimulação } \\
\text { ventricular }\end{array}$ & $\begin{array}{c}\text { Duração } \\
\text { QRS } \\
\text { estimulado } \\
\text { (ms) }\end{array}$ & $\begin{array}{c}\text { Eixo QRS } \\
\text { estimulado } \\
\left(^{\circ}\right)\end{array}$ & $\begin{array}{c}\text { Duração } \\
\text { QRS inibido } \\
\text { (ms) }\end{array}$ & $\begin{array}{c}\text { Eixo QRS } \\
\text { inibido } \\
\left({ }^{\circ}\right)\end{array}$ \\
\hline 1 & 8,7 & - & 97 & 127 & -33 & 87 & 65 \\
\hline 2 & 4,7 & 59 & 100 & 173 & 261 & 111 & 28 \\
\hline 3 & 0,4 & 95 & 95 & 110 & -85 & 75 & 71 \\
\hline 4 & 0 & - & 100 & 128 & -73 & $\begin{array}{l}\text { sem ritmo } \\
\text { de escape }\end{array}$ & $\begin{array}{l}\text { sem ritmo } \\
\text { de escape }\end{array}$ \\
\hline 5 & 5,3 & 2 & 100 & 165 & Indiferenciado & 93 & 7 \\
\hline 6 & 3,8 & - & 100 & 119 & 0 & 40 & 90 \\
\hline 7 & 4,4 & - & 100 & 180 & -120 & 80 & 70 \\
\hline 8 & 4,8 & 8 & 100 & 149 & 39 & 82 & 37 \\
\hline 9 & 9,3 & 30 & 100 & 160 & 70 & 120 & 0 \\
\hline 10 & 2,5 & 32 & 100 & 148 & 90 & 103 & 24 \\
\hline 11 & 5 & 0 & 96 & 150 & -59 & 90 & 30 \\
\hline 12 & 5 & 36 & 48 & 155 & -120 & 80 & 60 \\
\hline 13 & 0,5 & 66 & 97 & 156 & 122 & 73 & 48 \\
\hline 14 & 6,4 & 17 & 99 & 147 & 65 & 79 & 112 \\
\hline 15 & 4,6 & - & 100 & 176 & -41 & 103 & 32 \\
\hline 16 & 1,5 & 0 & 80 & 176 & -56 & 81 & 26 \\
\hline 17 & 1,3 & 16 & 99 & 110 & -41 & 80 & 20 \\
\hline 18 & 2,9 & 7 & 100 & 153 & -21 & 83 & 56 \\
\hline 19 & 1,1 & - & - & - & - & - & - \\
\hline 20 & 4,3 & 0 & 99 & 150 & 0 & 100 & 90 \\
\hline 21 & 0 & 0 & 99 & 139 & -82 & 96 & 80 \\
\hline 22 & 4,8 & 0 & 100 & 134 & -15 & 67 & 80 \\
\hline 23 & 4,1 & 0 & 69 & 171 & -70 & 93 & 61 \\
\hline 24 & 6,7 & 0 & 97 & 140 & 86 & $\begin{array}{l}\text { sem ritmo } \\
\text { de escape }\end{array}$ & $\begin{array}{l}\text { sem ritmo } \\
\text { de escape }\end{array}$ \\
\hline 25 & 3,3 & 0 & 96 & 141 & -82 & $\begin{array}{l}\text { sem ritmo } \\
\text { de escape }\end{array}$ & $\begin{array}{l}\text { sem ritmo } \\
\text { de escape }\end{array}$ \\
\hline 26 & 4,4 & 3 & 99 & 180 & -120 & 90 & -30 \\
\hline 27 & 5,4 & 49 & 99 & 155 & -30 & 100 & 40 \\
\hline 28 & 1 & 0 & 92 & 127 & -40 & 72 & 23 \\
\hline 29 & 6,1 & 0 & 100 & 160 & 90 & $\begin{array}{l}\text { sem ritmo } \\
\text { de escape }\end{array}$ & $\begin{array}{l}\text { sem ritmo } \\
\text { de escape }\end{array}$ \\
\hline 30 & 2,4 & - & 100 & 177 & -90 & 83 & 102 \\
\hline 31 & 2 & 60 & 100 & 153 & 19 & 82 & 74 \\
\hline 32 & 7,2 & 17 & 99 & 139 & 89 & 90 & 66 \\
\hline 33 & 4,4 & 0 & 100 & 155 & Indiferenciado & $\begin{array}{l}\text { sem ritmo } \\
\text { de escape }\end{array}$ & $\begin{array}{l}\text { sem ritmo } \\
\text { de escape }\end{array}$ \\
\hline 34 & 0,1 & 14 & 100 & 145 & -56 & 90 & 17 \\
\hline 35 & 5,3 & 0 & 80 & 148 & -65 & 102 & -25 \\
\hline 36 & 4,7 & 0 & 100 & 132 & 87 & 80 & 18 \\
\hline 37 & 1,4 & - & 100 & 164 & Indiferenciado & 0 & 0 \\
\hline 38 & 6,2 & - & 100 & 300 & 102 & 0 & 0 \\
\hline 39 & 1,9 & 15 & 95 & 164 & -33 & 99 & 5 \\
\hline 40 & 10,1 & 0 & 99 & 190 & Indiferenciado & 125 & 150 \\
\hline 41 & 3,8 & 0 & 99 & 160 & -90 & 105 & 0 \\
\hline 42 & 3,6 & 0 & 100 & 150 & -110 & 85 & 90 \\
\hline 43 & 0 & - & 99 & 140 & 90 & 95 & 40 \\
\hline 44 & 5,7 & 0 & 99 & 118 & Indiferenciado & 79 & 64 \\
\hline 45 & 7,1 & 0 & 100 & 173 & -59 & 0 & 0 \\
\hline 46 & 1,7 & - & 100 & 110 & 60 & 74 & 90 \\
\hline 47 & 9,3 & 0 & 100 & 115 & -30 & 90 & 60 \\
\hline 48 & 4,3 & - & 96 & 170 & -60 & 0 & 0 \\
\hline 49 & 2,8 & 2 & 100 & 180 & -60 & 75 & 30 \\
\hline 50 & 6 & 25 & 99 & 147 & -60 & 0 & 0 \\
\hline 51 & 4,3 & 8 & 99 & 131 & Indiferenciado & 86 & 65 \\
\hline 52 & 0,6 & 66 & 99 & 165 & -60 & 75 & 60 \\
\hline 53 & 0,7 & - & 100 & 186 & -63 & 0 & 0 \\
\hline 54 & 7,9 & 0 & 86 & 139 & Indiferenciado & 90 & 59 \\
\hline
\end{tabular}




\begin{tabular}{|c|c|c|c|c|c|c|c|}
\hline № & $\begin{array}{c}\text { Tempo } \\
\text { neste sítio } \\
\text { (anos) }\end{array}$ & $\begin{array}{c}\text { \% } \\
\text { estimulação } \\
\text { atrial }\end{array}$ & $\begin{array}{c}\% \\
\text { estimulação } \\
\text { ventricular }\end{array}$ & $\begin{array}{c}\text { Duração } \\
\text { QRS } \\
\text { estimulado } \\
(\text { ms) }\end{array}$ & $\begin{array}{c}\text { Eixo QRS } \\
\text { estimulado } \\
\left({ }^{\circ}\right)\end{array}$ & $\begin{array}{c}\text { Duração } \\
\text { QRS inibido } \\
\text { (ms) }\end{array}$ & $\begin{array}{c}\text { Eixo QRS } \\
\text { inibido } \\
\left({ }^{\circ}\right)\end{array}$ \\
\hline 55 & 4,6 & 7 & 100 & 167 & -58 & 71 & 66 \\
56 & 6,2 & 5 & 100 & 156 & 74 & 91 & 67 \\
57 & 0,1 & 30 & 95 & 155 & -75 & 87 & 84 \\
58 & 5,9 & 42 & 100 & 184 & -77 & 0 & 0 \\
59 & 2,1 & 30 & 100 & 184 & -71 & 0 & 0 \\
60 & 2,5 & 0 & 55 & 145 & Indiferenciado & 73 & 44 \\
61 & 6,9 & 0 & 99 & 164 & -90 & 0 & 0 \\
62 & 3,2 & 0 & 94 & 159 & 106 & 106 & 79 \\
63 & 4,4 & 31 & 99 & 155 & -86 & 89 & 81 \\
\hline
\end{tabular}

QRS= Complexo QRS; \%= porcentagem; ms= milisegundos, ${ }^{\circ}=$ graus 


\section{Anexo M - Avaliação do ritmo cardíaco durante avaliação eletrônica do marca-passo realizada no estudo}

\begin{tabular}{|c|c|c|c|}
\hline № & Ritmo inicial & MP inibido & Ritmo final \\
\hline 1 & MP ventricular com ondas $\mathrm{P}$ dissociadas & BAVT & MP ventricular com ondas $\mathrm{P}$ dissociadas \\
\hline 2 & MP AV sequencial & BAVT & MP AV sequencial \\
\hline 3 & $\begin{array}{l}\text { Ritmo sinusal seguido por estimulação } \\
\text { ventricular }\end{array}$ & BAVT & $\begin{array}{l}\text { Ritmo sinusal seguido por estimulação } \\
\text { ventricular sincronizada }\end{array}$ \\
\hline 4 & MP ventricular com ondas $\mathrm{P}$ dissociadas & $\begin{array}{l}\text { BAVT Sem } \\
\text { escape }\end{array}$ & MP ventricular com ondas $\mathrm{P}$ dissociadas \\
\hline 5 & $\begin{array}{l}\text { Ritmo sinusal seguido por estimulação } \\
\text { ventricular }\end{array}$ & BAVT & $\begin{array}{l}\text { Ritmo sinusal seguido por estimulação } \\
\text { ventricular sincronizada }\end{array}$ \\
\hline 6 & MP ventricular com ondas $\mathrm{P}$ dissociadas & BAVT & MP ventricular com ondas $\mathrm{P}$ dissociadas \\
\hline 7 & MP ventricular com ondas $P$ dissociadas & BAVT & MP ventricular com ondas $\mathrm{P}$ dissociadas \\
\hline 8 & $\begin{array}{l}\text { Ritmo sinusal seguido por estimulação } \\
\text { ventricular }\end{array}$ & BAVT & $\begin{array}{l}\text { Ritmo sinusal seguido por estimulação } \\
\text { ventricular sincronizada }\end{array}$ \\
\hline 9 & $\begin{array}{l}\text { Ritmo sinusal seguido por estimulação } \\
\text { ventricular }\end{array}$ & BAVT & MP AV sequencial \\
\hline 10 & MP AV sequencial & BAVT & MP AV sequencial \\
\hline 11 & MP ventricular com ondas $\mathrm{P}$ dissociadas & BAV 2:1 & MP ventricular com ondas $\mathrm{P}$ dissociadas \\
\hline 12 & MP AV sequencial & $\begin{array}{l}\text { Bradicardia } \\
\text { sinusal }\end{array}$ & MP AV sequencial \\
\hline 13 & MP AV sequencial & BAVT & MP AV sequencial \\
\hline 14 & MP AV sequencial & - & - \\
\hline 15 & MP ventricular com ondas $P$ dissociadas & BAVT & MP ventricular com ondas $P$ dissociadas \\
\hline 16 & $\begin{array}{l}\text { Ritmo sinusal seguido por estimulação } \\
\text { ventricular }\end{array}$ & BAVT & $\begin{array}{l}\text { Ritmo sinusal seguido por estimulação } \\
\text { ventricular sincronizada }\end{array}$ \\
\hline 17 & MP AV sequencial & BAVT & MP AV sequencial \\
\hline 18 & $\begin{array}{l}\text { Ritmo sinusal seguido por estimulação } \\
\text { ventricular }\end{array}$ & BAVT & $\begin{array}{l}\text { Ritmo sinusal seguido por estimulação } \\
\text { ventricular sincronizada }\end{array}$ \\
\hline 19 & - & - & \\
\hline 20 & MP ventricular com ondas $\mathrm{P}$ dissociadas & BAVT & MP ventricular com ondas $\mathrm{P}$ dissociadas \\
\hline 21 & MP ventricular com ondas $P$ dissociadas & BAVT & MP ventricular com ondas $P$ dissociadas \\
\hline 22 & MP ventricular com ondas $\mathrm{P}$ dissociadas & - & - \\
\hline 23 & MP ventricular com ondas $P$ dissociadas & BAVT & MP ventricular com ondas $P$ dissociadas \\
\hline 24 & MP ventricular com ondas $\mathrm{P}$ dissociadas & $\begin{array}{l}\text { BAVT sem } \\
\text { escape }\end{array}$ & MP ventricular com ondas $\mathrm{P}$ dissociadas \\
\hline 25 & MP ventricular com ondas $P$ dissociadas & $\begin{array}{l}\text { BAVT sem } \\
\text { escape }\end{array}$ & MP ventricular com ondas $P$ dissociadas \\
\hline 26 & MP AV sequencial & BAVT & MP AV sequencial \\
\hline 27 & MP AV sequencial & BAVT & MP AV sequencial \\
\hline 28 & MP ventricular com ondas $\mathrm{P}$ dissociadas & BAVT & MP ventricular com ondas $\mathrm{P}$ dissociadas \\
\hline 29 & MP ventricular com ondas $P$ dissociadas & $\begin{array}{l}\text { BAVT sem } \\
\text { escape }\end{array}$ & MP ventricular com ondas $\mathrm{P}$ dissociadas \\
\hline 30 & $\begin{array}{l}\text { Ritmo sinusal seguido por estimulação } \\
\text { ventricular }\end{array}$ & BAVT & $\begin{array}{l}\text { Ritmo sinusal seguido por estimulação } \\
\text { ventricular sincronizada }\end{array}$ \\
\hline 31 & MP AV sequencial & BAVT & MP AV sequencial \\
\hline 32 & $\begin{array}{l}\text { Ritmo sinusal seguido por estimulação } \\
\text { ventricular }\end{array}$ & BAVT & $\begin{array}{l}\text { Ritmo sinusal seguido por estimulação } \\
\text { ventricular sincronizada }\end{array}$ \\
\hline 33 & MP ventricular com ondas $\mathrm{P}$ dissociadas & $\begin{array}{l}\text { BAVT sem } \\
\text { escape }\end{array}$ & MP ventricular com ondas $\mathrm{P}$ dissociadas \\
\hline 34 & $\begin{array}{l}\text { Ritmo sinusal seguido por estimulação } \\
\text { ventricular }\end{array}$ & BAVT & $\begin{array}{l}\text { Ritmo sinusal seguido por estimulação } \\
\text { ventricular sincronizada }\end{array}$ \\
\hline 35 & MP ventricular com ondas $P$ dissociadas & BAVT & MP ventricular com ondas $P$ dissociadas \\
\hline 36 & MP ventricular com ondas $P$ dissociadas & BAVT & MP ventricular com ondas $P$ dissociadas \\
\hline 37 & MP AV sequencial & $\begin{array}{l}\text { BAVT sem } \\
\text { escape }\end{array}$ & MP AV sequencial \\
\hline 38 & MP AV sequencial & $\begin{array}{l}\text { BAVT sem } \\
\text { escape }\end{array}$ & MP AV sequencial \\
\hline 39 & $\begin{array}{l}\text { Ritmo sinusal seguido por estimulação } \\
\text { ventricular }\end{array}$ & BAVT & $\begin{array}{l}\text { Ritmo sinusal seguido por estimulação } \\
\text { ventricular sincronizada }\end{array}$ \\
\hline 40 & MP ventricular com ondas $\mathrm{P}$ dissociadas & BAVT & MP ventricular com ondas $\mathrm{P}$ dissociadas \\
\hline 41 & MP ventricular com ondas $\mathrm{P}$ dissociadas & BAVT & MP ventricular com ondas $\mathrm{P}$ dissociadas \\
\hline 42 & MP ventricular com ondas $\mathrm{P}$ dissociadas & BAVT & MP ventricular com ondas $\mathrm{P}$ dissociadas \\
\hline 43 & $\begin{array}{l}\text { Ritmo sinusal seguido por estimulação } \\
\text { ventricular }\end{array}$ & BAVT & $\begin{array}{l}\text { Ritmo sinusal seguido por estimulação } \\
\text { ventricular sincronizada }\end{array}$ \\
\hline 44 & MP ventricular com ondas $\mathrm{P}$ dissociadas & BAVT & MP ventricular com ondas $\mathrm{P}$ dissociadas \\
\hline
\end{tabular}




\begin{tabular}{|c|c|c|c|}
\hline № & Ritmo inicial & MP inibido & Ritmo final \\
\hline 45 & MP ventricular com ondas $\mathrm{P}$ dissociadas & $\begin{array}{l}\text { BAVT sem } \\
\text { escape }\end{array}$ & MP ventricular com ondas $P$ dissociadas \\
\hline 46 & MP ventricular com ondas $\mathrm{P}$ dissociadas & - & - \\
\hline 47 & MP ventricular com ondas $P$ dissociadas & BAVT & MP ventricular com ondas $P$ dissociadas \\
\hline 48 & MP AV sequencial & $\begin{array}{l}\text { BAVT sem } \\
\text { escape }\end{array}$ & MP AV sequencial \\
\hline 49 & $\begin{array}{l}\text { Ritmo sinusal seguido por estimulação } \\
\text { ventricular }\end{array}$ & BAV 2:1 & $\begin{array}{l}\text { Ritmo sinusal seguido por estimulação } \\
\text { ventricular sincronizada }\end{array}$ \\
\hline 50 & MP AV sequencial & $\begin{array}{l}\text { BAVT sem } \\
\text { escape }\end{array}$ & MP AV sequencial \\
\hline 51 & $\begin{array}{l}\text { Ritmo sinusal seguido por estimulação } \\
\text { ventricular }\end{array}$ & BAVT & $\begin{array}{l}\text { Ritmo sinusal seguido por estimulação } \\
\text { ventricular sincronizada }\end{array}$ \\
\hline 52 & $\begin{array}{l}\text { Ritmo sinusal seguido por estimulação } \\
\text { ventricular }\end{array}$ & BAVT & $\begin{array}{l}\text { Ritmo sinusal seguido por estimulação } \\
\text { ventricular sincronizada }\end{array}$ \\
\hline 53 & MP AV sequencial & $\begin{array}{l}\text { BAVT sem } \\
\text { escape }\end{array}$ & MP AV sequencial \\
\hline 54 & MP ventricular com ondas $\mathrm{P}$ dissociadas & BAVT & MP ventricular com ondas $P$ dissociadas \\
\hline 55 & MP AV sequencial & BAVT & MP AV sequencial \\
\hline 56 & $\begin{array}{l}\text { Ritmo sinusal seguido por estimulação } \\
\text { ventricular }\end{array}$ & BAVT & $\begin{array}{l}\text { Ritmo sinusal seguido por estimulação } \\
\text { ventricular sincronizada }\end{array}$ \\
\hline 57 & $\begin{array}{l}\text { Ritmo sinusal seguido por estimulação } \\
\text { ventricular }\end{array}$ & BAVT & $\begin{array}{l}\text { Ritmo sinusal seguido por estimulação } \\
\text { ventricular sincronizada }\end{array}$ \\
\hline 58 & MP AV sequencial & $\begin{array}{l}\text { BAVT sem } \\
\text { escape }\end{array}$ & MP AV sequencial \\
\hline 59 & MP AV sequencial & $\begin{array}{l}\text { BAVT sem } \\
\text { escape }\end{array}$ & MP AV sequencial \\
\hline 60 & MP ventricular com ondas $P$ dissociadas & Ritmo sinusal & Ritmo sinusal \\
\hline 61 & MP ventricular com ondas $P$ dissociadas & $\begin{array}{l}\text { BAVT sem } \\
\text { escape }\end{array}$ & MP ventricular com ondas $P$ dissociadas \\
\hline 62 & MP ventricular com ondas $\mathrm{P}$ dissociadas & BAVT & MP ventricular com ondas $P$ dissociadas \\
\hline 63 & MP AV sequencial & BAVT & MP AV sequencial \\
\hline
\end{tabular}

$\mathrm{MP}=$ Marca-passo; $\mathrm{AV}=$ atrioventricular; $\mathrm{BAV}=$ Bloqueio atrioventricular; $\mathrm{BAVT}=$ bloqueio atrioventricular total. 


\section{Anexo N - Características do cabo-eletrodo ventricular direito de acordo com a radiografia torácica}

\begin{tabular}{|c|c|c|c|}
\hline № & $\begin{array}{c}\text { Tipo de cabo- } \\
\text { eletrodo } \\
\text { ventricular }\end{array}$ & $\begin{array}{l}\text { Acesso } \\
\text { ventricular }\end{array}$ & $\begin{array}{c}\text { Posição do cabo-eletrodo } \\
\text { ventricular }\end{array}$ \\
\hline 1 & bipolar & Transvenoso femoral & Septo medio \\
\hline 2 & bipolar & Transvenoso VCS & Septo apical \\
\hline 3 & bipolar & Transvenoso VCS & Septo apical \\
\hline 4 & bipolar & Transvenoso femoral & Septo apical \\
\hline 5 & bipolar & Transvenoso VCS & Ponta \\
\hline 6 & bipolar & Transvenoso femoral & Parede anterior \\
\hline 7 & bipolar & Transvenoso VCS & Via de entrada \\
\hline 8 & bipolar & Transvenoso VCS & Parede anterior \\
\hline 9 & bipolar & Transvenoso VCS & Septo medio \\
\hline 10 & bipolar & Transvenoso VCS & Septo medio \\
\hline 11 & bipolar & Transvenoso femoral & Ponta \\
\hline 12 & bipolar & Transvenoso VCS & Septo apical \\
\hline 13 & bipolar & Transvenoso VCS & Septo apical \\
\hline 14 & bipolar & Transvenoso VCS & Septo medio \\
\hline 15 & bipolar & Epicardico & VD Epicardico - Parede diafragmatica \\
\hline 16 & bipolar & Transvenoso VCS & Ponta \\
\hline 17 & bipolar & Transvenoso VCS & Septo apical \\
\hline 18 & bipolar & Transvenoso VCS & Parede anterior \\
\hline 19 & bipolar & Transvenoso VCS & Septo apical \\
\hline 20 & bipolar & Transvenoso femoral & Septo apical \\
\hline 21 & bipolar & Transvenoso femoral & Ponta \\
\hline 22 & bipolar & Epicardico & VD Epicardico - Parede diafragmatica \\
\hline 23 & bipolar & Transvenoso femoral & Septo apical \\
\hline 24 & bipolar & Transvenoso femoral & Septo medio \\
\hline 25 & bipolar & Transvenoso femoral & Parede diafragmatica \\
\hline 26 & bipolar & Transvenoso VCS & Parede diafragmatica \\
\hline 27 & bipolar & Transvenoso VCS & Septo medio \\
\hline 28 & bipolar & Transvenoso femoral & Septo apical \\
\hline 29 & bipolar & Transvenoso VCS & Septo de saida \\
\hline 30 & bipolar & Transvenoso VCS & Septo medio \\
\hline 31 & bipolar & Transvenoso VCS & Septo medio \\
\hline 32 & bipolar & Transvenoso VCS & Septo de saida \\
\hline 33 & bipolar & Epicardico & VD Epicardico - Parede diafragmatica \\
\hline 34 & bipolar & Transvenoso VCS & Ponta \\
\hline 35 & bipolar & Transvenoso femoral & Septo medio \\
\hline 36 & bipolar & Epicardico & VD Epicardico - Parede diafragmatica \\
\hline 37 & bipolar & Transvenoso VCS & Septo apical \\
\hline 38 & bipolar & Transvenoso VCS & Septo apical \\
\hline 39 & bipolar & Transvenoso VCS & Septo medio \\
\hline 40 & bipolar & Transvenoso VCS & Ponta \\
\hline 41 & bipolar & Transvenoso femoral & Septo medio \\
\hline 42 & bipolar & Transvenoso femoral & Septo medio \\
\hline 43 & bipolar & Transvenoso VCS & Septo medio \\
\hline 44 & bipolar & Transvenoso femoral & Septo medio \\
\hline 45 & bipolar & Epicardico & VD Epicardico - Parede diafragmatica \\
\hline 46 & bipolar & Epicardico & VD Epicardico - Parede diafragmatica \\
\hline 47 & bipolar & Transvenoso femoral & Septo apical \\
\hline 48 & bipolar & Transvenoso VCS & Septo apical \\
\hline 49 & bipolar & Transvenoso VCS & Ponta \\
\hline 50 & unipolar & Transvenoso VCS & Ponta \\
\hline 51 & bipolar & Transvenoso VCS & Parede anterior \\
\hline 52 & bipolar & Epicardico & VD Epicardico - Parede diafragmatica \\
\hline 53 & bipolar & Transvenoso VCS & Septo apical \\
\hline 54 & unipolar & Transvenoso VCS & Septo apical \\
\hline 55 & bipolar & Transvenoso VCS & Septo medio \\
\hline 56 & bipolar & Transvenoso VCS & Via de saida \\
\hline 57 & bipolar & Transvenoso VCS & Ponta \\
\hline 58 & bipolar & Transvenoso VCS & Ponta \\
\hline 59 & bipolar & Transvenoso VCS & Septo apical \\
\hline 60 & bipolar & Transvenoso femoral & Septo de saida \\
\hline 61 & bipolar & Transvenoso VCS & Septo apical \\
\hline 62 & bipolar & Transvenoso VCS & Parede anterior \\
\hline 63 & bipolar & Transvenoso VCS & Septo apical \\
\hline
\end{tabular}




\section{Anexo 0 - Teste de caminhada de seis minutos}

\begin{tabular}{|c|c|c|c|c|}
\hline № & Idade & $\begin{array}{c}\text { Distância } \\
\text { total percorrida } \\
\text { (m) }\end{array}$ & $\begin{array}{c}\text { Distância } \\
\text { predita Iwama } \\
\text { (m) }\end{array}$ & $\begin{array}{l}\text { \% Distância } \\
\text { predita Iwama }\end{array}$ \\
\hline 1 & 18 & 556 & 648,9 & $85,7 \%$ \\
\hline 2 & 25 & 597 & 576,3 & $103,6 \%$ \\
\hline 3 & 22 & 431 & 581,8 & $74,1 \%$ \\
\hline 4 & 19 & 483 & 647,0 & $74,6 \%$ \\
\hline 5 & 26 & 525 & 636,0 & $82,6 \%$ \\
\hline 6 & 2 & Não realizou & Não realizou & Não realizou \\
\hline 7 & 15 & 610 & 592,9 & $102,9 \%$ \\
\hline 8 & 26 & 497 & 574,5 & $86,5 \%$ \\
\hline 9 & 29 & 568 & 568,9 & $99,8 \%$ \\
\hline 10 & 29 & 586 & 567,1 & $103,3 \%$ \\
\hline 11 & 24 & 585 & 576,3 & $101,5 \%$ \\
\hline 12 & 18 & 608 & 647,0 & $94,0 \%$ \\
\hline 13 & 29 & 591 & 568,9 & $103,9 \%$ \\
\hline 14 & 24 & 449 & 578,2 & $77,7 \%$ \\
\hline 15 & 12 & 485 & 600,3 & $80,8 \%$ \\
\hline 16 & 30 & 538 & 628,6 & $85,6 \%$ \\
\hline 17 & 19 & 659 & 583,7 & $112,9 \%$ \\
\hline 18 & 21 & 620 & 583,7 & $106,2 \%$ \\
\hline 19 & 17 & 600 & 585,5 & $102,5 \%$ \\
\hline 20 & 10 & 541 & 663,7 & $81,5 \%$ \\
\hline 21 & 12 & 453 & 661,8 & $68,4 \%$ \\
\hline 22 & 11 & 639 & 663,7 & $96,3 \%$ \\
\hline 23 & 25 & 562 & 576,3 & $97,5 \%$ \\
\hline 24 & 10 & 605 & 602,2 & $100,5 \%$ \\
\hline 25 & 14 & 663 & 654,4 & $101,3 \%$ \\
\hline 26 & 30 & 629 & 565,2 & $111,3 \%$ \\
\hline 27 & 29 & 436 & 568,9 & $76,6 \%$ \\
\hline 28 & 11 & 575 & 602,2 & $95,5 \%$ \\
\hline 29 & 13 & 547 & 598,5 & $91,4 \%$ \\
\hline 30 & 18 & 667 & 650,7 & $102,5 \%$ \\
\hline 31 & 26 & 478 & 574,5 & $83,2 \%$ \\
\hline 32 & 21 & 612 & 583,7 & $104,8 \%$ \\
\hline 33 & 9 & 520 & 605,8 & $85,8 \%$ \\
\hline 34 & 25 & 547 & 636,0 & $86,0 \%$ \\
\hline 35 & 11 & 534 & 661,8 & $80,7 \%$ \\
\hline 36 & 12 & 534 & 598,5 & $89,2 \%$ \\
\hline 37 & 36 & 541 & 554,2 & $97,6 \%$ \\
\hline 38 & 21 & 585 & 581,8 & $100,5 \%$ \\
\hline 39 & 27 & 420 & 572,6 & $73,3 \%$ \\
\hline 40 & 23 & 576 & 641,5 & $89,8 \%$ \\
\hline 41 & 9 & 506 & 665,5 & $76,0 \%$ \\
\hline 42 & 7 & 520 & 669,2 & $77,7 \%$ \\
\hline 43 & 18 & 605 & 650,7 & $93,0 \%$ \\
\hline 44 & 11 & 600 & 600,3 & $99,9 \%$ \\
\hline 45 & 18 & 609 & 587,4 & $103,7 \%$ \\
\hline 46 & 1 & Não realizou & Não realizou & Não realizou \\
\hline 47 & 13 & 537 & 598,5 & $89,7 \%$ \\
\hline 48 & 37 & 448 & 554,2 & $80,8 \%$ \\
\hline 49 & 29 & 760 & 626,7 & $121,3 \%$ \\
\hline 50 & 27 & 503 & 572,6 & $87,8 \%$ \\
\hline 51 & 29 & 432 & 568,9 & $75,9 \%$ \\
\hline 52 & 31 & 493 & 565,2 & $87,2 \%$ \\
\hline 53 & 37 & 548 & 554,2 & $98,9 \%$ \\
\hline 54 & 37 & 591 & 554,2 & $106,6 \%$ \\
\hline 55 & 41 & 436 & 546,8 & $79,7 \%$ \\
\hline 56 & 25 & 427 & 576,3 & $74,1 \%$ \\
\hline 57 & 28 & 452 & 570,8 & $79,2 \%$ \\
\hline 58 & 24 & 480 & 639,7 & $75,0 \%$ \\
\hline 59 & 35 & 557 & 557,9 & $99,8 \%$ \\
\hline 60 & 12 & 658 & 600,3 & $109,6 \%$ \\
\hline 61 & 18 & 535 & 650,7 & $82,2 \%$ \\
\hline 62 & 15 & 643 & 654,4 & $98,3 \%$ \\
\hline 63 & 23 & 370 & 580,0 & $63,8 \%$ \\
\hline
\end{tabular}

$\mathrm{m}=$ metros $; \%=$ porcentagem 


\section{Anexo P - Escores dos domínios do Questionário SF-36}

\begin{tabular}{|c|c|c|c|c|c|c|c|c|}
\hline № & $\begin{array}{l}\text { Capacidade } \\
\text { funcional }\end{array}$ & $\begin{array}{l}\text { Aspectos } \\
\text { físicos }\end{array}$ & Dor & $\begin{array}{c}\text { Estado } \\
\text { geral } \\
\text { da saúde }\end{array}$ & Vitalidade & $\begin{array}{c}\text { Aspectos } \\
\text { sociais }\end{array}$ & $\begin{array}{l}\text { Aspectos } \\
\text { emocionais }\end{array}$ & $\begin{array}{l}\text { Saúde } \\
\text { mental }\end{array}$ \\
\hline 1 & 95,0 & 100,0 & 77,5 & 60,0 & 60,0 & 100,0 & 100,0 & 84,0 \\
\hline 2 & 95,0 & 100,0 & 67,5 & 95,0 & 80,0 & 75,0 & 66,7 & 80,0 \\
\hline 3 & 80,0 & 100,0 & 100,0 & 80,0 & 70,0 & 100,0 & 100,0 & 84,0 \\
\hline 4 & 50,0 & 75,0 & 77,5 & 65,0 & 40,0 & 75,0 & 100,0 & 44,0 \\
\hline 5 & 90,0 & 50,0 & 77,5 & 80,0 & 70,0 & 100,0 & 100,0 & 88,0 \\
\hline $6^{*}$ & - & - & - & - & - & - & - & - \\
\hline 7 & 75,0 & 100,0 & 55,0 & 85,0 & 80,0 & 100,0 & 100,0 & 80,0 \\
\hline 8 & 85,0 & 100,0 & 77,5 & 95,0 & 90,0 & 100,0 & 100,0 & 92,0 \\
\hline 9 & 80,0 & 100,0 & 87,5 & 80,0 & 75,0 & 75,0 & 33,3 & 80,0 \\
\hline 10 & 95,0 & 100,0 & 100,0 & 80,0 & 80,0 & 87,5 & 100,0 & 76,0 \\
\hline 11 & 90,0 & 0,0 & 67,5 & 90,0 & 75,0 & 100,0 & 100,0 & 88,0 \\
\hline 12 & 35,0 & 25,0 & 77,5 & 75,0 & 80,0 & 87,5 & 0,0 & 80,0 \\
\hline 13 & 95,0 & 100,0 & 45,0 & 75,0 & 60,0 & 100,0 & 100,0 & 80,0 \\
\hline 14 & 75,0 & 0,0 & 67,5 & 90,0 & 45,0 & 50,0 & 0,0 & 28,0 \\
\hline $15^{\star}$ & - & - & - & - & - & - & - & - \\
\hline 16 & 95,0 & 100,0 & 100,0 & 100,0 & 85,0 & 75,0 & 100,0 & 88,0 \\
\hline 17 & 95,0 & 100,0 & 90,0 & 100,0 & 80,0 & 100,0 & 100,0 & 80,0 \\
\hline 18 & 100,0 & 75,0 & 90,0 & 95,0 & 95,0 & 100,0 & 100,0 & 92,0 \\
\hline 19 & 85,0 & 100,0 & 75,0 & 90,0 & 55,0 & 50,0 & 100,0 & 56,0 \\
\hline $20^{*}$ & - & - & - & - & - & - & - & - \\
\hline $21^{*}$ & - & - & - & - & - & - & - & - \\
\hline $22^{*}$ & - & - & - & - & - & - & - & - \\
\hline 23 & 88,9 & 100,0 & 57,5 & 50,0 & 50,0 & 100,0 & 100,0 & 64,0 \\
\hline $24^{*}$ & - & - & - & - & - & - & - & - \\
\hline 25 & 90,0 & 100,0 & 100,0 & 70,0 & 80,0 & 100,0 & 100,0 & 80,0 \\
\hline 26 & 95,0 & 100,0 & 70,0 & 60,0 & 50,0 & 75,0 & 100,0 & 44,0 \\
\hline 27 & 100,0 & 100,0 & 100,0 & 100,0 & 80,0 & 100,0 & 100,0 & 60,0 \\
\hline $28^{*}$ & - & - & - & - & - & - & - & - \\
\hline $29^{*}$ & - & - & - & - & - & - & - & - \\
\hline 30 & 90,0 & 50,0 & 22,5 & 75,0 & 40,0 & 12,5 & 0,0 & 28,0 \\
\hline 31 & 55,0 & 100,0 & 90,0 & 90,0 & 65,0 & 87,5 & 100,0 & 68,0 \\
\hline 32 & 100,0 & 100,0 & 80,0 & 90,0 & 70,0 & 100,0 & 100,0 & 96,0 \\
\hline $33^{*}$ & - & - & - & - & - & - & - & - \\
\hline 34 & 65,0 & 100,0 & 77,5 & 60,0 & 60,0 & 100,0 & 100,0 & 80,0 \\
\hline $35^{\star}$ & - & - & - & - & - & - & - & - \\
\hline $36^{*}$ & - & - & - & - & - & - & - & - \\
\hline 37 & 20,0 & 0,0 & 0,0 & 5,0 & 50,0 & 0,0 & 0,0 & 68,0 \\
\hline 38 & 75,0 & 100,0 & 57,5 & 65,0 & 60,0 & 37,5 & 66,7 & 44,0 \\
\hline 39 & 80,0 & 100,0 & 67,5 & 60,0 & 65,0 & 62,5 & 100,0 & 76,0 \\
\hline 40 & 90,0 & 100,0 & 100,0 & 75,0 & 80,0 & 100,0 & 100,0 & 88,0 \\
\hline $41^{*}$ & - & - & - & - & - & - & - & - \\
\hline $42^{*}$ & - & - & - & - & - & - & - & - \\
\hline 43 & 90,0 & 50,0 & 100,0 & 85,0 & 65,0 & 100,0 & 33,3 & 96,0 \\
\hline $44^{*}$ & - & - & - & - & - & - & - & - \\
\hline 45 & 80,0 & 100,0 & 77,5 & 80,0 & 75,0 & 75,0 & 33,3 & 80,0 \\
\hline $46^{*}$ & - & - & - & - & - & - & - & - \\
\hline $47^{\star}$ & - & - & - & - & - & - & - & - \\
\hline 48 & 80,0 & 75,0 & 57,5 & 40,0 & 65,0 & 62,5 & 66,7 & 80,0 \\
\hline 49 & 100,0 & 100,0 & 90,0 & 70,0 & 75,0 & 100,0 & 100,0 & 88,0 \\
\hline 50 & 90,0 & 0,0 & 12,5 & 25,0 & 30,0 & 62,5 & 100,0 & 52,0 \\
\hline 51 & 50,0 & 100,0 & 100,0 & 85,0 & 75,0 & 100,0 & 100,0 & 80,0 \\
\hline 52 & 90,0 & 100,0 & 55,0 & 75,0 & 55,0 & 62,5 & 100,0 & 76,0 \\
\hline 53 & 100,0 & 100,0 & 100,0 & 75,0 & 65,0 & 100,0 & 100,0 & 76,0 \\
\hline 54 & 100,0 & 100,0 & 100,0 & 75,0 & 75,0 & 100,0 & 100,0 & 84,0 \\
\hline 55 & 85,0 & 100,0 & 67,5 & 100,0 & 60,0 & 75,0 & 100,0 & 68,0 \\
\hline 56 & 100,0 & 100,0 & 100,0 & 55,0 & 85,0 & 100,0 & 100,0 & 88,0 \\
\hline 57 & 95,0 & 25,0 & 90,0 & 100,0 & 70,0 & 50,0 & 100,0 & 84,0 \\
\hline 58 & 80,0 & 75,0 & 32,5 & 70,0 & 60,0 & 75,0 & 66,7 & 64,0 \\
\hline 59 & 90,0 & 100,0 & 100,0 & 60,0 & 55,0 & 87,5 & 100,0 & 76,0 \\
\hline 60 & 65 & 100,0 & 90,0 & 85,0 & 90,0 & 50,0 & 100,0 & 92,0 \\
\hline 61 & 100,0 & 100,0 & 67,5 & 75,0 & 65,0 & 100,0 & 100,0 & 80,0 \\
\hline 62 & 75,0 & 75,0 & 67,5 & 20,0 & 70,0 & 62,5 & 100,0 & 64,0 \\
\hline 63 & 75,0 & 75,0 & 67,5 & 20,0 & 70,0 & 62,5 & 100,0 & 64,0 \\
\hline
\end{tabular}

$\left(^{\star}\right)=$ Pacientes avaliados pelo CHQ-PF50; SF-36= Medical Outcomes Study 36 - Item Short-Form Health Survey 


\begin{tabular}{|c|c|c|}
\hline № & $\begin{array}{c}\text { Sumário } \\
\text { físico }\end{array}$ & $\begin{array}{c}\text { Sumário } \\
\text { mental }\end{array}$ \\
\hline 1 & 83,1 & 86,0 \\
\hline 2 & 89,4 & 75,4 \\
\hline 3 & 90,0 & 88,5 \\
\hline 4 & 66,9 & 64,8 \\
\hline 5 & 74,4 & 89,5 \\
\hline $6^{*}$ & - & - \\
\hline 7 & 78,8 & 90,0 \\
\hline 8 & 89,4 & 95,5 \\
\hline 9 & 86,9 & 65,8 \\
\hline 10 & 93,8 & 85,9 \\
\hline 11 & 61,9 & 90,8 \\
\hline 12 & 53,1 & 61,9 \\
\hline 13 & 78,8 & 85,0 \\
\hline 14 & 58,1 & 30,8 \\
\hline $15^{*}$ & - & - \\
\hline 16 & 98,8 & 87,0 \\
\hline 17 & 96,3 & 90,0 \\
\hline 18 & 90,0 & 96,8 \\
\hline 19 & 87,5 & 65,3 \\
\hline $20^{*}$ & - & - \\
\hline $21^{*}$ & - & - \\
\hline $22^{*}$ & - & - \\
\hline 23 & 74,1 & 78,5 \\
\hline $24^{*}$ & - & - \\
\hline 25 & 90,0 & 90,0 \\
\hline 26 & 81,3 & 67,3 \\
\hline 27 & 100,0 & 85,0 \\
\hline $28^{*}$ & - & - \\
\hline $29^{*}$ & - & - \\
\hline 30 & 59,4 & 20,1 \\
\hline 31 & 83,8 & 80,1 \\
\hline 32 & 92,5 & 91,5 \\
\hline $33^{*}$ & - & - \\
\hline 34 & 75,6 & 85,0 \\
\hline $35^{*}$ & - & - \\
\hline $36^{*}$ & - & - \\
\hline 37 & 6,3 & 29,5 \\
\hline 38 & 74,4 & 52,0 \\
\hline 39 & 76,9 & 75,9 \\
\hline 40 & 91,3 & 92,0 \\
\hline $41^{*}$ & - & - \\
\hline $42^{*}$ & - & - \\
\hline 43 & 81,3 & 76,4 \\
\hline $44^{*}$ & - & - \\
\hline 45 & 84,4 & 65,8 \\
\hline $46^{*}$ & - & - \\
\hline $47^{*}$ & - & - \\
\hline 48 & 63,1 & 68,5 \\
\hline 49 & 90,0 & 90,8 \\
\hline 50 & 31,9 & 61,1 \\
\hline 51 & 83,8 & 88,8 \\
\hline 52 & 80,0 & 73,4 \\
\hline 53 & 93,8 & 85,3 \\
\hline 54 & 93,8 & 89,8 \\
\hline 55 & 88,1 & 75,8 \\
\hline 56 & 88,8 & 93,3 \\
\hline 57 & 77,5 & 78,0 \\
\hline 58 & 64,4 & 66,4 \\
\hline 59 & 87,5 & 79,6 \\
\hline 60 & 85,0 & 83,0 \\
\hline 61 & 85,6 & 86,3 \\
\hline 62 & 59,4 & 74,1 \\
\hline 63 & 59,4 & 74,1 \\
\hline
\end{tabular}


Anexo Q - Escores dos domínios do Questionário CHQ-PF50

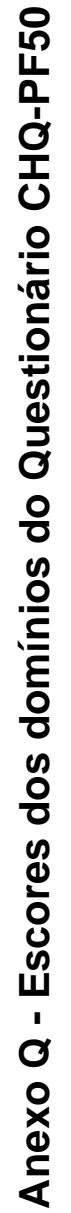

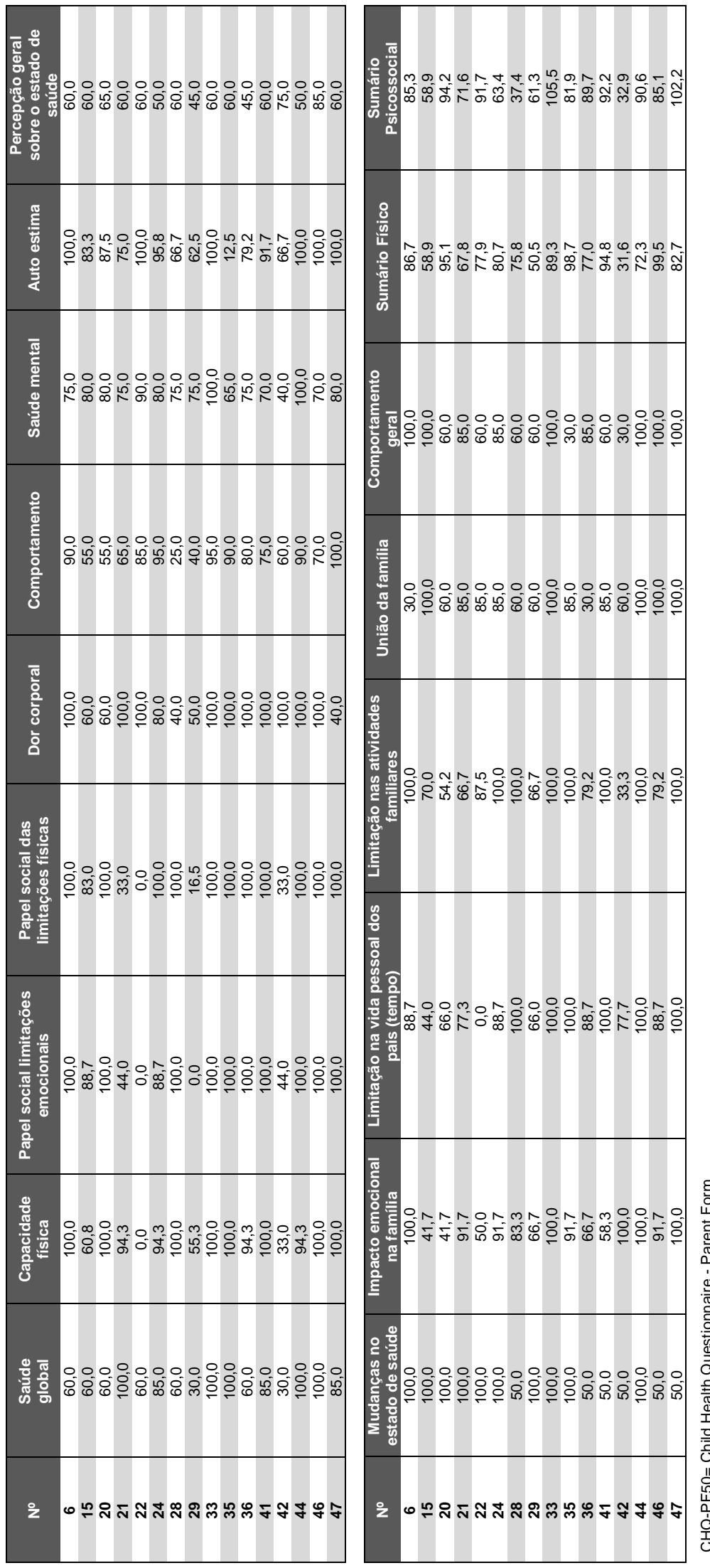


Anexo R - Medidas ecocardiográficas das dimensões das cavidades cardíacas, volumes ventriculares e função sistólica (Modo M e Modo bidimensional)

\begin{tabular}{|c|c|c|c|c|c|c|c|c|c|c|c|}
\hline № & $\begin{array}{l}\text { Idade } \\
\text { (anos) }\end{array}$ & $\begin{array}{l}\text { Septo } \\
(\mathrm{mm})\end{array}$ & $\begin{array}{l}\text { PPVE } \\
(\mathrm{mm})\end{array}$ & $\begin{array}{c}\mathrm{AE} \\
(\mathrm{mm})\end{array}$ & $\begin{array}{c}\text { Ao } \\
(\mathrm{mm})\end{array}$ & $\begin{array}{c}\text { VDVE } \\
(\mathrm{ml})\end{array}$ & $\begin{array}{c}\text { VSVE } \\
(\mathrm{ml})\end{array}$ & $\begin{array}{l}\text { DDVE } \\
(\mathrm{mm})\end{array}$ & $\begin{array}{l}\text { DSVE } \\
(\mathrm{mm})\end{array}$ & $\begin{array}{c}\text { FEVE (S) } \\
(\%)\end{array}$ & $\begin{array}{c}\text { PSVD } \\
(\mathrm{mmHg})\end{array}$ \\
\hline 1 & 18 & 8,0 & 11,0 & - & - & - & 56,0 & 53 & 34 & 64 & 24,0 \\
\hline 2 & 25 & 8,0 & 7,0 & 27,0 & 30,0 & 110,0 & 37,0 & 54 & 33 & 62 & 26,0 \\
\hline 3 & 22 & 10,0 & 10,0 & 23,0 & 24,0 & 48,0 & 19,0 & 44 & 29 & 57 & 23,0 \\
\hline 4 & 19 & 8,0 & 8,0 & - & 36,0 & - & - & 55 & 38 & 49 & 53,0 \\
\hline 5 & 26 & 11,0 & 10,0 & 32,0 & 29,0 & 106,0 & 63,0 & 48 & 30 & 44 & 29,0 \\
\hline 6 & 2 & 5,0 & 5,0 & 15,0 & 16,0 & - & - & 27 & 17 & 60 & 30,0 \\
\hline 7 & 15 & 8,0 & 7,0 & 29,0 & 26,0 & 72,0 & 35,0 & 46 & 29 & 56 & 27,0 \\
\hline 8 & 26 & 8,0 & 8,0 & 31,0 & 25,0 & 122,0 & 76,0 & 49 & 34 & 39 & 35,0 \\
\hline 9 & 29 & 8,0 & 9,0 & 34,0 & 33,0 & 52,0 & 31,0 & 56 & 39 & 48 & 29,0 \\
\hline 10 & 29 & 6,0 & 7,0 & 29,0 & 27,0 & - & - & 50 & 30 & 51 & - \\
\hline 11 & 24 & 8,0 & 8,0 & 34,0 & 30,0 & 143,0 & 58,0 & 51 & 34 & 56 & 16,0 \\
\hline 12 & 18 & 7,0 & 8,0 & 28,0 & 27,0 & - & - & 46 & 27 & 59 & 27,0 \\
\hline 13 & 29 & 7,0 & 7,0 & - & - & 65,0 & 27,0 & 43 & 30 & 63 & 30,0 \\
\hline 14 & 24 & 8,0 & 8,0 & 24,0 & 22,0 & 50,0 & 23,0 & 46 & 27 & 60 & 31,0 \\
\hline 15 & 12 & 6,1 & 5,6 & - & 30,0 & 76,0 & 35,0 & 44,5 & 30,1 & 58 & 31,0 \\
\hline 16 & 30 & 8,0 & 7,0 & 36,0 & 33,0 & 91,0 & 49,0 & 50 & 30 & 54 & 25,0 \\
\hline 17 & 19 & 8,0 & 7,0 & 28,0 & 24,0 & 106,0 & 54,0 & 43 & 27 & 49 & 25,0 \\
\hline 18 & 21 & 8,0 & 8,0 & 27,0 & 24,0 & 66,0 & 31,0 & 48 & 33 & 57 & 27,0 \\
\hline 19 & 17 & - & - & - & - & - & - & 48 & 29 & 56 & - \\
\hline 20 & 10 & 8,6 & 6,1 & - & - & 47,0 & 14,0 & 42,3 & 28,1 & 61 & 35,0 \\
\hline 21 & 12 & 5,0 & 6,0 & 24,0 & 29,0 & 47,0 & 19,0 & 42 & 25,7 & 54 & 34,0 \\
\hline 22 & 11 & 7,0 & 7,0 & 30,0 & 21,0 & 72,0 & 37,0 & 45 & 33 & 52 & 35,0 \\
\hline 23 & 25 & 7,0 & 8,0 & 34,0 & 31,0 & 95,0 & 51,0 & 53 & 31 & 56 & 27,0 \\
\hline 24 & 10 & 8,0 & 7,0 & 24,0 & 22,0 & 55,0 & 26,0 & 44 & 30 & 54 & 27,0 \\
\hline 25 & 14 & - & - & - & - & - & - & 46 & 25 & 55 & - \\
\hline 26 & 30 & 7,0 & 8,0 & & & 65,0 & 25,0 & 50 & 33 & 57 & 30,0 \\
\hline 27 & 29 & 7,0 & 7,0 & 29,0 & 28,0 & 117,0 & 56,0 & 51 & 32 & 51 & 31,0 \\
\hline 28 & 11 & 6,1 & 6,0 & 26,0 & 20,0 & 48,0 & 21,0 & 44 & 29 & 58 & 37,0 \\
\hline 29 & 13 & 8,0 & 8,0 & 31,0 & 23,0 & 89,0 & 57,0 & 50 & 35 & 38 & 27,0 \\
\hline 30 & 18 & - & - & - & - & 57,0 & 27,0 & 54 & 36 & 53 & - \\
\hline 31 & 26 & 7,0 & 7,0 & 30,0 & 27,0 & 77,0 & 35,0 & 54 & 36 & 62 & 29,0 \\
\hline 32 & 21 & 8,0 & 6,0 & 27,0 & 28,0 & 59,0 & 24,0 & 48 & 23 & 59 & 21,0 \\
\hline 33 & 9 & 6,4 & 6,1 & 26,0 & 27,0 & 59,0 & 27,0 & 44,3 & 30,5 & 58 & 22,0 \\
\hline 34 & 25 & 10,0 & 8,0 & 28,0 & 31,0 & 94,0 & 56,0 & 55 & 40 & 45 & 25,0 \\
\hline 35 & 11 & 33,0 & 9,0 & 7,0 & 28,0 & 99,0 & 52,0 & 28 & 48 & 52 & 24,0 \\
\hline 36 & 12 & 10,0 & 9,0 & - & - & 53,0 & 22,0 & 49 & 33 & 61 & 32,0 \\
\hline 37 & 36 & 9,0 & 9,0 & 35,0 & 25,0 & 95,0 & 55,0 & 55 & 32 & 52 & 32,0 \\
\hline 38 & 21 & 11,0 & 8,0 & 33,0 & 30,0 & 93,0 & 38,0 & 58 & 33 & 58 & 22,0 \\
\hline 39 & 27 & 8,0 & 8,0 & 42,0 & 30,0 & 126,0 & 80,0 & 41 & 24 & 29 & 26,0 \\
\hline 40 & 23 & 12,0 & 12,0 & 38,0 & 31,0 & 121,0 & 38,0 & 51 & 29 & 60 & 37,0 \\
\hline 41 & 9 & 4,5 & 4,5 & - & - & 39,0 & 14,0 & 41 & 28,3 & 64 & 33,0 \\
\hline 42 & 7 & 5,6 & 6,9 & 22,0 & 19,0 & 29,0 & 12,0 & 36,3 & 22,6 & 52 & 30,0 \\
\hline 43 & 18 & 8,0 & 8,0 & 32,0 & 28,0 & 84,0 & 44,0 & 50 & 35 & 54 & 35,0 \\
\hline 44 & 11 & - & - & - & - & - & - & 45,4 & 27,5 & 62 & - \\
\hline 45 & 18 & - & - & - & - & - & - & 46 & 28 & 57 & - \\
\hline 46 & 1 & 4,4 & 4,4 & 12,0 & 9,0 & 20,0 & 8,0 & 18 & 12 & 60 & - \\
\hline 47 & 13 & 5,0 & 6,0 & 23,0 & 22,0 & 41,0 & 16,0 & 40 & 25 & 61 & 27,0 \\
\hline 48 & 37 & 11,0 & 7,0 & 31,0 & 26,0 & 61,0 & 25,0 & 48 & 30 & 57 & 21,0 \\
\hline 49 & 29 & - & - & - & - & - & - & 54 & 34 & 56 & - \\
\hline 50 & 27 & 8,0 & 7,0 & 32,0 & 32,0 & 95,0 & 53,0 & 53 & & 52 & 29,0 \\
\hline 51 & 29 & 7,0 & 7,0 & 35,0 & 34,0 & 100,0 & 61,0 & 46 & 30 & 49 & 26,0 \\
\hline 52 & 31 & 7,0 & 9,0 & - & - & 81,0 & 27,0 & 43 & 27 & 56 & 29,0 \\
\hline 53 & 37 & 18,0 & 11,0 & - & - & 133,0 & 83,0 & 54 & 36 & 33 & 23,0 \\
\hline 54 & 37 & 8,0 & 8,0 & 26,0 & 31,0 & 83,0 & 27,0 & 45 & 29 & 64 & 24,0 \\
\hline 55 & 41 & 10,0 & 10,0 & 30,0 & 25,0 & 68,0 & 38,0 & 45 & 24 & 60 & 24,0 \\
\hline 56 & 25 & 8,0 & 7,0 & 27,0 & 27,0 & 49,0 & 24,0 & 50 & 30 & 56 & 32,0 \\
\hline
\end{tabular}




\begin{tabular}{|c|c|c|c|c|c|c|c|c|c|c|c|}
\hline № & $\begin{array}{c}\text { Idade } \\
\text { (anos) }\end{array}$ & $\begin{array}{c}\text { Septo } \\
(\mathbf{m m})\end{array}$ & $\begin{array}{c}\text { PPVE } \\
(\mathbf{m m})\end{array}$ & $\begin{array}{c}\text { AE } \\
(\mathbf{m m})\end{array}$ & $\begin{array}{c}\text { Ao } \\
(\mathbf{m m})\end{array}$ & $\begin{array}{c}\text { VDVE } \\
(\mathbf{m l})\end{array}$ & $\begin{array}{c}\text { VSVE } \\
(\mathbf{m l})\end{array}$ & $\begin{array}{c}\text { DDVE } \\
(\mathbf{m m})\end{array}$ & $\begin{array}{c}\text { DSVE } \\
(\mathbf{m m})\end{array}$ & $\begin{array}{c}\text { FEVE (S) } \\
(\%)\end{array}$ & $\begin{array}{c}\text { PSVD } \\
(\mathbf{m m H g})\end{array}$ \\
\hline 57 & 28 & 7,0 & 7,0 & 27,0 & 24,0 & 80,0 & 40,0 & 50 & 33 & 54 & $-60,0$ \\
58 & 24 & 10,0 & 9,0 & 33,0 & 29,0 & 126,0 & 40,0 & 59 & 37 & 61 & 26,0 \\
59 & 35 & 8,0 & 7,0 & 26,0 & 26,0 & 76,0 & 47,0 & 47 & 30 & 51 & 27,0 \\
60 & 12 & 8,0 & 8,0 & 29,0 & 29,0 & 58,0 & 27,0 & 45 & 28 & 55 & 34,0 \\
61 & 18 & 8,0 & 10,0 & 35,0 & 32,0 & 66,0 & 31,0 & 48 & 31 & 61 & 28,0 \\
62 & 15 & 8,0 & 8,0 & 39,0 & 37,0 & 164,0 & 91,0 & 64 & 44 & 54 & 32,0 \\
63 & 23 & 7,0 & 7,0 & 30,0 & 23,0 & 66,0 & 37,0 & 54 & 33 & 58 & 30,0 \\
\hline
\end{tabular}

$\mathrm{SIV}=$ septo interventricular; $\mathrm{PPVE}=$ parede posterior do ventrículo esquerdo; $\mathrm{AE}=$ átrio esquerdo; $\mathrm{Ao}=\mathrm{aorta}$; VDVE = volume diastólico do ventrículo esquerdo; VSVE = volume sistólico do ventrículo esquerdo;

DDVE = diâmetro diastólico do ventrículo esquerdo; DSVE = diâmetro sistólico do ventrículo esquerdo

VE = ventrículo esquerdo; FEVE = fração de ejeção do ventrículo esquerdo pelo Simpson;

$(\%)=$ porcentagem; PSVD = pressão sistólica do ventrículo direito; $\mathrm{mm}=$ milímetros;

$\mathrm{mL}=$ mililitros; $\mathrm{mmHg}=$ milimetros de mercúrio 
Anexo S - Avaliação de sincronia cardíaca intra e interventricular ao Doppler tecidual

\begin{tabular}{|c|c|c|}
\hline № & $\begin{array}{l}\text { Atraso eletromecânico intraventricular } \\
\qquad(\mathrm{ms})\end{array}$ & $\begin{array}{l}\text { Atraso eletromecânico interventricular } \\
\text { (ms) }\end{array}$ \\
\hline 1 & 47 & 74 \\
\hline 2 & 52 & 78 \\
\hline 3 & 60 & 81 \\
\hline 4 & 72 & 110 \\
\hline 5 & 55 & 94 \\
\hline 6 & 48 & 67 \\
\hline 7 & 67 & 106 \\
\hline 8 & 48 & 69 \\
\hline 9 & 55,3 & 111 \\
\hline 10 & 89,7 & 102,1 \\
\hline 11 & 109 & 114 \\
\hline 12 & 57 & 64 \\
\hline 13 & 30,3 & 86,7 \\
\hline 14 & 78,7 & 104,4 \\
\hline 15 & 70,7 & 97,7 \\
\hline 16 & 84 & 144 \\
\hline 17 & 49,4 & 132,6 \\
\hline 18 & 195 & 263 \\
\hline 19 & 88 & 139 \\
\hline 20 & 98,6 & 129 \\
\hline 21 & 15 & 61 \\
\hline 22 & 22 & 64 \\
\hline 23 & 213,9 & 338,5 \\
\hline 24 & 82 & 146 \\
\hline 25 & 113 & 208 \\
\hline 26 & 21 & 95 \\
\hline 27 & 33 & 111,4 \\
\hline 28 & 132,3 & 187,3 \\
\hline 29 & 175 & 184,3 \\
\hline 30 & 242 & 396 \\
\hline 31 & 53 & 129,7 \\
\hline 32 & 40,7 & 90,7 \\
\hline 33 & 37,7 & 67 \\
\hline 34 & 135 & 187 \\
\hline 35 & 77,7 & 128,1 \\
\hline 36 & 22,6 & 83,9 \\
\hline 37 & 100 & 178,6 \\
\hline 38 & 166,6 & 307,2 \\
\hline 39 & 205,3 & 342,6 \\
\hline 40 & 49 & 87 \\
\hline 41 & 41 & 76 \\
\hline 42 & 110 & 117 \\
\hline 43 & 49 & 87 \\
\hline 44 & 176 & 271 \\
\hline 45 & 288 & 457 \\
\hline 46 & 48 & 84 \\
\hline 47 & 92 & 115 \\
\hline 48 & 45 & 61 \\
\hline 49 & 67 & 105 \\
\hline 50 & 67 & 115 \\
\hline 51 & 93,6 & 111,2 \\
\hline 52 & 138,3 & 211,4 \\
\hline 53 & 69 & 115 \\
\hline 54 & 56 & 94 \\
\hline 55 & 79,3 & 162,3 \\
\hline 56 & 100,7 & 175 \\
\hline 57 & 91,4 & 180,4 \\
\hline 58 & 63,6 & 115 \\
\hline 59 & 54 & 94 \\
\hline 60 & 47 & 90 \\
\hline 61 & 180 & 377 \\
\hline 62 & 45 & 74 \\
\hline 63 & 61 & 94 \\
\hline
\end{tabular}



Anexo T - Valores laboratoriais dos anticorpos de doença
reumatológica autoimune dosados nos pacientes do estudo

\begin{tabular}{|c|c|c|c|c|c|c|}
\hline № & $\begin{array}{c}\text { Anti-RNP } \\
\text { (Ul/ml) }\end{array}$ & $\begin{array}{l}\text { Anti-SM } \\
\text { (Ul/ml) }\end{array}$ & $\begin{array}{c}\text { Anti-RO/SS-A } \\
(\mathrm{Ul} / \mathrm{ml})\end{array}$ & $\begin{array}{c}\text { Anti-LA/SS-B } \\
\text { (UI/ml) }\end{array}$ & $\begin{array}{c}\text { Anti-RO52 } \\
\text { (Ul/ml) }\end{array}$ & $\begin{array}{c}\text { Anti-RO60 } \\
\text { (Ul/ml) }\end{array}$ \\
\hline 1 & 5 & 5 & 6 & 3 & 2 & 1 \\
\hline 2 & 4 & 6 & 3 & 3 & 1 & 3 \\
\hline 3 & 5 & 4 & 4 & 3 & 1 & 2 \\
\hline 4 & 7 & 5 & 11 & 3 & 2 & 3 \\
\hline 5 & 10 & 4 & 3 & 4 & 1 & 3 \\
\hline 6 & 6 & 4 & 8 & 3 & 2 & 3 \\
\hline 7 & 7 & 3 & 4 & 3 & 1 & 2 \\
\hline 8 & 81 & 3 & 3 & 2 & 1 & 2 \\
\hline 9 & 7 & 6 & 3 & 3 & 2 & 2 \\
\hline 10 & 5 & 4 & 3 & 2 & 2 & 1 \\
\hline 11 & 19 & 4 & 3 & 2 & 2 & 2 \\
\hline 12 & 4 & 3 & 3 & 10 & 2 & 1 \\
\hline 13 & 6 & 4 & 3 & 6 & 4 & 2 \\
\hline 14 & 10 & 5 & 4 & 3 & 9 & 2 \\
\hline $\begin{array}{l}15 \\
15\end{array}$ & 11 & 4 & 5 & 6 & 3 & 2 \\
\hline 16 & 9 & 5 & 3 & 2 & 1 & 2 \\
\hline 17 & 5 & 4 & 5 & 4 & 1 & 2 \\
\hline 18 & 4 & 3 & 4 & 3 & 1 & 2 \\
\hline 19 & & & & & 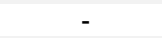 & \\
\hline 20 & 5 & 3 & 4 & 3 & 3 & 2 \\
\hline 21 & 6 & 4 & 3 & 3 & 5 & 2 \\
\hline 22 & 7 & 5 & 4 & 3 & 2 & 1 \\
\hline 23 & 6 & 3 & 4 & 2 & 1 & 2 \\
\hline 24 & 8 & 5 & 4 & 3 & 1 & 1 \\
\hline 25 & 5 & 4 & 4 & 2 & 1 & 1 \\
\hline 26 & 5 & 4 & 4 & 3 & 1 & 1 \\
\hline 27 & 5 & 4 & 3 & 3 & 5 & 2 \\
\hline 28 & 11 & 7 & 3 & 3 & 1 & 4 \\
\hline 29 & 7 & 4 & 4 & 4 & 4 & 2 \\
\hline 30 & 8 & 4 & 4 & 3 & 1 & 2 \\
\hline 31 & 4 & 3 & 3 & 2 & 1 & 1 \\
\hline 32 & 28 & 11 & 4 & 3 & 3 & 5 \\
\hline 33 & 13 & 8 & 5 & 4 & 4 & 3 \\
\hline 34 & 5 & 3 & 4 & 3 & 2 & 1 \\
\hline 35 & 5 & 4 & 4 & 3 & 9 & 4 \\
\hline 36 & 8 & 5 & 3 & 3 & 1 & 3 \\
\hline 37 & 8 & 6 & 4 & 4 & 3 & 1 \\
\hline 38 & 5 & 4 & 3 & 2 & 1 & 1 \\
\hline 39 & 7 & 4 & 4 & 3 & 1 & 2 \\
\hline 40 & 4 & 3 & 4 & 3 & 1 & 2 \\
\hline 41 & 13 & 11 & 7 & 5 & 2 & 2 \\
\hline 42 & 7 & 9 & 6 & 4 & 3 & 6 \\
\hline 43 & 3 & 4 & 4 & 3 & 1 & 1 \\
\hline 44 & 6 & 4 & 3 & 3 & 1 & 2 \\
\hline 45 & 6 & 6 & 6 & 3 & 1 & 1 \\
\hline 46 & - & - & 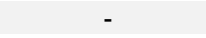 & - & - & - \\
\hline 47 & 5 & 4 & 3 & 3 & 4 & 6 \\
\hline 48 & 7 & 5 & 3 & 4 & 1 & 3 \\
\hline 49 & 2 & 3 & 3 & 2 & 4 & 2 \\
\hline 50 & 6 & 5 & 3 & 3 & 1 & 3 \\
\hline 51 & 9 & 6 & 4 & 3 & 2 & 4 \\
\hline 52 & 8 & 4 & 4 & 20 & 4 & 2 \\
\hline 53 & 4 & 3 & 4 & 2 & 1 & 1 \\
\hline 54 & 4 & 3 & 4 & 4 & 1 & 1 \\
\hline 55 & 6 & 4 & 3 & 4 & 3 & 2 \\
\hline 56 & 5 & 5 & 3 & 2 & 1 & 1 \\
\hline 57 & 9 & 6 & 4 & 5 & 2 & 4 \\
\hline 58 & 14 & 6 & 7 & 3 & 4 & 2 \\
\hline 59 & 6 & 5 & 3 & 7 & 1 & 2 \\
\hline 60 & 7 & 5 & 7 & 3 & 3 & 5 \\
\hline 61 & 9 & 7 & 3 & 3 & 2 & 2 \\
\hline 62 & 5 & 4 & 4 & 3 & 2 & 2 \\
\hline 63 & 7 & 4 & 4 & 5 & 2 & 2 \\
\hline
\end{tabular}

$\mathrm{UI}=$ Unidade Internacional; $\mathrm{mL}=$ mililitros 
Anexo U- Valores laboratoriais dos anticorpos de doença reumatológica autoimune dosados nas mães dos pacientes do estudo

\begin{tabular}{|c|c|c|c|c|c|c|}
\hline № & $\begin{array}{c}\text { Anti-RNP } \\
\text { (Ul/ml) }\end{array}$ & $\begin{array}{l}\text { Anti-SM } \\
\text { (Ul/ml) }\end{array}$ & $\begin{array}{c}\text { Anti-RO/SS-A } \\
\text { (Ul/ml) }\end{array}$ & $\begin{array}{c}\text { Anti-LA/SS-B } \\
(\mathrm{Ul} / \mathrm{ml})\end{array}$ & $\begin{array}{c}\text { Anti-RO52 } \\
\text { (Ul/ml) }\end{array}$ & $\begin{array}{c}\text { Anti-RO60 } \\
\text { (Ul/ml) }\end{array}$ \\
\hline 1 & 6 & 5 & 3 & 3 & 2 & 2 \\
\hline 2 & 3 & 5 & 3 & 2 & 2 & 2 \\
\hline 3 & 5 & 3 & 4 & 2 & 2 & 1 \\
\hline 4 & 13 & 5 & 148 & 103 & 405 & 383 \\
\hline 5 & 5 & 4 & 4 & 3 & 2 & 1 \\
\hline 6 & - & - & - & - & - & - \\
\hline 7 & 7 & 4 & 4 & 3 & 4 & 3 \\
\hline 8 & 16 & 13 & 4 & 5 & 2 & 2 \\
\hline 9 & 6 & 4 & 3 & 3 & 2 & 2 \\
\hline 10 & 3 & 4 & 3 & 5 & 1 & 2 \\
\hline 11 & 20 & 10 & 88 & 5 & 11 & 313 \\
\hline 12 & 4 & 3 & 4 & 4 & 2 & 1 \\
\hline 13 & 8 & 5 & 84 & 83 & 26 & 291 \\
\hline 14 & 8 & 8 & 8 & 5 & 2 & 4 \\
\hline 15 & 18 & 19 & 67 & 30 & 13 & 124 \\
\hline 16 & 7 & 5 & 4 & 3 & 5 & 2 \\
\hline 17 & 12 & 5 & 165 & 147 & 553 & 336 \\
\hline 18 & 32 & 5 & 176 & 153 & 565 & 367 \\
\hline 19 & - & - & - & - & - & - \\
\hline 20 & 8 & 12 & 141 & 65 & 200 & 322 \\
\hline 21 & 7 & 4 & 152 & 71 & 514 & 332 \\
\hline 22 & 4 & 3 & 3 & 4 & 1 & 1 \\
\hline 23 & - & - & - & - & - & - \\
\hline 24 & 12 & 9 & 5 & 4 & 3 & 1 \\
\hline 25 & 7 & 11 & 4 & 4 & 1 & 1 \\
\hline 26 & 4 & 3 & 20 & 5 & 2 & 20 \\
\hline 27 & 5 & 4 & 11 & 2 & 11 & 15 \\
\hline 28 & 4 & 3 & 3 & 3 & 2 & 2 \\
\hline 29 & - & - & - & - & - & - \\
\hline 30 & 8 & 5 & 6 & 4 & 3 & 6 \\
\hline 31 & 7 & 3 & 3 & 5 & 1 & 1 \\
\hline 32 & 1 & 3 & 3 & 1 & 3 & 2 \\
\hline 33 & 16 & 6 & 123 & 98 & 714 & 306 \\
\hline 34 & - & - & - & - & - & - \\
\hline 35 & 5 & 4 & 3 & 3 & 2 & 3 \\
\hline 36 & 27 & 6 & 149 & 31 & 578 & 318 \\
\hline 37 & - & - & - & - & - & - \\
\hline 38 & 9 & 6 & 3 & 2 & 1 & 2 \\
\hline 39 & 44 & 6 & 156 & 150 & 782 & 340 \\
\hline 40 & 10 & 7 & 139 & 105 & 788 & 313 \\
\hline 41 & 14 & 5 & 110 & 68 & 464 & 167 \\
\hline 42 & - & - & - & - & - & - \\
\hline 43 & 7 & 4 & 3 & 2 & 1 & 1 \\
\hline 44 & 7 & 4 & 172 & 123 & 562 & 277 \\
\hline 45 & 8 & 5 & 5 & 4 & 3 & 2 \\
\hline 46 & 6 & 4 & 30 & 41 & 1 & 37 \\
\hline 47 & 7 & 4 & 4 & 2 & 5 & 4 \\
\hline 48 & 4 & 3 & 10 & 3 & 1 & 1 \\
\hline 49 & 7 & 3 & 3 & 2 & 1 & 1 \\
\hline 50 & - & - & - & - & - & - \\
\hline 51 & 8 & 6 & 4 & 3 & 3 & 2 \\
\hline 52 & 8 & 3 & 6 & 2 & 4 & 2 \\
\hline 53 & 20 & 5 & 4 & 3 & 1 & 2 \\
\hline 54 & 16 & 5 & 131 & 47 & 751 & 346 \\
\hline 55 & 5 & 4 & 3 & 3 & 5 & 2 \\
\hline 56 & 13 & 5 & 135 & 85 & 758 & 321 \\
\hline 57 & 26 & 6 & 114 & 136 & 162 & 313 \\
\hline 58 & 5 & 4 & 4 & 2 & 4 & 1 \\
\hline 59 & 9 & 4 & 10 & 3 & 1 & 1 \\
\hline 60 & 6 & 4 & 4 & 3 & 2 & 3 \\
\hline 61 & 9 & 4 & 3 & 2 & 1 & 1 \\
\hline 62 & 5 & 3 & 4 & 4 & 2 & 2 \\
\hline 63 & 7 & 5 & 3 & 2 & 1 & 2 \\
\hline
\end{tabular}




\section{REFERÊNCIAS}


1. Michaëlsson M, Riesenfeld T, Jonzon A. Natural history of congenital complete atrioventricular block. Pacing Clin Electrophysiol. 1997;20(8 Pt 2):2098-101.

2. Udink ten Cate FE, Breur JM, Cohen MI, Boramanand N, Kapusta L, Crosson JE, Brener JI, Lubbers LJ, Friedman AH. Dilated cardiomyopathy in isolated congenital complete atrioventricular block: early and long-term risk in children. J Am Coll Cardiol. 2001;37(4):112934.

3. Lopes LM, Tavares GM, Damiano AP, Lopes MA, Aiello VD, Schultz R, Zugaib M. Perinatal outcome of fetal atrioventricular block: one-hundred sixteen cases from a single institution. Circulation. 2008;118(12):126875. Erratum in: Circulation. 2008;118(16): e671.

4. Costedoat-Chalumeau N, Georgin-Lavialle S, Amoura Z, Piette JC. Anti-SSA/Ro and anti-SSB/La antibody-mediated congenital heart block. Lupus. 2005;14(9):660-64.

5. McCue CM, Mantakas ME, Tingelstad JB, Ruddy S. Congenital heart block in newborn of mothers with connective tissue disease. Circulation. 1977;56(1):82-90. 
6. Taylor PV, Scott JS, Gerlis LM, Esscher E, Scott O. Maternal antibodies against fetal cardiac antigens in congenital complete heart block. $N$ Engl J Med. 1986;315(11):667-72.

7. Reed KL, Appleton CP, Anderson CF, Shenker L, Sahn DJ. Doppler studies of vena cava flows in human fetuses. Insights into normal and abnormal cardiac physiology. Circulation. 1990;81(2):498-505.

8. Fouron JC, Proulx F, Miró J, Gosselin J. Doppler and M-Mode ultrasonography to time fetal atrial and ventricular contractions. Obstet Gynecol. 2000;96(5 Pt 1):732-6.

9. Michaëlsson M, Jonzon A, Riesenfeld T. Isolated congenital complete atrioventricular block in adult life a prospective study. Circulation. $1995 ; 92(3): 442-9$

10. Jaeggi ET, Hamilton RM, Silverman ED, Zamora SA, Hornberger LK. Outcome of children with fetal, neonatal or childhood diagnosis of isolated congenital atrioventricular block a single institution's experience of 30 years. J Am Coll Cardiol. 2002;39(1):130-7.

11. Van Bergen AH, Cuneo BF, Davis N. Prospective echocardiographic evaluation of atrioventricular conduction in fetuses with maternal Sjögren's antibodies. Am J Obstet Gynecol. 2004;191(3):1014-8. 
12. Askanase AD, Friedman DM, Copel J, Dische MR, Dubin A, Starc TJ, Katholi MC, Buyon JP. Spectrum and progression of conduction abnormalities in infants born to mothers with anti-SSA/Ro-SSB/La antibodies. Lupus. 2002;11(3):145-51.

13. Groves AM, Allan LD, Rosenthal E. Outcome of isolated congenital complete heart block diagnosed in utero. Heart. 1996;75(2):190-4.

14. Jaeggi ET, Fouron JC, Silverman ED, Ryan G, Smallhorn J, Hornberger LK. Transplacental fetal treatment improves the outcome of prenatally diagnosed complete atrioventricular block without structural heart disease. Circulation. 2004;110(12):1542-8.

15. Villain E. Indications for pacing in patients with congenital heart disease. Pacing Clin Electrophysiol. 2008;31 Suppl 1:S17-20.

16. Bordachar P, Zachary W, Ploux S, Labrousse L, Haissaguerre M, Thambo JB. Pathophysiology, clinical course, and management of congenital complete atrioventricular block. Heart Rhythm. 2013;10(5):760-6.

17. Sholler GF, Walsh EP. Congenital complete heart block in patients without anatomic cardiac defects. Am Heart J. 1989;118(6):1193-8.

18. Friedman RA. Congenital AV block. Pace me now or pace me later? Circulation. 1995;92(3):283-5. 
19. Robledo-Nolasco R, Ortiz-Avalos M, Rodriguez-Diez G, JimenezCarrillo C, Ramírez-Machuca J, De Haro S, Castro-Villacorta H. Transvenous pacing in children weighing less than 10 kilograms. Pacing Clin Electrophysiol. 2009;32 Suppl 1:S177-81.

20. Kammeraad JA, Rosenthal E, Bostock J, Rogers J, Sreeram N. Endocardial pacemaker implantation in infants weighing $<$ or $=10$ kilograms. Pacing Clin Electrophysiol. 2004;27(11):1466-74.

21. Costa R, Filho MM, Tamaki WT, Crevelari ES, Nishioka SD, Moreira LF, Oliveira SA. Transfemoral pediatric permanent pacing: long-term results. Pacing Clin Electrophysiol. 2003;26(1 Pt 2):487-91.

22. Villain E, Martelli H, Bonnet D, Iserin L, Butera G, Kachaner J. Characteristics and results of epicardial pacing in neonates and infants. Pacing Clin Electrophysiol. 2000;23(12):2052-6

23. Berul $\mathrm{Cl}$, Cecchin F. Indications and techniques of pediatric cardiac pacing. Expert Rev Cardiovasc. 2003;1(2)165-76.

24. Cohen MI, Bush DM, Vetter VL, Tanel RE, Wieand TS, Gaynor JW, Rhodes LA. Permanent epicardial pacing in pediatric patients: seventeen years of experience and 1200 outpatient visits. Circulation. $2001 ; 103(21): 2585-90$.

25. Janousek J. Cardiac resynchronisation in congenital heart disease. Heart. 2009;95(11):940-7. 
26. Balmer C, Fasnacht M, Rahn M, Molinari L, Bauersfeld U. Long-term follow up of children with congenital complete atrioventricular block and the impact of pacemaker therapy. Europace. 2002;4(4):345-9.

27. Janousek J, Tomek V, Chaloupecky V, Gebauer RA. Dilated cardiomyopathy associated with dual-chamber pacing in infants: improvement through either left ventricular cardiac resynchronization or programming the pacemaker off allowing intrinsic normal conduction. $J$ Cardiovasc Electrophysiol. 2004;15(4):470-4.

28. Villain E, Coastedoat-Chalumeau N, Marijon E, Boudjemline Y, Piette JC, Bonnet D. Presentation and prognosis of complete atrioventricular block in childhood, according to maternal antibody status. J Am Coll Cardiol. 2006;48(8):1682-7.

29. Gebauer RA, Tomek V, Salameh A, Marek J, Chaloupecký V, Gebauer R, Matejka T, Vojtovic P, Janousek J. Predictors of left ventricular remodelling and failure in right ventricular pacing in the young. Eur Heart J. 2009;30(9):1097-104.

30. Moak JP, Barron KS, Hougen TJ, Wiles HB, Balaji S, Sreeram N, Cohen $\mathrm{MH}$, Nordenberg A, Van Hare GF, Friedman RA, Perez M, Cecchin F, Schneider DS, Nehgme RA, Buyon JP. Congenital heart block: development of late-onset cardiomyopathy, a previously underappreciated sequela. J Am Coll Cardiol. $2001 ; 37(1): 238-42$. 
31. Karpawich PP, Rabah R, Haas JE. Altered cardiac histology following apical right ventricular pacing in patients with congenital atrioventricular block. Pacing Clin Electrophysiol. 1999;22(9):1372-7.

32. Breur JM, Udink Ten Cate FE, Kapusta L, Cohen MI, Crosson JE, Boramanand N, Lubbers LJ, Friedman AH, Brenner Jl, Vetter VL, Sreeram N, Meijboom EJ. Pacemaker therapy in isolated congenital complete atrioventricular block. Pacing Clin Electrophysiol. $2002 ; 25(12): 1685-91$.

33. Thambo JB, Bordachar P, Garrigue S, Lafitte S, Sanders P, Reuter S, Girardot R, Crepin D, Reant P, Roudaut R, Jaïs $P$, Haïssaquerre $M$, Clementy J, Jimenez M. Detrimental ventricular remodeling in patients with congenital complete heart block and chronic right ventricular apical pacing. Circulation. 2004;110(25):3766-72.

34. Tantengco MV, Thomas RL, Karpawich PP. Left ventricular dysfunction after long-term right ventricular apical pacing in the young. J Am Coll Cardiol. 2001;37(8):2093-100

35. Gillis AM, Chung MK. Pacing the right ventricle: to pace or not to pace? J Am Coll Cardiol. 2005;2(2):201-6.

36. Thambo JB, Bordachar P, Lafitte S, Crepin D, Garrigue S, Reuter S, Roudaut R, Haïssaquerre M, Clementy J, Jimenez M. Asynchronism and right ventricular pacing. Arch Mal Coeur Vaiss. 2005;98(5):519-23. 
37. Sweeney MO, Prinzen FW. A new paradigm for physiologic ventricular pacing. J Am Coll Cardiol. 2006;47(2):282-8.

38. Kim JJ, Friedman RA, Eidem BW, Cannon BC, Arora G, Smith EO, Fenrich AL, Kertesz NJ. Ventricular function and long-term pacing in children with congenital complete atrioventricular block. J Cardiovasc Electrophysiol. 2007;18(4):373-7.

39. Nothroff J, Norozi K, Alpers V, Arnhold JO, Wessel A, Ruschewski W, Buchhorn R. Pacemaker implantation as a risk factor for heart failure in young adults with congenital heart disease. Pacing Clin Electrophysiol. 2006;29(4):386-92.

40. Leon AR, Greenberg JM, Kanuru N, Baker CM, Mera FV, Smith AL, Lanqberg JJ, DeLurgio DB. Cardiac resynchronization in patients with congestive heart failure and chronic atrial fibrillation: effect of upgrading to biventricular pacing after chronic right ventricular pacing. J Am Coll Cardiol. 2002;39(8):1258-63.

41. Bordachar P, Garrigue S, Lafitte S, Reuter S, Jaïs $P$, Haïssaguerre M, Clementy J. Interventricular and intra-left ventricular electromechanical delays in right ventricular paced patients with heart failure: implications for upgrading to biventricular stimulation. Heart. 2003;89(12):1401-5.

42. Horwich T, Foster E, De Marco T, Tseng Z, Saxon L. Effects of resynchronization therapy on cardiac function in pacemaker patients "upgraded" to biventricular devices. J Cardiovasc Electrophysiol. 2004;15(11):1284-9. 
43. Moak JP, Hasbani K, Ramwell C, Freedenberg V, Berger JT, DiRusso G, Callahan P. Dilated cardiomyopathy following right ventricular pacing for AV block in young patients: resolution after upgrading to biventricular pacing systems. J Cardiovasc Electrophysiol. $2006 ; 17(10): 1068-71$.

44. van Beek E, Backx A, Singh S. Cardiac resynchronization as therapy for congestive cardiac failure in children dependent on chronic cardiac pacing. Cardiol Young. 2006;16(2):187-9.

45. Takabayashi S, Shimpo H, Mitani Y, Komada Y. Pediatric cardiac remodeling after cardiac resynchronization therapy. Pediatr Cardiol; 2006.27(4):485-9.

46. Höijer CJ, Meurling C, Brandt J. Upgrade to biventricular pacing in patients with conventional pacemakers and heart failure: a double-blind, randomized crossover study. Europace. 2006;8(1):51-5.

47. Silva RT, Filho MM, Lima CE, Martins DG, Nishioka SA, Pedrosa AA, Crevelari ES, Costa R, Sosa EA, Ramires JA. Functional behavior of patients with conventional pacemakers undergoing cardiac resynchronization. Arq Bras Cardiol. 2008;90(2):138-43.

48. Vatankulu MA, Goktekin O, Kaya MG, Ayhan S, Kucukdurmaz Z, Sutton R, Henein M. Effect of long-term resynchronization therapy on left ventricular remodeling in pacemaker patients upgraded to biventricular devices. Am J Cardiol. 2009;103(9):1280-4. 
49. Kim HW, Kim GB, Bae EJ, Noh Cl, Kim WH. Cardiac resynchronization therapy for left ventricular dysfunction induced by chronic right ventricular pacing in a child. J Korean Med Sci. 2010;25(12):1809-13.

50. Dubin AM, Janousek J, Rhee E, Strieper MJ, Cecchin F, Law $I H$, Shannon KM, Temple J, Rosenthal E, Zimmerman FJ, Davis A, Karpawich PP, Al Ahmad A, Vetter VL, Kertesz NJ, Shah M, Snyder C, Stephenson E, Emmel M, Sanatani S, Kanter R, Batra A, Collins KK. Resynchronization therapy in pediatric and congenital heart disease patients: an international multicenter study. J Am Coll Cardiol. 2005;46(12):2277-83.

51. van Geldorp IE, Vanagt WY, Bauersfeld U, Tomaske M, Prinzen FW, Delhaas T. Chronic left ventricular pacing preserves left ventricular function in children. Pediatr Cardiol. 2009;30(2):125-32.

52. Cruz RB, Viana VS, Nishioka SA, Martinelli-F M, Bonfa E. Is isolated congenital heart block associated to neonatal lupus requiring pacemaker a distinct cardiac syndrome? Pacing Clin Electrophysiol. $2004 ; 27(5): 615-20$.

53. McLeod KA. Cardiac pacing in infants and children. Heart. 2010;96(18):1502-8. 
54. van Geldorp IE, Delhaas T, Gebauer RA, Frias P, Tomaske M, Friedberg MK, Tisma-Dupanovic S, Elders J, Früh A, Gabbarini F, Kubus P, Illikova V, Tsao S, Blank AC, Hiippala A, Sluysmans T, Karpawich P, Clur SA, Ganame X, Collins KK, Dann G, Thambo JB, Trigo C, Nagel B, Papagiannis J, Rackowitz A, Marek J, Nürnberg JH, Vanagt WY, Prinzen FW, Janousek J; Working Group for Cardiac Dysrhythmias and Electrophysiology of the Association for European Paediatric Cardiology. Impact of the permanent ventricular pacing site on left ventricular function in children: a retrospective multicentre survey. Heart. 2011;97(24):2051-5.

55. Serwer GA, Shetty I. Pediatric Pacing and Defibrillator Use. In: Ellenbogen KA, Kay, GN, Lau CPK, Wilkoff BL, editors. Clinical Cardiac Pacing, Defibrillation, and Resynchronization Therapy. Philadelphia: ELSEVIER, 2011. p. 393-427.

56. Silka MJ, Kron J, Dunnigan A, Dick M 2nd. Sudden cardiac death and the use of implantable cardioverter-defibrillators in pediatric patients. Circulation. 1993;87(3):800-7.

57. Costa R, Martinelli M, Silva KR, Crevelari, Elisabeth, Tamaki WT, Júnior JCTC, Oliveira SA. Implante pediátrico de cardioversor-desfibrilador pela via transtorácica transatrial. Reblampa. 2003;16(1):43-48. 
58. European Society of Cardiology (ESC); European Heart Rhythm Association (EHRA), Brignole M, Auricchio A, Baron-Esquivias G, Bordachar P, Boriani G, Breithardt OA, Cleland J, Deharo JC, Delgado V, Elliott PM, Gorenek B, Israel CW, Leclercq C, Linde C, Mont L,Padeletti L, Sutton R, Vardas PE. 2013 ESC guidelines on cardiac pacing and cardiac resynchronization therapy: the task force on cardiac pacing and resynchronization therapy of the European Society of Cardiology (ESC). Developed in collaboration with the European Heart Rhythm Association (EHRA). Europace. 2013;15(8):1070-118.

59. Martinelli Filho M, Zimerman LI, Lorga MA, Vasconcelos JTM, Lorga Filho A, Fagundes AA, et al. Diretriz Brasileira de Dispositivos Cardíacos Eletrônicos Implantáveis (DCEI). Arq Bras Cardiol. 2007;89(6):210-37.

60. Epstein AE, Dimarco JP, Ellenbogen KA, Estes NA 3rd, Freedman RA, Gettes LS, Gillinov AM, Gregoratos G, Hammill SC, Hayes DL, Hlatky MA, Newby LK, Page RL, Schoenfeld MH, Silka MJ, Stevenson LW, Sweeney MO; American College of Cardiology/American Heart Association Task Force on Practice; American Association for Thoracic Surgery; Society of Thoracic Surgeons. ACC/AHA/HRS 2008 guidelines for Device-Based Therapy of Cardiac Rhythm Abnormalities: executive summary. Heart Rhythm. 2008;5(6):934-55.

61. Departamento de Estimulação Cardíaca Artificial. RBM. Disponível em: <http://www.deca.org.br/Medica/RBM_DadosGlobaisNew.aspx>. Acesso em: 17 de fevereiro 2014. 
62. Nawa S, Kioka Y, Shimizu A, Tsuji H, Miyachi Y, Ebara K, Kino K, Shigenobu M, Murakami T, Senoo Y, et al. Characteristics of chronically paced cardiac functions in the congenital complete atrioventricular block. Artif Organs. 1987;11(3):252-8.

63. Kurosaki K, Miyazaki A, Watanabe K, Echigo S. Long-term outcome of isolated congenital complete atrioventricular block pacing since neonatal period: experience at a single Japanese institution. Circ J. $2008 ; 72(1): 81-7$

64. Pham PP, Balaji S, Shen I, Ungerleider R, Li X, Sahn DJ. Impact of conventional versus biventricular pacing on hemodynamics and tissue Doppler imaging indexes of resynchronization postoperatively in children with congenital heart disease. $J$ Am Coll Cardiol. 2005;46(12):2284-9.

65. Tissot C, Aggoun Y, Rimensberger PC, Sierra J, Kalangos A, Beghetti M, da Cruz E. Left ventricular epicardial VVI pacing for a congenital complete heart block with severe myocardial dysfunction: shall epicardial pacing wires be positioned left? Int J Cardiol. 2007;116(1):e7-9.

66. Vanagt WY, Prinzen FW, Delhaas T. Physiology of cardiac pacing in children: the importance of the ventricular pacing site. Pacing Clin Electrophysiol. 2008;31 Suppl 1:S24-7. 
67. Da Silva KR, Costa R, De Oliveira RM Jr, Lacerda MS, Um Huang Al, Rossi MB, Crevelari ES, Tamaki WT, Filho MM, Pietrobon R. Quality of life and functional capacity after long-term right ventricular pacing in pediatrics and young adults with congenital atrioventricular block. Pacing Clin Electrophysiol. 2013;36(12):1539-49.

68. Lev M, Silverman J, Fitzmaurice FM, Paul MH, Cassels DE, Miller RA. Lack of connection between the atria and the more peripheral conduction system in congenital atrioventricular block. Am J Cardiol. $1971 ; 27(5): 481-90$.

69. Pinsky WW, Gillette PC, Garson A, McNamara DG. Diagnosis, management, and long-term results of patients with congenital complete atrioventricular block. Pediatrics. 1982;69(6):728-33.

70. Michaëlsson M, Engle MA. Congenital complete heart block: an international study of the natural history. Cardiovasc Clin. 1972;4(3)85101.

71. Anderson $\mathrm{RH}$, Wenick AC, Losekoot TG, Becker AE. Congenitally complete heart block. Developmental aspects. Circulation. $1977 ; 56(1): 90-101$.

72. Boutjdir M, Chen L, Zhang ZH, Tseng CE, El-Sherif N, Buyon JP. Serum and immunoglobulin $\mathrm{G}$ from the mother of a child with congenital heart block induce conduction abnormalities and inhibit L-type calcium channels in a rat heart model. Pediatr Res. 1998;44(1):11-9. 
73. Buyon JP, Clancy RM. Autoantibody-associated congenital heart block: TGFbeta and the road to scar. Autoimmun Rev. 2005;4(1):1-7.

74. Jaeggi E, Laskin C, Hamilton R, Kingdom J, Silverman E. The importance of the level of maternal anti-Ro/SSA antibodies as a prognostic marker of the development of cardiac neonatal lupus erythematosus a prospective study of 186 antibody-exposed fetuses and infants. J Am Coll Cardiol. 2010;55(24):2778-84.

75. Buyon JP, Waltuck J, Kleinman C, Copel J. In utero identification and therapy of congenital heart block. Lupus. 1995;4(2):116-21.

76. Buyon JP, Winchester R. Congenital complete heart block. A human model of passively acquired autoimmune injury. Arthritis Rheum. $1990 ; 33(5): 609-14$.

77. Clancy RM, Buyon JP. More to death than dying: apoptosis in the pathogenesis of SSA/Ro-SSB/La-associated congenital heart block. Rheum Dis Clin North Am. 2004;30(3):589-602.

78. Hubscher O, Batista N, Rivero S, Marletta C, Arriagada M, Boire G, Ménard HA, Arana RM. Clinical and serological identification of 2 forms of complete heart block in children. J Rheumatol. 1995;22(7):1352-5.

79. Brucato A, Jonzon A, Friedman D, Allan LD, Vignati G, Gasparini M, Stein JI, Montella S, Michaëlsson M, Buyon J. Proposal for a new definition of congenital complete atrioventricular block. Lupus. $2003 ; 12(6): 427-35$. 
80. Buyon JP, Hiebert R, Copel J, Craft J, Friedman D, Katholi M, Lee LA, Provost TT, Reichlin M, Rider L, Rupel A, Saleeb S, Weston WL, Skovron ML. Autoimmune-associated congenital heart block: demographics, mortality, morbidity and recurrence rates obtained from a national neonatal lupus registry. J Am Coll. 1998;31(7):1658-66.

81. Brucato A, Frassi M, Franceschini F, Cimaz R, Faden D, Pisoni MP, Muscarà M, Vignati G, Stramba-Badiale M, Catelli L, Lojacono A, Cavazzana I, Ghirardello A, Vescovi F, Gambari PF, Doria A, Meroni PL, Tincani A. Risk of congenital complete heart block in newborns of mothers with anti-Ro/SSA antibodies detected by counterimmunoelectrophoresis: a prospective study of 100 women. Arthritis Rheum. 2001;44(8):1832-5.

82. Julkunen $\mathrm{H}$, Eronen $\mathrm{M}$. Long-term outcome of mothers of children with isolated heart block in Finland. Arthritis Rheum. 2001;44(3):647-52.

83. Buyon JP, Clancy RM, Friedman DM. Cardiac manifestations of neonatal lupus erythematosus: guidelines to management, integrating clues from the bench and bedside. Nat Clin Pract Rheumatol. 2009;5(3):139-48.

84. Baruteau AE, Behaghel A, Fouchard S, Mabo P, Schott JJ, Dina C, Chatel S, Villain E, Thambo JB, Marçon F, Gournay V, Rouault F, Chantepie A, Guillaumont S, Godart F, Martins RP, Delasalle B, Bonnet C, Fraisse A, Schleich JM, Lusson JR, Dulac Y, Daubert JC, Le Marec $H$, Probst V. Parental electrocardiographic screening identifies a high degree of inheritance for congenital and childhood nonimmune isolated atrioventricular block. Circulation. 2012;126(12):1469-77. 
85. Ho SY, Esscher E, Anderson $\mathrm{RH}$, Michaëlsson M. Anatomy of congenital complete heart block and relation to maternal anti-Ro antibodies. Am J Cardiol. 1986;58(3):291-4.

86. Nasrallah AT, Gillette PC, Mullins CE. Congenital and surgical atrioventricular block within the His bundle. Am $J$ Cardiol. $1975 ; 36(7): 914-20$.

87. Miranda-Carús ME, Askanase AD, Clancy RM, Di Donato F, Chou TM, Libera MR, Chan EK, Buyon JP. Anti-SSA/Ro and anti-SSB/La autoantibodies bind the surface of apoptotic fetal cardiocytes and promote secretion of TNF-alpha by macrophages. $J$ Immunol. $2000 ; 165(9): 5345-51$.

88. Garcia S, Nascimento JH, Bonfa E, Levy R, Oliveira SF, Tavares AV, de Carvalho AC. Cellular mechanism of the conduction abnormalities induced by serum from anti-Ro/SSA-positive patients in rabbit hearts. $J$ Clin Invest. 1994;93(2):718-24.

89. Xiao GQ, Hu K, Boutjdir M. direct inhibition of expressed cardiac L- and T-type calcium channels by IgG from mothers whose children. Circulation. 2001;103(11):1599-604.

90. Nield LE, Silverman ED, Taylor GP, Smallhorn JF, Mullen JB, Silverman NH, Finley JP, Law YM, Human DG, Seaward PG, Hamilton RM, Hornberger LK. Maternal anti-Ro and anti-La antibody-associated endocardial fibroelastosis. Circulation. 2002;105(7):843-8. 
91. Glickstein JS, Buyon J, Friedman D. Pulsed Doppler echocardiographic assessment of the fetal PR interval. Am J Cardiol. 2000;86(2):236-9.

92. Rosenthal E. Spectrum of conduction abnormalities associated with maternal anti-Ro antibodies. Lupus. 2002;11(3):135-6.

93. Friedman DM, Kim MY, Copel JA, Davis C, Phoon CK, Glickstein JS, Buyon JP. Utility of cardiac monitoring in fetuses at risk for congenital heart block: the PR Interval and Dexamethasone Evaluation (PRIDE) prospective study. Circulation. 2008;117(4):485-93.

94. Dewey RC, Capeless MA, Levy AM. Use of ambulatory electrocardiographic monitoring to identify high-risk patients with congenital complete heart block. N Engl J Med. 1987;316(14):835-9.

95. Esscher E, Michaëlsson M. Q-T interval in congenital complete heart block. Pediatr Cardiol.1983;4(2)121-4.

96. Levy AM, Camm AJ, Keane JF. Multiple arrhythmias detected during nocturnal monitoring in patients with congenital complete heart block. Circulation. 1977;55(2):247-53.

97. Ikkos D, Hanson JS. Response to exercise in congenital complete atrioventricular block. Circulation. 1960;22:583-90.

98. Winkler RB, Freed MD, Nadas AS. Exercise-induced ventricular ectopy in children and young adults with complete heart block. Am Heart J. 1980;99(1):87-92. 
99. Pordon CM, Moodie DS. Adults with congenital complete heart block: 25-year follow-up. Cleve Clin J Med. 1992;59(6):587-90.

100. Hochberg MC. Updating the American College of Rheumatology revised criteria for the classification of systemic lupus erythematosus. Arthritis Rheum. 1997;40(9):1725.

101. Vitali C, Bombardieri S, Moutsopoulos HM, Coll J, Gerli R, Hatron PY, Kater L, Konttinen YT, Manthorpe R, Meyer O, Mosca M, Ostuni P, Pellerito RA, Pennec Y, Porter SR, Richards A, Sauvezie B, Schiødt M, Sciuto M, Shoenfeld Y, Skopouli FN, Smolen JS, Soromenho F, Tishler M, Wattiaux MJ, et al. Assessment of the European classification criteria for Sjögren's syndrome in a series of clinically defined cases: results of a prospective multicentre study. The European Study Group on Diagnostic Criteria for Sjögren's Syndrome. Ann Rheum Dis. 1996;55(2):116-21.

102. Saleeb S, Copel J, Friedman D, Buyon JP. Comparison of treatment with fluorinated glucocorticoids to the natural history of autoantibodyassociated congenital heart block: retrospective review of the research registry for neonatal lupus. Arthritis Rheum. 1999;42(11):2335-45.

103. Pisoni CN, Brucato A, Ruffatti A, Espinosa G, Cervera R, BelmonteSerrano M, Sánchez-Román J, García-Hernández FG, Tincani A, Bertero MT, Doria A, Hughes GR, Khamashta MA. Failure of intravenous immunoglobulin to prevent congenital heart block: Findings of a multicenter, prospective, observational study. Arthritis Rheum. 2010;62(4):1147-52. 
104. Assad RS, Zielinsky P, Kalil R, Lima G, Aramayo A, Santos A, Costa R, Marcial MB, Oliveira SA. New lead for in utero pacing for fetal congenital heart block. J Thorac Cardiovasc Surg. 2003. 126(1):300-2.

105. Baruteau AE, Fouchard S, Behaghel A, Mabo P, Villain E, Thambo JB, Marçon F, Gournay V, Rouault F, Chantepie A, Guillaumont S,Godart F, Bonnet C, Fraisse A, Schleich JM, Lusson JR, Dulac Y, Leclercq C, Daubert JC, Schott JJ, Le Marec H, Probst V. Characteristics and longterm outcome of non-immune isolated atrioventricular block diagnosed in utero or early childhood: a multicentre study. Eur Heart J. $2012 ; 33(5): 622-9$.

106. Thomson JD, Blackburn ME, Van Doorn C, Nicholls A, Watterson KG. Pacing activity, patient and lead survival over 20 years of permanent epicardial pacing in children. Ann Thorac Surg. 2004;77(4):1366-70.

107. Kwak JG, Kim S-J, Song JY, Choi EY, Lee SY, Shim WS, Lee CH, Lee C, Park CS. Permanent epicardial pacing in pediatric patients: 12-year experience at a single center. Ann Thorac Surg. 2012;93(2):634-9.

108. Sachweh JS, Vazquez-Jimenez JF, Schöndube FA, Daebritz SH, Dörge H, Mühler EG, Messmer BJ. Twenty years experience with pediatric pacing: epicardial and transvenous stimulation. Eur $J$ Cardiothorac Surg. 2000;17(4):455-61. 
109. Beaufort-Krol GC, Schasfoort-van Leeuwen MJ, Stienstra Y, BinkBoelkens MT. Longitudinal echocardiographic follow-up in children with congenital complete atrioventricular block. Pacing Clin Electrophysiol. $2007 ; 30(11): 1339-43$.

110. Solti F, Szatmáry L, Vecsey T, Rényi-Vámos F, Bodor E. Congenital complete heart block associated with QT prolongation. Eur Heart J. 1992;13(8):1080-3.

111. Silva KR, Costa R, Abi Rached R, Martinelli Filho M, Caldas JG, Carnevale FC, Moreira LF, Stolf NA. Warfarin prevents venous obstruction after cardiac devices implantation in high-risk patients: partial analysis. Rev Bras Cir Cardiovasc. 2008;23(4):542-9.

112. Cecchin F, Atallah J, Walsh EP, Triedman JK, Alexander ME, Berul Cl. Lead extraction in pediatric and congenital heart disease patients. Circ Arrhythm Electrophysiol. 2010;3(5):437-44.

113. Sagar S, Shen WK, Asirvatham SJ, Cha YM, Espinosa RE, Friedman PA, Hodge DO, Munger TM, Porter CB, Rea RF, Hayes DL, Jahangir A. Effect of long-term right ventricular pacing in young adults with structurally normal heart. Circulation. 2010;121(15):1698-705.

114. Chen CA, Chang Cl, Wang JK, Lin MT, Chiu SN, Chiu HH, Wu MH. Restoration of cardiac function by setting the ventricular pacing at a lower range in an infant with congenital complete atrioventricular block and dilated cardiomyopathy. Int J Cardiol. 2008;131(1):e38-40. 
115. Kertesz NJ, Fenrich AL, Friedman RA. Congenital complete atrioventricular block. Tex Heart Inst J. 1997;24(4):301-7.

116. Tuzcu V, Bodtke JP, Best TH. Early detection of regional myocardial dysfunction in paced children with congenital complete atrioventricular block. Pacing Clin Electrophysiol. 2007;30(6):764-71.

117. Vatasescu R, Shalganov T, Paprika D, Kornyei L, Prodan Z, Bodor G, Szatmari A, Szili-Torok T. Evolution of left ventricular function in paediatric patients with permanent right ventricular pacing for isolated congenital heart block: A medium term follow-up. Europace. 2007;9(4):228-32.

118. Hong WJ, Yung TC, Lun KS, Wong SJ, Cheung YF. Impact of right ventricular pacing on three-dimensional global left ventricular dyssynchrony in children and young adults with congenital and acquired heart block associated with congenital heart disease. Am J Cardiol. 2009;104(5):700-6.

119. Gebauer RA, Tomek V, Kubus P, Rázek V, Matejka T, Salameh A, Kostelka M, Janousek J. Differential effects of the site of permanent epicardial pacing on left ventricular synchrony and function in the young: implications for lead placement. Europace. 2009;11(12):1654-9.

120. Bar-Cohen $\mathrm{Y}$, Berul $\mathrm{Cl}$, Alexander ME, Fortescue EB, Walsh EP, Triedman JK, Cecchin F. Age, size, and lead factors alone do not predict venous obstruction in children and young adults with transvenous lead systems. J Cardiovasc Electrophysiol. 2006;17(7):754-9. 
121. de Oliveira JC, Martinelli M, Nishioka SA, Varejão T, Uipe D, Pedrosa AA, Costa R, D’Avila A, Danik SB. Efficacy of antibiotic prophylaxis before the implantation of pacemakers and cardioverter-defibrillators: results of a large, prospective, randomized, double-blinded, placebocontrolled trial. Circ Arrhythm Electrophysiol. 2009;2(1):29-34.

122. DeRose JJ, Ashton RC, Belsley S, Swistel DG, Vloka M, Ehlert F, Shaw R, Sackner-Bernstein J, Hillel Z, Steinberg JS. Robotically assisted left ventricular epicardial lead implantation for biventricular pacing. J Am Coll Cardiol. 2003;41(8):1414-19.

123. Jansens JL, Jottrand M, Preumont N, Stoupel E, Cannière D. Roboticenhanced biventricular resynchronization: an alternative to endovenous cardiac resynchronization therapy in chronic heart failure. Ann Thorac Surg. 2003;76(2):413-7.

124. Beck H, Boden WE, Patibandla S, et al. 50th Anniversary of the first successful permanent pacemaker implantation in the United States: historical review and future directions. Am J Cardiol. 2010;106(6):81018.

125. Rosen MR, Robinson RB, Brink PR, Cohen IS. The road to biological pacing. Nat Rev Cardiol. 2011;8(11):656-66.

126. World Medical Association. Declaration of Helsinki. Disponível em: <http://www.wma.net/en/30publications/10policies/b3>. Acesso em: 17 de fevereiro 2014. 
127. Ware JE Jr, Gandek B. Overview of the SF-36 Health Survey and the International Quality of Life Assessment (IQoLA) project. J Clin Epidemiol 1998; 51(11):903-12.

128. Ware JE, Snow KK, Kosinski M, Gandek B. SF-36 Health Survey Manual and Interpretation Guide. Boston, MA, The Health Institute, 1993.

129. Cicconelli RM, Ferraz MB, Santos W, Meinão I, Quaresma MR. Traducão para a língua portuguesa e validacao do questionário genérico de avaliação de qualidade de vida SF-36 (Brasil SF-36). Rev Bras Reumatol. 1999; 39:143-50.

130. Machado CSM, Ruperto N, Silva CHM, Ferriani VPL, Roscoe I, Campos LM, Oliveira SK, Kiss MH, Bica BE, Sztajnbok F, Len CA, Melo-Gomes JA. The Brazilian version of the Childhood Health Assessment Questionnaire (CHAQ) and the Child Health Questionnaire (CHQ). Clin Exp Rheumatol. 2001; 19(4 Suppl 23):S25-9.

131. Landgraf JM, Albertz L, Ware JE Jr. The Child Health Questionnaire: A User's Manual, 2nd Ed. Boston, The Health Act, 1999.

132. Brooks D, Solway S, GibbonsWJ. ATS statement: Guidelines for the six-minute walk test. Am J Crit Care Med. 2002; 166(1):111-7.

133. Pereira de Sousa LA, Britto RR, Ribeiro AL, Baracho SM, da Costa Val Barros V, Carvalho VT, Parreira VF. Six-minute walk test in patientswith permanent cardiac pacemakers. J Cardiopulm Rehabil Prev. 2008; 28(4):253-7. 
134. Iwama AM, Andrade GN, Shima P, Tanni SE, Godoy I, Dourado VZ. The six-minute walk test and body weight-walk distance product in healthy Brazilian subjects. Braz J Med Biol Res. 2009; 42(11):1080-5.

135. Gorcsan J 3rd, Abraham T, Agler DA, Bax JJ, Derumeaux G, Grimm RA, Martin R, Steinberg JS, Sutton MS, Yu CM. American Society of Echocardiography Dyssynchrony Writing Group. Echocardiography for cardiac resynchronization therapy: recommendations for performance and reporting-a report from the American Society of Echocardiography Dyssynchrony Writing Group endorsed by the Heart Rhythm Society. J Am Soc Echocardiogr. 2008;21(3):191-213.

136. Mathias Jr W. Manual de Ecocardiografia. 2a ed. São Paulo: Manole; 2009.

137. Harris PA, Taylor R, Thielke R, Payne J, Gonzalez N, Conde JG. Research electronic data capture (REDCap) - A metadata-driven methodology and workflow process for providing translational research informatics support. J Biomed Inform. 2009;42(2):377-81.

138. Chung ES, Leon AR, Tavazzi L, Sun JP, Nihoyannopoulos P, Merlino J, Abraham WT, Ghio S, Leclercq C, Bax JJ, Yu CM, Gorcsan J 3rd, St John Sutton M, De Sutter J, Murillo J. Results of the Predictors of Response to CRT (PROSPECT) trial. Circulation. 2008;117(20):260816. 
139. Moreira LFP, Costa R, Pêgo-Fernandes PM, Stolf NAG, Jatene AD, Armelin E. Reevaluation of the Role of Atrial Systole in the Closure of Atrioventricular Valves. In: Gómez FP, Botella S, Corbalán JA, Cosin J, Cosío FG, García-Civera R. Cardiac Pacing - Electrophysiology. Tachyarrhythmias. Madrid: Goiclea; 1985. 554-60.

140. Kaltman JR, Ro PS, Zimmerman F, Moak JP, Epstein M, Zeltser IJ, Shah MJ, Buck K, Vetter VL, Tanel RE. Managed ventricular pacing in pediatric patients and patients with congenital heart disease. Am J Cardiol. 2008;102(7):875-8.

141. Sweeney MO, Shea JB, Fox V, Adler S, Nelson L, Mullen TJ, Belk P, Casavant D, Sheldon T. Randomized pilot study of a new atrial-based minimal ventricular pacing mode in dual-chamber implantable cardioverter-defibrillators. Heart Rhythm. 2004;1(2):160-7.

142. Sweeney MO, Ellenbogen $\mathrm{K}$ a, Casavant D, Betzold R, Sheldon T, Tang F, Mueller M, Lingle J; Marquis MVP Download Investigators. Multicenter, prospective, randomized safety and efficacy study of a new atrial-based managed ventricular pacing mode (MVP) in dual chamber ICDs. J Cardiovasc Electrophy. 2005;16(8):811-7.

143. Cleland JG, Daubert JC, Erdmann E, Freemantle N, Gras D, Kappenberger L, Tavazzi L. Cardiac Resynchronization-Heart Failure (CARE-HF) Study Investigators. The effect of cardiac resynchronization on morbidity and mortality in heart failure. $N$ Engl $J$ Med. 2005;352(15):1539-49. 
144. Linde C, Leclercq C, Rex S, Garrigue S, Lavergne T, Cazeau S, McKenna W, Fitzgerald M, Deharo JC, Alonso C, Walker S, Braunschweig F, Bailleul C, Daubert JC. Long-term benefits of biventricular pacing in congestive heart failure: results from the MUltisite STimulation in cardiomyopathy (MUSTIC) study. J Am Coll Cardiol. $2002 ; 40(1): 111-8$

145. Prinzen FW, Peschar M. Relation between the pacing induced sequence of activation and left ventricular pump function in animals. Pacing Clin Electrophysiol. 2002; 25:484-498.

146. Blanc JJ, Etienne Y, Gilard M, Mansourati J, Munier S, Boschat J, Benditt DG, Lurie KG. Evaluation of different ventricular pacing sites in patients with severe heart failure: Results of an acutehemodynamic study. Circulation. 1997; 96:3273-77.

147. Vanagt WY, Verbeek XA, Delhaas T, Mertens L, Daenen WJ, Prinzen FW. The left ventricular apex is the optimal site for pediatric pacing. Pacing Clin Electrophysiol. 2004; 27:837-43.

148. Lupi G, Sassone B, Badano L, Peraldo C, Gaddi O, Sitges M, Parthenakis F, Molteni S, Pagliuca MR, Grovale N, Menozzi C, Brignole M; Ablate and Pace in Atrial Fibrillation (APAF) Pilot Echocardiographic Trial Investigators. Effects of right ventricular pacing on intra-left ventricular electromechanical activation in patients with native narrow QRS. Am J Cardiol. 2006;98(2):219-22. 
149. Schmidt M, Brömsen J, Herholz C, Adler K, Neff F, Kopf C, Block M. Evidence of left ventricular dyssynchrony resulting from right ventricular pacing in patients with severely depressed left ventricular ejection fraction. Europace. 2007;9(1)34-40. 
10 APÊNDICE 


\section{Apêndice A - Escala Modificadade Borg}

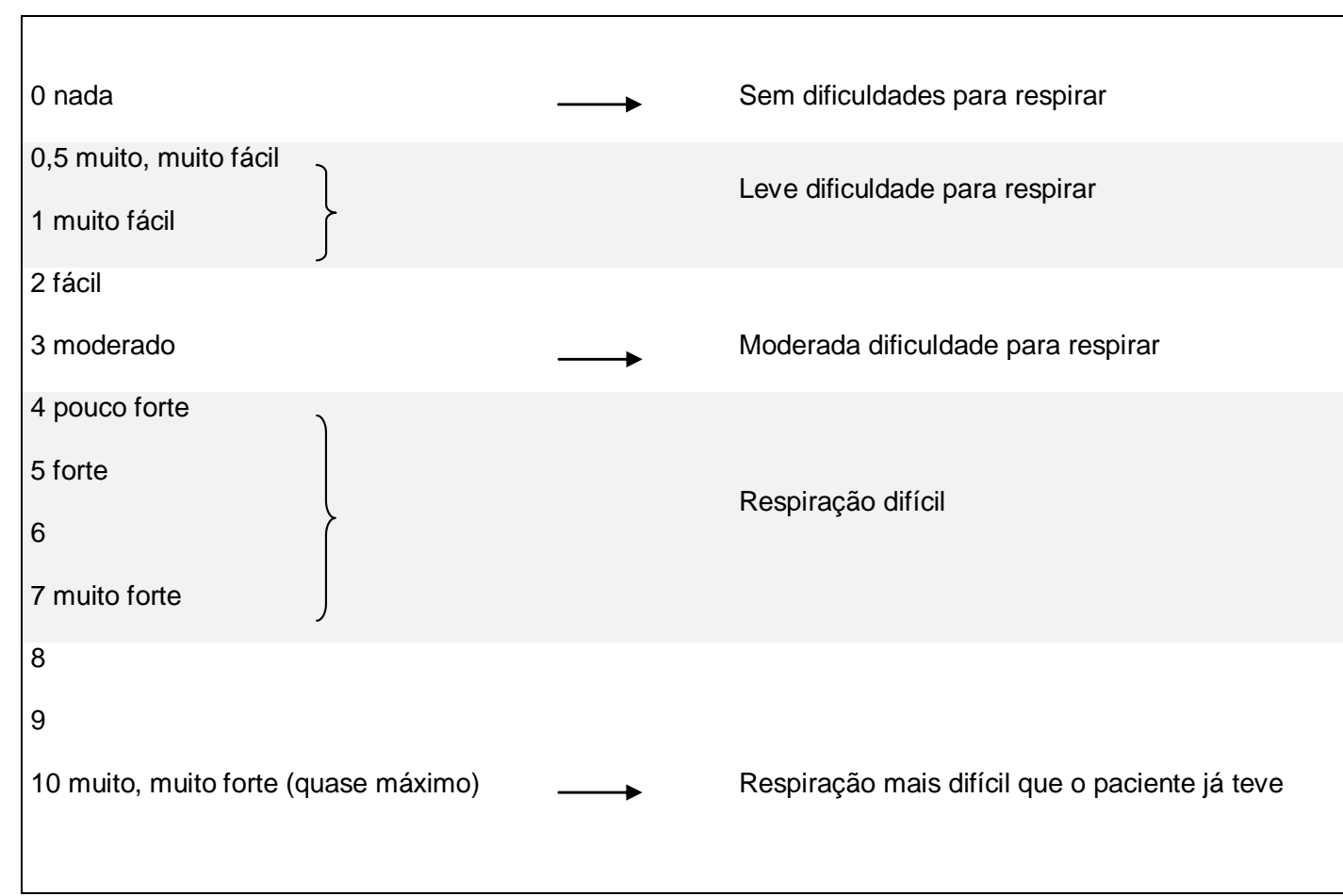

Fonte Brooks et al. ${ }^{132}$ 